خطاب الدبلوماسية الشعبية الفلسطينية عبر (تويتر) مِ مواجهة خطاب

التلاعب السياسي: دراسة حالة للعلدوان الإسرائيلي على غزة 2021

- The Palestinian Digital Public Diplomacy Discourse via

Twitter in the face of the Political Manipulation Discourse:

A case study of the Israeli aggression on Gaza 2021

$$
\text { مد د هبة محمد شفيق عبد الرازق بقسم علوم الاتصال والإعلام، كلية الآداب، جامعة عين شمس }
$$

heba.shafik@art.asu.edu.eg 


\section{ملـخص الدراسة}

سـعت الدراســة لتحديـد بنيـة خطـاب الدبلوماسـية الثـعبية الرقِميـة ومرتكزاتـه، ومعرفـة طبيعسة الرهـوز ودلالاتهـا

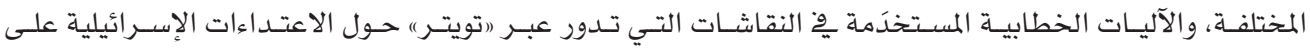

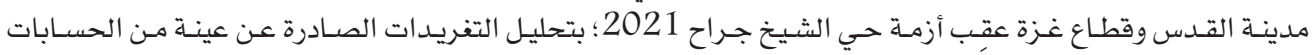

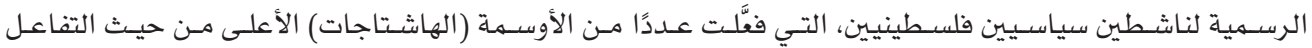

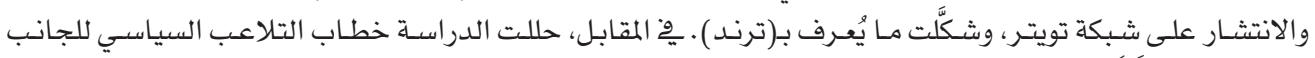

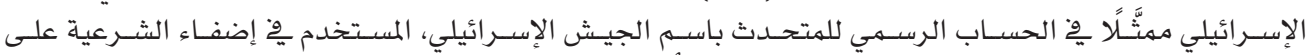

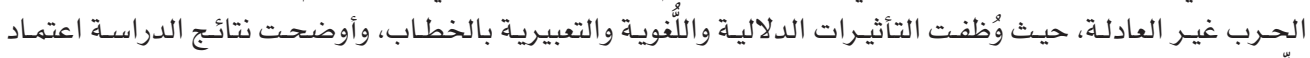

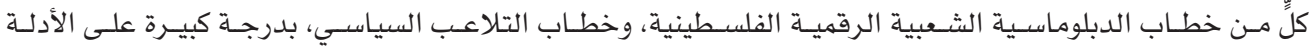
والشـواهد ، بجانب توظيـف خط الأسـاليب اللفويـة.

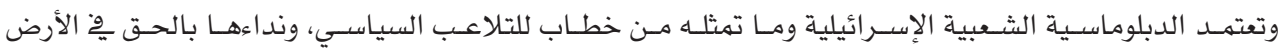

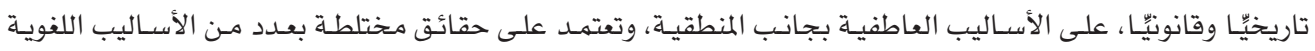

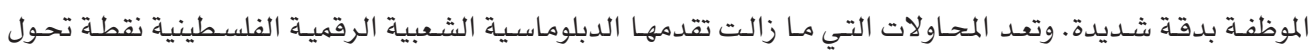

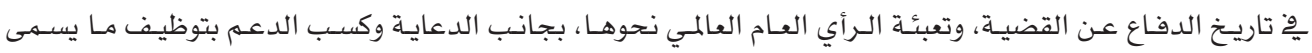

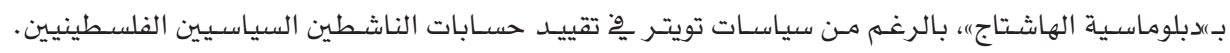
الكلهـات المفتاحيـة: الدبلوماسـية الشـبيـة الرقميـة، خطـاب التلاعـب السياسـي، أعلمــة السياســة، الصـراع

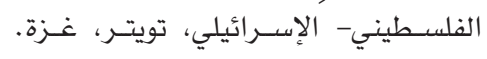

\footnotetext{
Abstract

The study aimed to determine the structure of the digital public diplomacy discourse and its foundations, and the nature of the symbols and their different significance in addition to the rhetorical mechanisms used in the discussions via "Twitter" about the Israeli attacks on Jerusalem and the Gaza Strip as a reaction after "Sheikh Jarrah" crisis 2021. This study analyzed the tweets of five official accounts for Palestinian political activists, which activated a number of hashtags with the highest percentage of receiving, following, interacting and spreading on Twitter, and formed what is known as "Trending". In contrast, the study analyzed the discourse of political manipulation by the Israeli side, represented by the official account of the Israeli army spokesman, "Avichay Adraee", used to legitimize the unjust war, where semantic, linguistic and expressive influences were employed in the discourse.

The results showed that "evidence" in addition to "linguistic methods" represented the majority regarding the methods of persuasion in the discourse of political manipulation as well as the Palestiniane digital public diplomacy discourse.

The Israeli public diplomacy calls for the right of "land dispute" historically, using emotional and logical strategies, "facts mixed up with a number of linguistic methods". On the other hand, the Palestinian public diplomacy attempts are a turning point in the history of the The Palestinian cause as it helps in mobilizing the world public opinion, along with gaining support through the hashtag diplomacy.

Key Words: Digital Public diplomacy, Manipulation in political discourse, Mediatization of Politics, the Palestinian-Israeli conflict, Twitter, Gaza.
} 


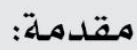

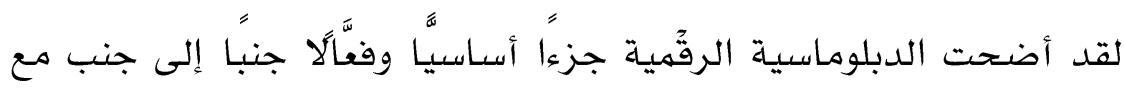

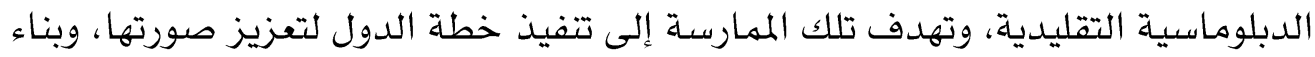

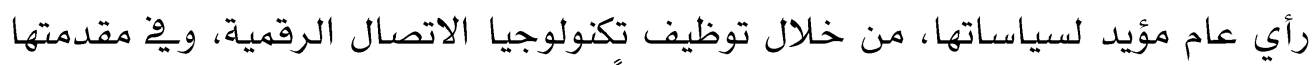

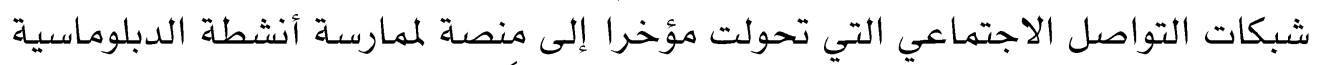

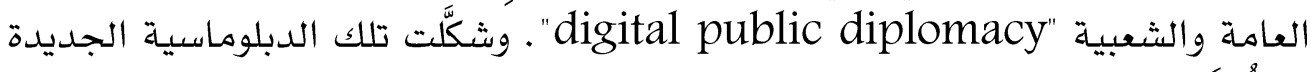
ما يعرَف بهصطلح "القوة الناعمة"، كوسيلة للتعبير عن الأهداف الاتصالية والسياسية

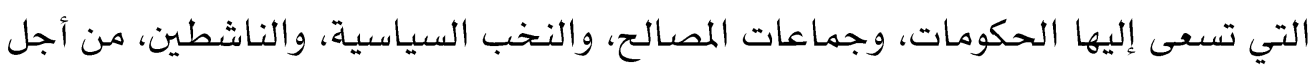

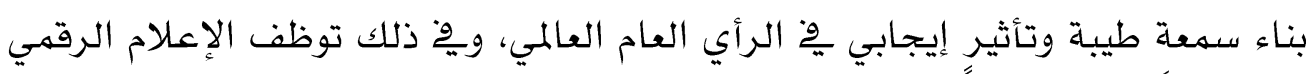
للوصول لتَلك الجماهيرً

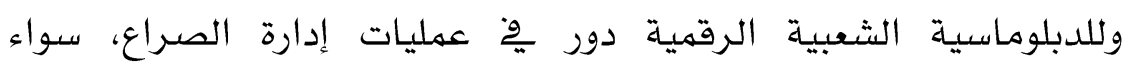

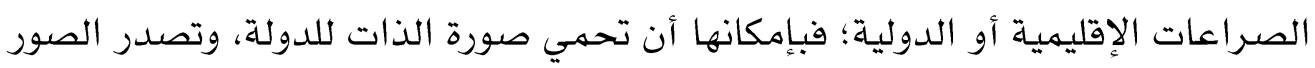

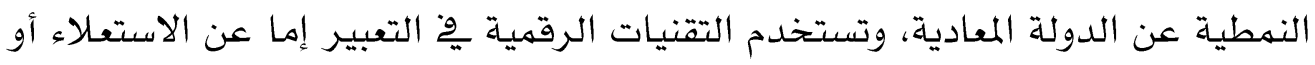

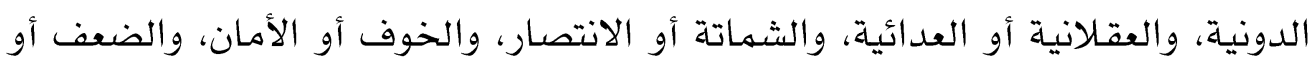

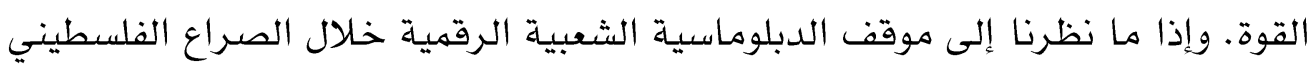

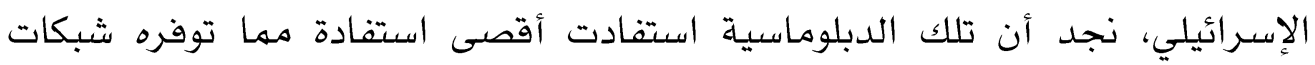

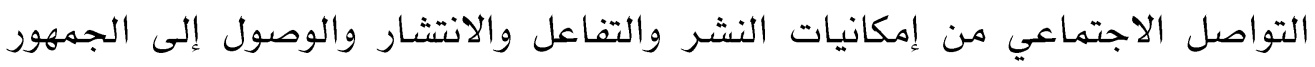

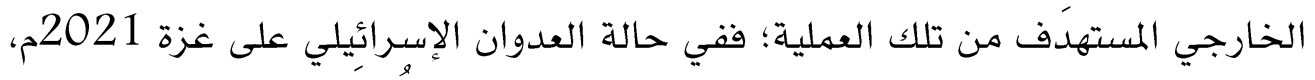

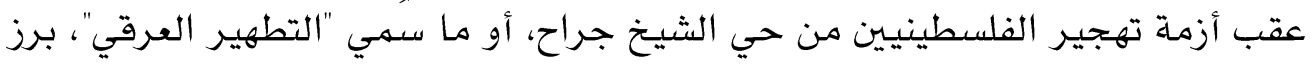

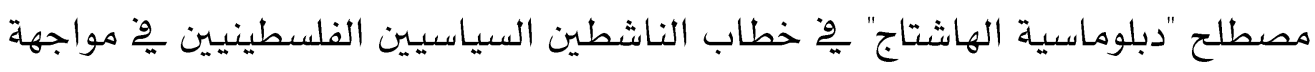

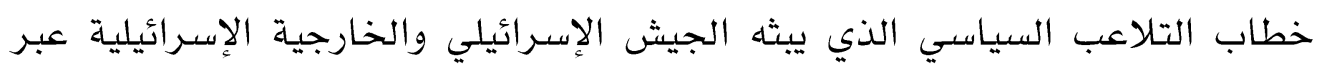

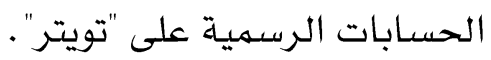

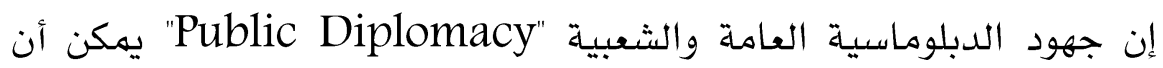
تقودها المؤسسات الحكومية وغير الحكومية المختلفة، التي تسعى لتحقيق التواصل 
المفتوح على المستوى الشعبي كشرط لتأسيس علاقات هادفة ومستدامة، وتتمية الثقة بين

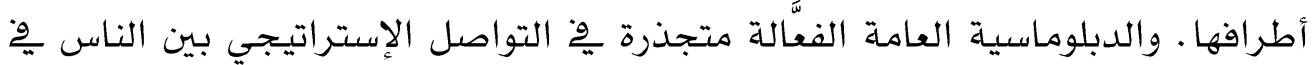

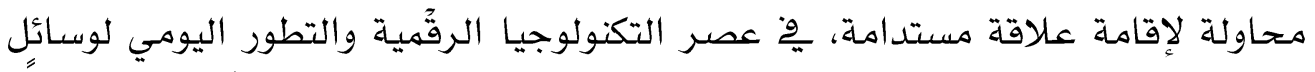

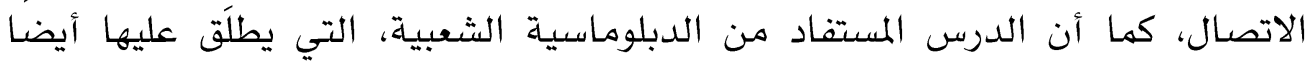

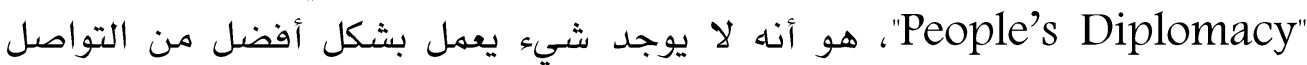

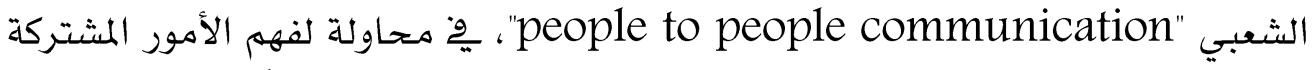

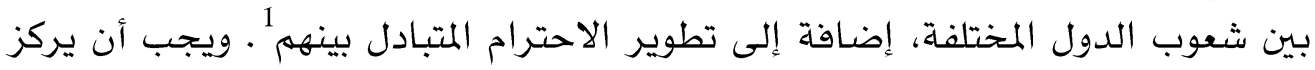

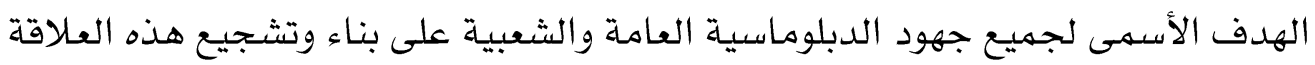

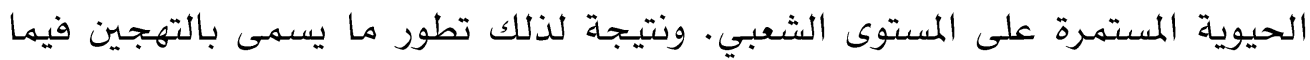

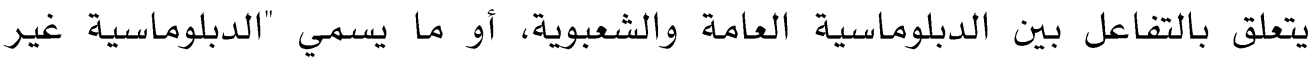

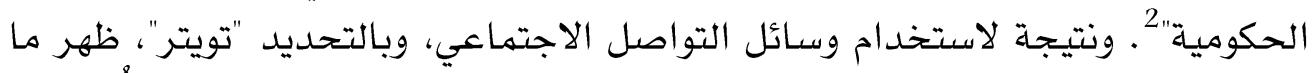

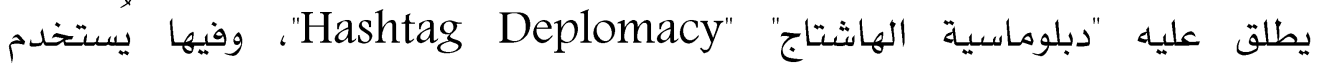
"الهاشتاج" أو "علامات التصنيف" من أجل توسيع نطاق تأثير التفريدات، وسهولة

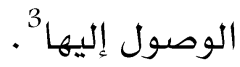

أما التلاعب السياسي "manipulation in political discourse" ، كما

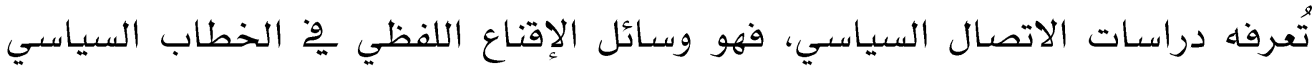

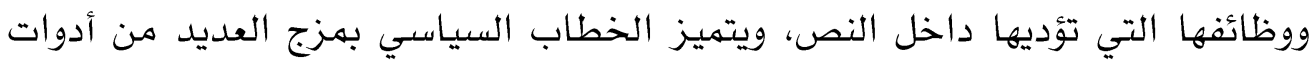

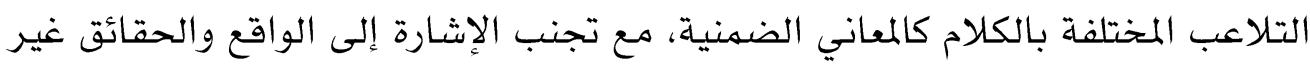

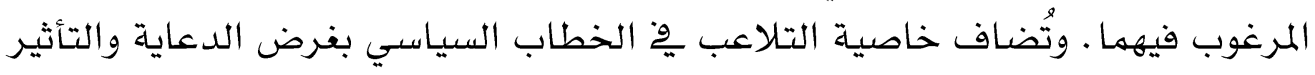

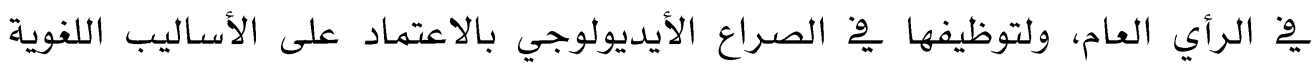

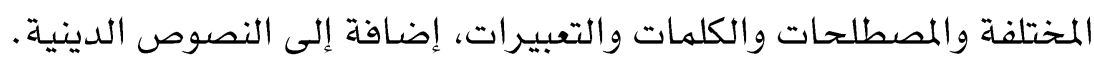

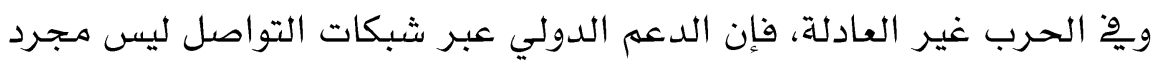

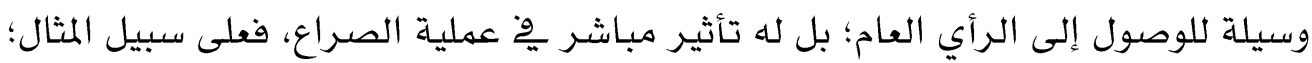

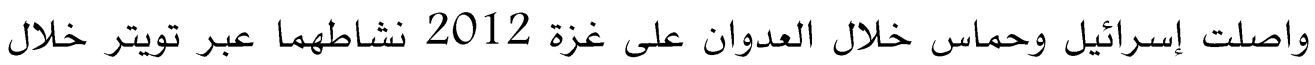

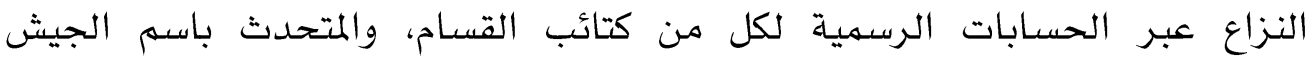

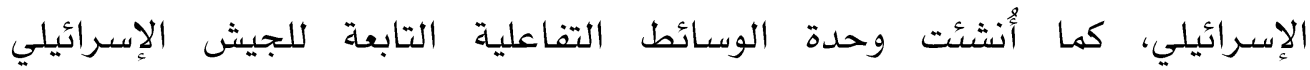

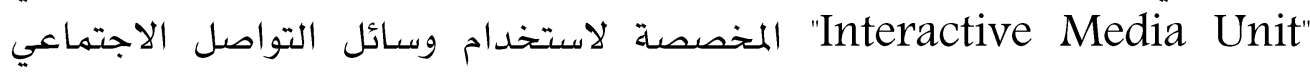

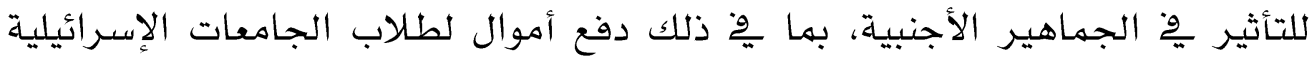

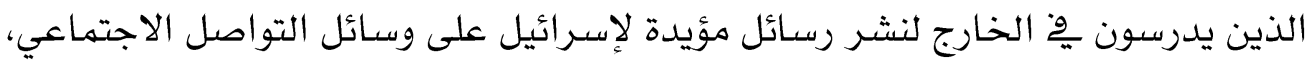


مها يؤكد كذلك على أولوية إسرائيل على وسائل التواصل الاجتماعي ودورها ِوحة

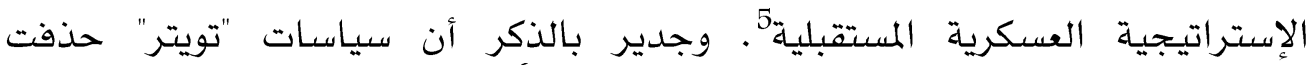

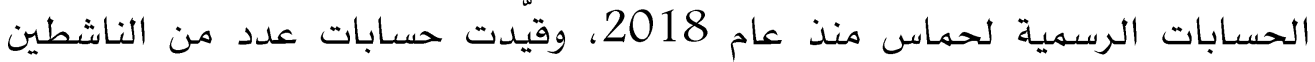

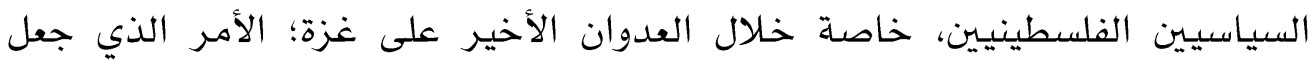

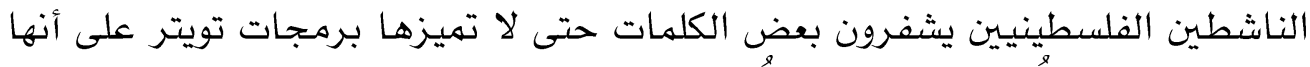

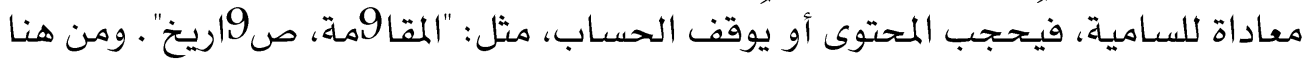

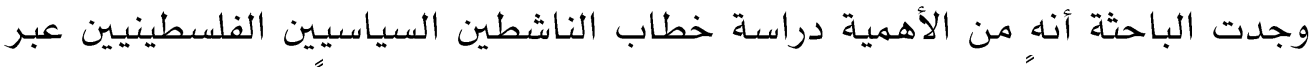

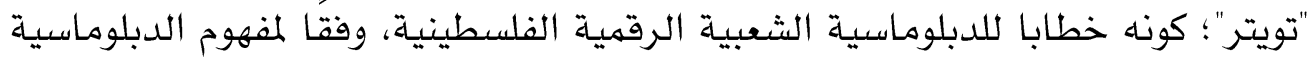

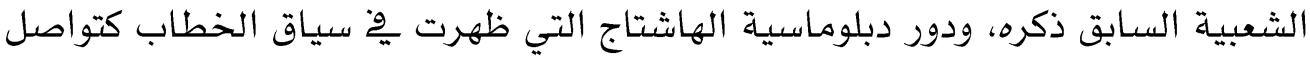

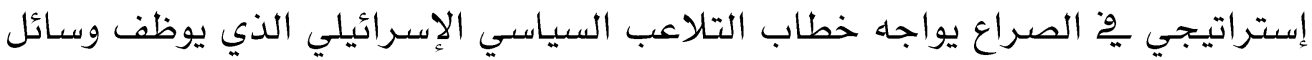

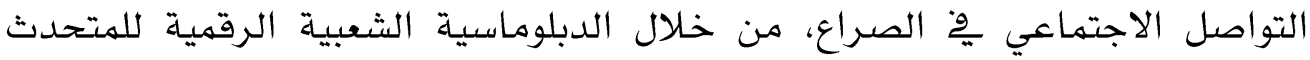

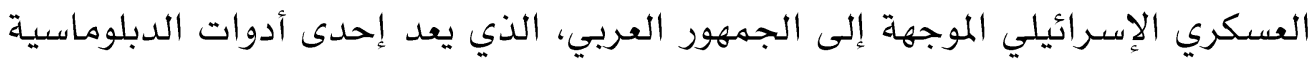

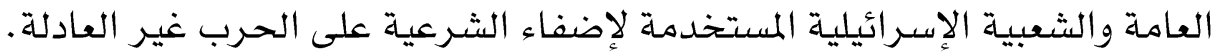

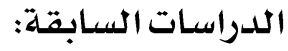

من خلال تتبع الدراسات السابقة، ومراجعة الإسهامات البحثية المتعلقة بالدبلوماسية الشعبية الرقمية الفلسطينية، أمكن تقسيمها إلى محورين؛ أولهما:

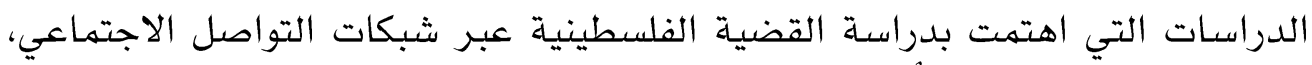

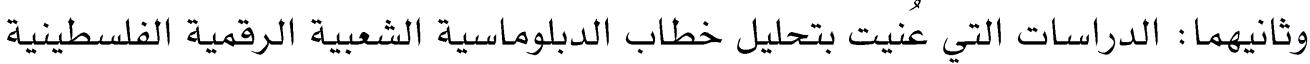

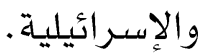

- - ملمور الأول: الدراسات التى عنيت بلدراسة القضية الفلسطينية عبر شبكات

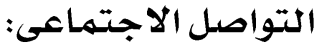

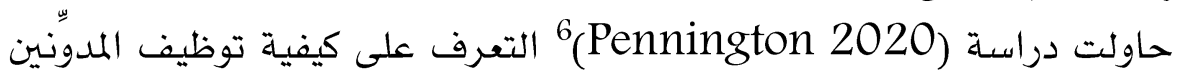
موقع التواصل الاجتماعي "تمبلر" "Tumblr" واستخدامه خلال العدوان الإسـرائيلي على غزة 2014، ويعد "تهبلر" إحدى المدونات التي نقلت أحداث الصرات الصراع ومعاناة

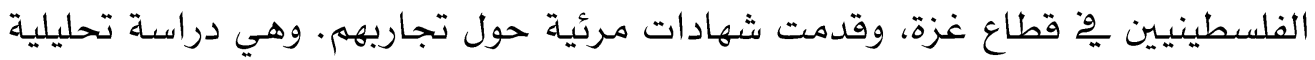

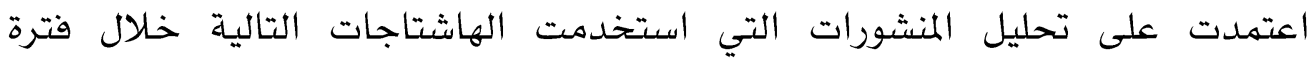

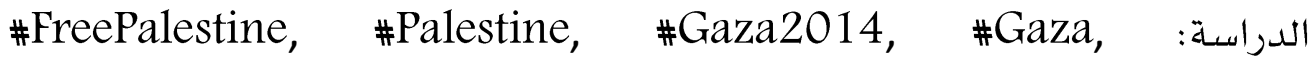
تGazaUnderAttack, \#Gaza

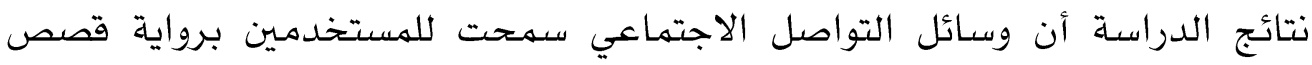


الضحايا تحت القصف، وتسليط الضوء على ما سيهي بالصراع غير المتكافئ، ونشر صور

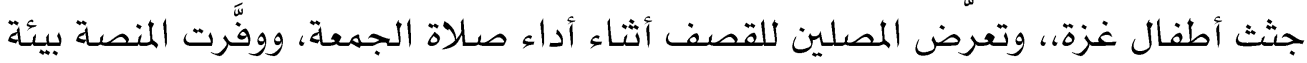

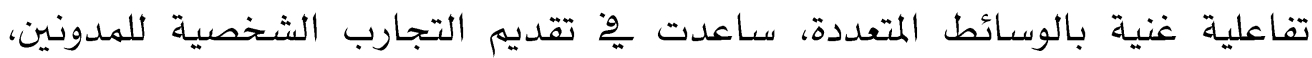

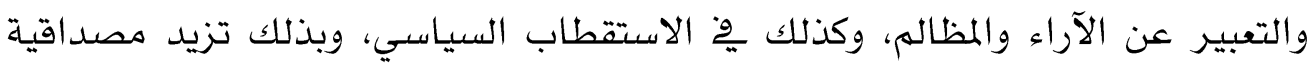

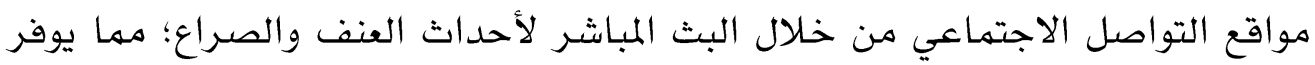
معلومات الاتصال لصانعي السياسات وللتأثير مِ فُ الرأي العام.

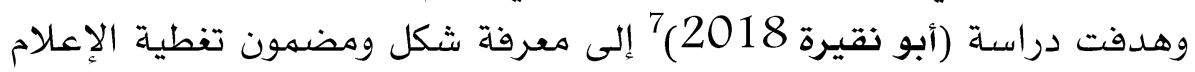

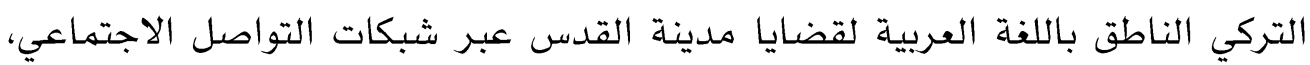

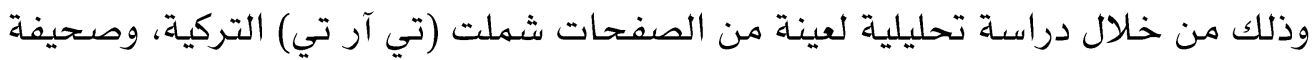

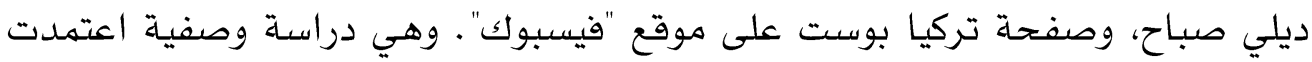

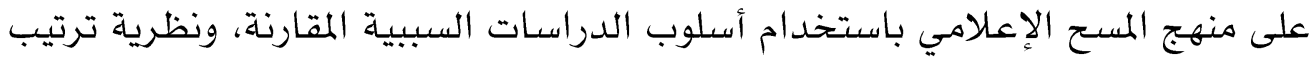

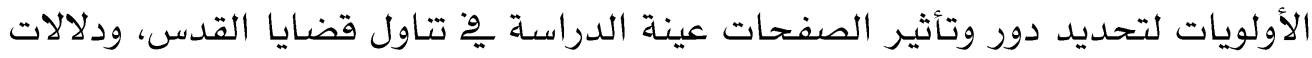

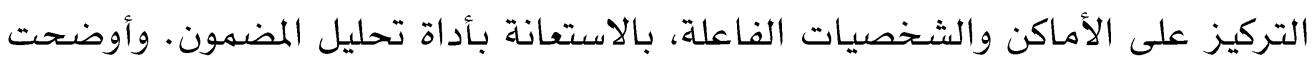

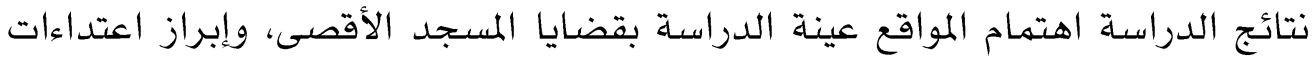

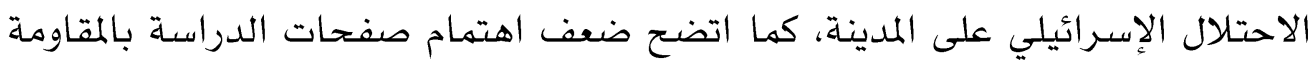

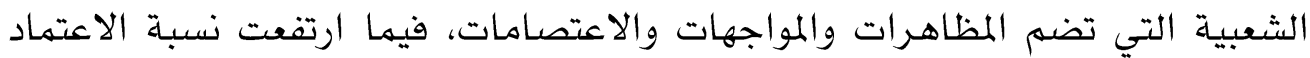

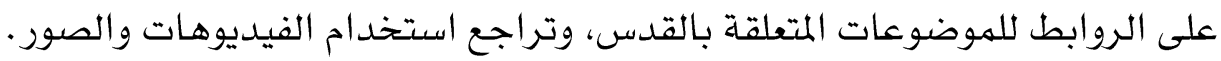

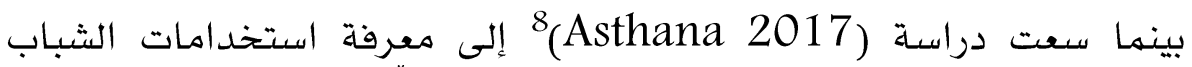

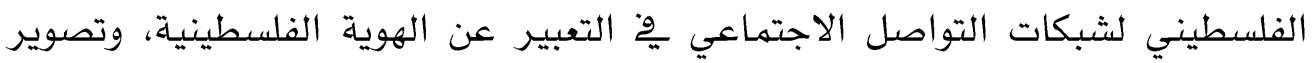

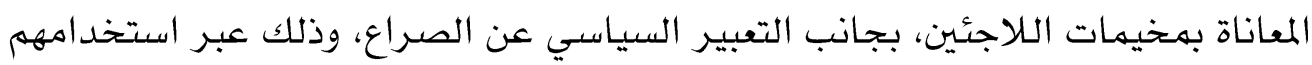

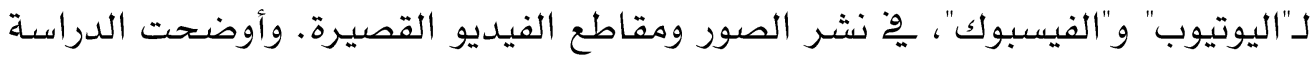

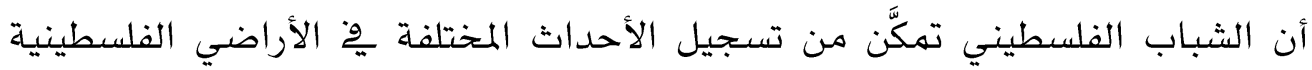

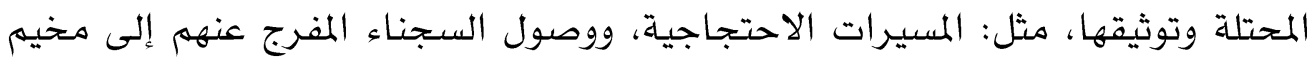

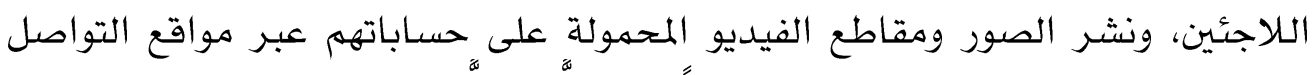

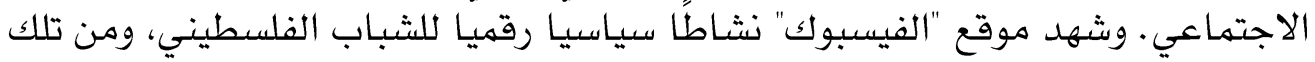

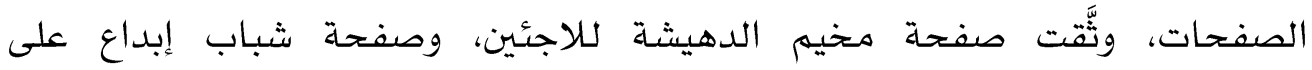

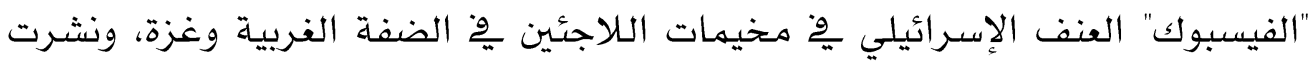

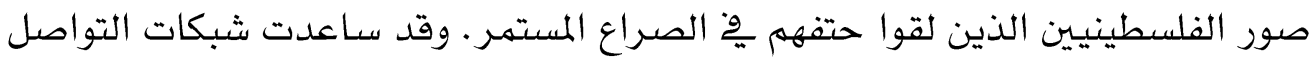

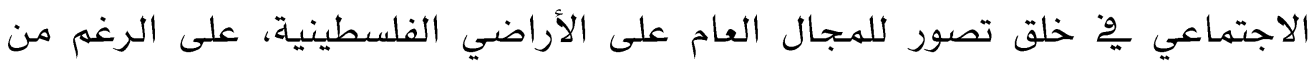


انقسام العائلات بين مخيمات ومناطق أخرى مجزَّأة ومنفصلة، وقد أوجدت المجموعات

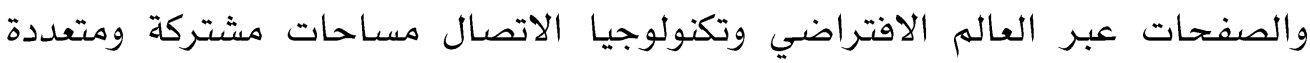

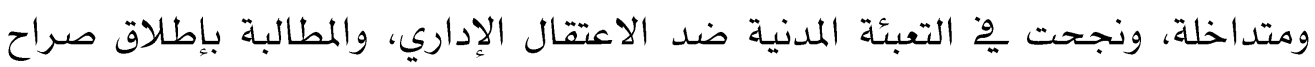

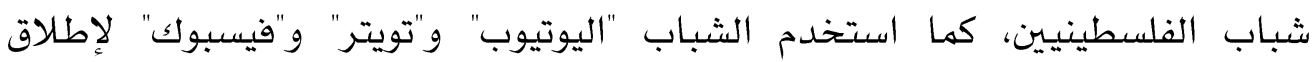
هاشتاج شater_and_Salt \#StopAD وكثفت دراسة (Abu Mualla 2017) 9 عن أساليب استخدام إسـرائيل

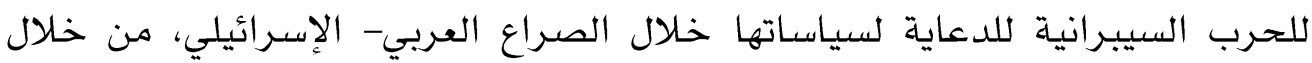

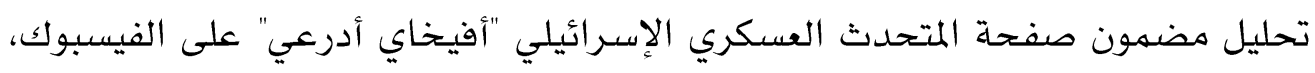

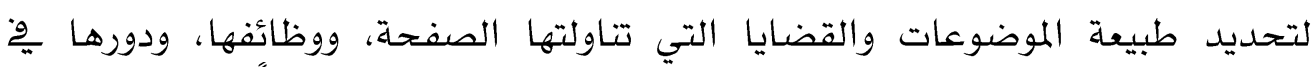

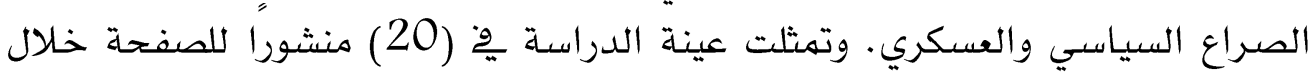

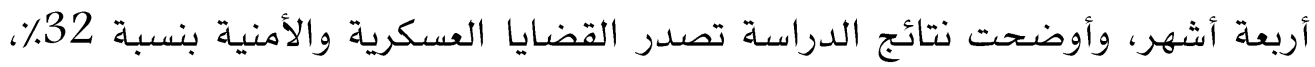

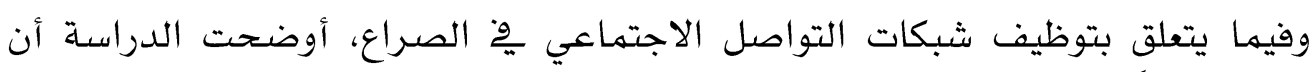

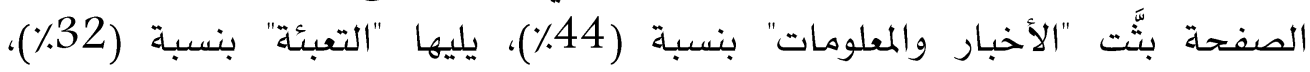

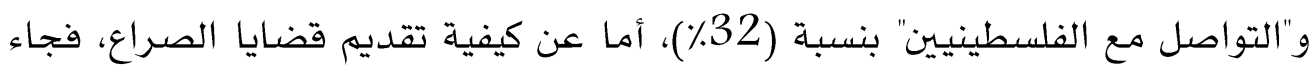

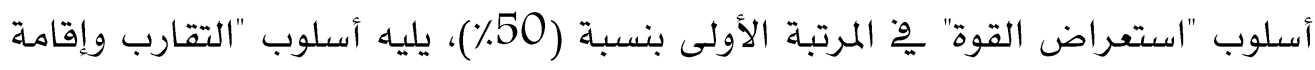

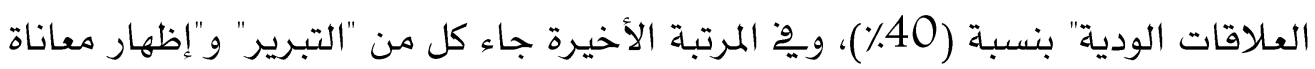

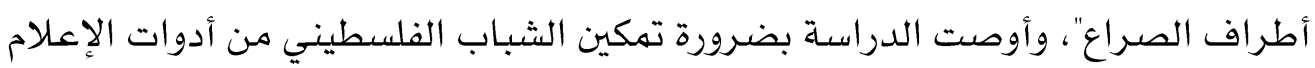

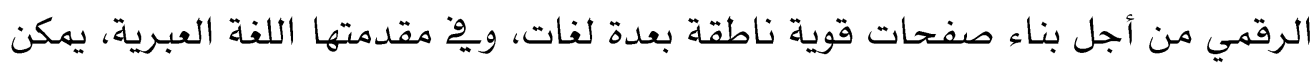

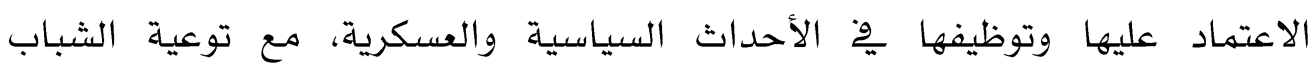

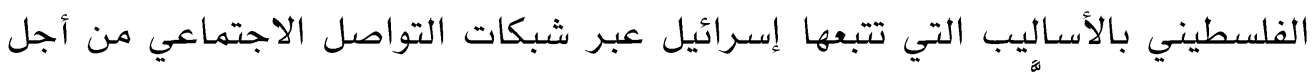

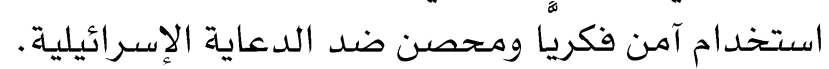

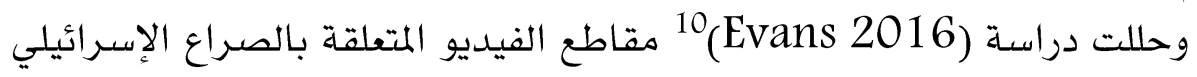

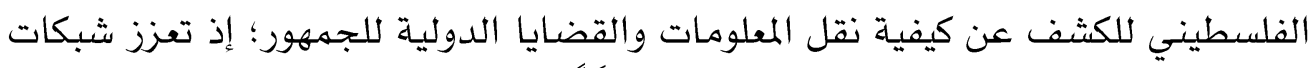

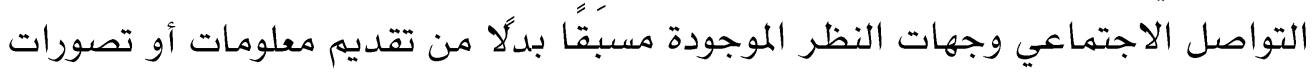

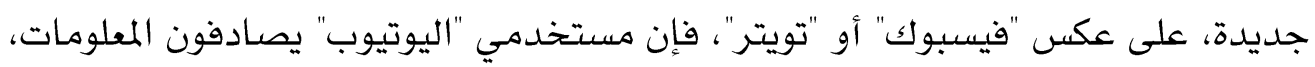

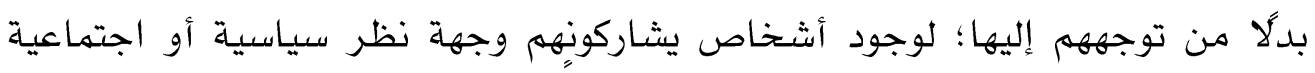

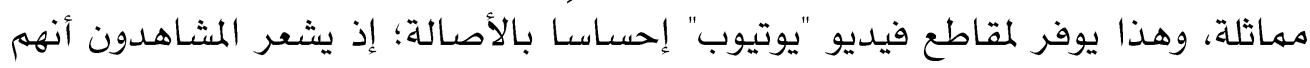

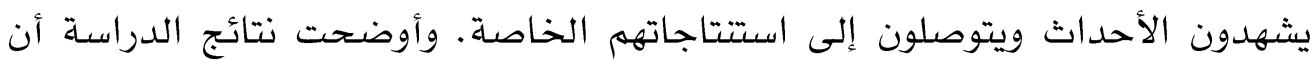

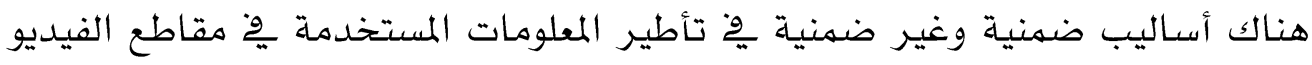


المنشورة بـ"اليوتيوب" لتتوافق مع الروايات التي يدعمها القائمون بتحميل الفيديوهات

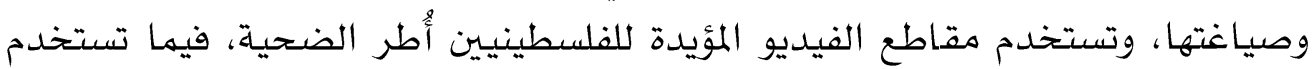

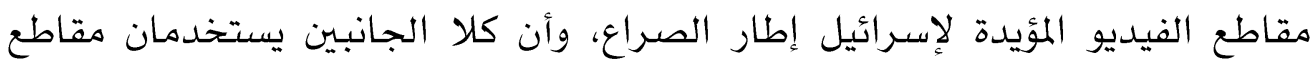

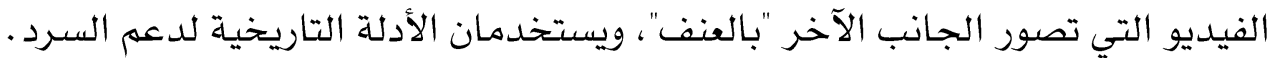

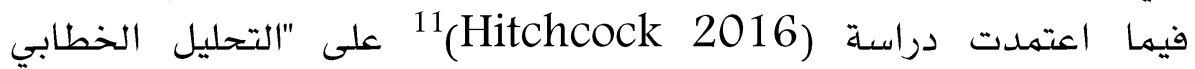
"rhetorical analysis

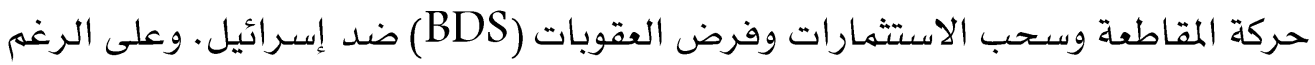

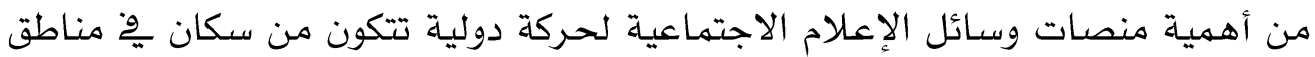

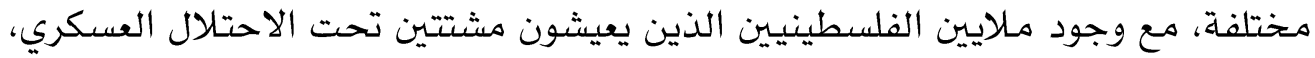

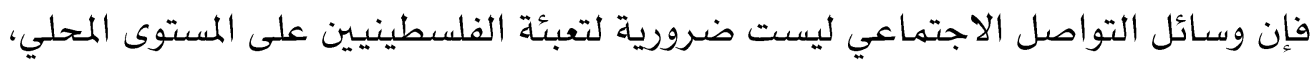
وأوضحت نتائج الدراسـة أن العديد من صفحات التئ وفيسبوك" وحسابات "تويتر" المرتبطة

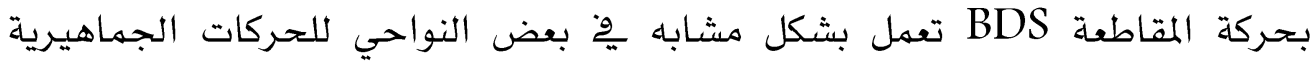

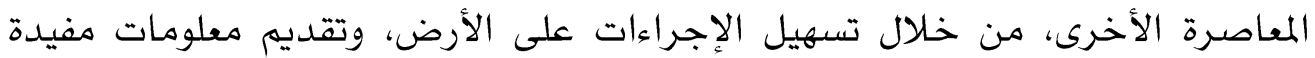

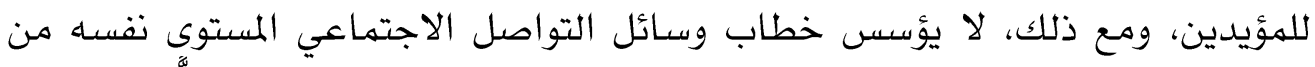

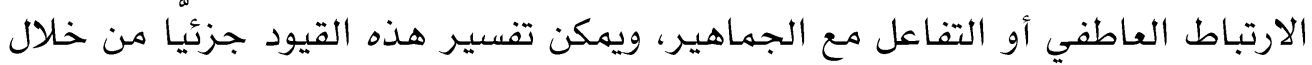

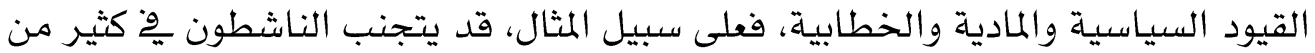

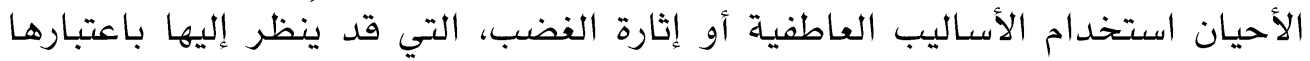
معاداة للسامية، ومن ثم إحداث رد فعل عنيف من جانب المدافعين عن إسرائيل.

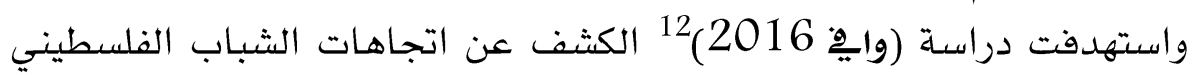

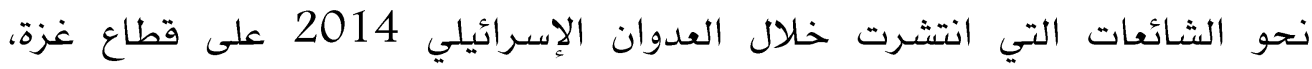

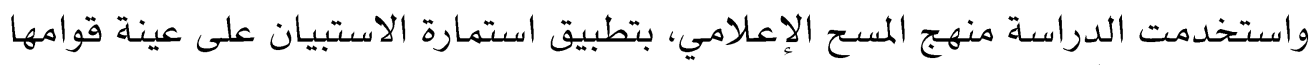

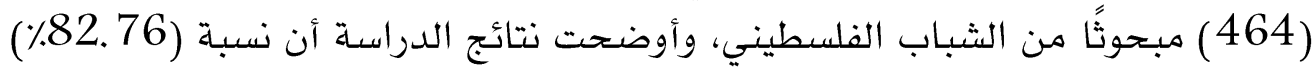

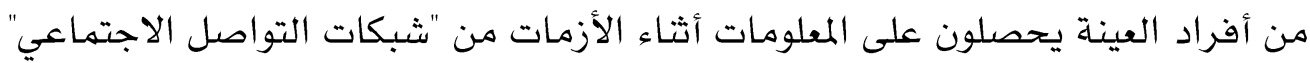

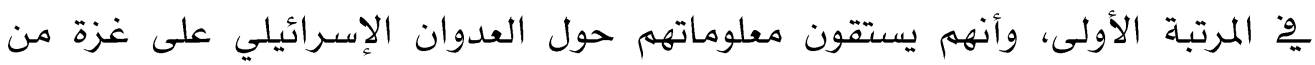

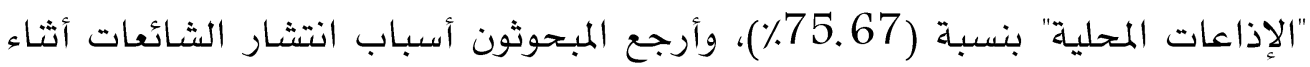

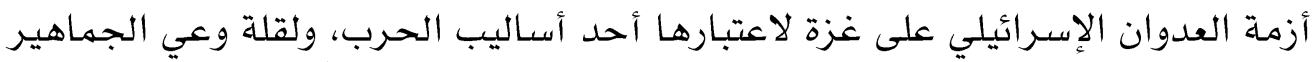

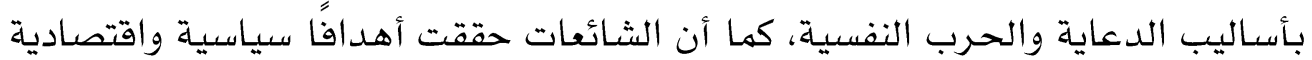
وعسكرية وأمنية واجتماعية وتفسية. 


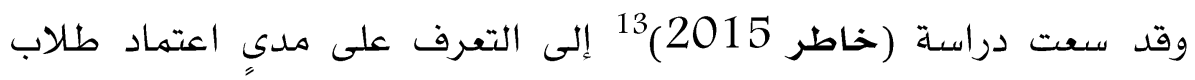

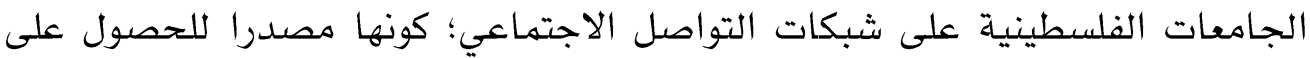

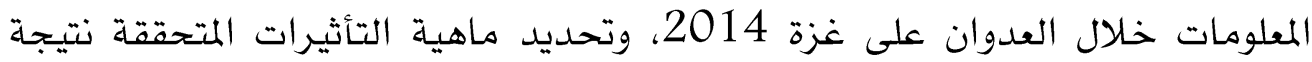

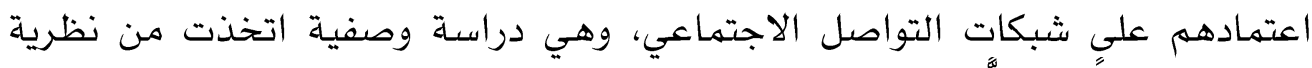

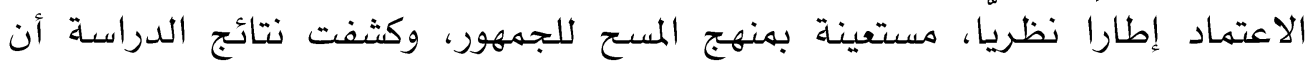

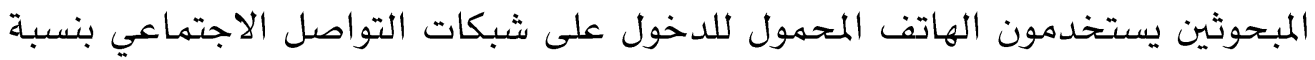
بلغت (67.8٪)، وقد تصدرت شبكات التواصل الاجتماعي المصادر التي يعتمد عليها

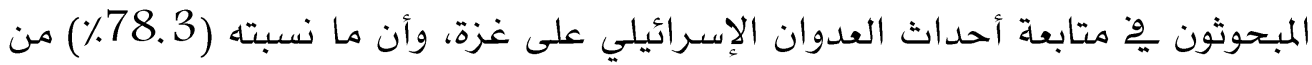

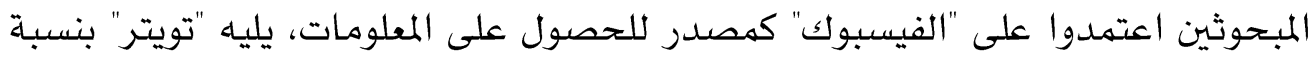

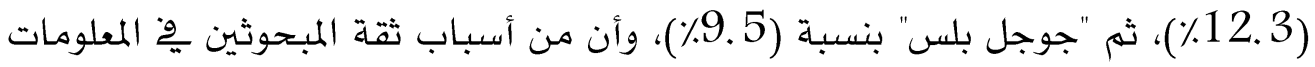

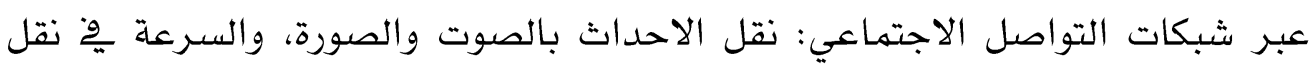
الأخبار، بجانب التغطية الحية للأحداث.

وحاولت دراسة (بريخ 2015) 14 تحديد درجة التعات العتماد النخب السياسية

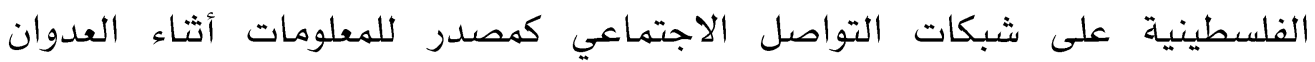
الإسـرائيلي على غزة 2014، وماهية التأثيرات المعرفية والوجدانية واتية والسلوكية المتحققة.

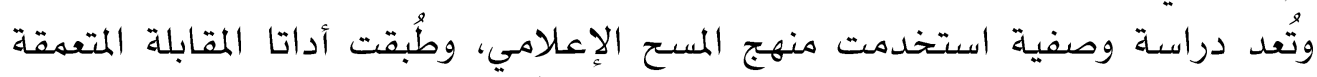

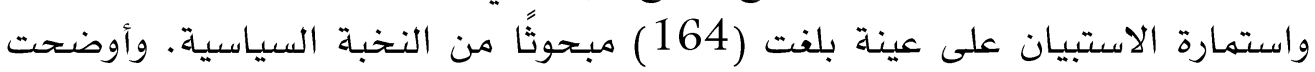

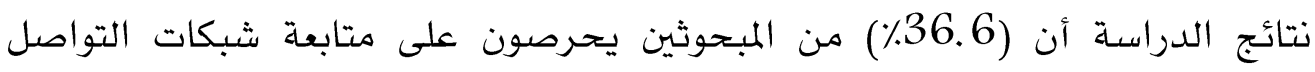

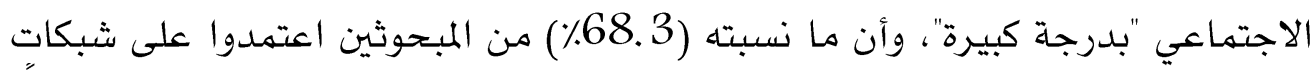

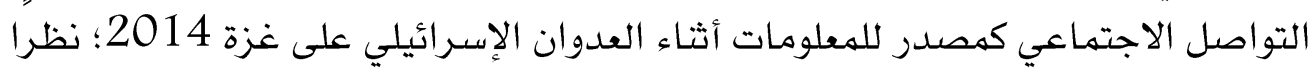

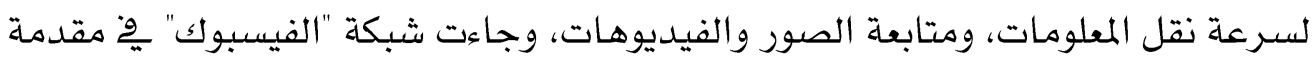

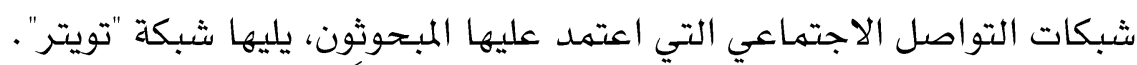

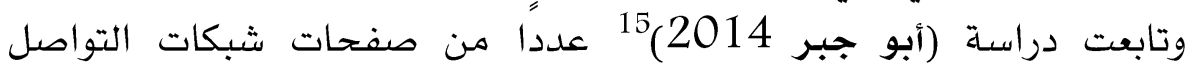
الاجتماعي بهدف تحليل المواد التي تتاولت قضية العدوان على غزة على مستوى الثكل

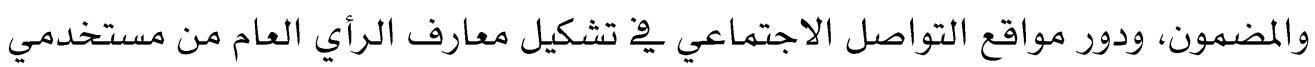

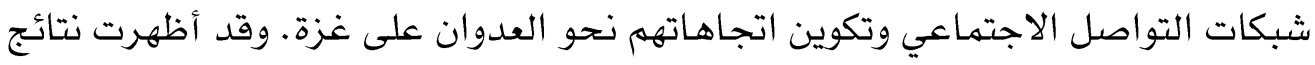

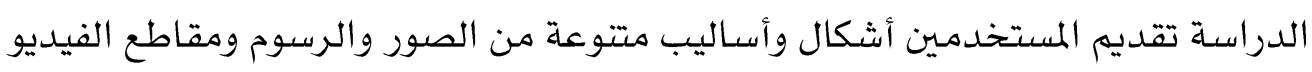

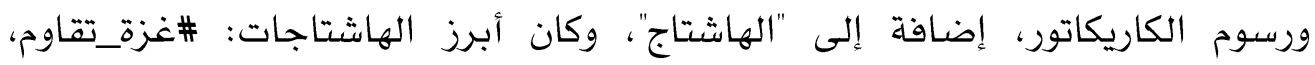

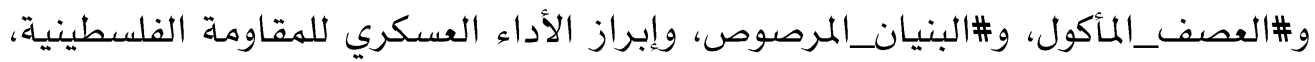


بجانب مشاركة صور وفيديوهات تُبين حجم الدمار للهنازل والمؤسسات وقتل الأطفال، فقد اعتمدت تلك الصفحات على ما يقدمه الأشخاص من مواد مصورة التقطها أفراد

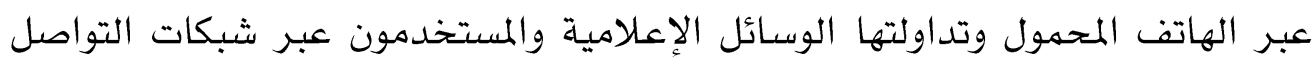
الاجتماعي.

واستهدفت دراسة (المصري 2013)16 الكثف عن مدى تفاعل الناشطين السياسيين عبر شبكات التواصل الاجتماعي ومدى قدرتهم على دعم قضية الأسـرى درى

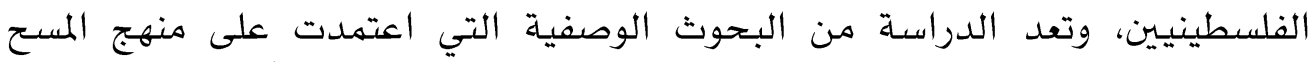

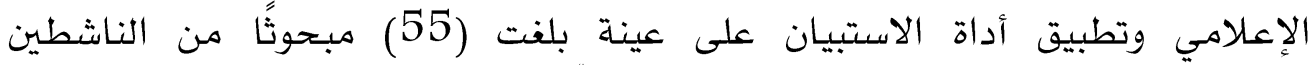

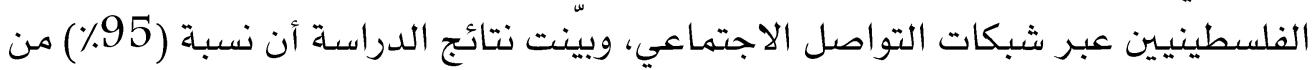

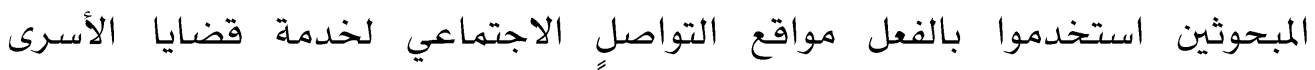

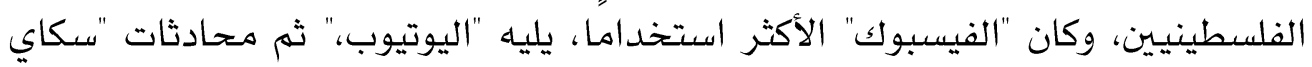

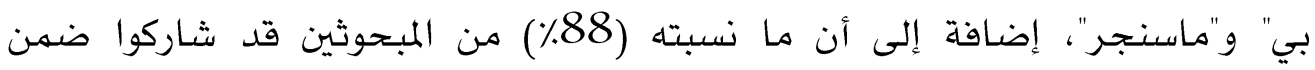

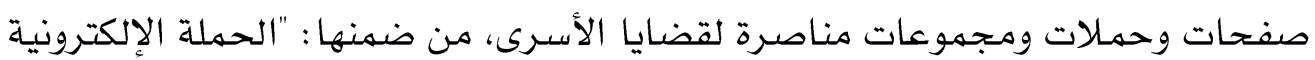

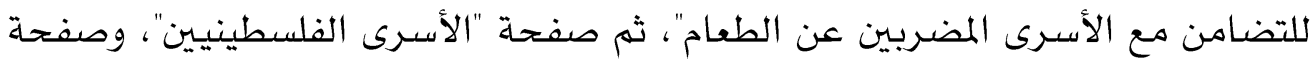

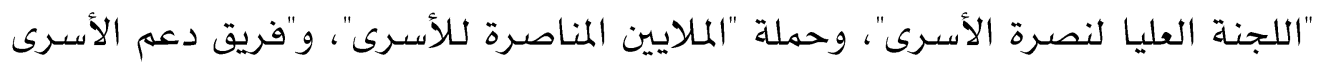

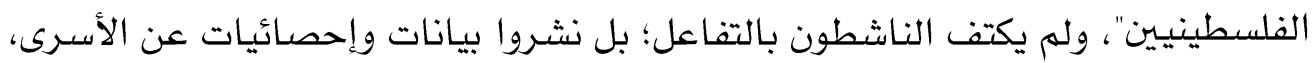

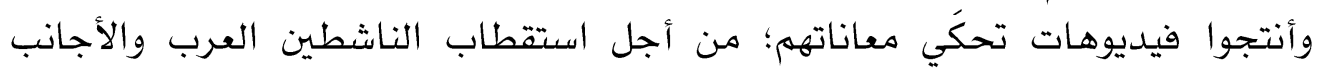
للتضامن مع القضية.

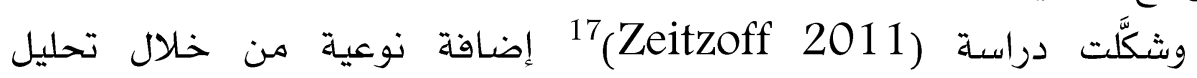
الديناميكيات قصيرة المدى للصراع مع حماس عقب إدخال القوات البرية الإسرائيلية،

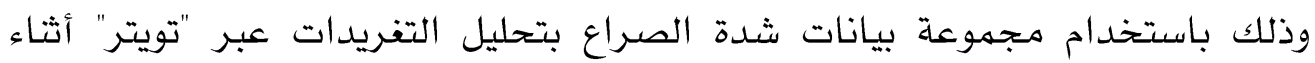

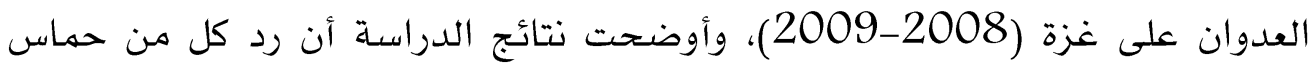

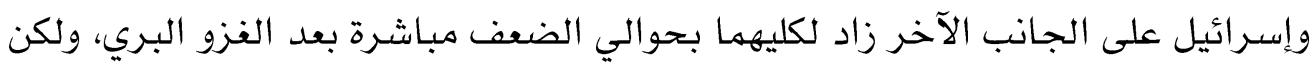

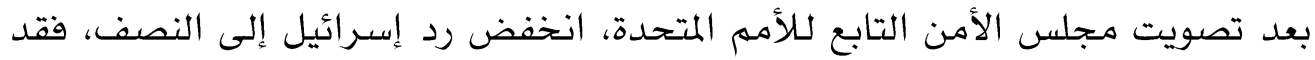

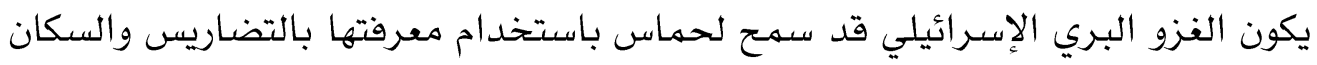

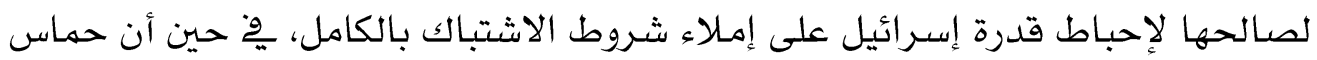

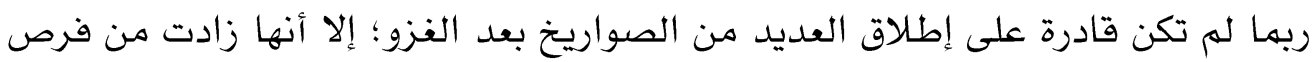

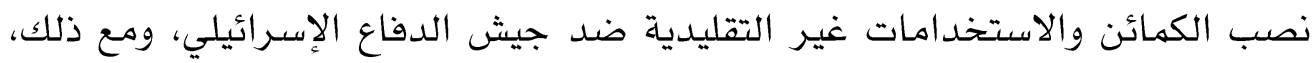

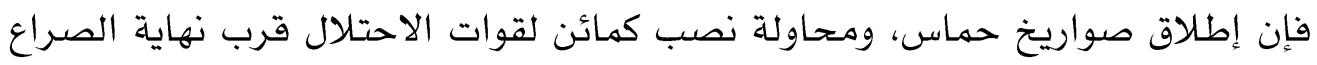


تشير إلى أن "اليقين" المتزايد بثأن رد فعل حماس بعد الغزو ليس انتصارًا مستدامًا لإسـرائيل.

وسعت دراسـة (طالب 2011) 18 لمعرفة الدور الذي تؤديه وسـائل الإعلام المختلفة

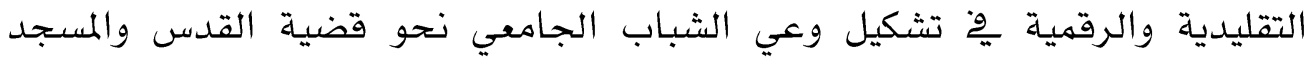

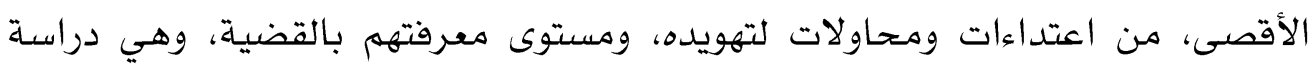

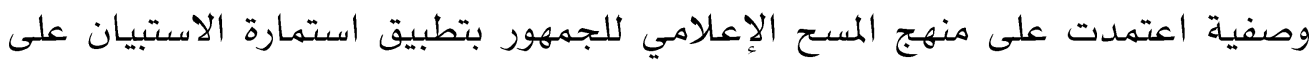

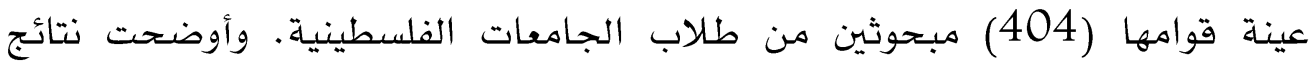

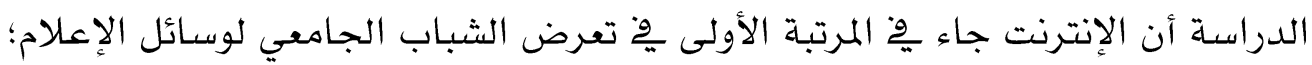

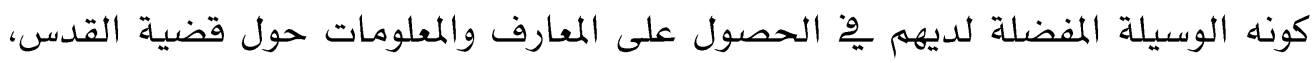

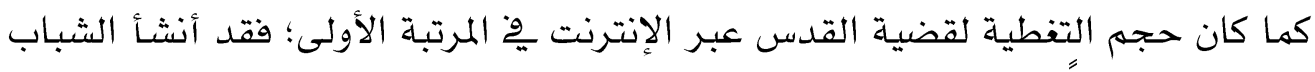

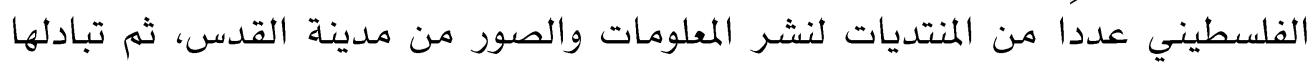

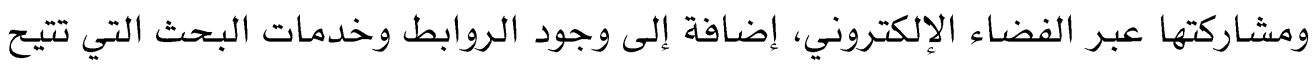

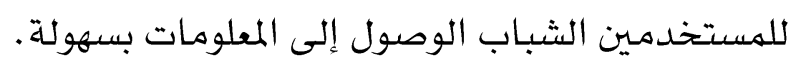

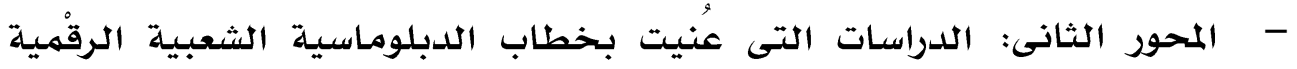

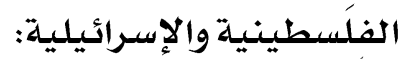

استهدفت دراسة (قاعود وأبو خصيوان 2020)19 التعرف على مالى ماهية الدبلوماسية الثعبية الرقمية، وتحدياتها وإيجابياتها، من أجل تحقيق الفان الاستفادة

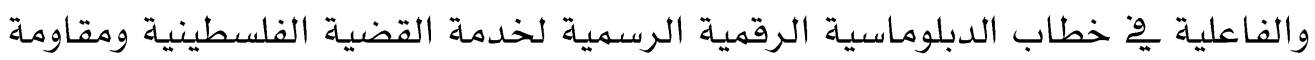

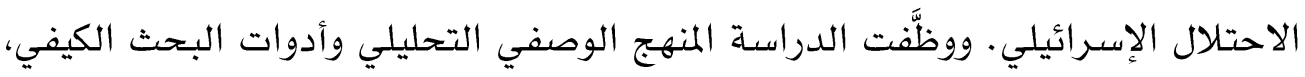

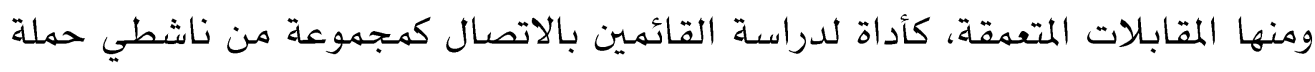

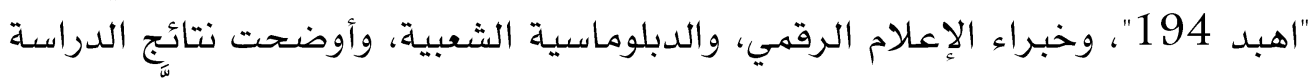

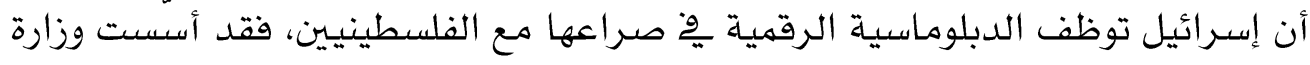

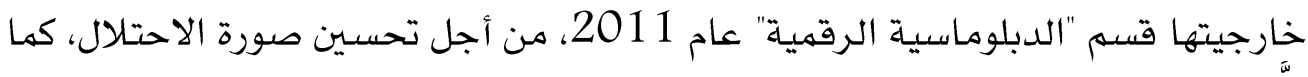

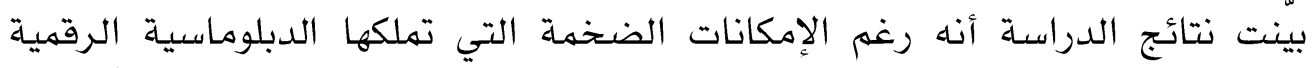

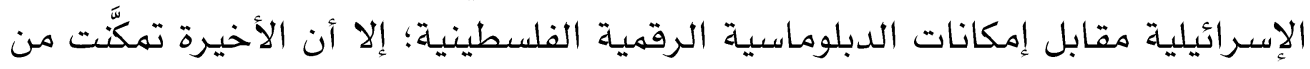

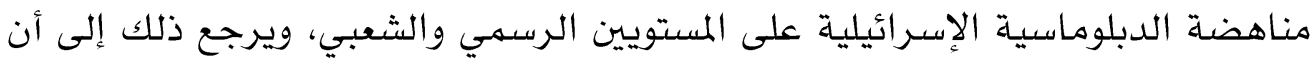

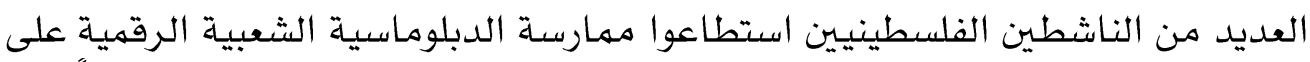

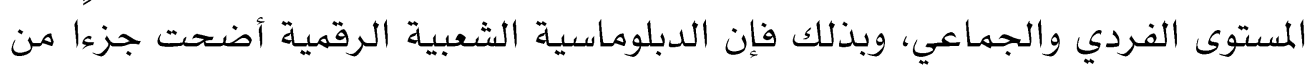

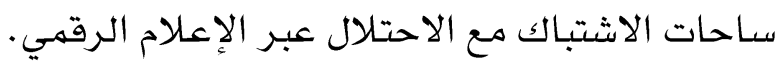


وركَّزت دراسـة (علوان، 2020) 20 على صورة الذات الإسـرائيلية، وصورة الآخر

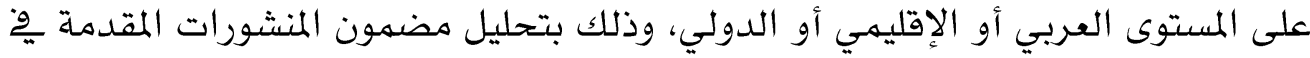

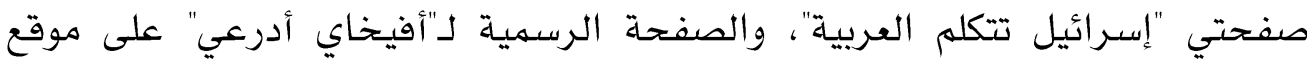
"الفيس بوك"، للكثف عن الموضوعات التي تتاولتها، وأهدافها، ومعرفة السمات والتوصيفات التي ظهرت بها، والأسـاليب المنطقية والاستمالات المستخدمة، وهي دراسـة

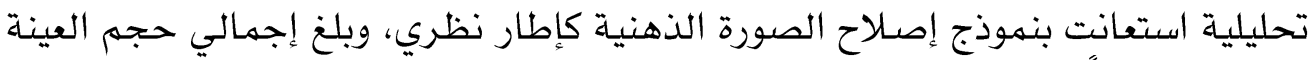

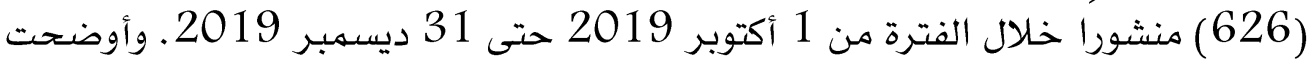

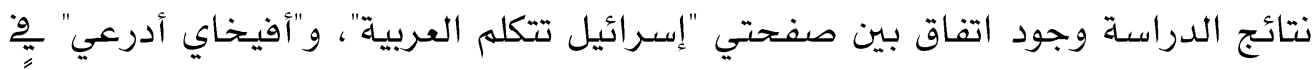
المنشورات؛ مها يشير إلى وجود تتسيق بين القائمين على إدارة الصفحتين، ووظفا عددا

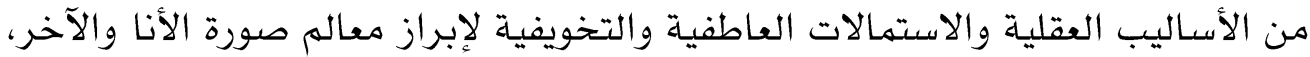

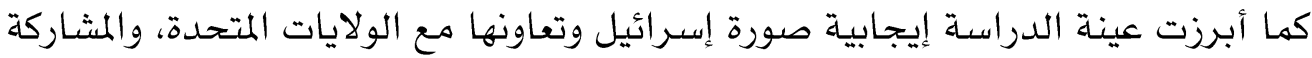

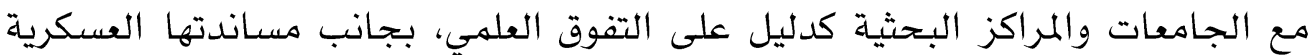

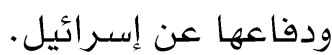

وطرحت دراسة (Zeitzoff 2018) تساؤَّأل رئيسًا حول كيفية تأثير

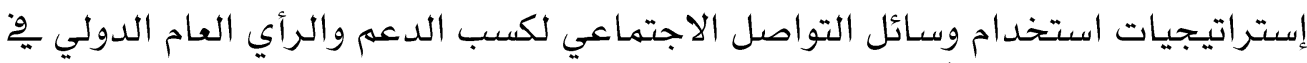

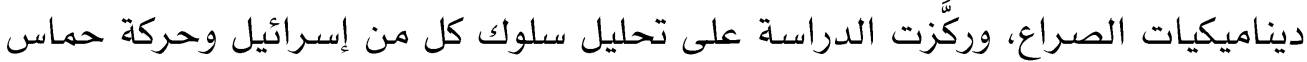
خلال العدوان على غزة 2012، بجانب الدعم الشعبي لكل جانب من الجماهير الدولية

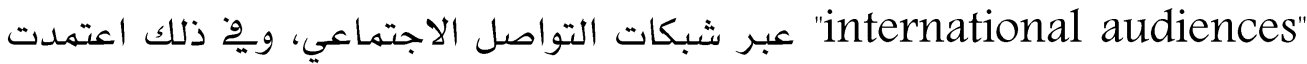

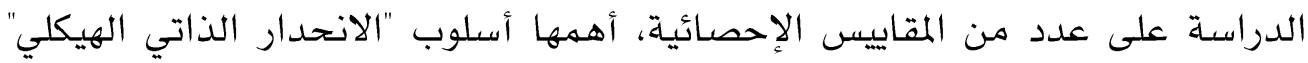

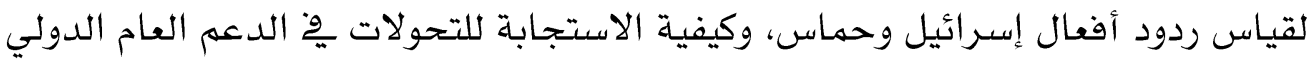

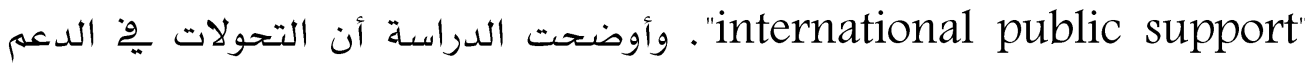

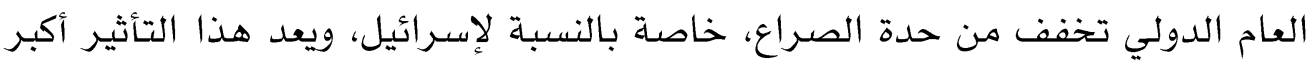

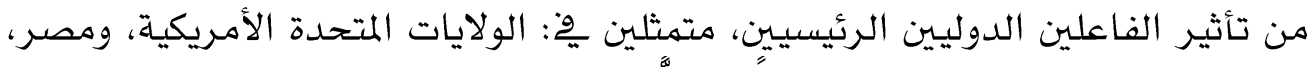

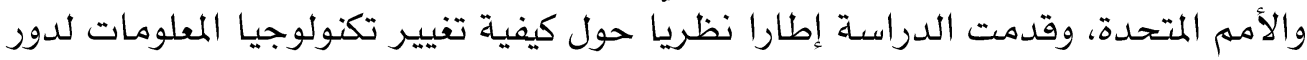

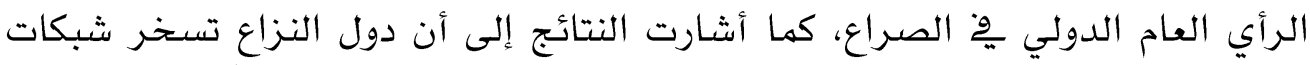

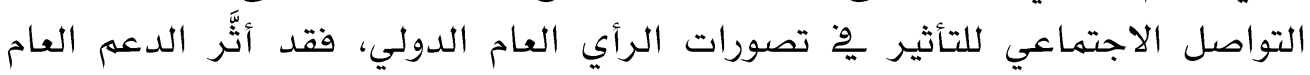

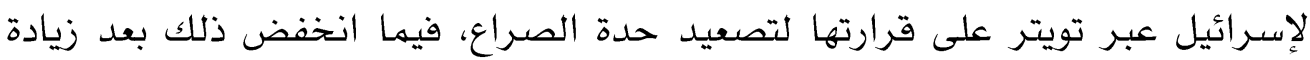

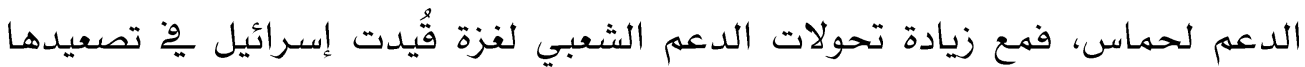

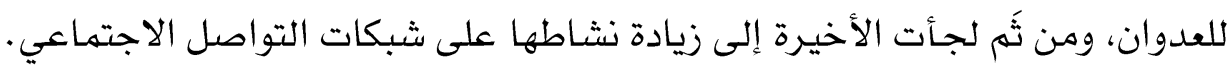


وبحثت دراسـة (Manor \& Crilley 2018) الإسرائيلية صور الصراع الفلسطيني الإسـرائيلي عبر توظيف شبكات التهات التواصل

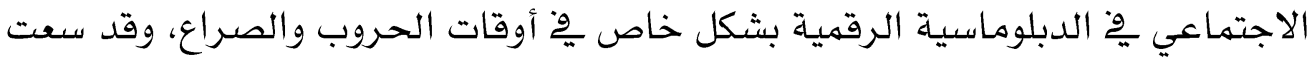

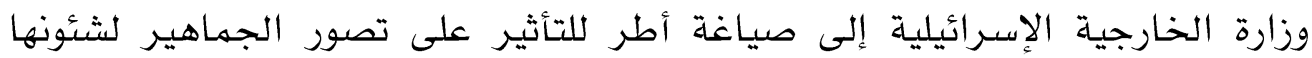

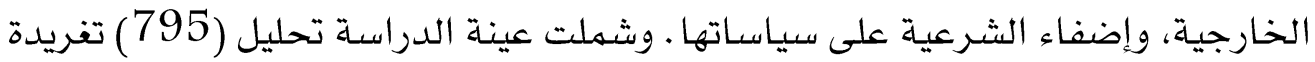

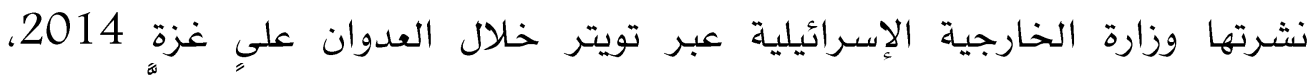

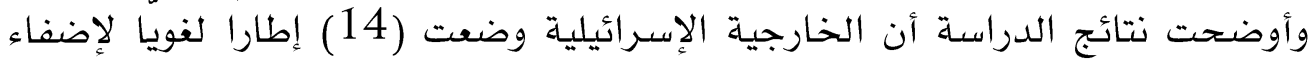

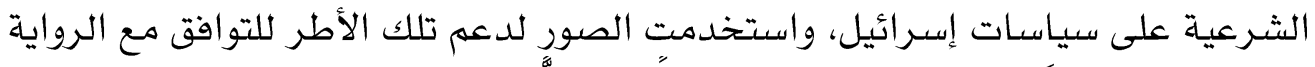

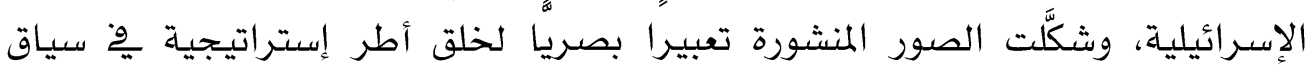

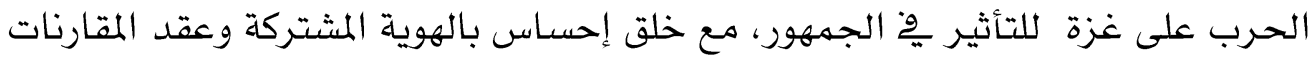

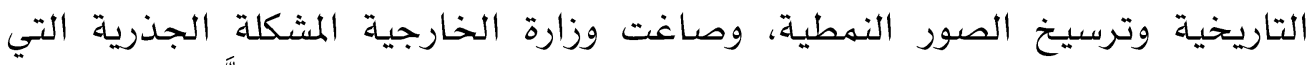

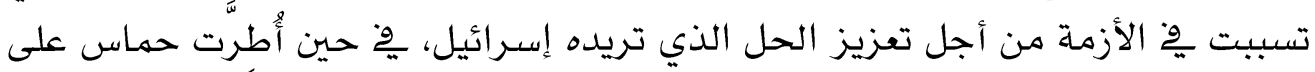

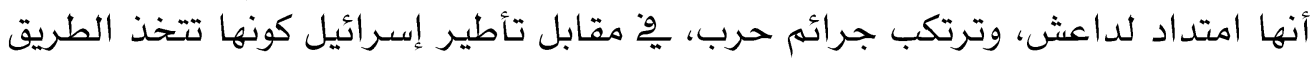

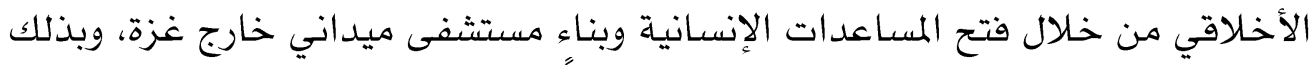

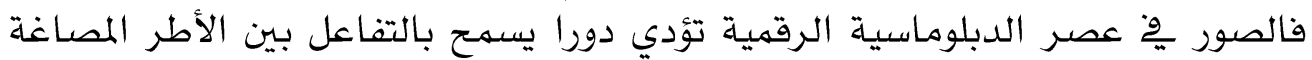
والسياق السردي الموظفة من خلاله.

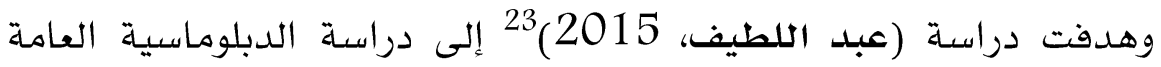

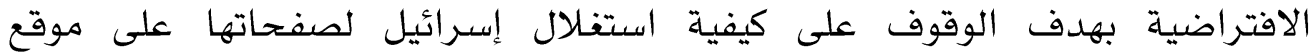

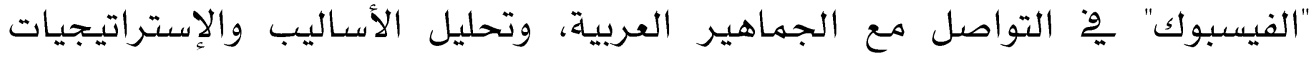

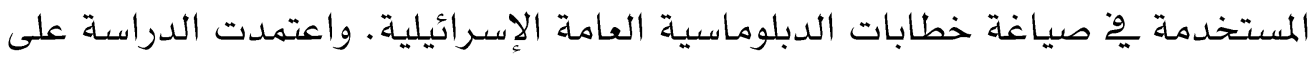

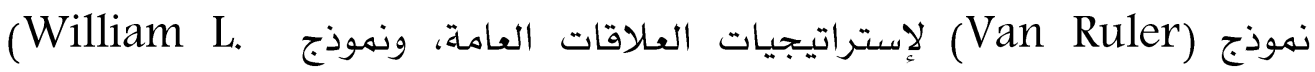

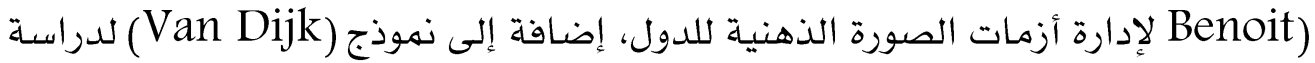

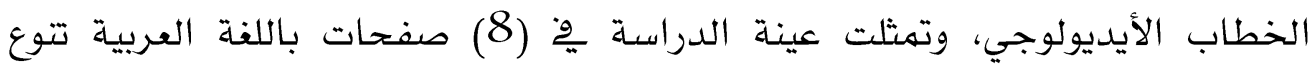

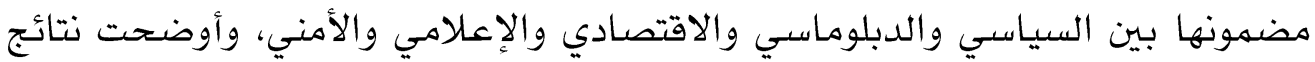

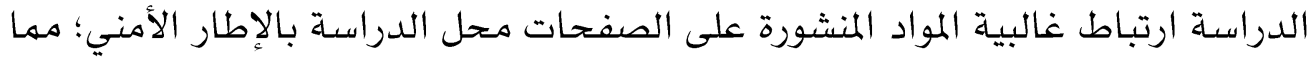

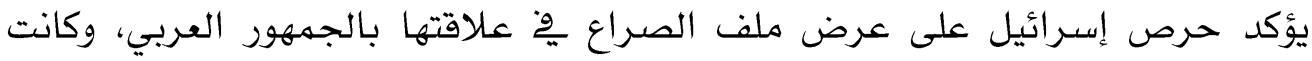

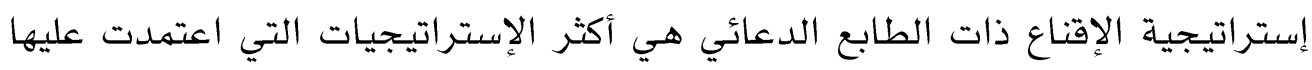

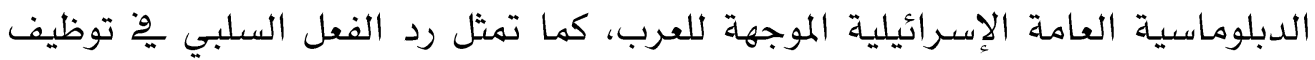
إسرائيل لإستراتيجية التملص من قتل المدنيين والخروج من المفاوضات دون حل لعل للأزمة. 
وتتاولت دراسـة (Siapera 2014) 24 العلاقة بين وسـائل التواصل الاجتماعي

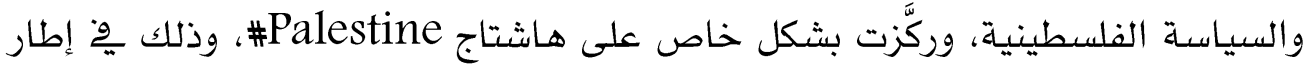
نظرية الوساطة "mediation" التي تقسر العلاقة الجدلية، إذ يكون فيها المنتجون/

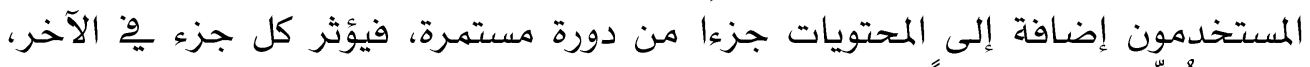
وبذلك يغير بعضهم بعضا، واعتمدت الدراسة على أداة تحليل المضمون، وشملت عينة

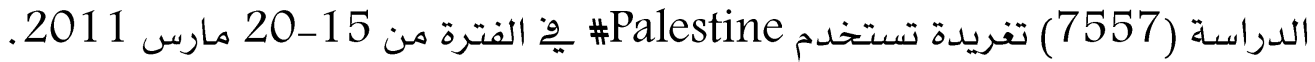

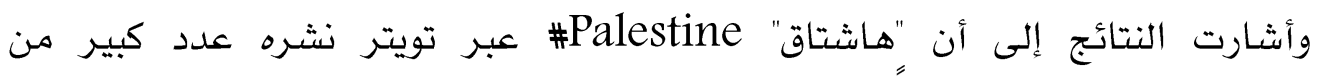

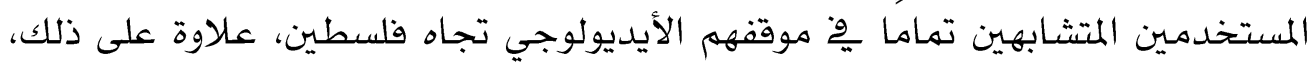

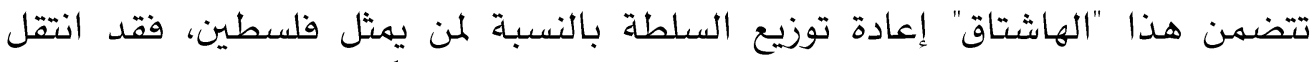
Palestine\#

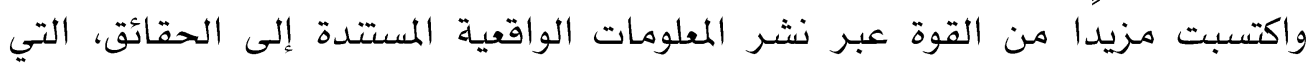

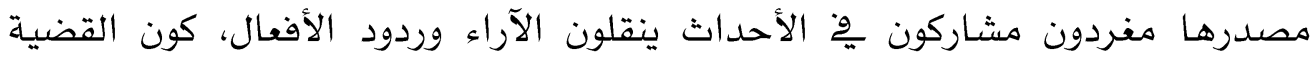

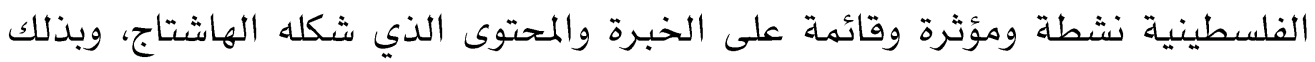

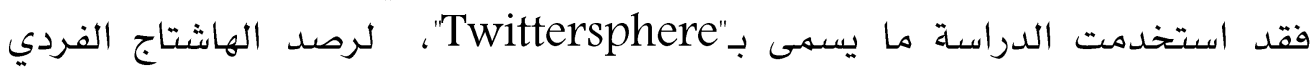
لشريحة محددة من مستخدمي تويتر .

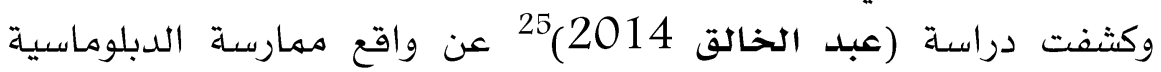

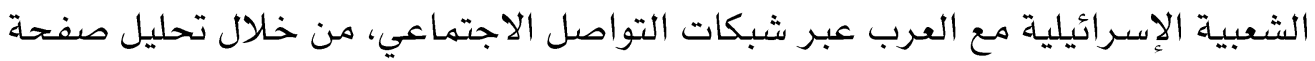

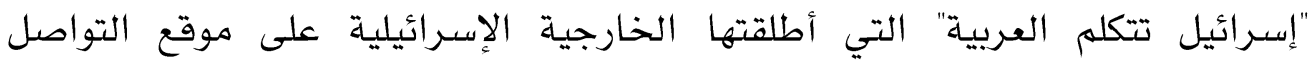

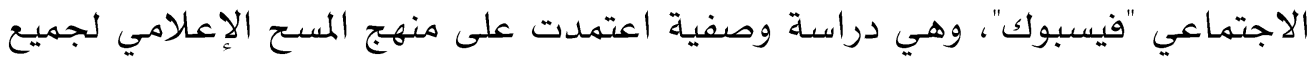

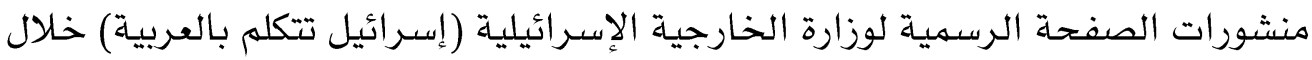

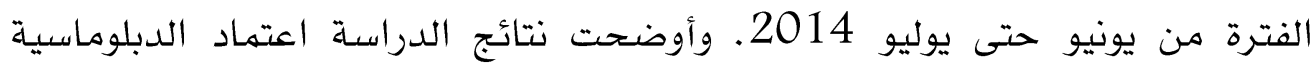

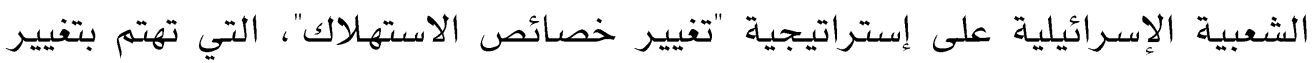

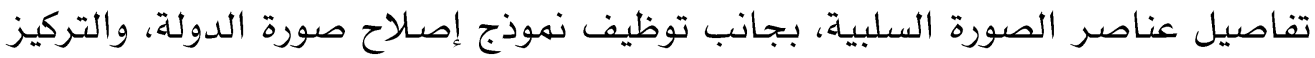

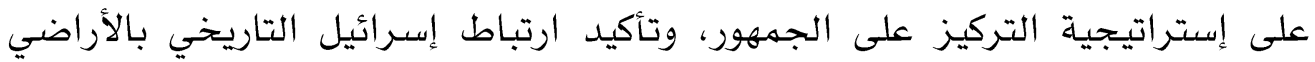

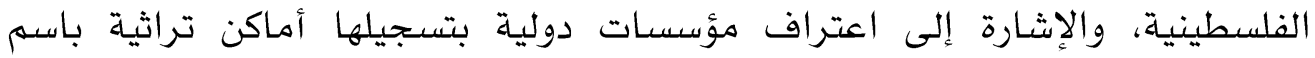

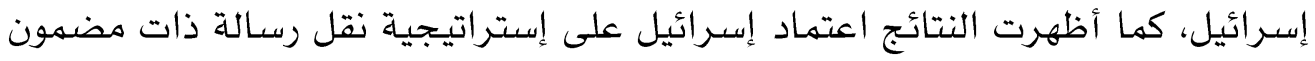

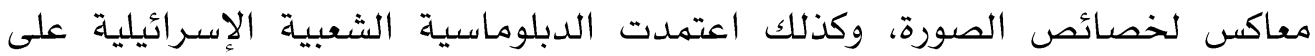
أسلوب القوالب النمطية لتعكس صورة الذات وكنة 


\section{التعليق على الدراسات السـابقة:}

1- يلاحظ قلة الدراسـات السـابقة العربية والأجنبية التي تتاولت الدبلوماسية الشعبية الرقمية الفلسطينية، وكان تركيز أغلب الدراسـات على أسـاليب توظيف الجانب الإسـرائيلي لشبكات التواصل الاجتهاعي من أجل الدعاية ِوْ إطار الصراع، وتحسين صورتها بالدبلوماسية العامة والشعبية. 2- تعددت الدراسات العربية والأجنبية التي تتاولت كيفية تقديم القضية الفلسطينية عبر شبكات التواصل الاجتماعي، وركَّز أغلبها على الجانب التحليلي

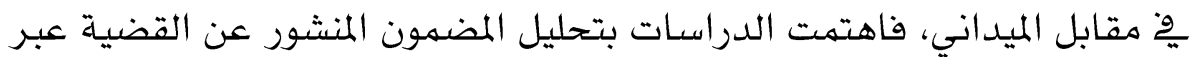
شبكات التواصل الاجتماعي، ويخ مقدمتها تويتر، وفيسبول، ويوتيوب، بالاعتماد

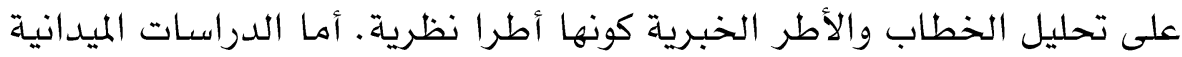
فكان تطبيقها إما على جههور النخبة والناشطين السياسيين، أو الشباب

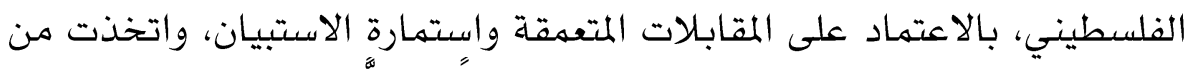
نظرية الاعتهاد، والاستخدامات والإشباعات إطارا نظريا. 3- حللت الدراسات السابقة محتوى الصفحات والحسابات الإسـرائيلية الناطقة بالعربية، سواء كانت رسـمية أو غير رسهية، لكن لم تتطرق الدراسـات إلى تحليل خطاب التلاعب السياسي پِّ الصراع.

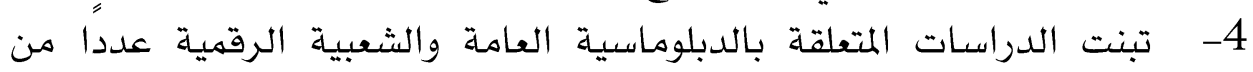
المداخل النظرية، شملت: الوسـاطة، ومدخل إدارة الصراع، ونموذج إصـلاح الصورة الذهنية، ومدخل تحليل الخطاب، ونموذج (Van Ruler)

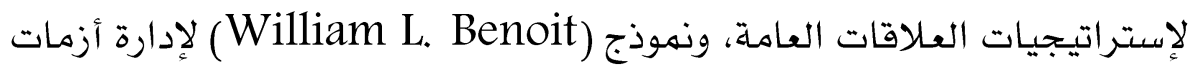
الصورة الذهنية للدول، ونهوذج (Van Dijk) لدراسـة الخطاب الأيديولوجي.

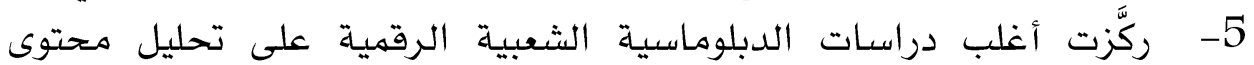
الحسابات الرسـية عبر تويتر لوزارات الخارجية والقنصليات؛ كونها منصة لبناء أجندة الحكومات، وبناء صورة الدولة، إضـافة إلى الدبلوماسية الثعبية

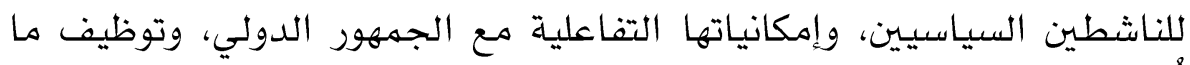
يعرف بـ"دبلوماسية الهاشتاج)" . 
1- معرفة كيفية تتاول الدراسـات السـابقة قضية الصراع الفلسطيني الإسـرائيلي عبر شبكات التواصل الاجتماعي، مما أفاد ِِّ بلورة مشكلة الدراسـة ومنهجيتها،

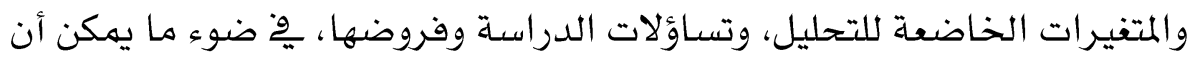
تضيفه الدراسـة لتلك الأدبيات. 2- صياغة الإطار المنهجي والإجرائي للدراسـة الحالية، ومعرفة كيفية التطبيق العملي فيما يتعلق بتحليل التفريدات المنشورة بالحسابات الرسـمية للناشطين

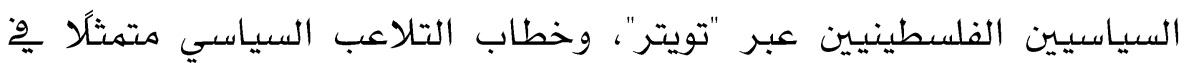

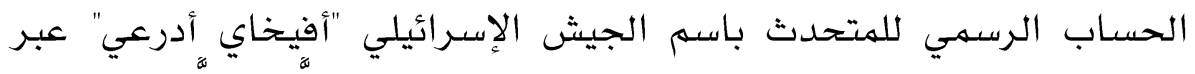
"تويتر"، وكيفية صياغة استمارة تحليل الخطاب وتطبيقها كميا وكيفيا . 3- تحديد الأطر النظرية والمعرفية المستخدمة وفخ دراسة الدبلوماسية الرقمية

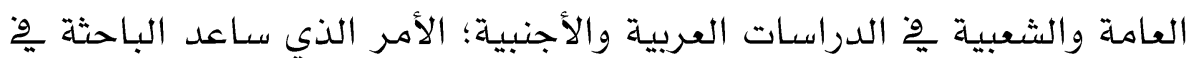

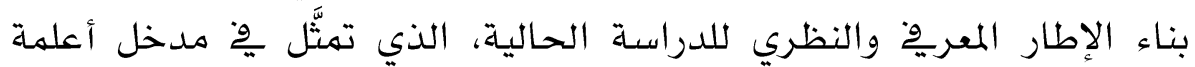
السياسـة ومدخل تحليل الخطاب.

اللدراسة الاستطلاعية: الاسية

لتحديد مشكلة الدراسـة بدقة، أجرت الباحثة دراسـة استطلاعية بهدف الكثف عن عدد من المحددات والمتغيرات المتعلقة بالدراسـة الحالية، وتمثلت آليات إجراء الدراسـة الاستطلاعية مِّ الآتي:

1-متابعة حسابات الناشطين السياسيين الفلسطينيين خلانل فترة العدوان الإسـرائيلي على غزة من 6 حتى 21 مايو عام 2021، وبعد حصر حسابات الناشطين الفلسطينيـين، استبعدت الباحثة الحسابات غير الرسـيـية على تويتر،

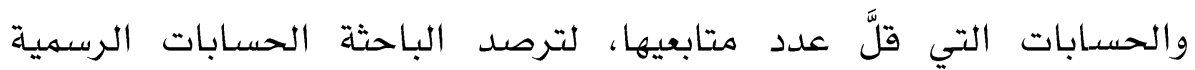
للناشطين السياسيـين التي تتميز بوضنع علامهة زرقاء اللون بجانب اسهم الحسـاب. 2-تحديد الحسابات الرسـمية للناشطين السياسيين الفلسطينيين عبر تويتر، التي كانت فاعلة ِوْ الدبلوماسية الشعبية الرقمية خلال فترة العدوان الإسـرائيلي على غزة من 6 حتى 21 مايو 2021، وشهملت: 


\begin{tabular}{|c|c|c|c|}
\hline عدد المتابعين & الحساب الرسمى عبر تويتر & اسم الناشط السياسى & r \\
\hline 377.3 ألف & https://twitter.com/Dima_Khatib & ديمة الخطيب & 1 \\
\hline 341.8 ألف & https://twitter.com/adham922 & أدهم أبو سليمة & 2 \\
\hline 332.7 ألف & https://twitter.com/MohamdNashwan & محمد سعيد نشوان & 3 \\
\hline 295.4 ألف & https://twitter.com/rdooan & رضوان الأخرس & 4 \\
\hline 193.1 ألف & https://twitter.com/Farah_Gazan & فرح باكر & 5 \\
\hline 138.4 ألف & https://twitter.com/khaledsafi & خالد صايْ & 6 \\
\hline 62.6 ألف & https://twitter.com/mohamed_mdn & محمد المدهون & 7 \\
\hline 51 & https://twitter.com/TareqFarra & طارق الفرًا & 8 \\
\hline 33.8 ألف & https://twitter.com/nidalalwaheidi & نضال الوحيدي & 9 \\
\hline 22.8 ألف & https://twitter.com/abierkhatib & عبير خطيب & 10 \\
\hline
\end{tabular}

3-وبذلك تمثلت عينة الدراسة بالنسبة للناشطين السياسيين الفلسطينيين فو

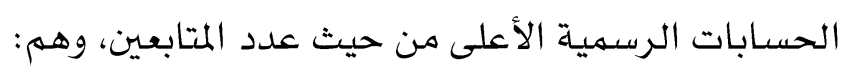

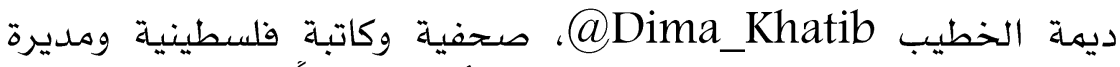

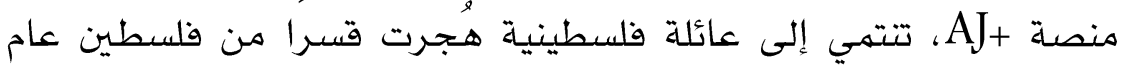

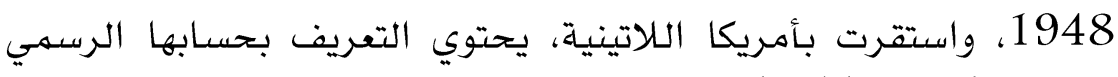

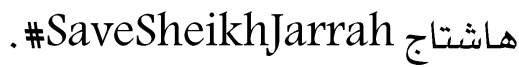
أدهم أبو سليمة adham922، هاشط سياسي فلسطيني بارز ومحلل سياسي وباحث يِّ العلاقات الدولية، له عدد من المقالات المنشورة، ويتضهن 
اسمى الحساب الرسـهي على تويتر هاشتاج \#فلسطين، بجانب علم فلسطين،

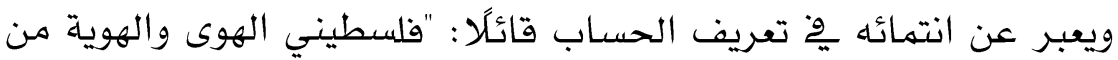

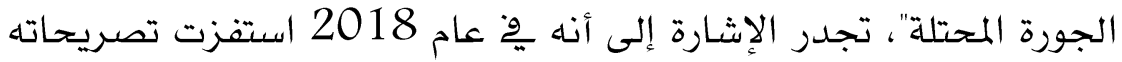

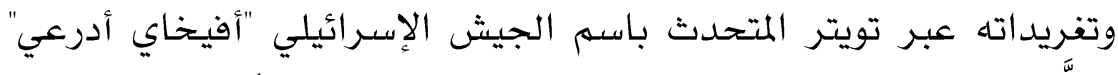

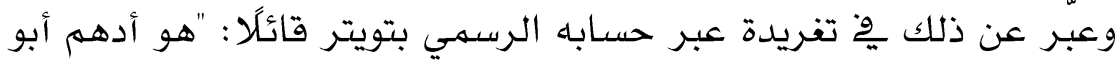

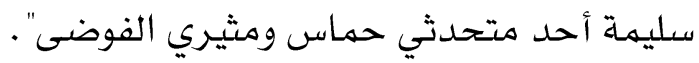

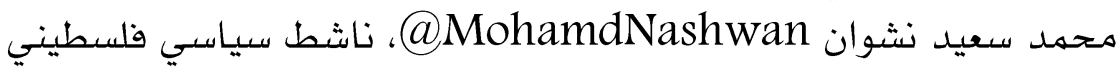

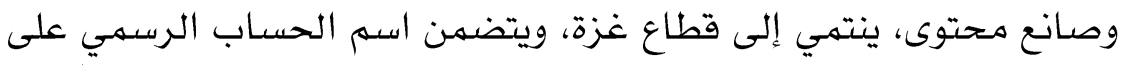

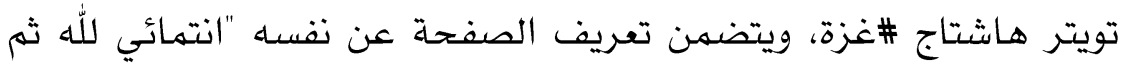

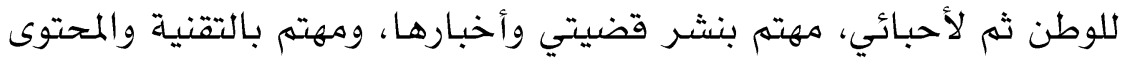

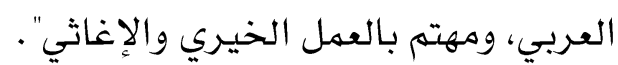

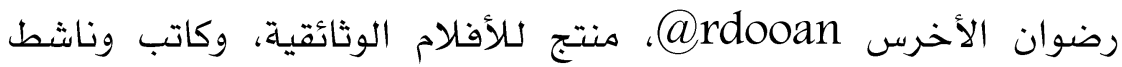

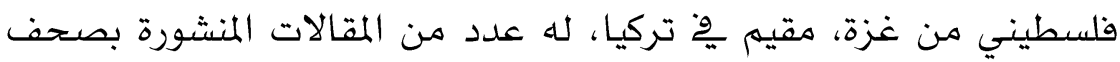

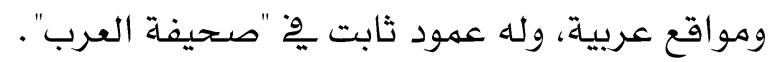

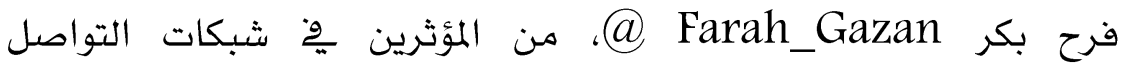

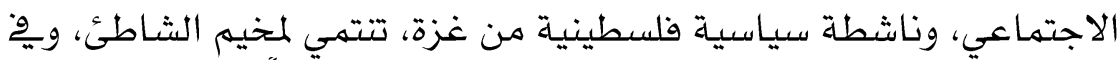

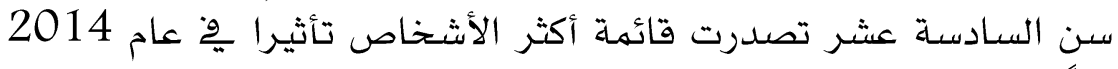
وفقًا لتصنيف مجلة "Forigen Policy" الأمريكية، وذلك بسبب تغريد تلفريداتها

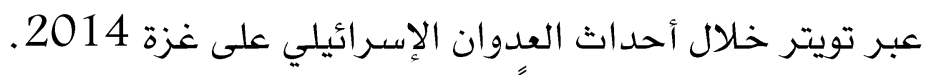

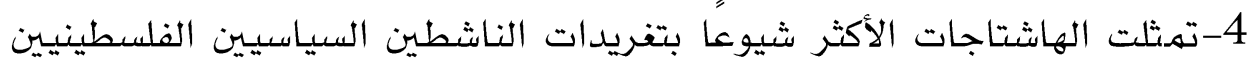

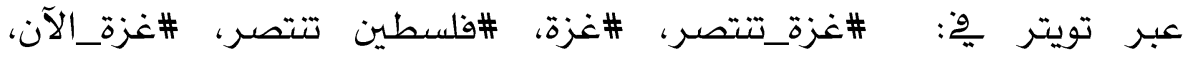

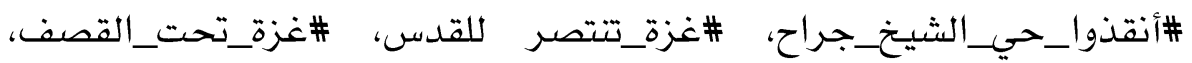

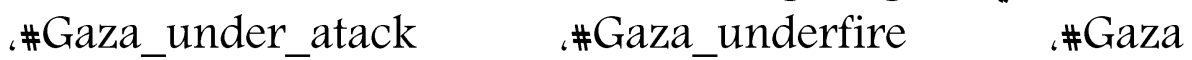
.\#Israel_exposed،\#free_Palestine ،\#Israel_terrorist 5-أها بالنسبة لخطاب التلاعب السياسي الموجه من الجانب الإسـرائيلي، فقد تمثَّل

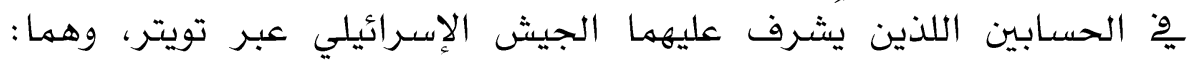

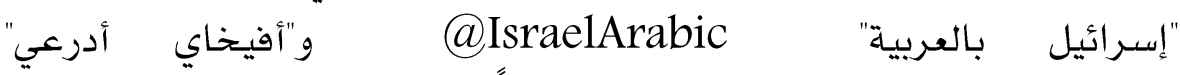

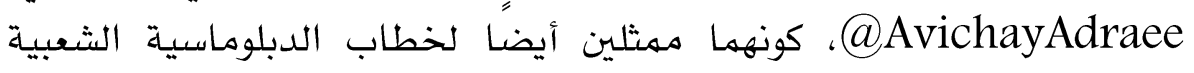
الإسرائيلية الموجهة إلى العرب، ويبلغ عدد المتابعين 444.4 ألف متابع، الفيل الفئل 
و434.8 ألف متابع على التوالي؛ إلا أن الحساب الرسمي للمتحدث باسهم

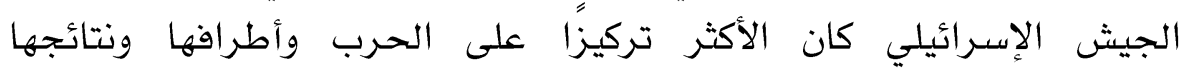

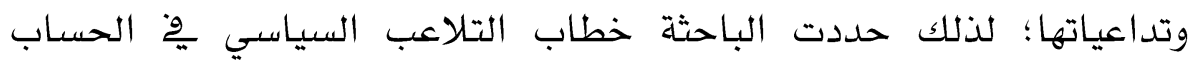
مشكلة الدراسة: الرسمي لـ"أفيخاي أدرعي" عبر تويتر .

تمثلت مشكلة الدراسة پوْ السعي لتحديد بنية خطاب الدبلوماسية الشعبية الرقمية ومرتكزاته، ومعرفة طبيعة الرموز ودلالتها المختلفة والآليات الخطابية

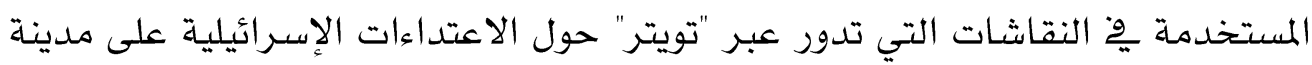
القدس وقطاع غزة عقب أزمة حي الشيخ جراح (Tweets)

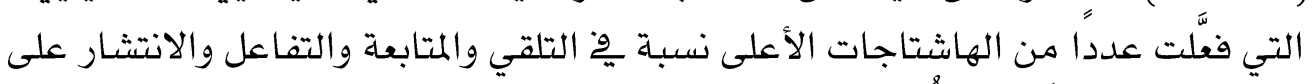

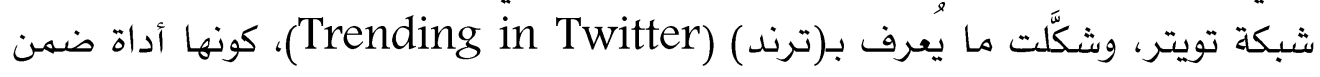

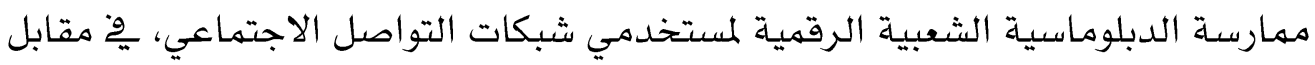

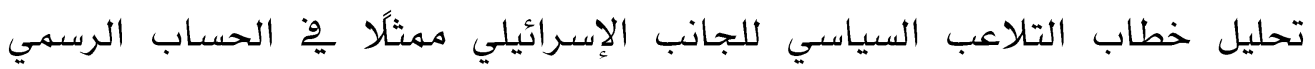

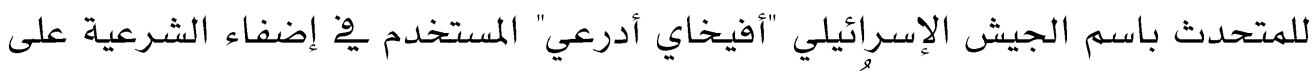

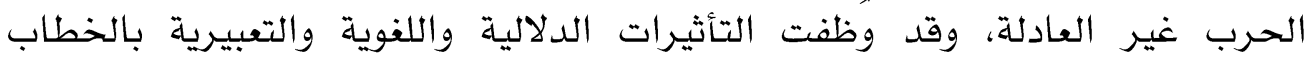

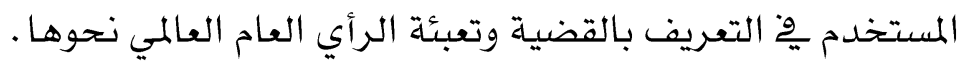

أهمية الدراسة:

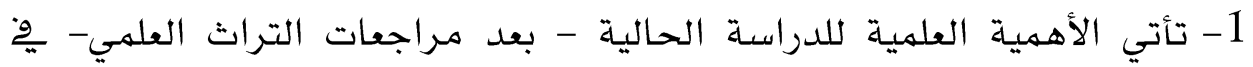

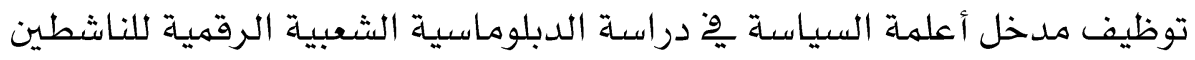

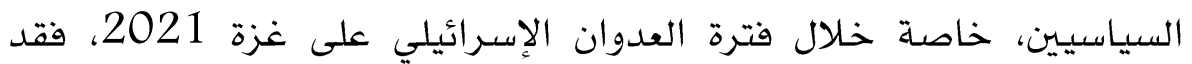

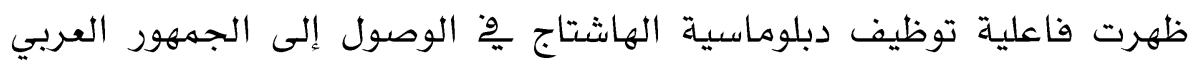
والعالمي وصناعة رأي عام عالمي مناهض لكاعلاعتداءات الإسرائيلية.

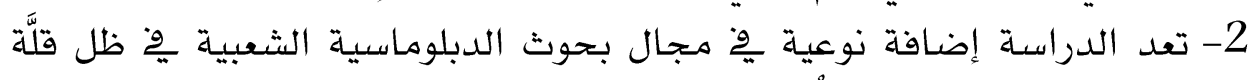

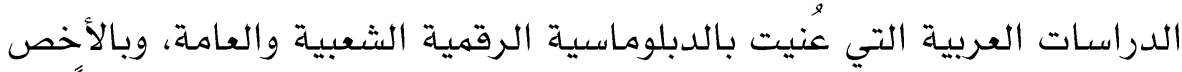

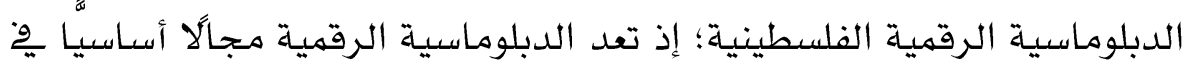

تحقيق أهداف السياسـة الفلسطينية على مستوى العلاقات الإقليمية والدولية.

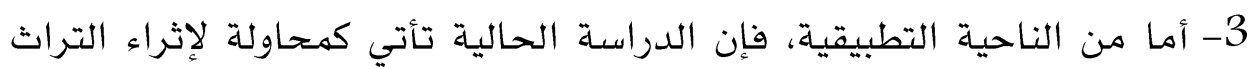

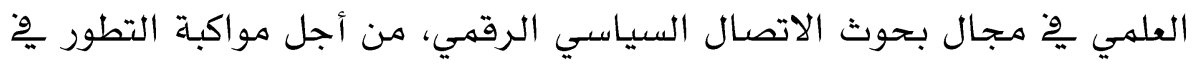


بحوث الاتصال السياسي، وتحديد مؤشرات توظيف شبكات التواصل الاجتماعي بِّ2 الدبلوماسية الرقمية.

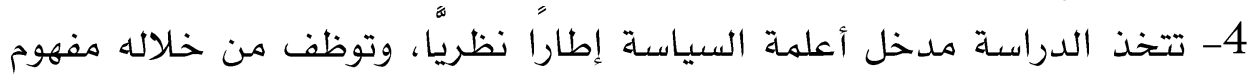
التلاعب السياسي ومفهوم الدبلوماسية الشعبية الرقمية، بالاعتماد على التحليل التهليل النقدي للخطاب. - ابل 5- التركيز على الدبلوماسية الثعبية الرقمية بالتحديد واستخدامها بوصفها أداة

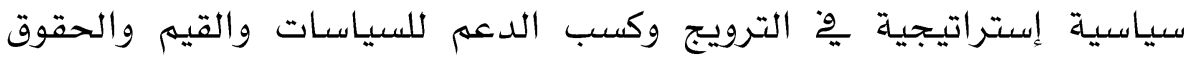

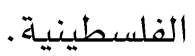

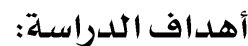
تهدف الدراسة الحالية إلى: 1- تحديد سهات الثكل والمضمون، من حيث لغة التغريدة وشكلها وتطبيقاتها

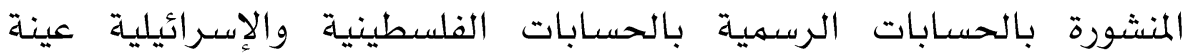
الدراسـة. 2- رصد الهاشتاجات المستخدمة ِِّ إطار "دبلوماسية الهاشتاج" عبر تغريدات الحسابات الرسمية الفلسطينية والإسـرائيلية عينة الدراسة.

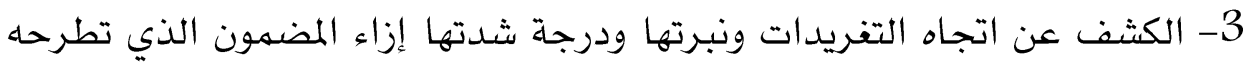
الحسابات الرسمية الفلسطينية والإسـرائيلية عينة الدراسـة.

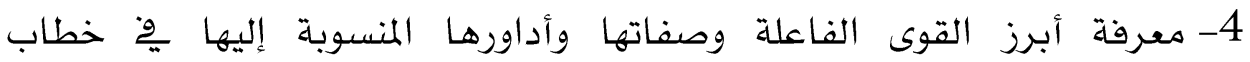

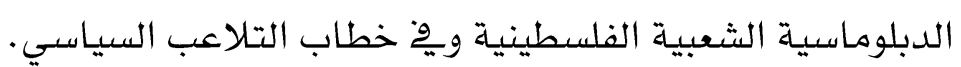

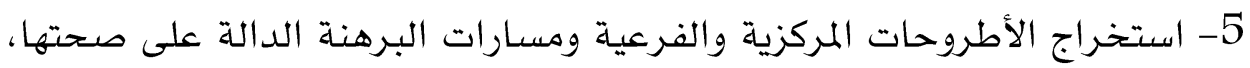

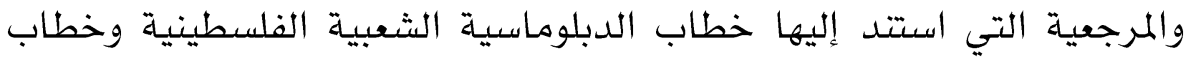

$$
\text { التلاعب السياسي. }
$$

6- تحليل فئات السياق والإستراتيجيات التي ارتكز عيها خطاب الدبلوماسية الشعبية الفلسطينية وخطاب التلاعب السياسي.

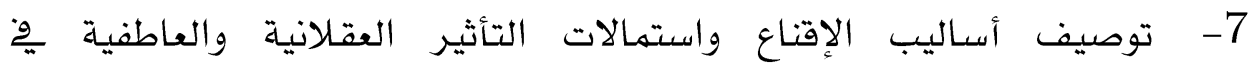

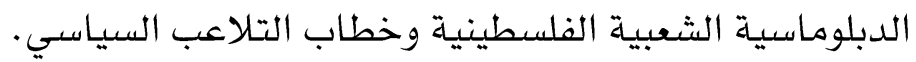
8- تفسير الكيفية التي تعامل بها خطاب الدبلوماسية الشعبية الرقمية الفلسطينية وخلية الفية الفيلية مع خطاب التلاعب السياسي الإسـرائيلي. 
أولاً: مدخل الأعلمة Mediatization Approach

يعرف مدخل الأعلمة يِّ الأدبيات السابقة على أنه تحويل أي مجال إلى البيئة

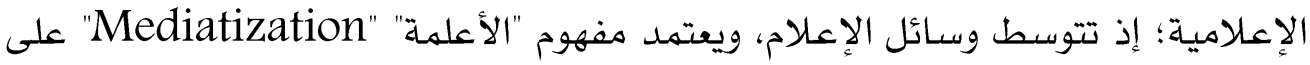

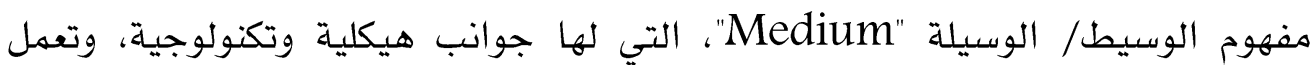

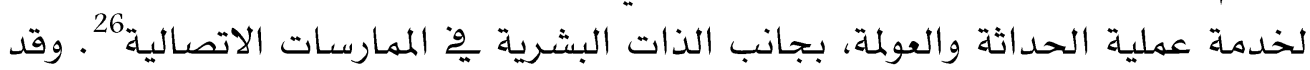

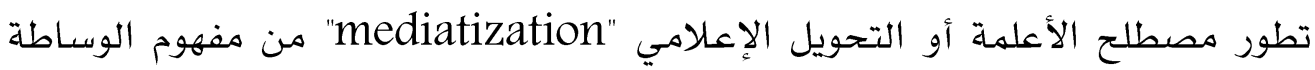

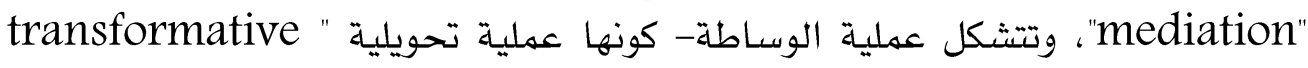
process

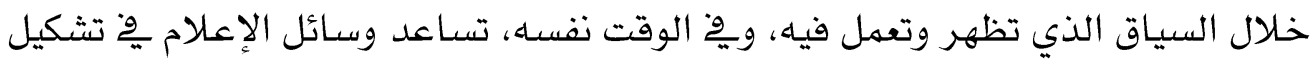

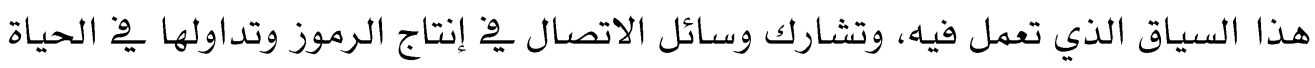

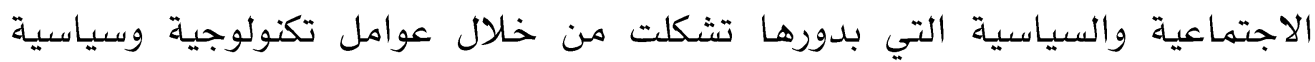

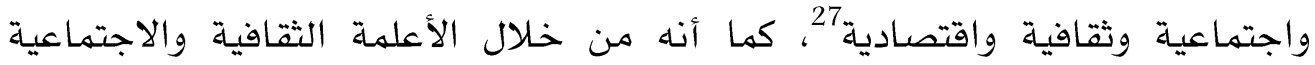

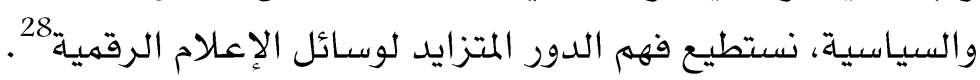

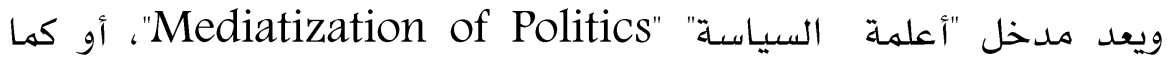

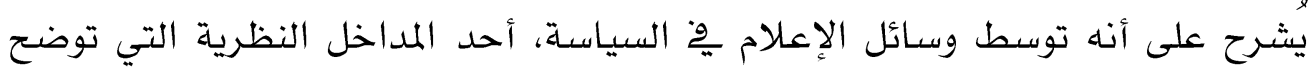

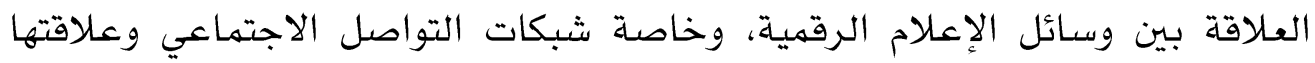

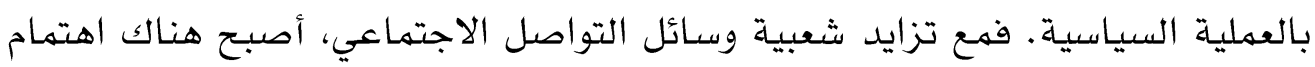

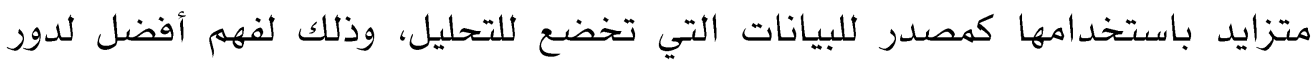

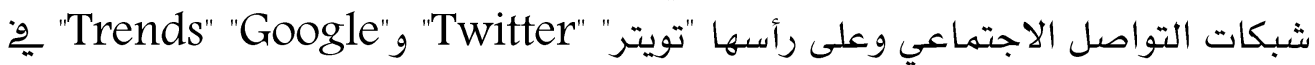

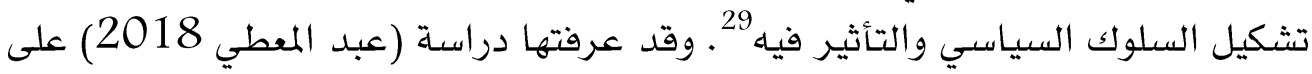

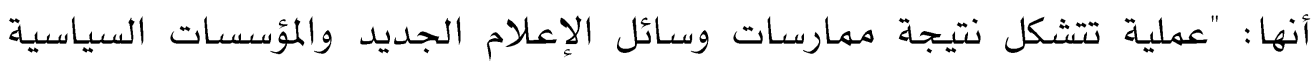

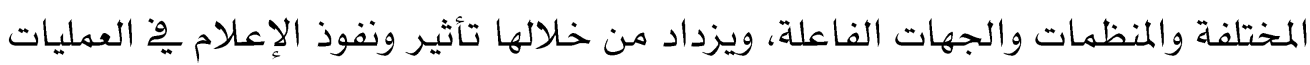
السياسية وٍِِ المؤسسات والفاعلين السياسيسين"

ولا يمكن النظر إلى وسائل التواصل الاجتماعي على أنها ذاتيات التأثير أحادي

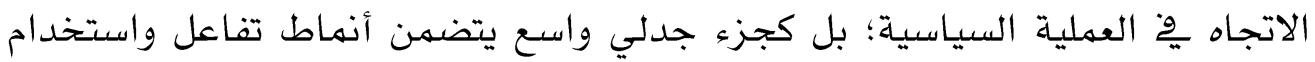

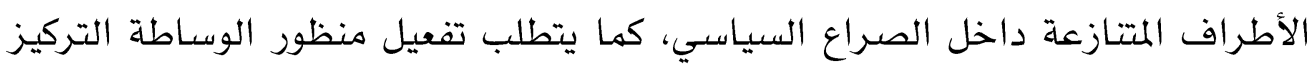

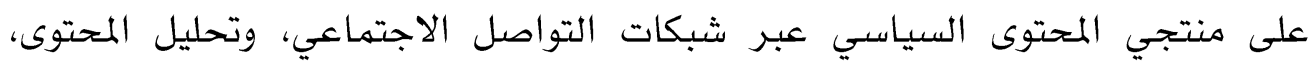

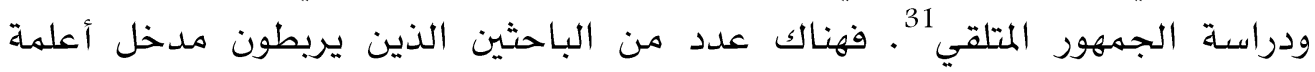


السياسـة بنظرية المجال العام والثقافة الديهقراطية، وبالتحديد عند دراسـة تويتر، أو ما التا

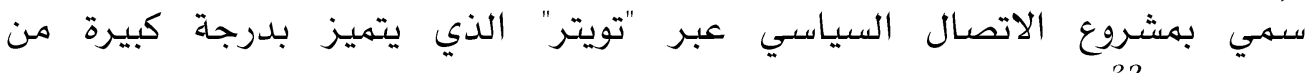
الديناميكية 32

فإذا نظرنا بعمق إلى شبكات التواصل الاجتماعي، وِّ2ْ مقدمتها تويتر، من خلال

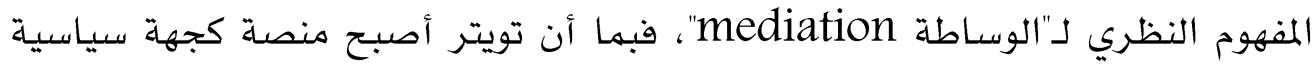

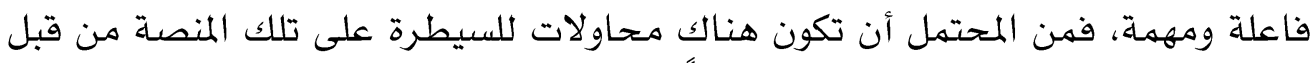

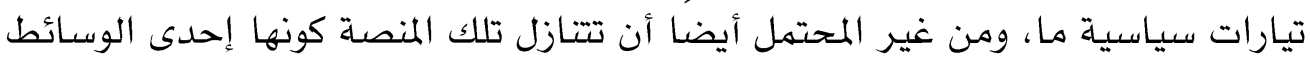

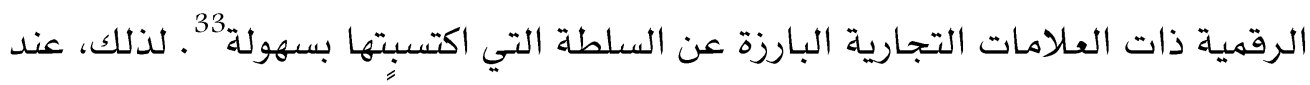

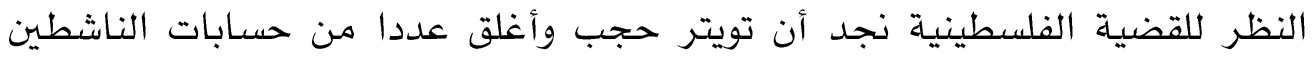

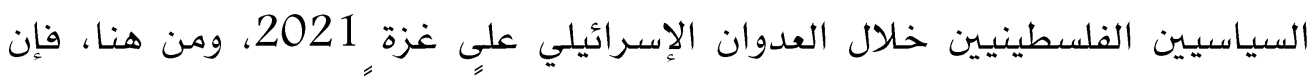

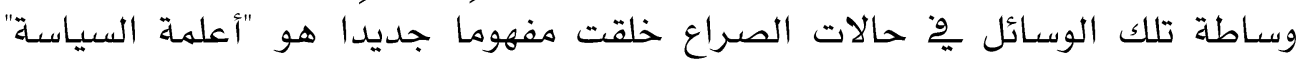

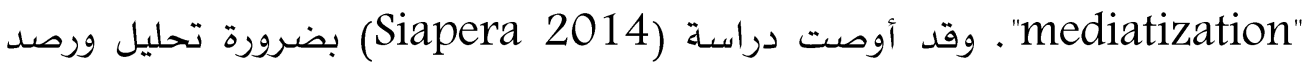
الهاشتاجات المتعلقة بالقضية الفلسطينية عبر تويتر وِ فترات زمنية مختلفة، لتحديد

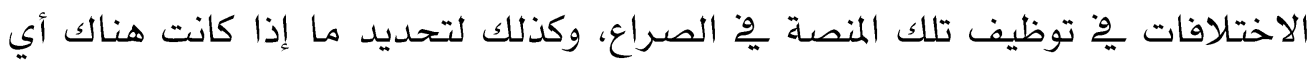

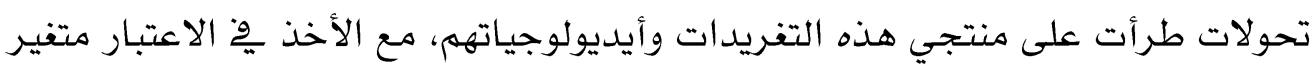

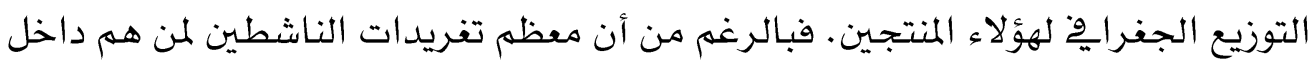

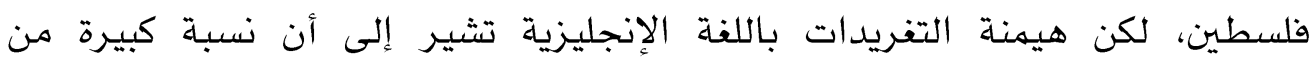

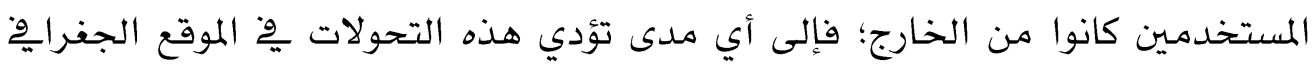

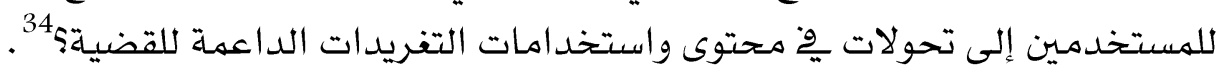

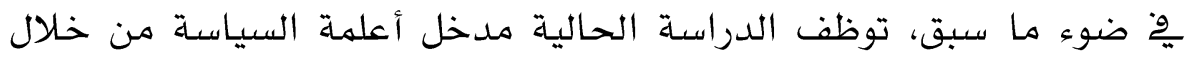

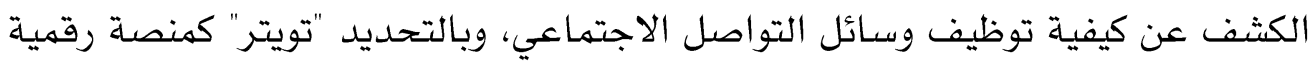

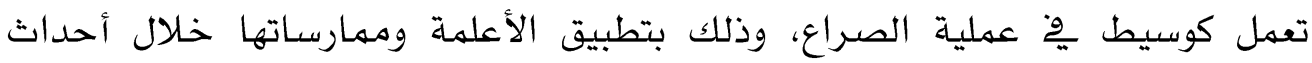
العدوان الإسـرائيلي على غزة 2021، بجانب دراسة الحسابات الرسمية للناشطين

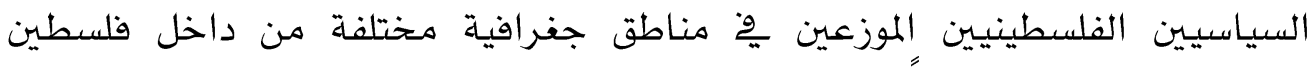

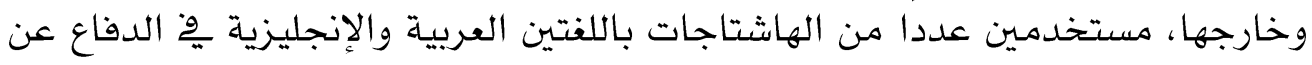

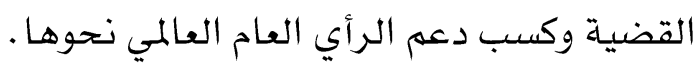

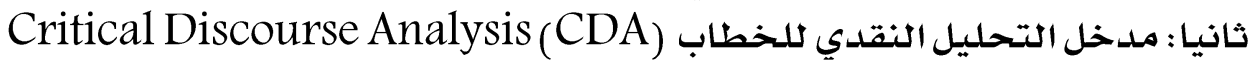
يسعى تحليل الخطاب النقدي إلى إظهار كيف أن الخطابات التي تبدو

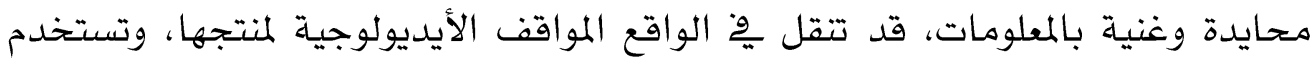




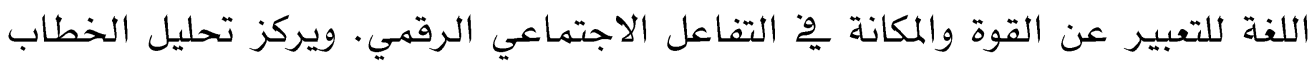

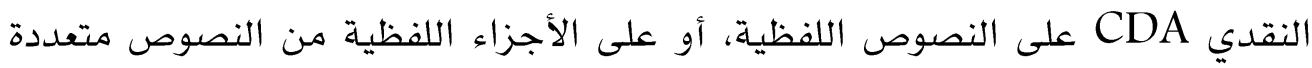

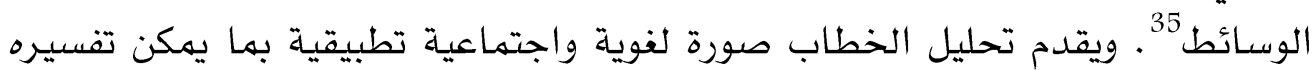

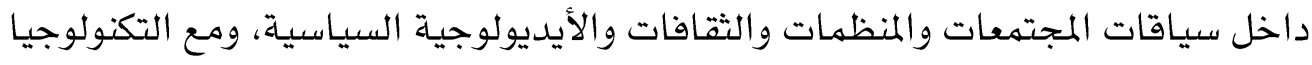

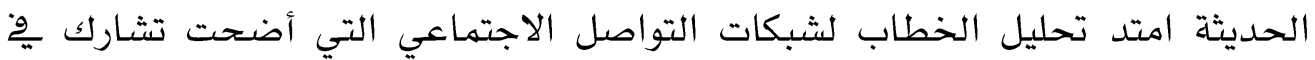

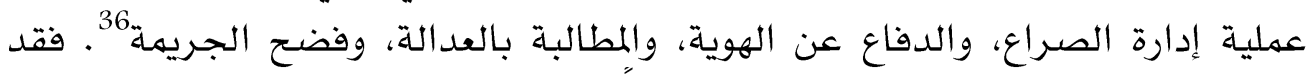

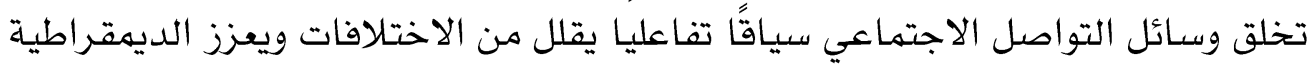

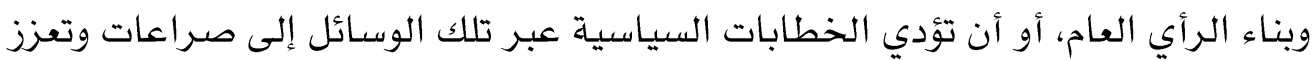

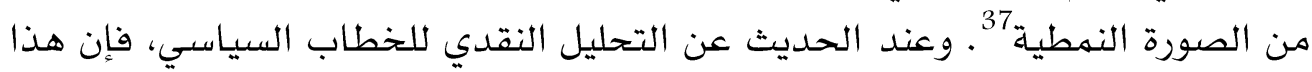
الخطاب يركز على تحليل خطاب الموقف السياسي الاجتماعي " sociopolitical

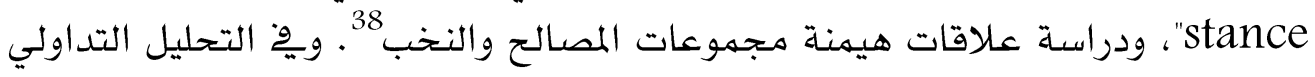

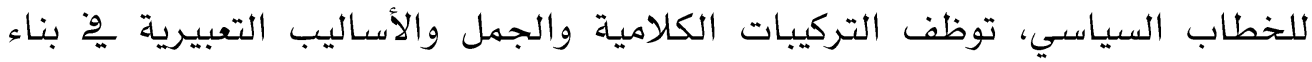

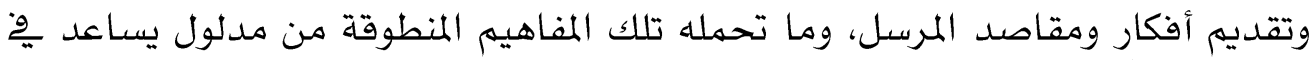

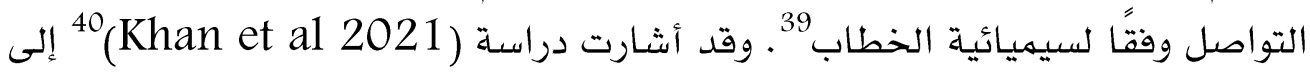

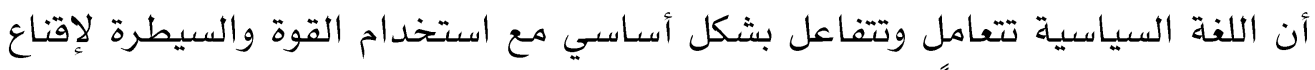
عقول الناس، فهي عادةً ما تبث عبر الإنترنت وتصبح ستريعة الانتشار على وسائل

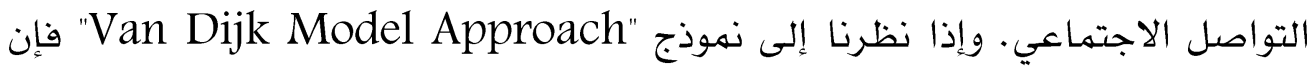

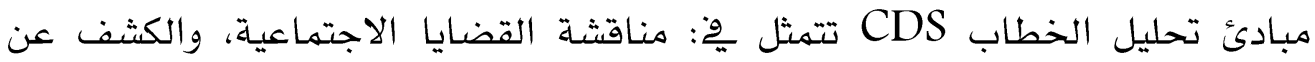

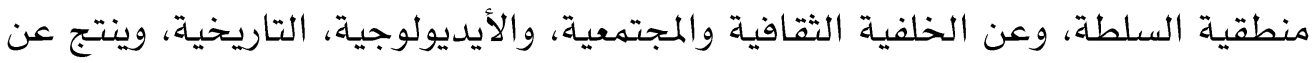

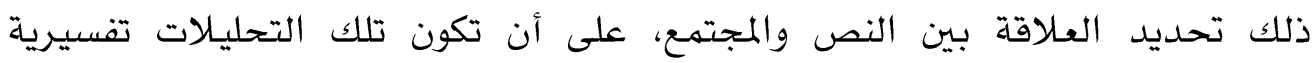

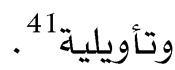

ويعد "تويتر Twitter" منصة مهمة لمشـاركة المواطنين آراءهم حول

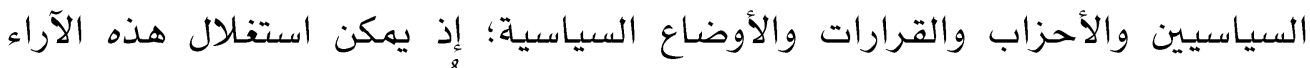

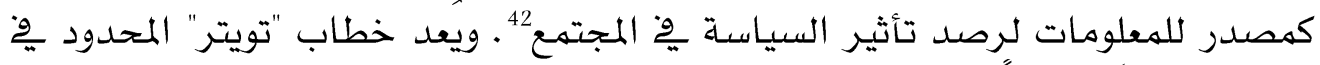

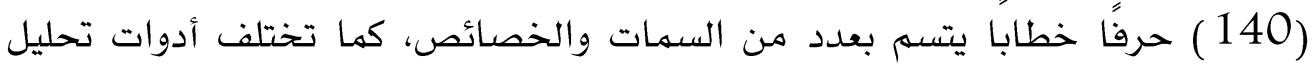

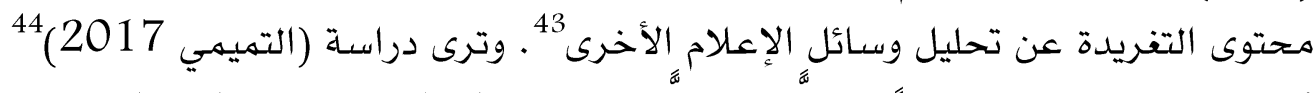

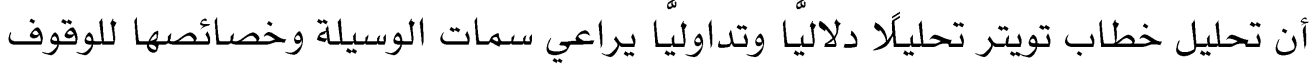

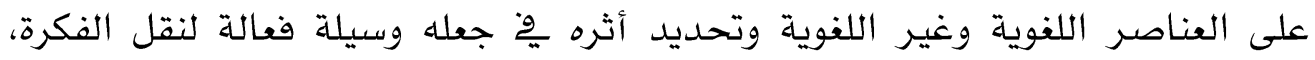
وتحقيق التواصل، وأشكال التأثير المستخدمة؛ فالخطاب عبر ونجر شبكات التواصل 
الاجتماعي هو سلسلة من الجمل المتتاسقة التي تحكمها ضوابط وظروف إنتاجها؛ نظرا

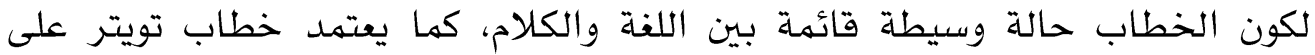
الهاشتاج أو ما يسهى بـ"علامات التصنيف" التي تعد علامة محادثة مشتركة يحتاج

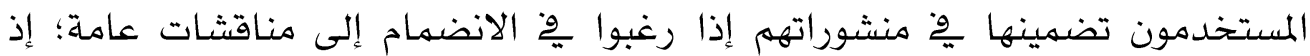
تحاول جماهير الهاشتاج "hashtag publics" الوصول إلى نتائج ملموسـة، خاصة الانفة

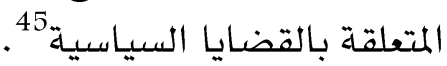
وبذلك، ترى الباحثة أنه عند تحليل خطابات الناشطين السياسيين عبر "توتير" لا بدَّ من

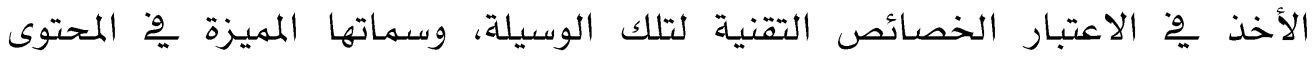

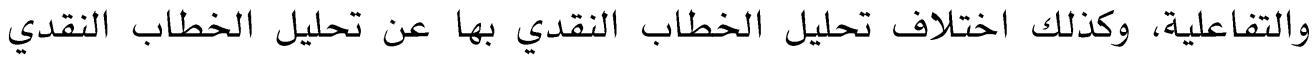
للوسائل الإعلامية التقليدية. عِّ ضوء ما سبق، توظف الدراسة الحالية مدخل تحليل الخطاب النقدي من

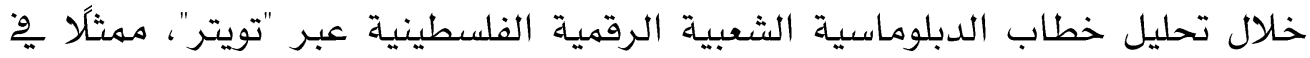
تغريدات حسابات الناشطين السياسيين الفلسطينيين عينة الدراسـة، وكيفية مواجهتها

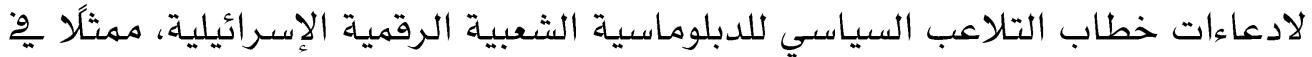
تغريدات الحساب الرسمي للمتحدث العسكري باسهم الجيش الإسـرائيلي "أفيخاي

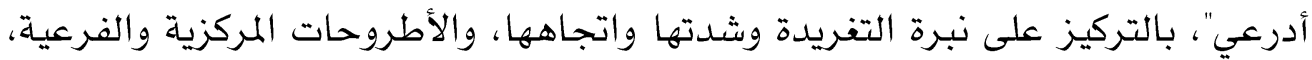

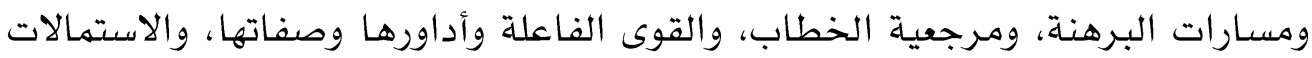

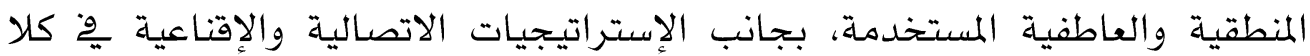

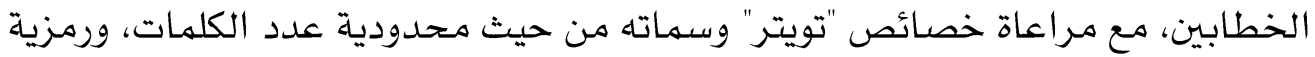

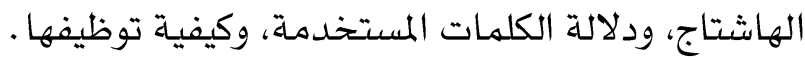

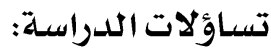

1-ما لغة التفريدة المنشورة بالحسابات الرسهية بالحسابات الفلسطينية والإسـرائيلية عينة الدراسـة العيدة

2-ما الأشكال التي اتخذتها التغريدات المنشورة بالحسابات الفلسطينية والإسـرائيلية عينة الدراسـة التئي

3-ما الهاشتاج المستخدم بِّن التغريدات المنشورة بالحسابات الفلسطينية والإسـرائيلية عينة الدراسـة الماتح

4-ما تطبيقات تويتر التي وظفتها الحسابات الرسمية الفلسطينية والإسـرائيلية عينة الدراسةة 
5- ما اتجاه التغريدات عينة الدراسة إزاء المضهون الذي تطرحه؟

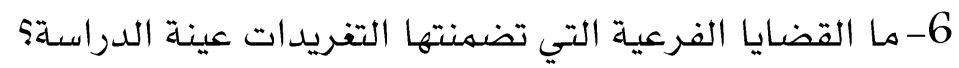

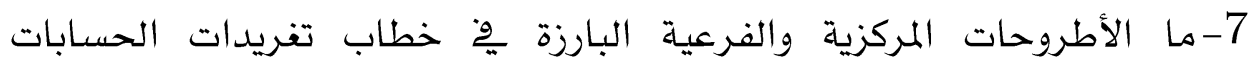

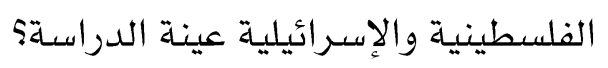

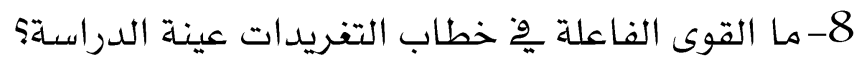

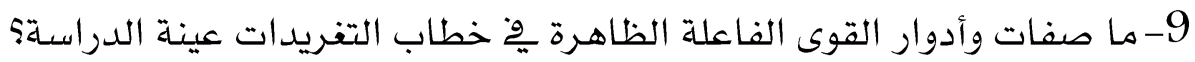

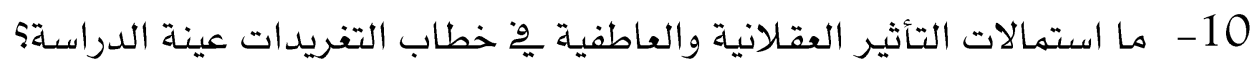

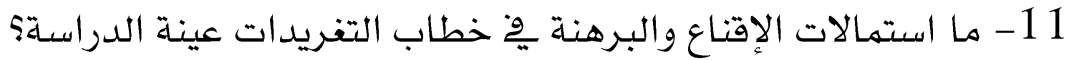

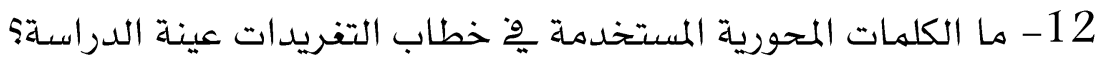

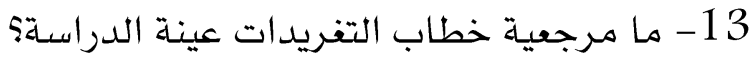

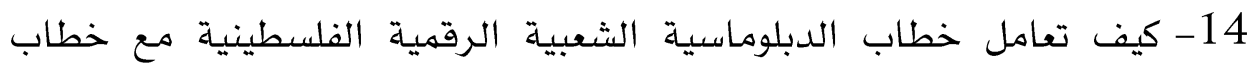

$$
\text { الإجراءات المنهجية للدراسلة: السياسي الإسـرائيلي؟ }
$$

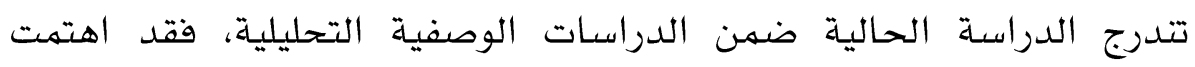
الدراسة برصد وتحليل التغريدات عينة الدراسـة، للوقوف على مدى توظيف الرموز

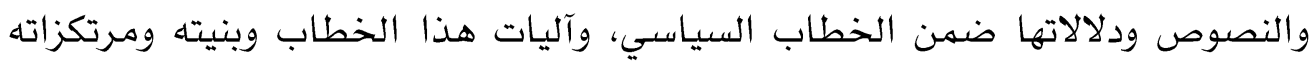

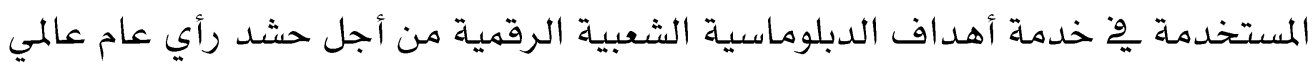

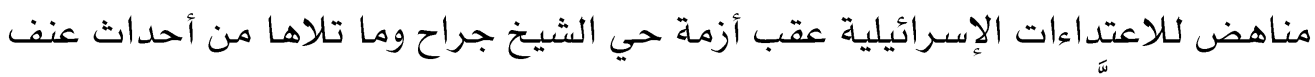

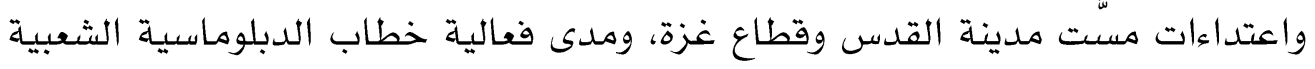

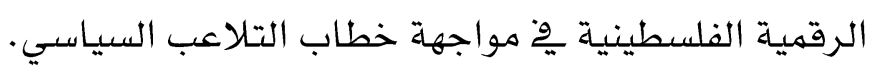

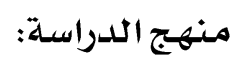

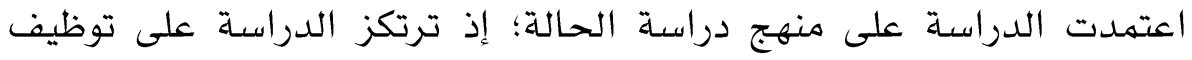

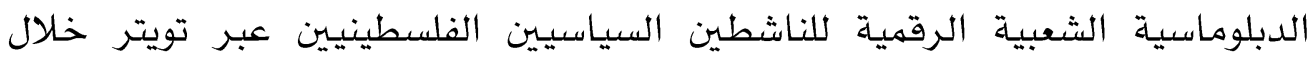
العدوان الإسـرائيلي على غزة 2021، وتحليله كموقف كلي لظاهرة الدبلوماسية الشعبية الشية الشيكية

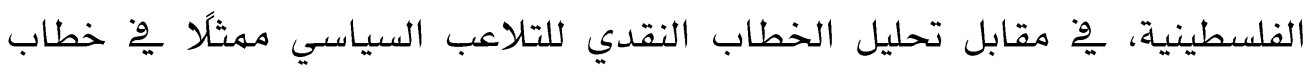

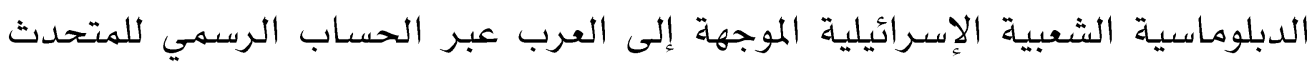

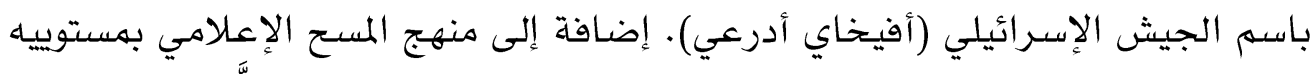

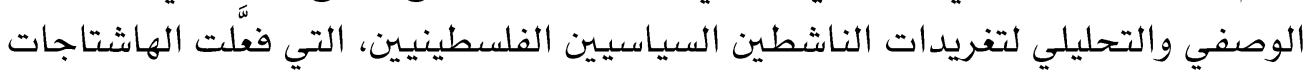


المناهضدة للاعتداءات الإسـرائيلية على غزة عقب أزمة حي الشيخ جراح، وتغريدات

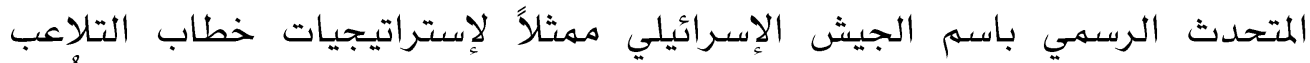

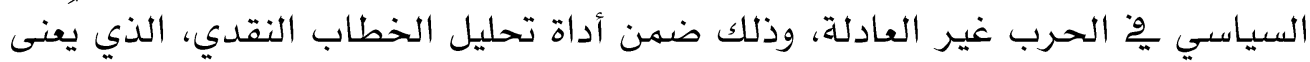

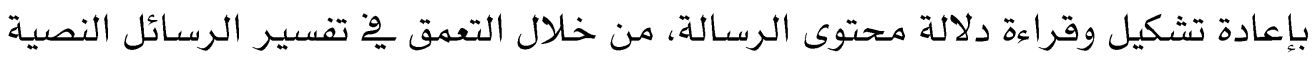
لخطاب الدبلوماسية الشعبية الرقمية الفلسطينية والإسرائيلية.

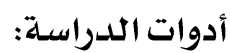

استخدمت الدراسة أداة تحليل الخطاب، وتضهنت عملية التحليل إضافة مجموعة من الفئات الكمية والكيفية لتحليل أطروحات الخطاب، ومسارات البرهنة،

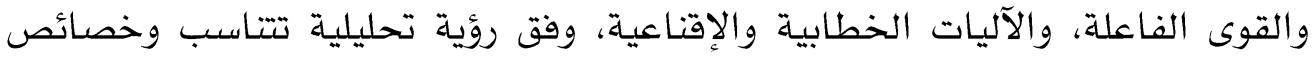

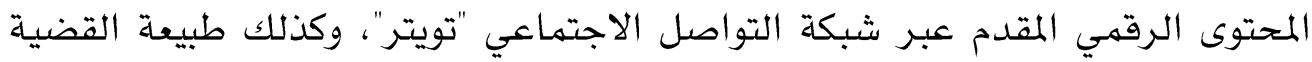

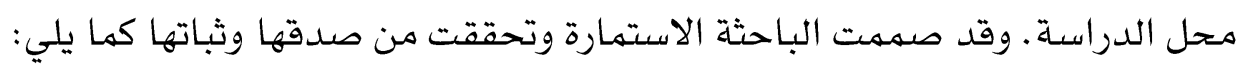

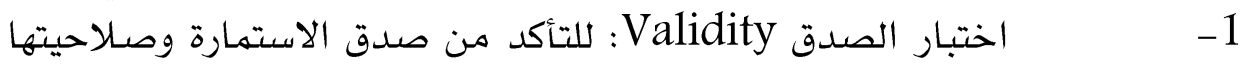

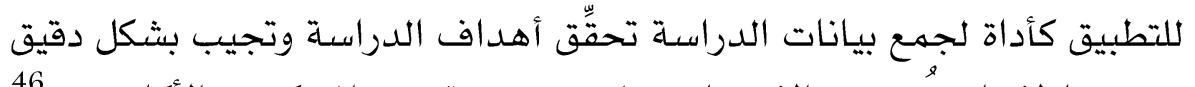

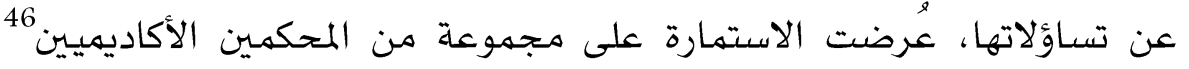
لاستشارتهم وإبداء الملاحظات، وقد أشاروا بصلاحية الاستمارة، بعد إجراء عدد من التعديلات وِّ تقسيم محاور وفنّات التحليل.

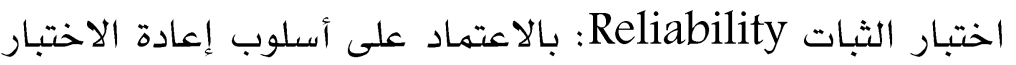
Test-Retest

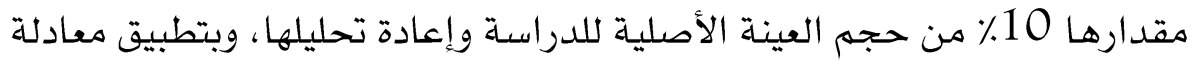
هولستي Holsti نحساب درجة التوافق والثبات:

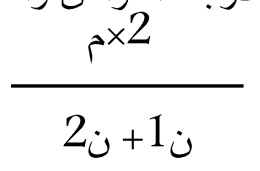

وقد بلغت قيمة معامل الثبات (89٪)، وهي قيمة مرتفعة تشير إلى فاعلية المقياس.

وقد قُسمت محاور استهارة تحليل الخطاب وفئاتها كالآتي:

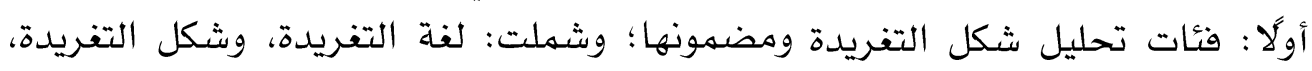

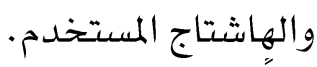

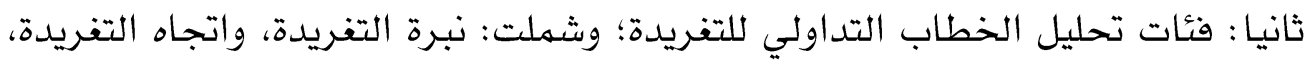

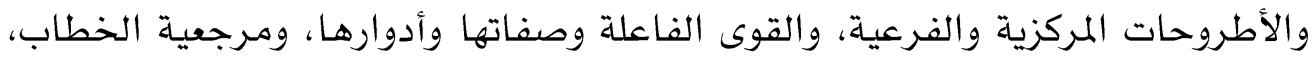


والكلمات المحورية ودلالاتها، واستهالات التأثير العاطفية، واستمالات التأثير العقلانية،

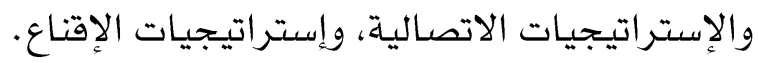

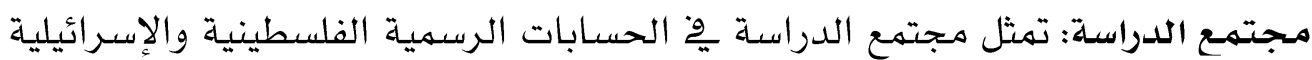
المعبرة عن الدبلوماسية الثعبية الرقمية.

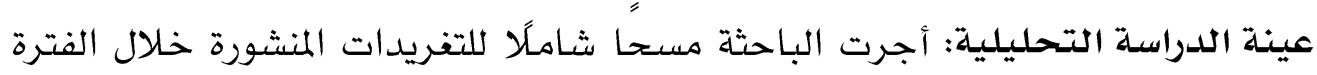

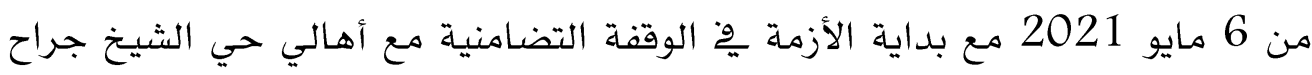

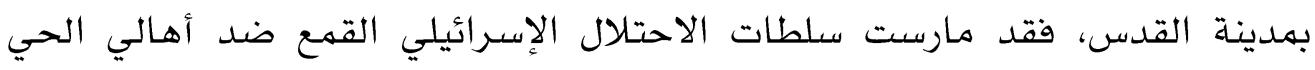

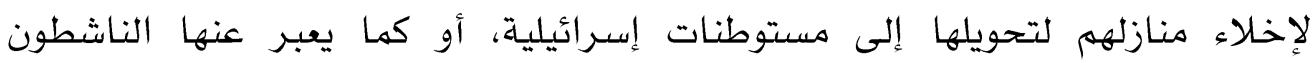

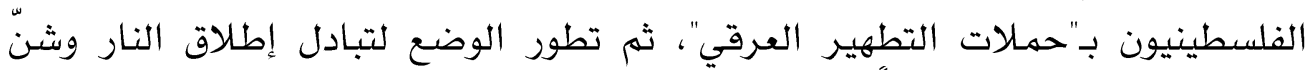

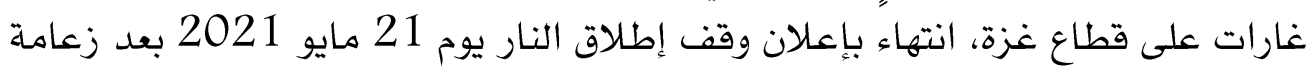

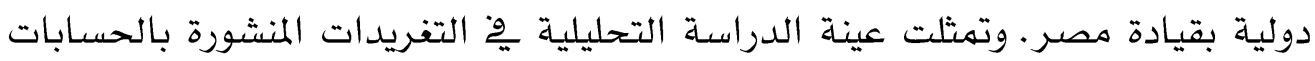

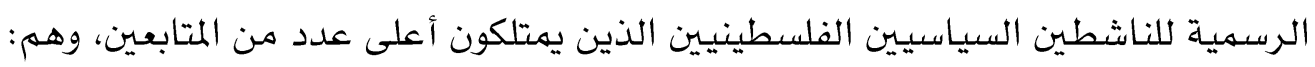

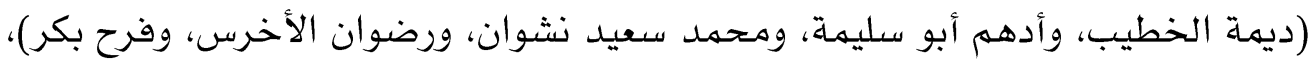

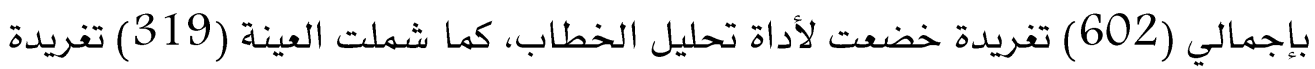

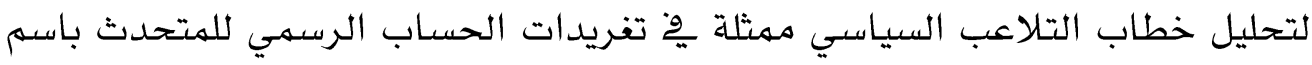

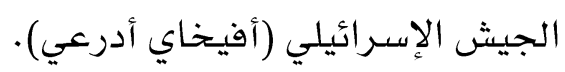

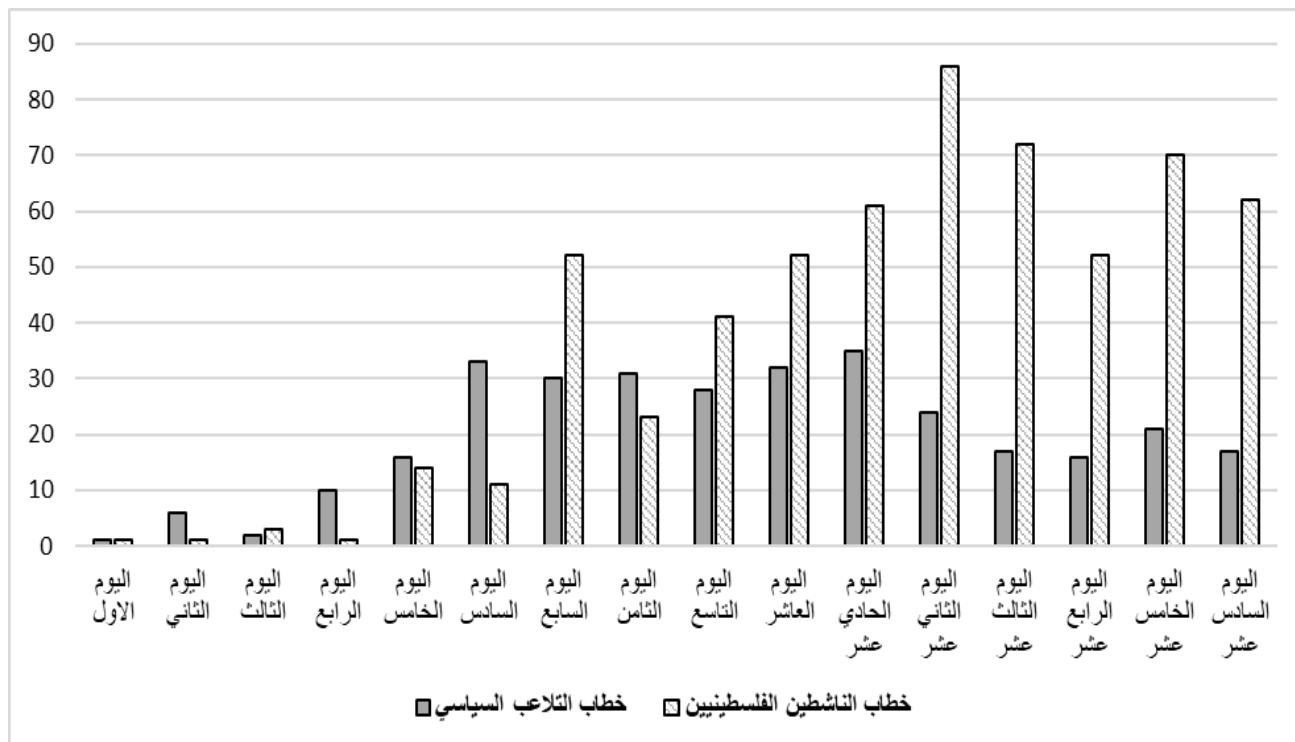

شكل رقم (1 ) : يوضح توزيع أعداد التغريدات زمنيـا للحسابات عينة الدراسة 


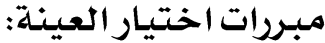

- الحسابات الرسمية للناشطين السياسيين الفلسطينيين عبر تويتر الأعلى من حيث عدد المتابعين، والتي نشرت التغريدات المناهضة لممارسات قوات

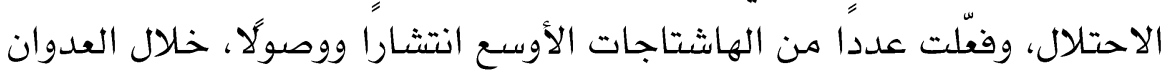

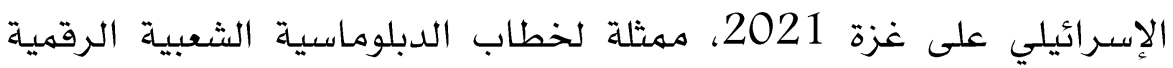

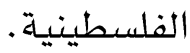
- مثنّلت الحسابات الرسمية فئات مختلفة من الناشطين السياسيين؛ إذ ينتمي كل

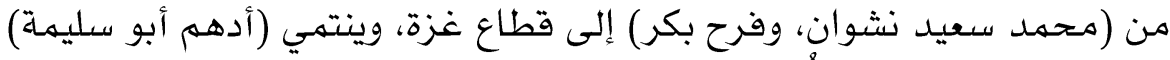

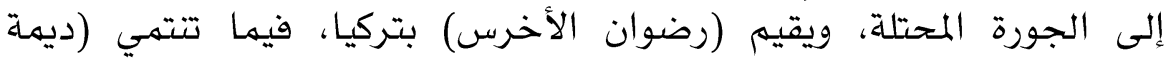

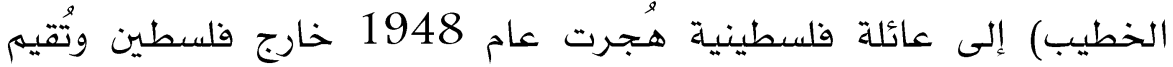

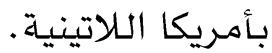

الحساب الرسهي للمتحدث باسهم الجيش الإسرائيلي (أفيخاي أدرعي) الموجها

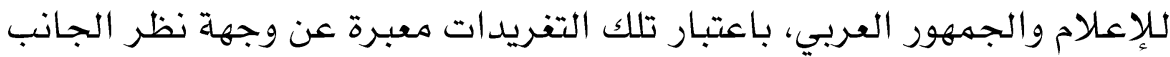

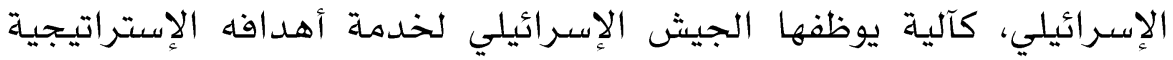

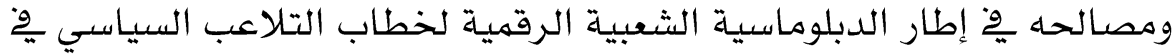

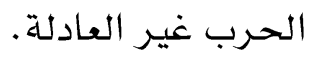

المعاملات الإحصائية المستخدمة فِِ تحليل بيانات الدراسلة:

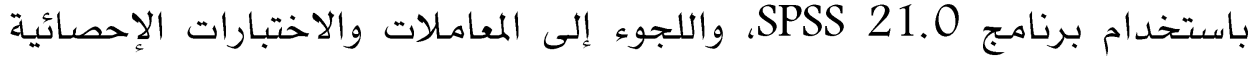
التالية يِّْ تحليل بيانات الدراسـة: التكرارات البسيطة، والنسب المئوية. التعريفات الإجرائية للدراسلة:

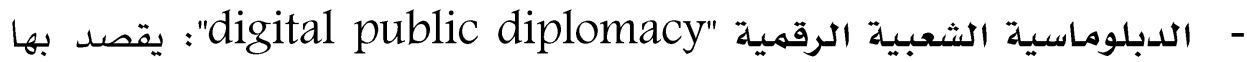

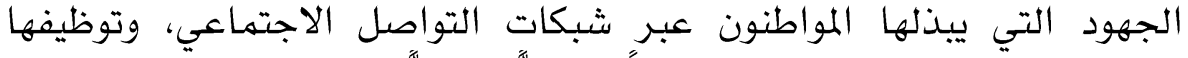

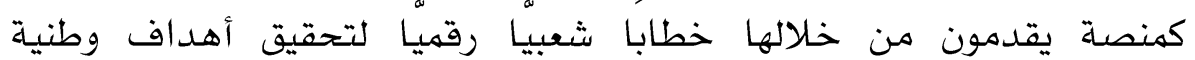
ودبلوماسية، من خلال التفاعل مع مواطني شعوب أخرى، وبناء علاقات تواصل

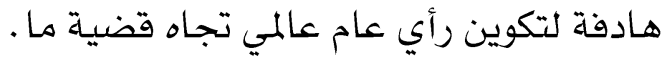
- خطاب التلاعب السياسى "manipulation in political discourse" توظيف الألفاظ ودلالاتها ِِّ إحداث تأثير نفسي وسلوكي مدروس، من أجل

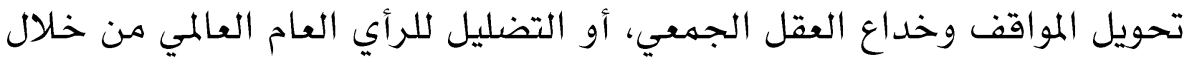




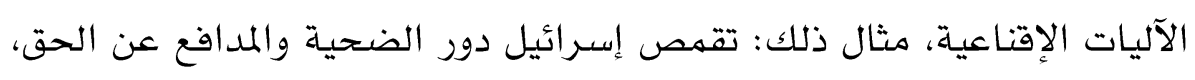

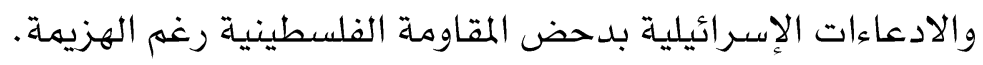

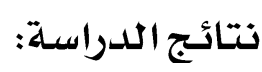

تستعرض الدراسة نتائج تحليل خطاب الدبلوماسية الشعبية الفلسطينية

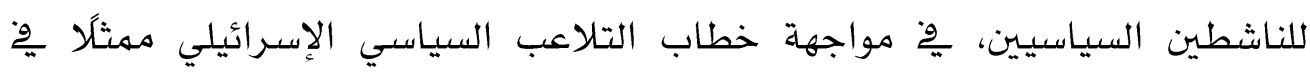

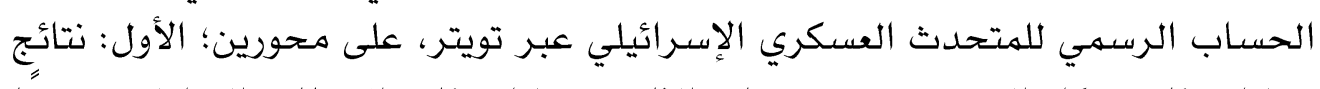

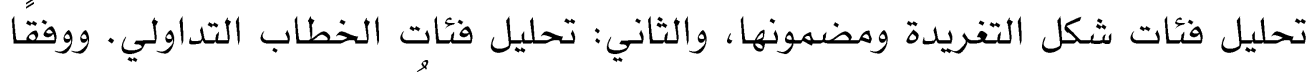

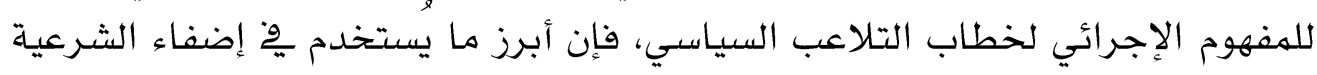

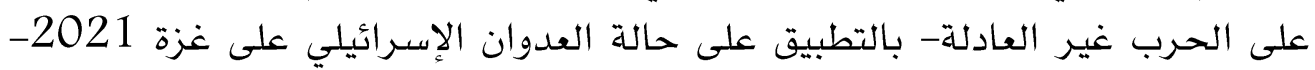

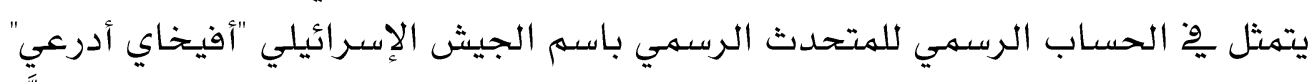

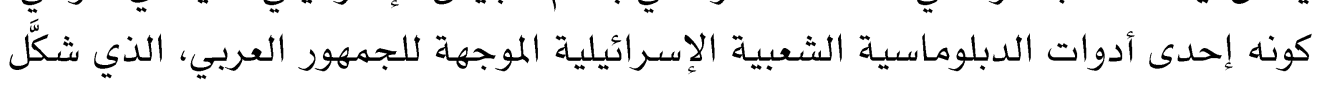

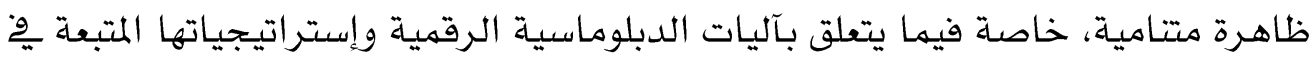

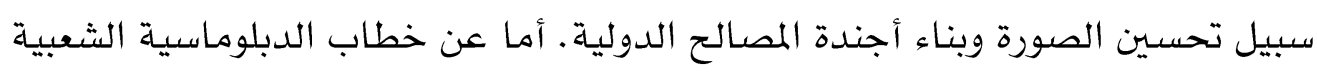

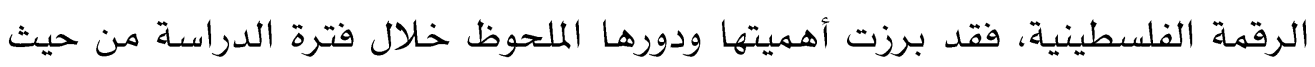

التعريف بالقضية الفلسطينية والتوعية والتعبئة تجاهها .

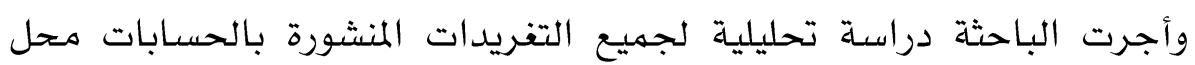

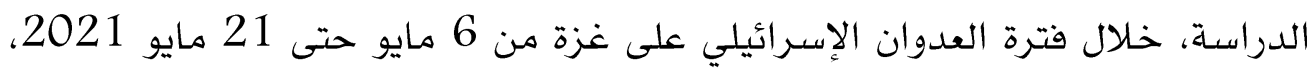

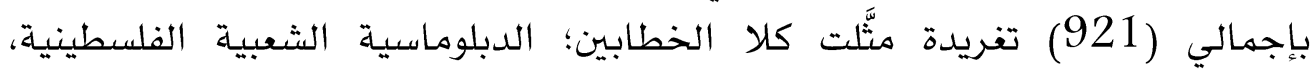

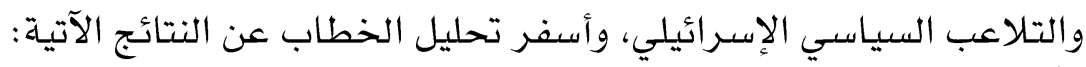

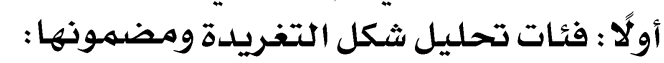
1 - لغية التغريدة تصليل

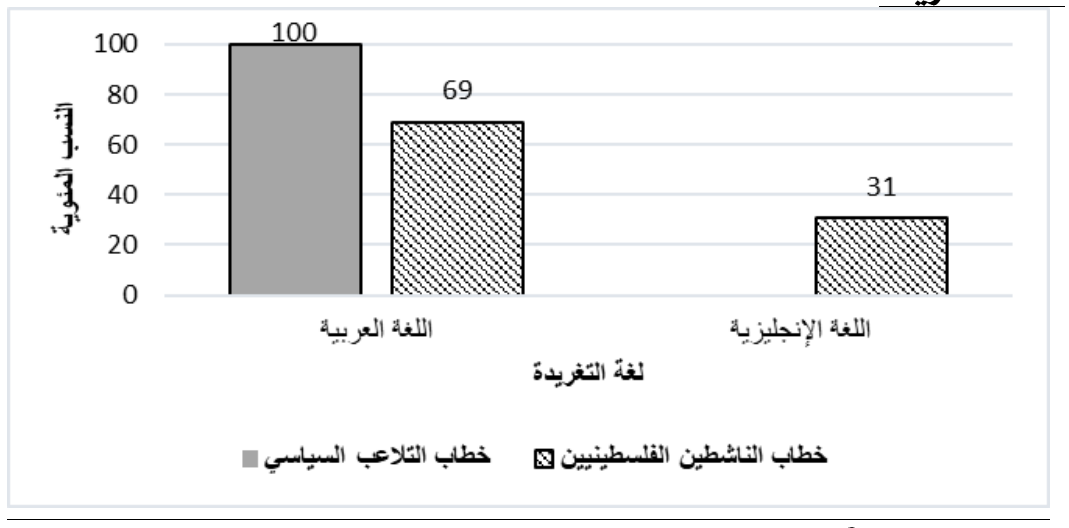

شكل رقم (2) : يوضح النسب المئوية للغة التغريدة بالحسـابات عينة الدراسـة 
يتضح من بيانات الشكل السابق: أن خطاب التلاعب السياسي الإسرائيلي قدٍ

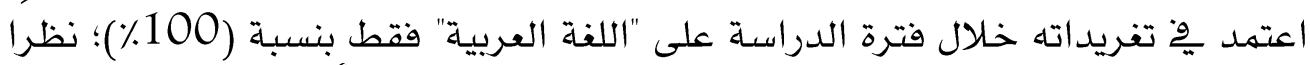

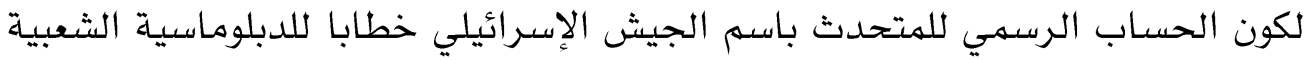

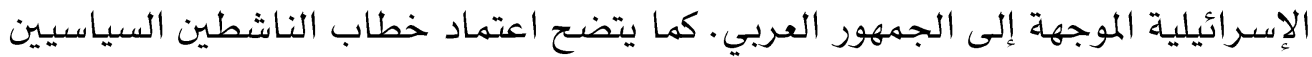

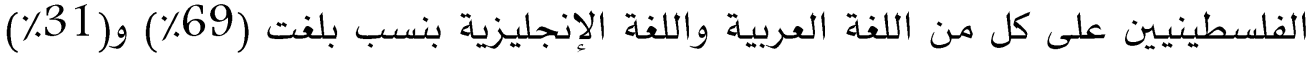
على التوالي، وقد يرجع ذلك لكون هدف الدبلوماسية الشعبية الفلسطينية إيصال صوتها للهواطنين العرب والأجانب على حدً سواء.

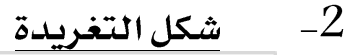

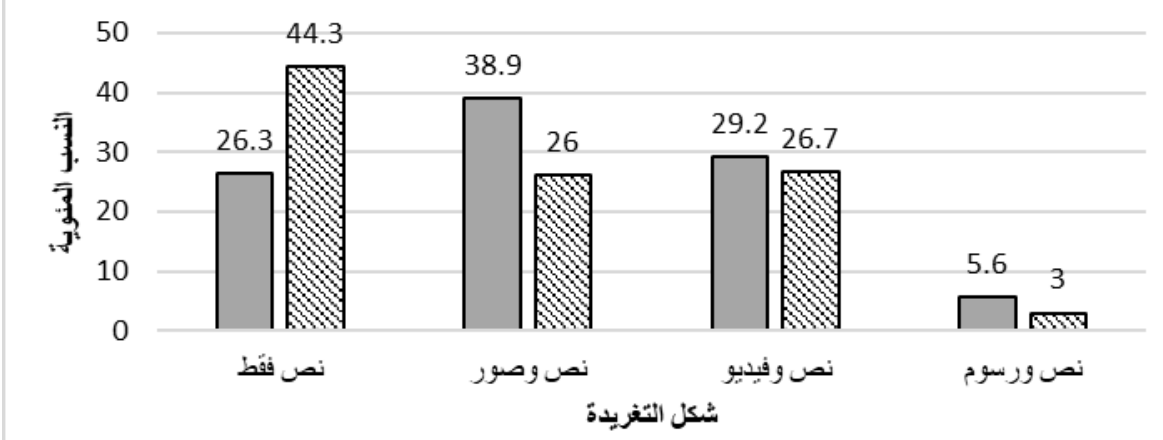

\section{خطاب الناشطين الفلسطينين هـ خطاب التّلاعب السباسيه}

شكل رقم (3) : يوضح النسب المئوية لشكل التغريدة بالحسابات عينة الدراسة

يتضح من بيانات الشكل السابق: اعتمدلٍت تفريدات التلاعب السياسي

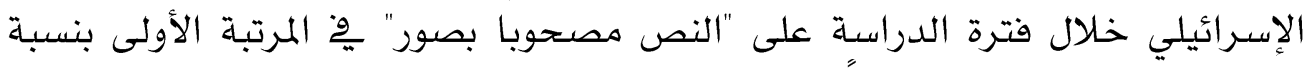

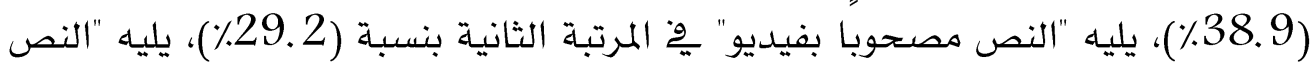

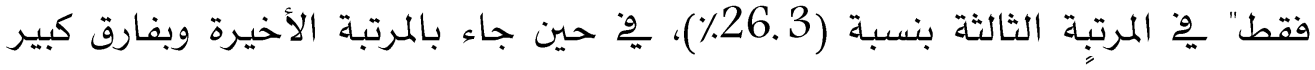

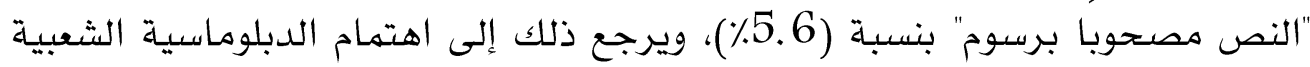

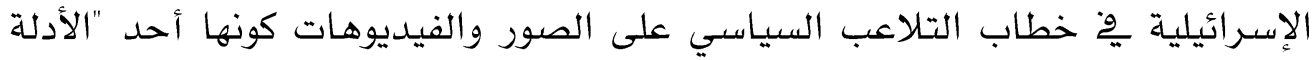

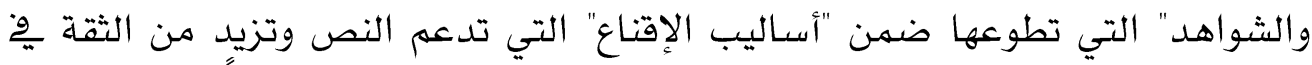

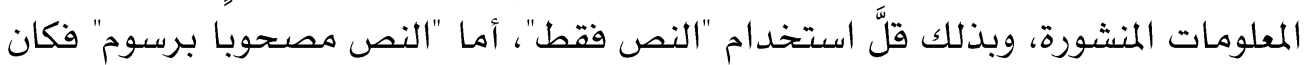

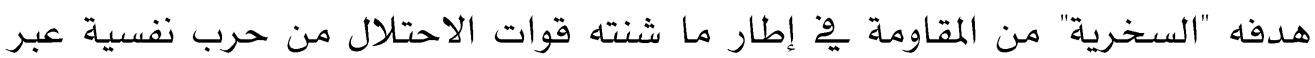
منصات التواصل الاجتهاعي.

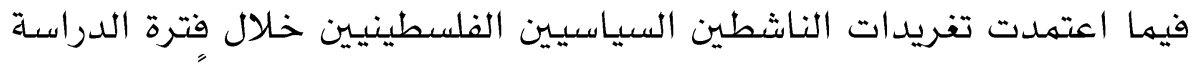

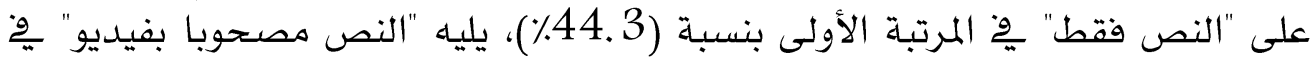




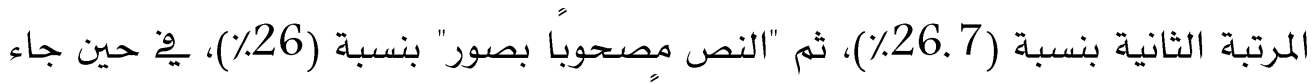

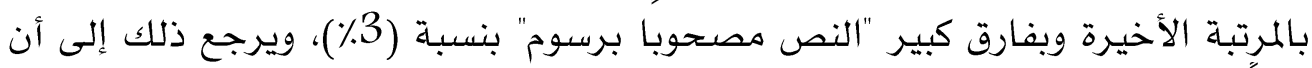

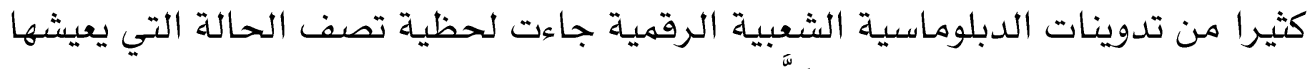

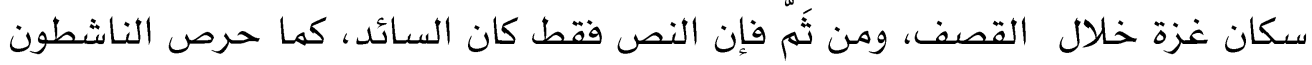

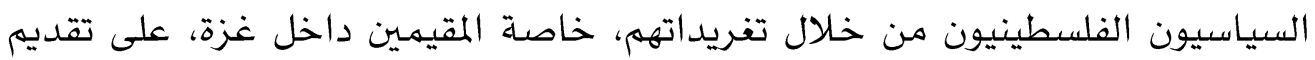

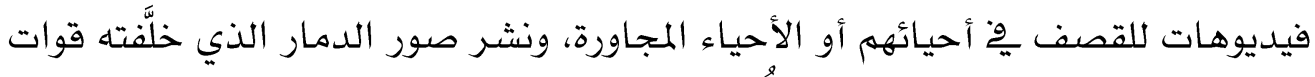

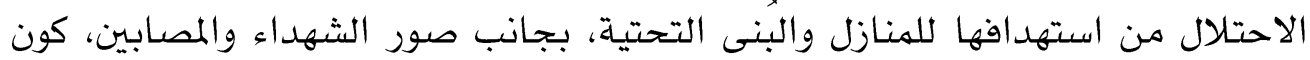

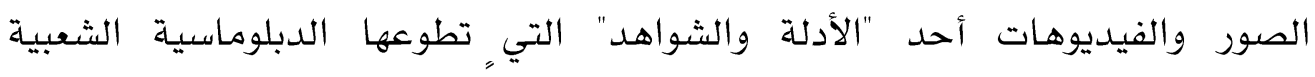

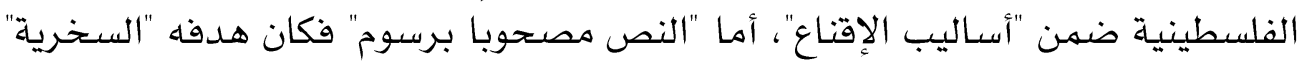

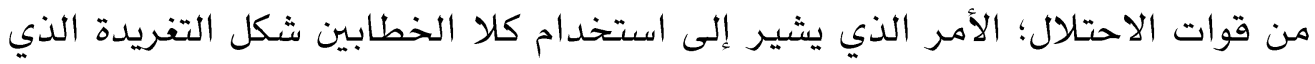

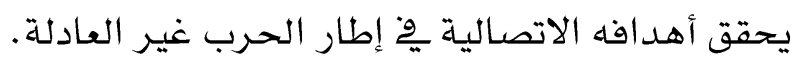

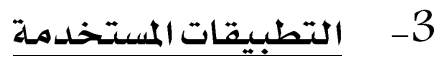
ويقصد بها التطبيقات التي يتيحها "تويتر" مثل التدوينات، وإعادة النشر،

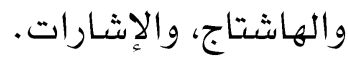

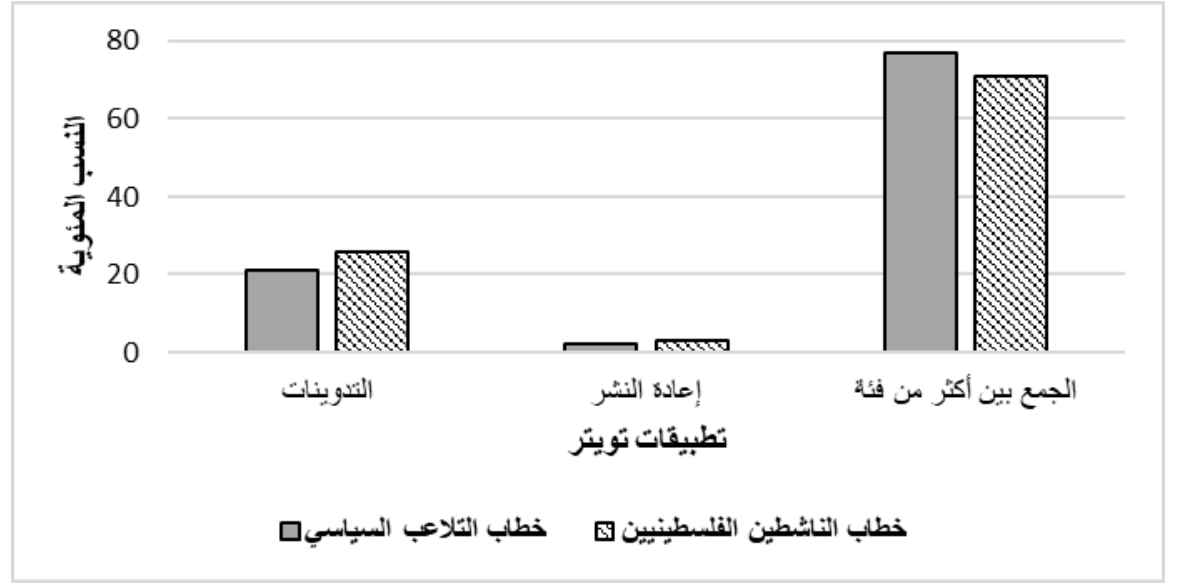

شكل رقم (4) : يوضح النسب المئوية لتطبيقات تويتر المستخدمة بالحسابات عينة الدراسة

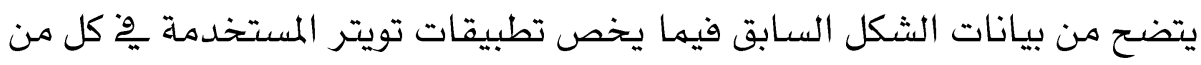

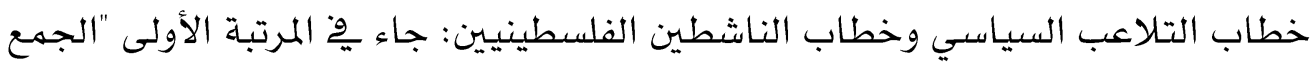

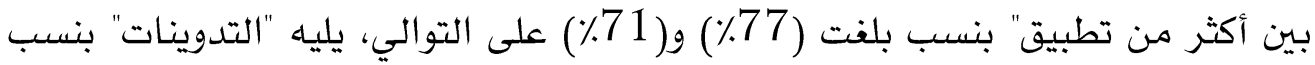

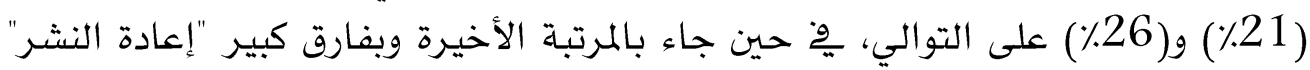
بنسب (2٪) و(3٪) على التوالي، ويرجع ذلك إلى حرص كلى كلاء الخطابين من خلال 
التغريدات على توظيف مختلف تطبيقات تويتر داخل التغريدة من أجل تحقيق الانتشار

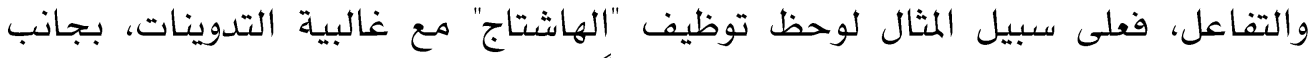

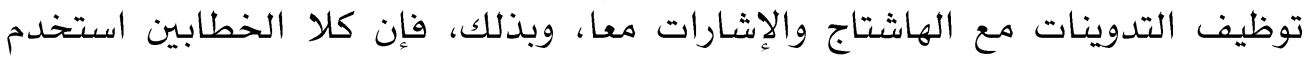
دبلوماسية الهاشتاج من أجل توسيع نطاق تأثير التغريدات، وسهولة الوصول إليها عبر تويتر .

وأمكن حصر الهاشتاجات المستخدمة وِ خطاب التلاعب السياسي كالآتي:

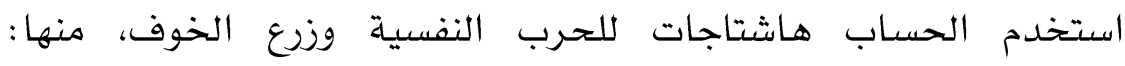
\#ماس_تحت_القصف، \#حماس_الإرهابية، \#تخريبية، \#خطيئة_حماس،

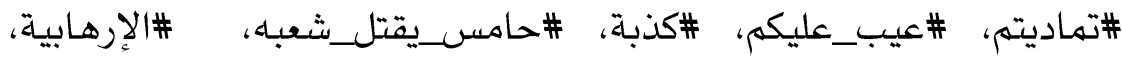

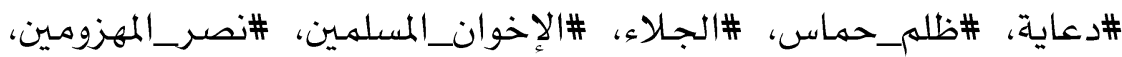

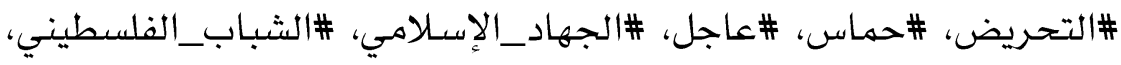

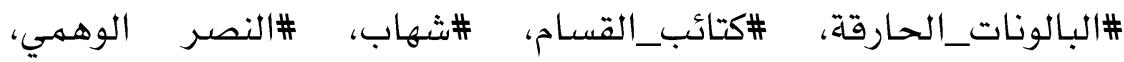

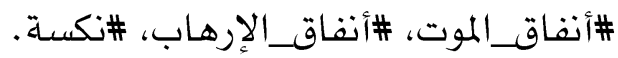
وهاشتاجات أخرى أعلت من الذات: \#إنانه_جيش_الدفاع_أيها_الإرهابيون،

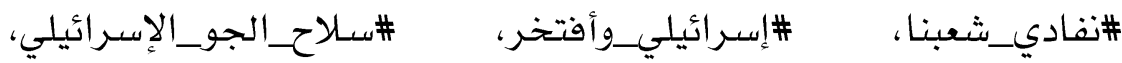

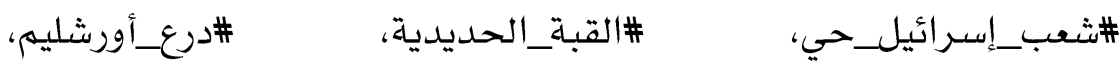

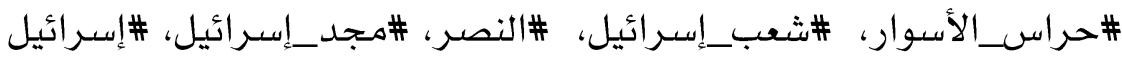

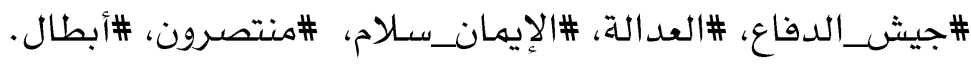

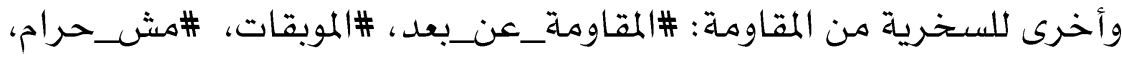

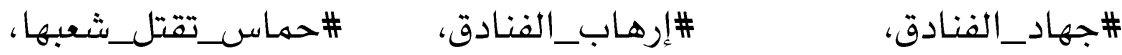

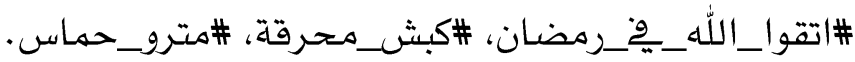

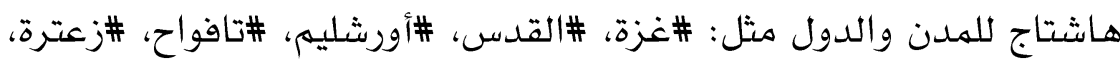
\#القدس_أقرب، \#إيران، \#الرمال، \#قطر، \#السعودية، \#لبنان، \#العراق،

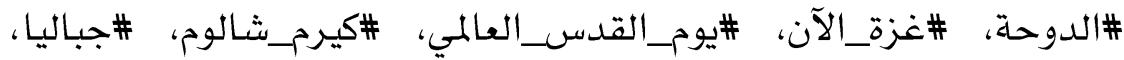
هاثتيم_الشاطئ.

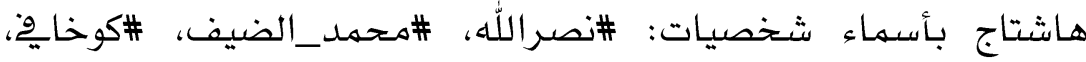
السنوار، \#خالد_مشعل، \#إسماعيل_هنية، \#كابتن_إيلا.

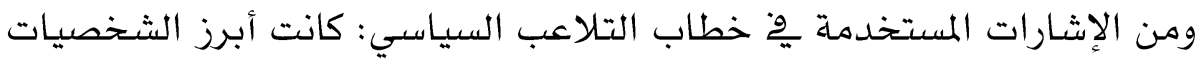
التي أشار إليها الحساب أو أعاد تغريداتها والتعليق عليها هو الحساب التهاب الرسهي 
للإماراتي وسيم يوسف Waseem_yuosef، يليه حساب المنسق الرسهي لوحدة

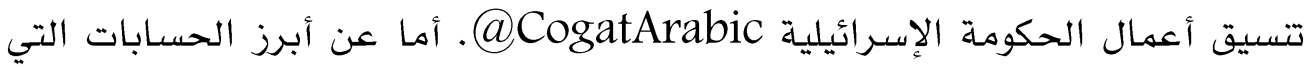

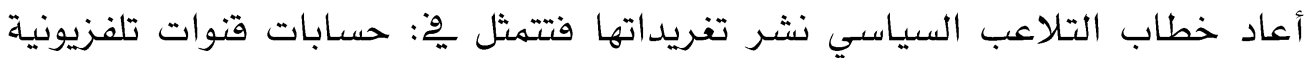

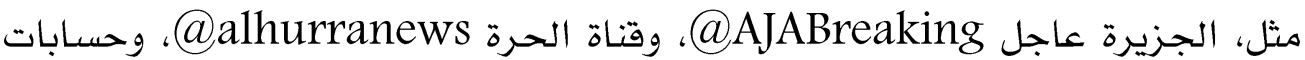

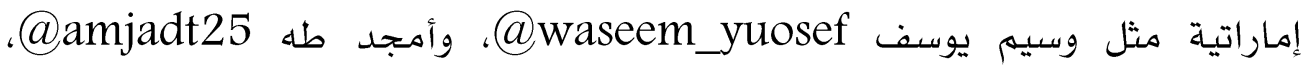
وضاحي خلفان Dhahi_Khalfan مثل وندان

وأمكن حصر الهاشتاجات المستخدمة يِ خطاب الناشطين السياسيين الفلسطينيين:

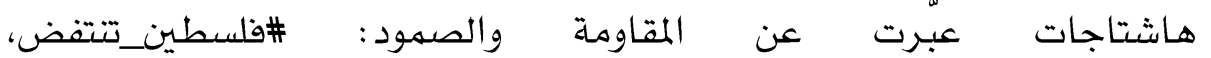

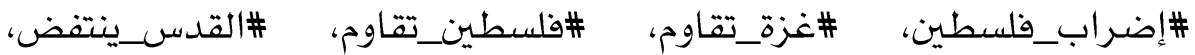

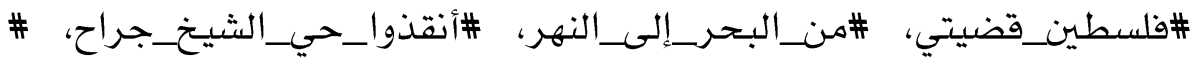

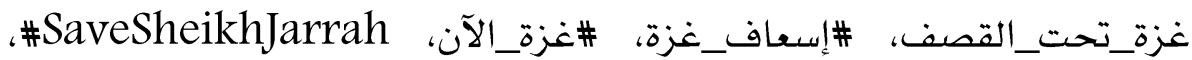
.\#SavePalestine

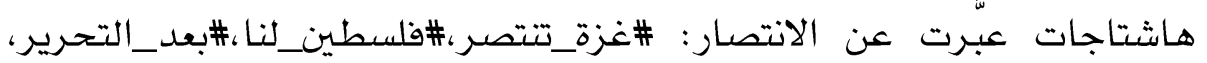

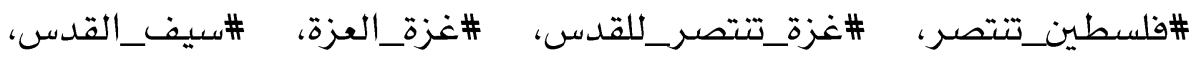
.\#free_Palestine ،\#PalestineWillBeFree ،\#GazaVictory هاشتاج للأماكن والمدن والدول مثل: \#فلسطين، \#مصر، \#الأردن، \#البيرة، \#عكا،

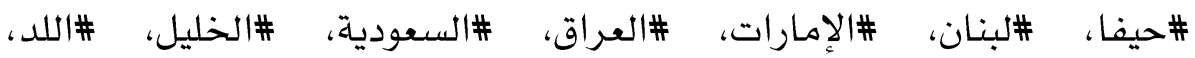

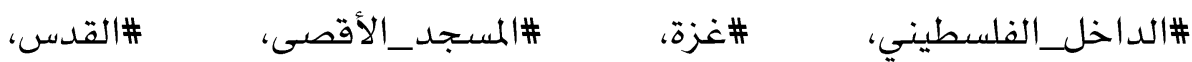

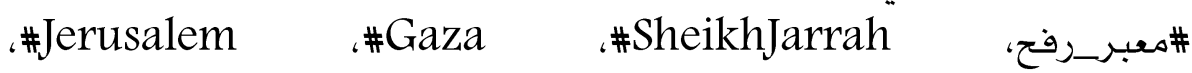
.\#AlAqsa ،\#AlAqsaMosque هاشتاجات عبرت عن مناهضة التطبيع وأبرزت جرائم إسرائيل: ،Israel_exposed ،Israel_terrorist ، ، \#PalestinianLivesMatter ،\#IsraealTerrorism ،\#AlAqsaunderattack ،\#Gaza_underfire ‘\#GenocideinGaza .\#Gaza_under_atack هاشتاجات بأسماء شخصيات: \#محمد_الضيف، \#تنتياهو، \#عرب_الداخل. إضافة إلى هاشتاجات من أجل الحث على التفاعل والتتويه إلى سياسات تويتر

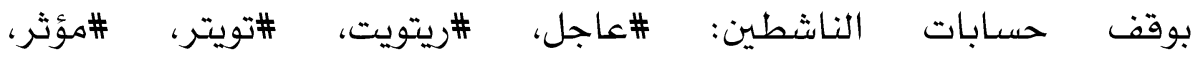
.\#unmutepalestine 
ومن الإشارات المستخدمة ِِّ خطاب الناشطين السياسيين الفلسطينيين: كانت

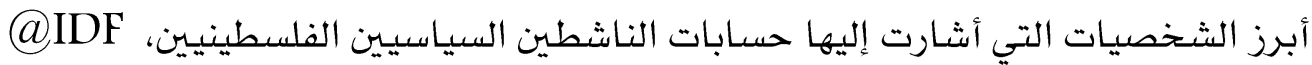

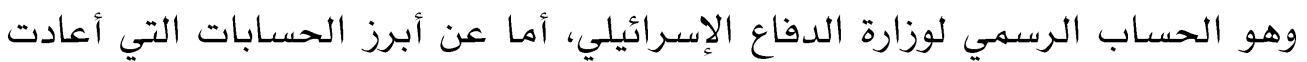

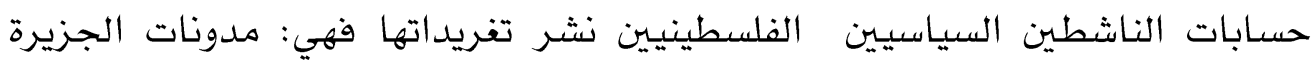
AAfro-Palestine Forum (Afropal)،AJABlogs

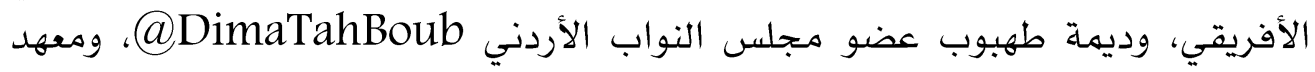

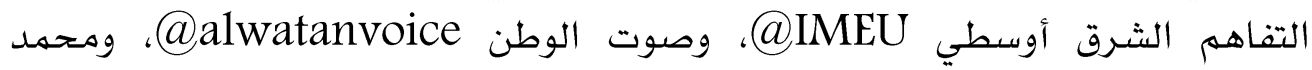

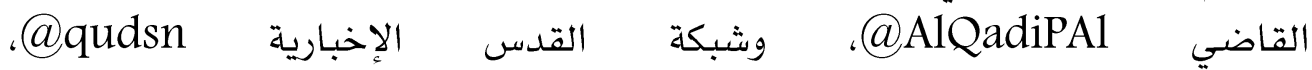
DrHananAshrawi, ثانيا : فئات تحليل الخطاب التداولى للتغريدة 4- نبرة التغريل الخريدة

جلدول رقم (2) : يوضرة النسب والتكرارات لنبرة التغريدة المستخدمة بالحسابات عينة الدراسة

\begin{tabular}{|c|c|c|c|c|}
\hline \multicolumn{2}{|c|}{ خطاب الناشطينين } & \multicolumn{2}{|c|}{ خطاب التلاعب السياسى } & \multirow[t]{2}{*}{ نبرة التغريدة } \\
\hline$\%$ & ك ك ك & $\%$ & ك & \\
\hline 9 & 55 & 15 & 48 & استعلاء/ مفاخرة \\
\hline 0.7 & 4 & 1.6 & 5 & استعطاف \\
\hline 4.2 & 25 & 1.6 & 5 & خوف \\
\hline 12 & 73 & 12.5 & 40 & شماتة \\
\hline 29.9 & 180 & 44.5 & 142 & انتصار \\
\hline 1.3 & 8 & 5 & 16 & سخرية \\
\hline 0.2 & 1 & 4.1 & 13 & تحريض \\
\hline 0.2 & 1 & 3.1 & 10 & تحذير \\
\hline 2.7 & 16 & 1.3 & 4 & نداء/ دعاء \\
\hline 17.8 & 107 & 9.7 & 31 & غضب/ استنكار \\
\hline 0.5 & 3 & 1.6 & 5 & تهايد \\
\hline 12 & 72 & - & - & حزن \\
\hline 9.5 & 57 & - & - & صمود وإصرار \\
\hline
\end{tabular}

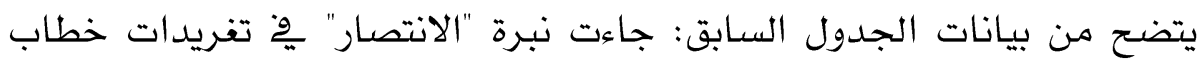

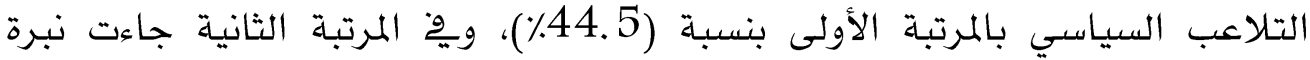
"الاستعلاء والمفاخرة" بنسبة (15٪)، مثال ذلك: "ينام شعبي لأن عيونتا سـاهرة على أمنه 


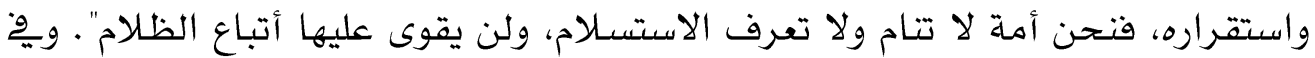

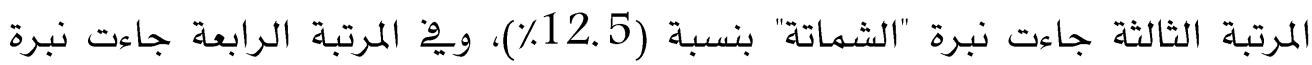

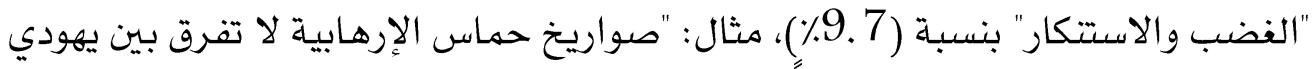

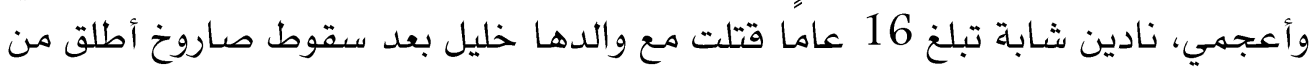

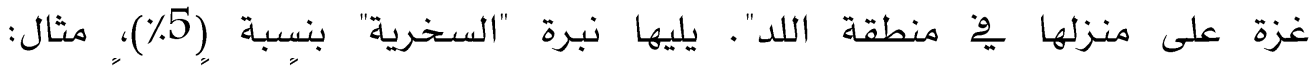

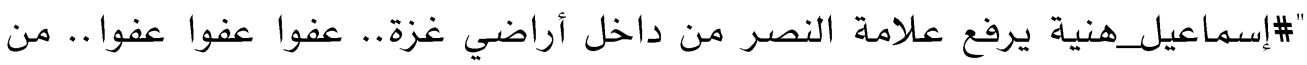

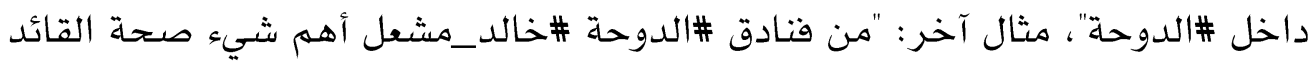

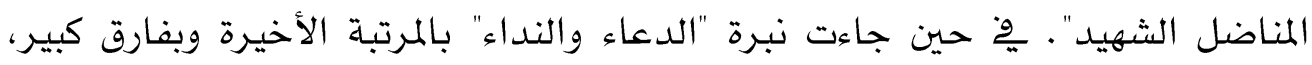

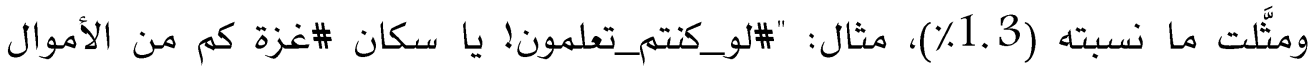

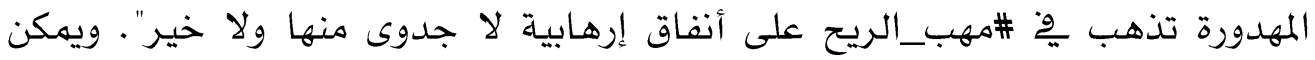

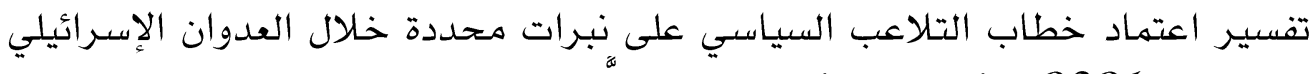
على غزة 2021، لأن هذا الأمر يتوافت كليا مع سياسات علئ إسرائيل وإستراتيجيات

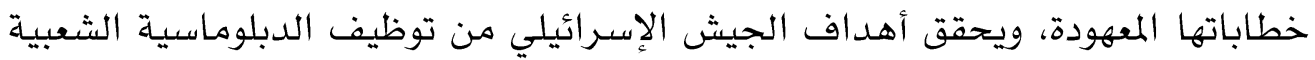

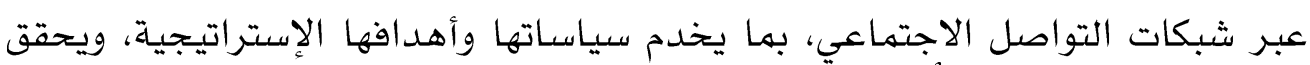

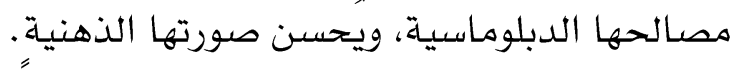
ويتضح من بيانات الجدول السابق أيضا: جاءت نبرة " الانتصار" بِّ تغريدات

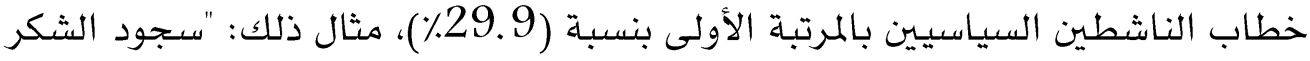

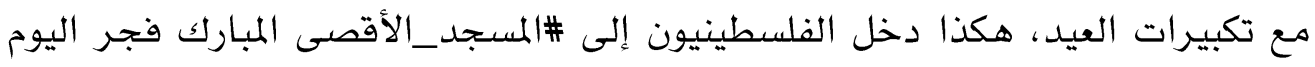

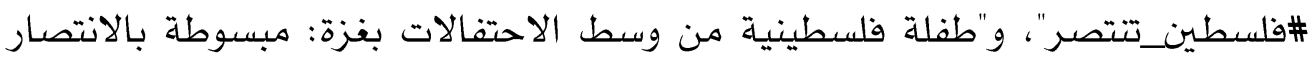
وأشكر المقاومة"، ووالشباب الفلسطينيون يتحدون قوات الاحتلال بالتكبيرات وشئلات وشارة

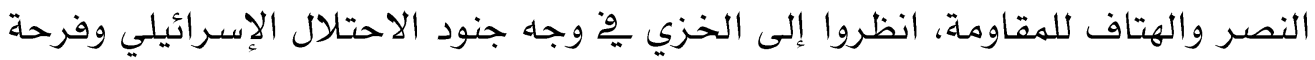

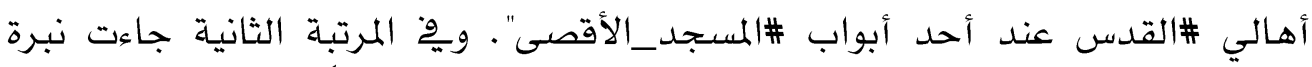

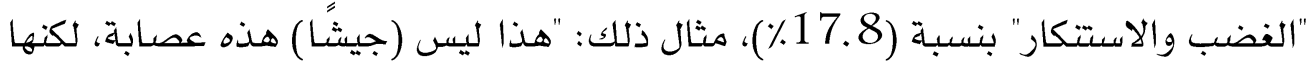

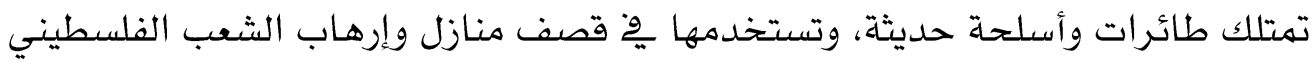

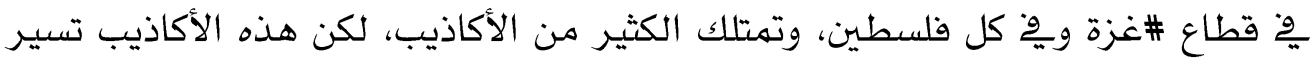

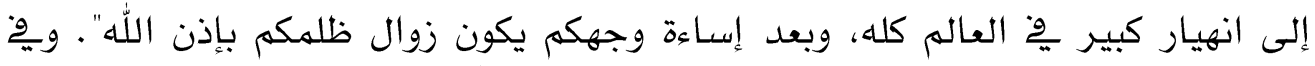

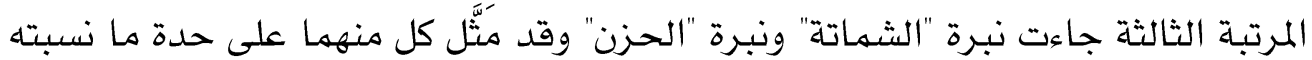

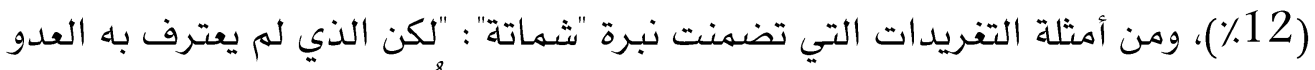

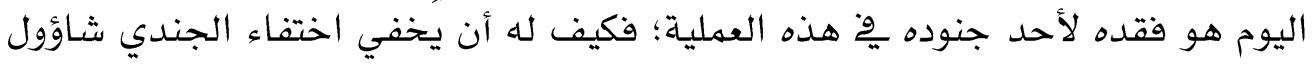


آرون صاحب الرقم (6092065).. إن هذا الجندي هو أسير لدى كتائب القسام"، ومن

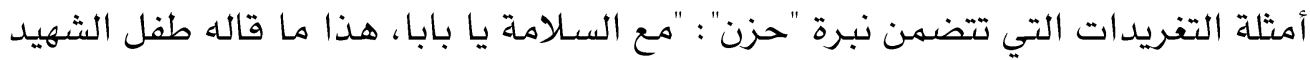

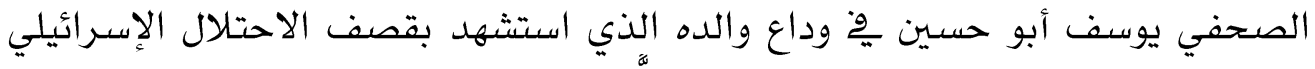

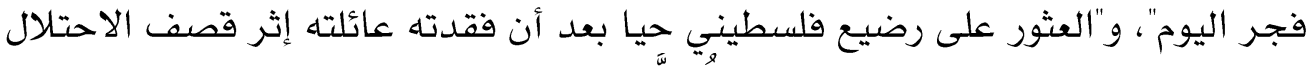

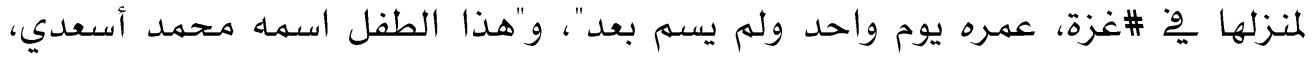
قامت وحدة خاصة من قوات الاحتلال (وحدة المستعربين) باختطافه واعتقاله قبل فيل قليل

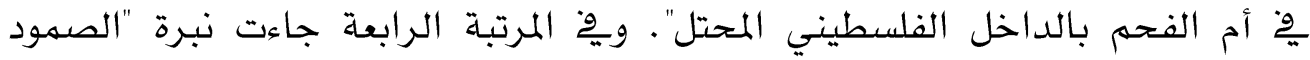

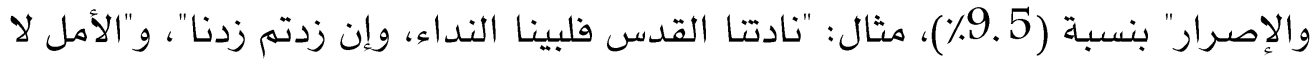

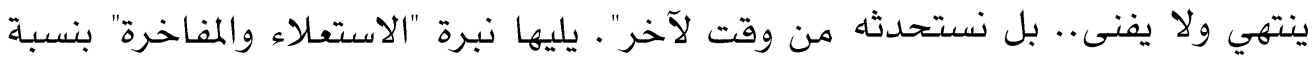

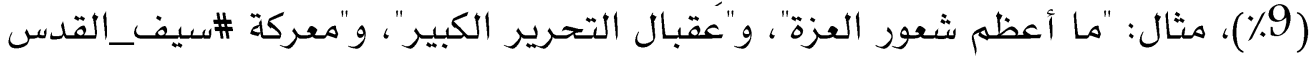

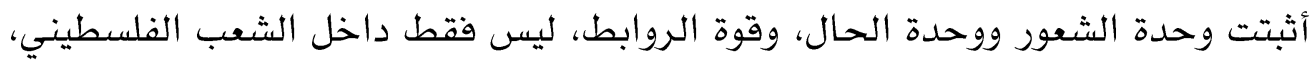

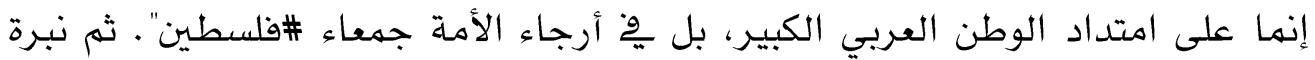

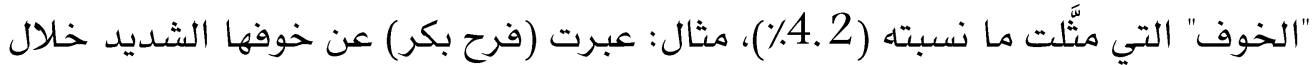

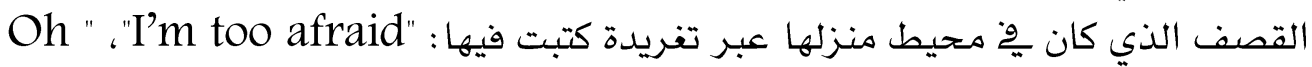
الاخبرة

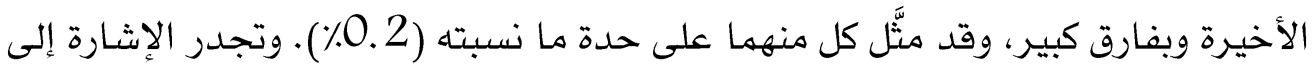

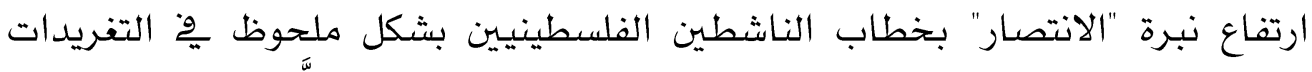

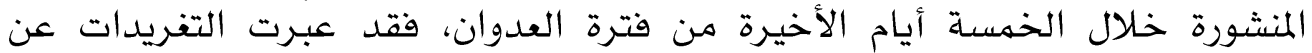

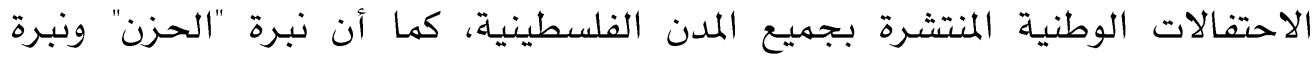

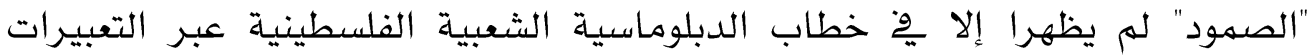

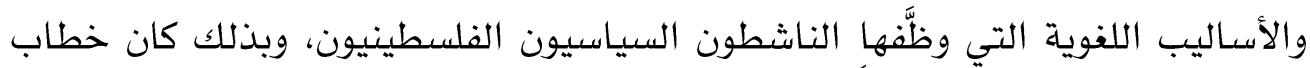

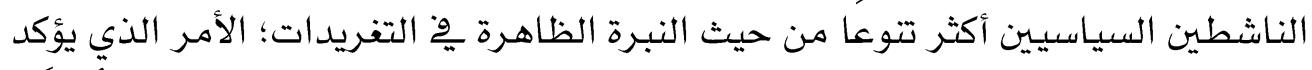

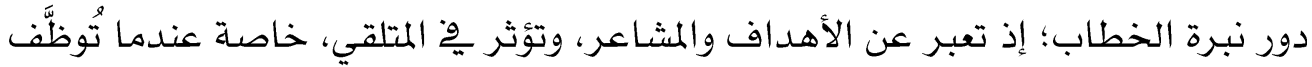

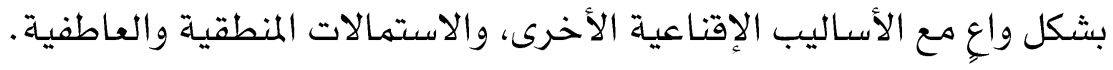


5 - مرجة نبـرة التغريدة

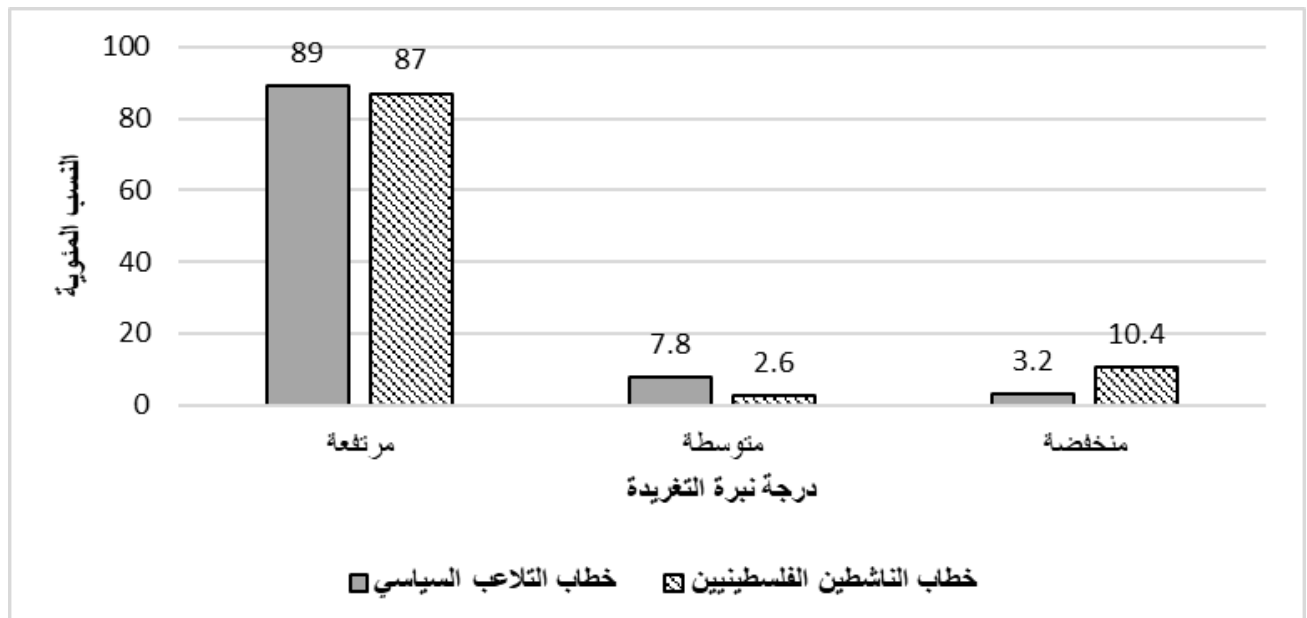

شكل رقم (5) : يوضح درجة نبرة التفريدة المستخلممة بالحسابات عينة الدراسة

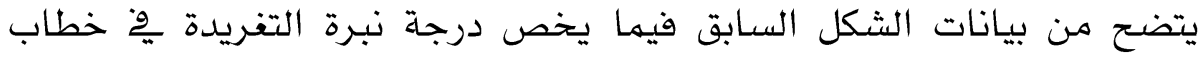

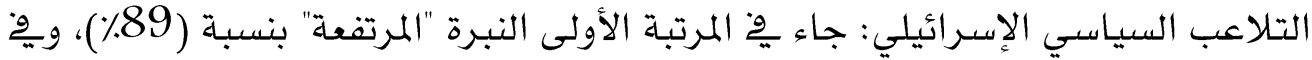

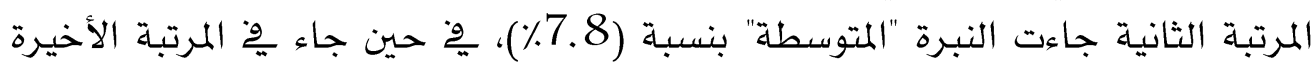

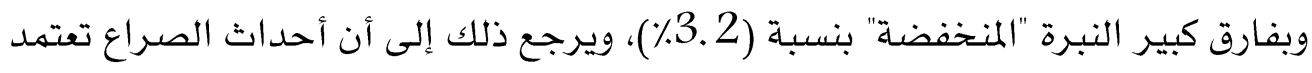

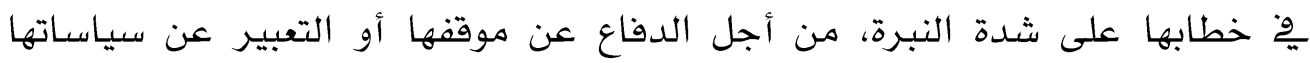

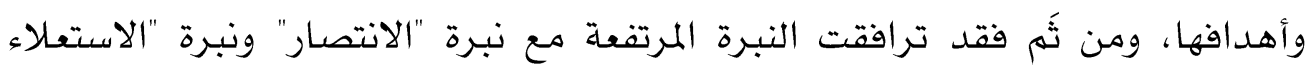

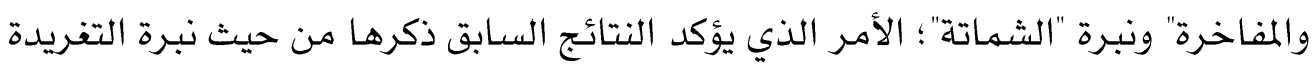
ودرجتها .

وجاءت النبرة "المرتفعة" ِوخ المرتبة الأولى بخطاب الناشطين السياسيين

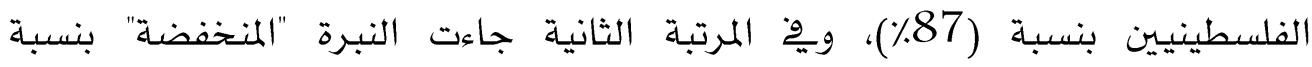

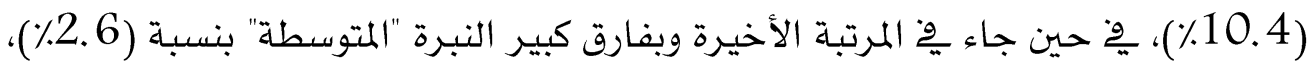

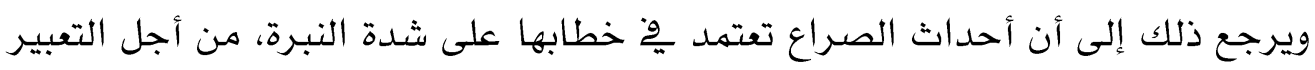

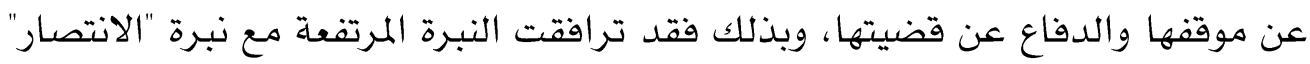

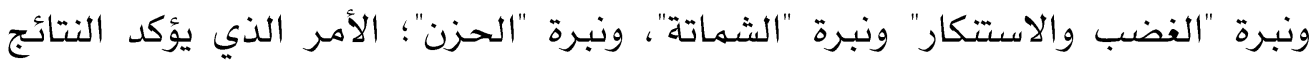

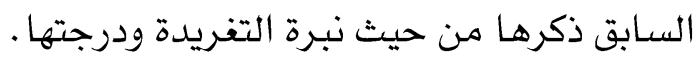

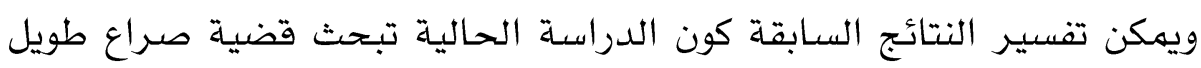

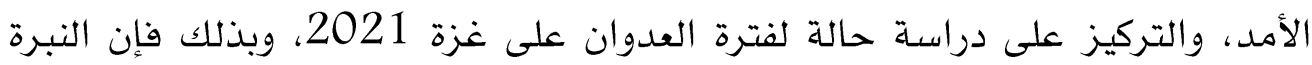


خطاب الدبلوماسية الشعبية الفلسطينية عبر "تويتر) هِّفواجهة خطاب التلاعب السياسي

"مرتفعة" الشدة هي بالتأكيد المسيطرة على حالات الصراع، وتتوافق مع: نبرة الانتصار، ونبرة الاستعلاء، ونبرة الشماتة، ونبرة الغضب.

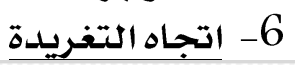

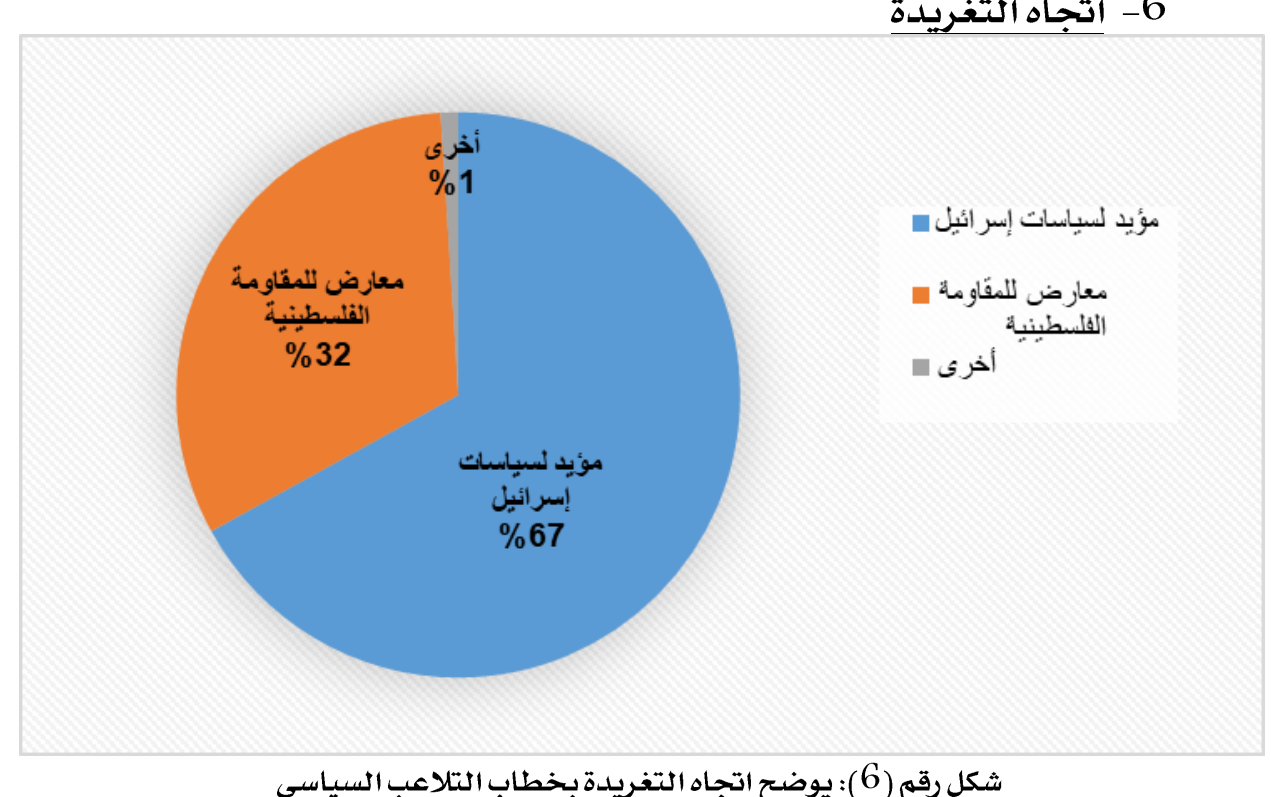

شكل رقم (6): يوضح اتجاه التغريدة بخطاب التلاعب السياسى

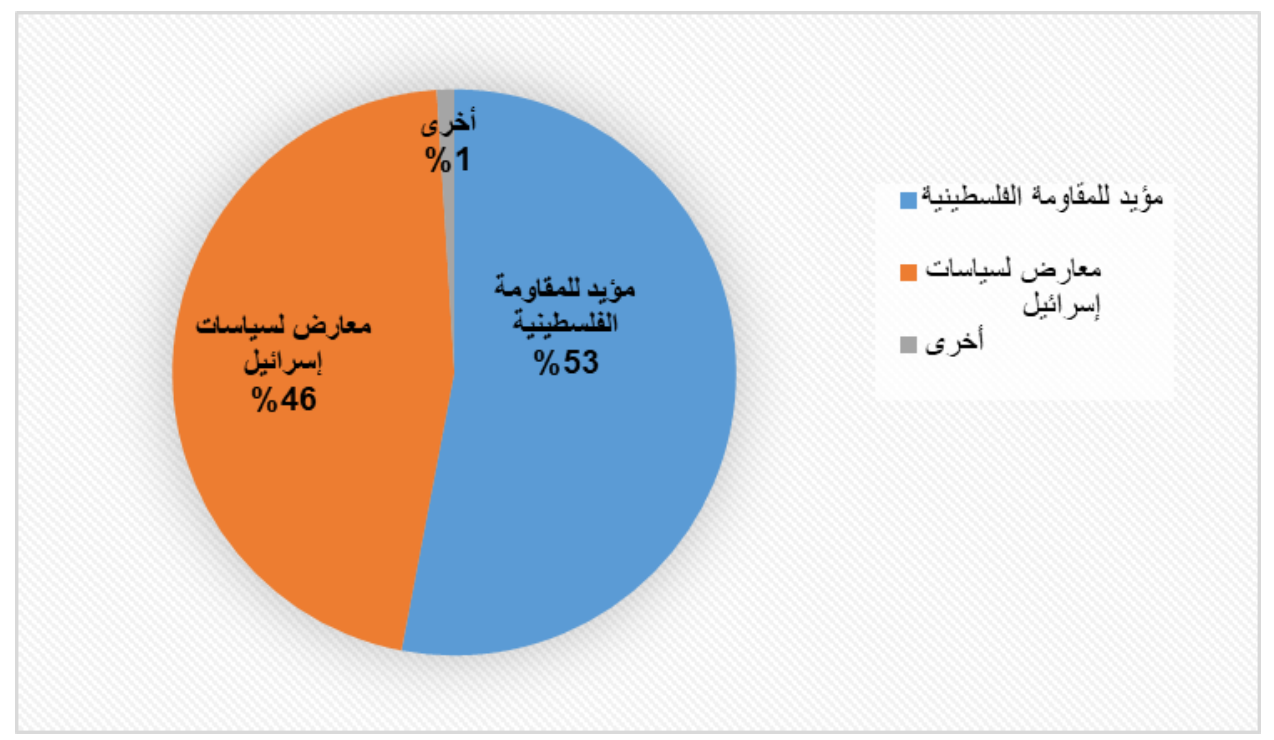

شكل رقم (7) : يوضح اتجاه التغريدة بخطاب الناشطين السياسيين الفلسطينيين 


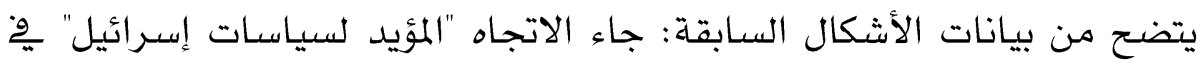

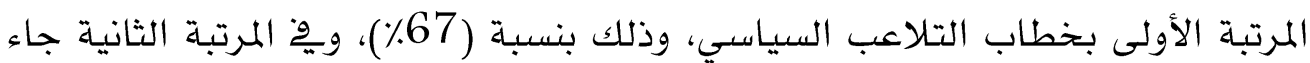

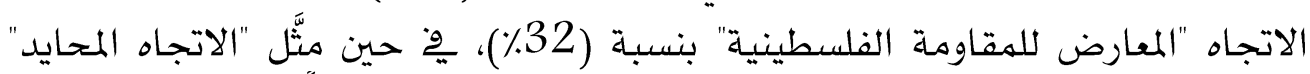

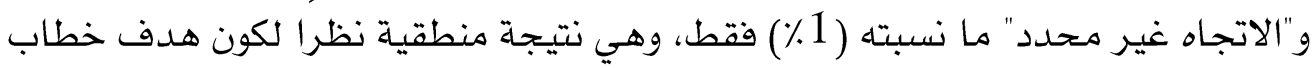

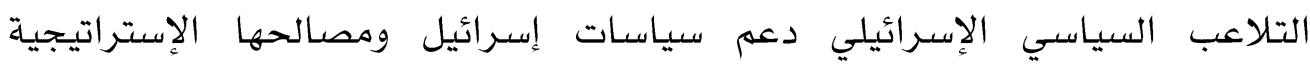

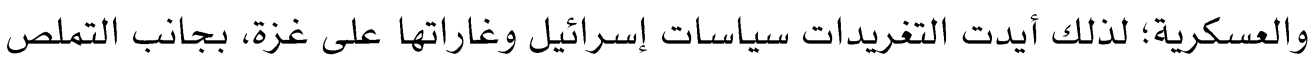
من قتلها المدنيين، والادعاء باستهداف عناصر إرهابية من حهاس لتبرير عملياتها العسكرية.

فيها جاء الاتجاه "المؤيد للهقاومة الفلسطينية" وِّ المرتبة الأولى بخطاب

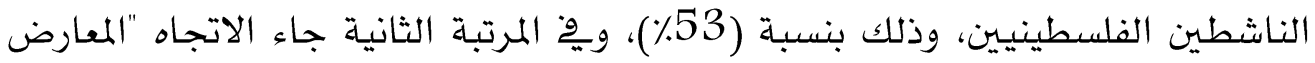

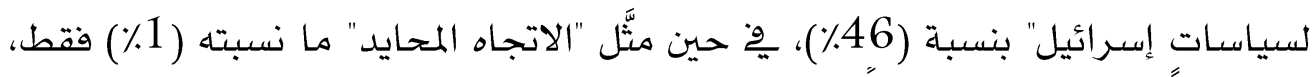

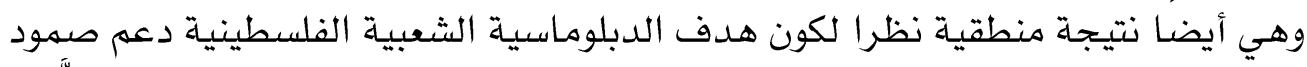

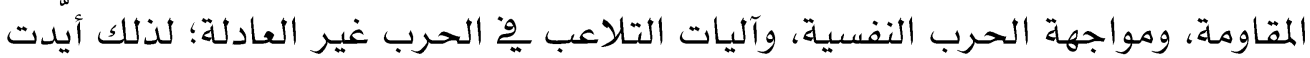

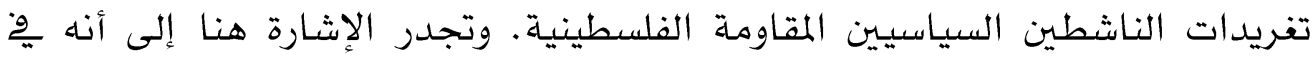

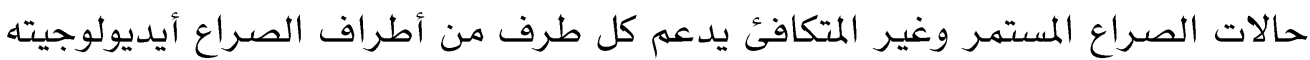
السياسية، ويعزز موقفه، من خلال محاولات حثيثة لكسب الدعم الدولي. 
خطاب الدبلوماسية الشعبية الفلسطينية عبر "تويتر) هُّ مواجهة خطاب التلاعب السياسي

$$
\text { 7- أطروحات الخطاب }
$$

جدول رقم (3) : يوضح نسب وتكرارات الأطروحات الفرعية لخطاب التلاعب السياسى

\begin{tabular}{|c|c|c|}
\hline \multicolumn{2}{|c|}{ خطاب التلاعب السياسى } & \multirow{2}{*}{ أطروحات الخطاب } \\
\hline$\%$ & ك & \\
\hline 6.9 & 22 & الحرب النفسية \\
\hline 8.8 & 28 & إحباط هجمات حماس وكتائب القسام \\
\hline 2.5 & 8 & عملية حارس الأسواروفاعلية القبة الحديدية \\
\hline 0.9 & 3 & عملية جيش الدفاع والشاباك \\
\hline 2.5 & 8 & تعزيز الجهود الدفاعية الإسرائيلية \\
\hline 31.7 & 101 & النجاح حِ استهداف مواقع تابعة لحماس وكتائب القسام \\
\hline 10 & 32 & النجاح حِّ استهداف ناشطين وقادة بحماس وكتائب القسام \\
\hline 4.7 & 15 & انتصارات إسرائيل \\
\hline 1.6 & 5 & المصالح الإيرانية \\
\hline 3.8 & 12 & الحفاظ على أمن واستقرار إسرائيل \\
\hline 3.4 & 11 & استهلداف ملدن إسرائيلية \\
\hline 0.3 & 1 & غلق المجال الجوي والبحري لغزة \\
\hline 0.6 & 2 & استهداف القدس \\
\hline 9.1 & 29 & حماس تستهدف المدنيين الفلسطينيين والإسرائيليين \\
\hline 3.8 & 12 & حرص إسرائيل على أرواح المدنيين \\
\hline 1.3 & 4 & نداء إسرائيل بحقها التاريخى يِّ الأرض \\
\hline 2.8 & 9 & دمار البنى التحتية لغزة \\
\hline 2.2 & 7 & القضاء على الجماعات الإرهابية \\
\hline 2.8 & 9 & اختباء قيادات حماس بالدوحة \\
\hline 0.3 & 1 & المساعدات الإنسانية \\
\hline
\end{tabular}

$$
319=0 *
$$

يتضح من بيانات الجدول السـابق: أنه بالنسبة لأطروحات الخطاب المركزية والفرعية يخ خطاب التلاعب السياسي للجانب الإسـرائيلي، فقد تمثلت الأطروحات المركزية ِوٌ: "عمليات جيش الدفاع ضد حماس الإرهابية". وكان هنالك عدد هن الأطروحات الفرعية يمكن عرضها كالآتي: - جاءت الأطروحة الفرعية "النجاح قو استهداف مواقع تابعة لحماس وكتائب

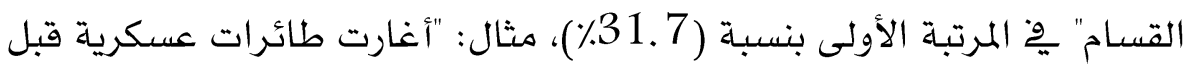




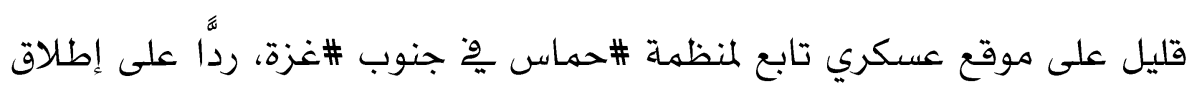

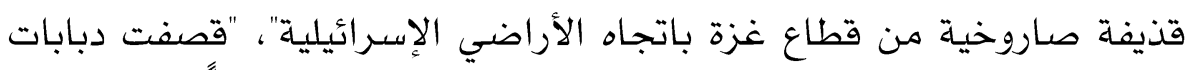

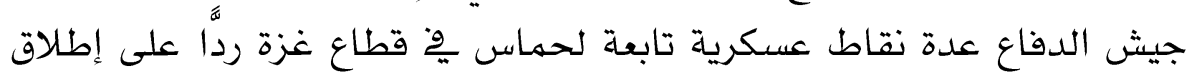
ـالبالونات_الحارقة". - جاءت الأطروحة الفرعية "النجاح وِّات استهداف ناشطين وقادة بحماس وكتائب القسام" بنسبة بلغت (10٪)، مثال: "القضاء على خلية الفرعية تخريبية تضمى ثلاثة

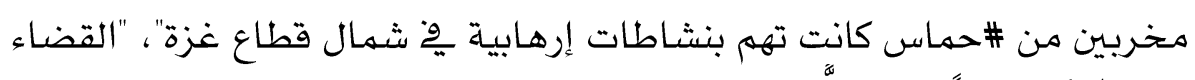

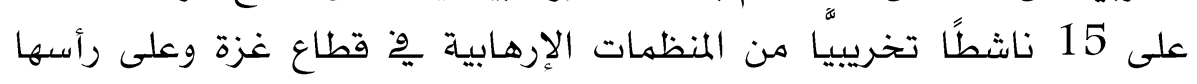

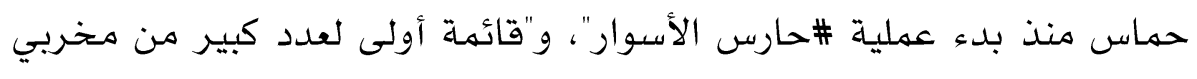

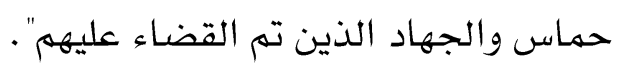

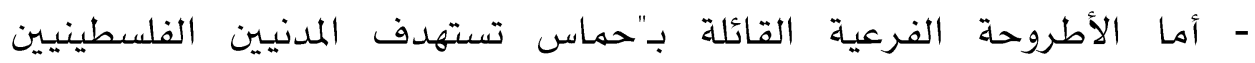

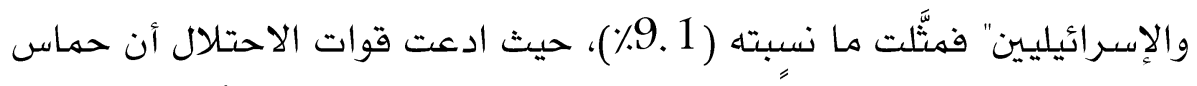

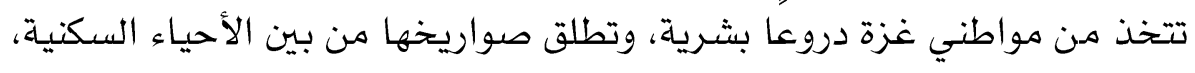

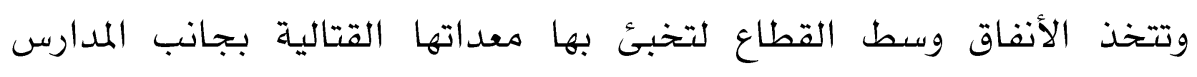

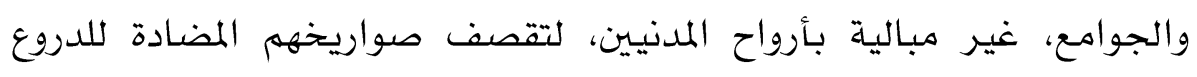

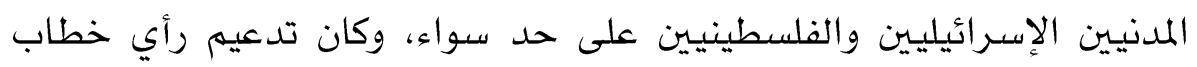

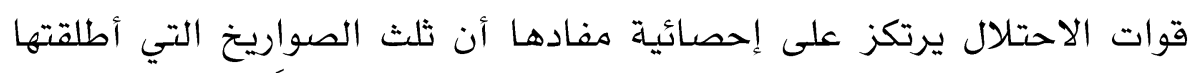

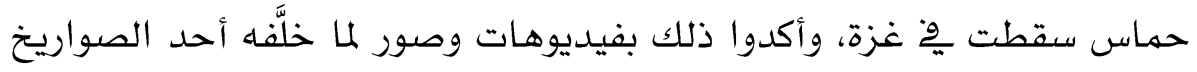
الذي سقط بجوار مستشفى بالضفة الغربية.

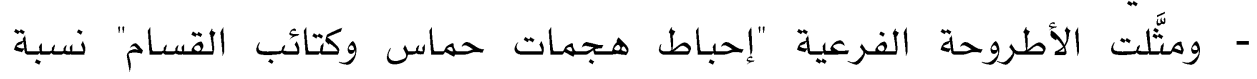

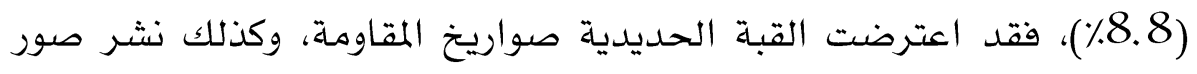

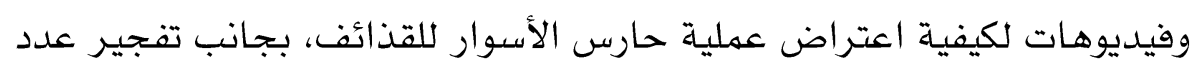

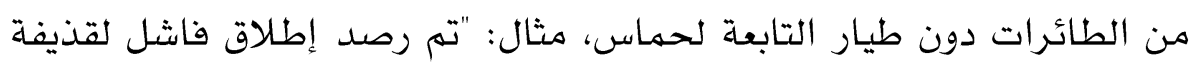

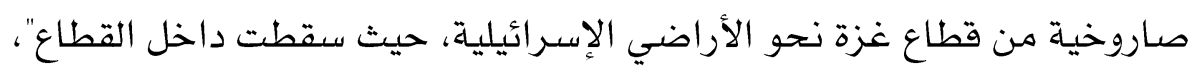

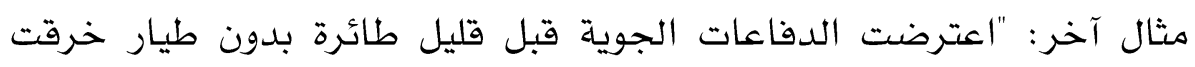

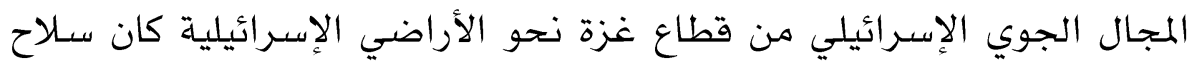

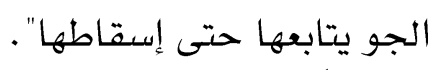

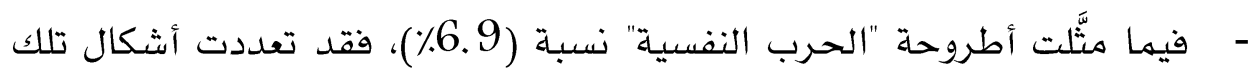

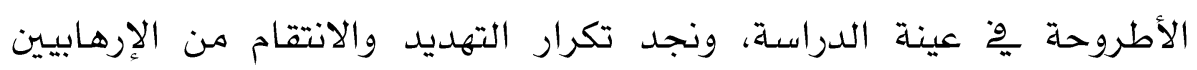


(المقاوهـة) موْ التفريدات، مثال ذلك: "ها هن ظالم إلا وسيدفع ثهن ظلمها يوها، وها من قاتل إلا وسيذل أبدا، قواتـا وبالتعاون مع أجهزة الأمن الإسـرائيلية

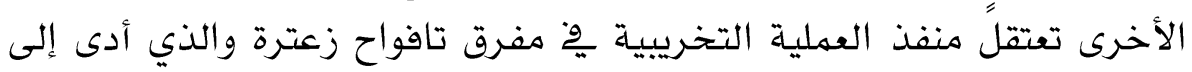
مقتل مواطن وجرح مواطنين إسـرائيليين، فلا مفر لـإرهابيين والقتلة هن

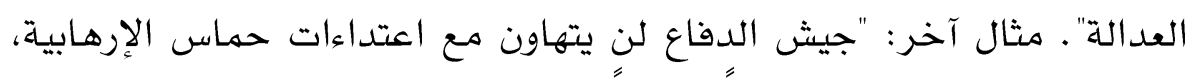
وسيواصل دك معاقلها مستهدفًا أهدافًا لها، تهاديتم فادفعوا الثمن"، مثال آخر: "يضجون الإعلام بإنجازاتهم وأسلحتهم التي جاؤوا بها على حسـاب معيشـة

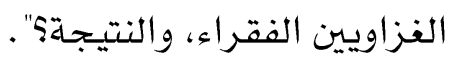
- ومثَّنت الأطروحة الفرعية "انتصارات إسرائيل" ما نسبته (4.7٪)، وارتبطت أيضًا بهعالم الحرب النفسية التي شنَّها خطاب التلاعب، وذلك بتكرار نشر صور

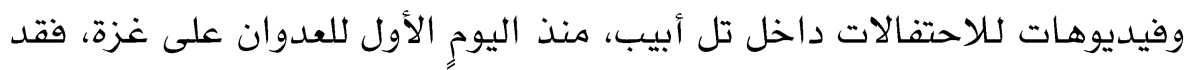
نشر, الحساب الرسهي لـ(أفيخاي أدرعي) عددا هن فيديوهات الاحتفالات وصورا للحياة بشكل طبيعي داخل الأراضي المحتلة لمقارنتها بالوضع عْ غزة، كما نشر الحساب يوم 21 مايو 2021 اليوم الأخير بعد إعلان وقف إطلاق النار قائلاً: "كلّ يفخر بهويته. أما نحن! فقخرنا يتضاعف بأمة ترفع رايات النصر أينما كان وِو كل مكان، جيش الدفاع \#مجد_إسـرائيل \#درع_أورشليم" . مثال آخر يؤكد محاولات خطاب التلاعب المستمـرة فِّ التمادي بالحرب النفسية: "إرادتا أقوى من إرهابهم .. حياتتا أسهى من محاولاتهم" .

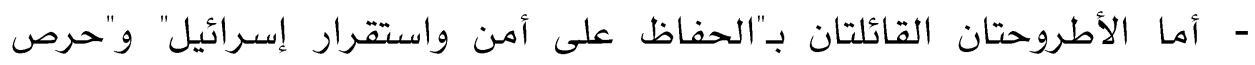

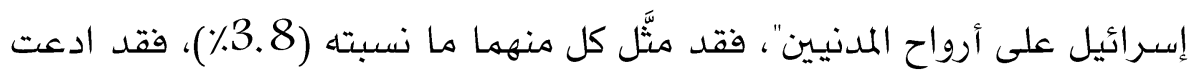

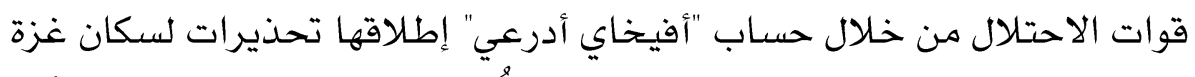
من المدنيين للابتعاد عن مواقع حماس التي ستقصف. مثال: "حينها يتعلق الأمر

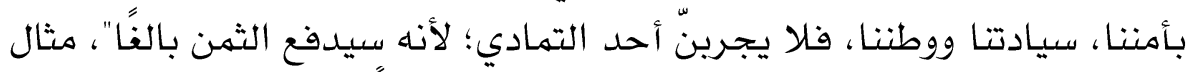
آخر: "إن قتل نفس بريئة هي من أشد الأمور إرهابا، وهذا ما تفعله حركة

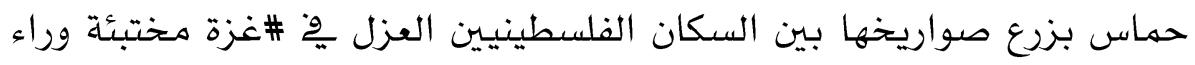

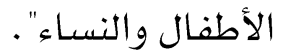

ـ ـ ومثَّلت الأطروحة القائلة بـ"اختباء قيادات حماس بالدوحة" نسبة (2.8\%)، فقد تكرر نشر صور قيادات حماس داخل فنادق الدوحة، ونشر حساب "أفيخاي

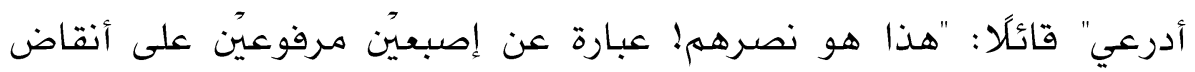


شعبهم ودماره ومعاناته، من أفخم الفنادق والقصور"، و"هذا ما يسمى انتصارًا،

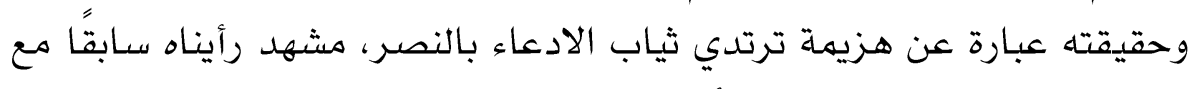

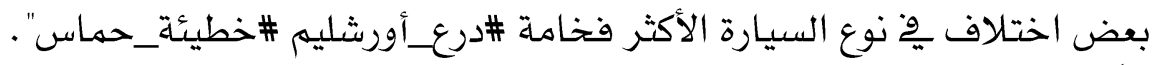

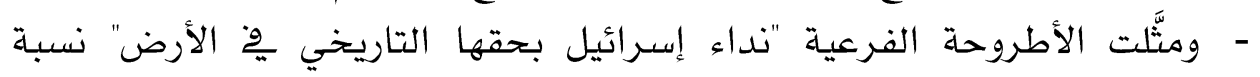

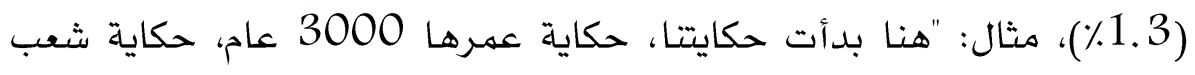

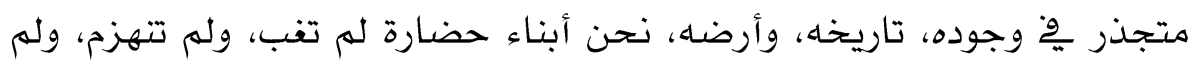

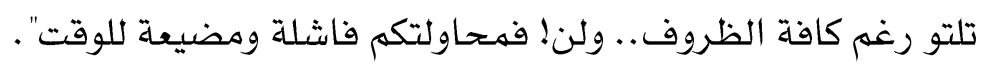

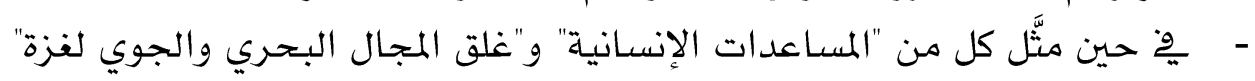

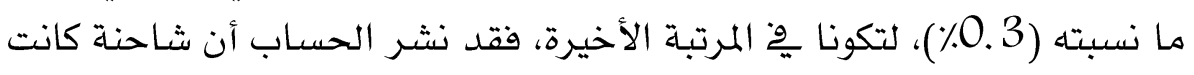

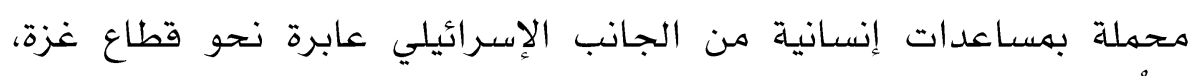

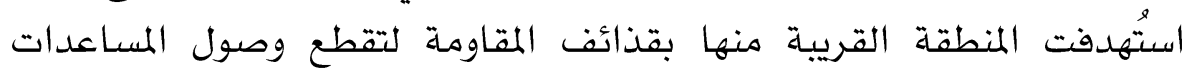

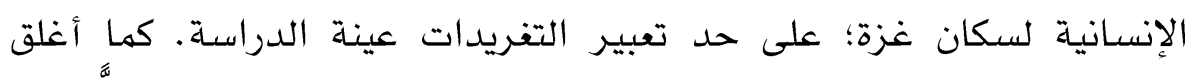

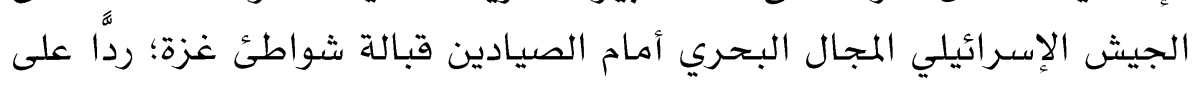
إطلاق صاروخ باتجاه إسـرائيل.

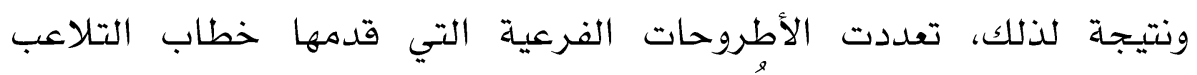

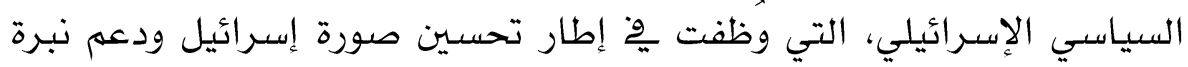

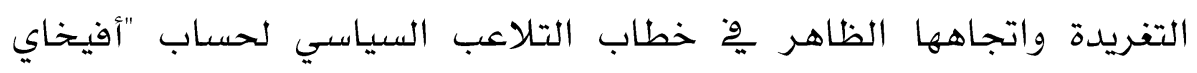

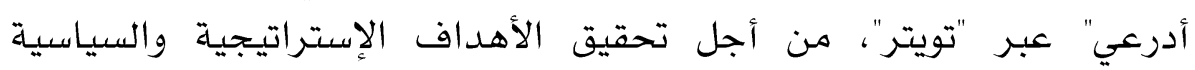
للدبلوماسية الشعبية الإسـرائيلية التي يديرها الجيش تحقيق الإهدافئ الإسرائيلي، عبر مواقع

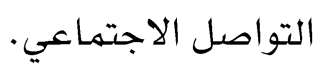


خطاب الدبلوماسية الشعبية الفلسطينية عبر "تويتر) هُّ مواجهة خطاب التلاعب السياسي

جدول رقم (4) : يوضح النسب والتكرارات للأطروحات الفرعية لخطاب الناشطين الفلسطينيين

\begin{tabular}{|c|c|c|}
\hline \multicolumn{2}{|c|}{ خطاب الناشطين الفلسطينيين } & \multirow{2}{*}{ أطروحات الخطاب } \\
\hline$\%$ & ك & \\
\hline 1 & 6 & التطهير العرقى \\
\hline 7 & 42 & انتهاك حقوق الإنسان \\
\hline 0.2 & 1 & النداء بالحق ٍِِ الأرض \\
\hline 14.1 & 58 & إرهاب إسرائيل \\
\hline 8.8 & 53 & استشهاد الأطفال والشباب والأسر \\
\hline 4.3 & 26 & دمار البنية التحتية \\
\hline 10.8 & 65 & رد المقاومـة \\
\hline 3.3 & 20 & الحرب النفسية \\
\hline 0.8 & 5 & ردود الفعل الدولية \\
\hline 1.3 & 8 & المشاركة المجتمعية \\
\hline 0.2 & 1 & وقف إطلاق النار \\
\hline 14.5 & 87 & قصف المنازل بغزة \\
\hline 1.3 & 8 & التطبيـع مـع إسرائيل \\
\hline 0.2 & 1 & تقسيهم فلسطين أرضا وشعبا \\
\hline 0.3 & 2 & القيادات النسائية الفلسطينية \\
\hline 2.8 & 17 & ردود الفعل العربية \\
\hline 10 & 60 & هزيهـة إسـرائيل \\
\hline 0.3 & 2 & تقييد حسابات الناشطين عبر تويتر \\
\hline 10.8 & 65 & صمود أهل غزة \\
\hline 0.2 & 1 & استهـداف المقاومـة لقوات الاحتلال \\
\hline 0.2 & 1 & 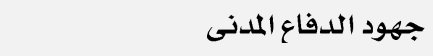 \\
\hline 0.7 & 4 & إمداد أمريكا إسرائيل بالصواريخ \\
\hline 6.6 & 40 & الاحتفال بانتصار المقاومة \\
\hline 0.3 & 2 & تدمير البنوك والمراكز التجارية بغزة \\
\hline
\end{tabular}

يتضح من بيانات الجدول السـابق: أنه بالنسبة للأطروحات المركزية والفرعية يوّة

خطاب الناشطين السياسيين الفلسطينيـين، فقد تمثلت الأطروحات المركزية يِّ: "عمليات 


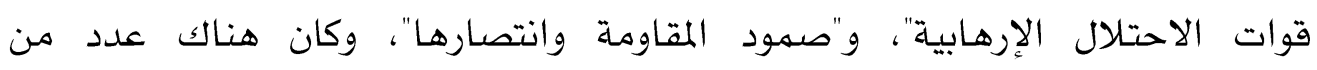

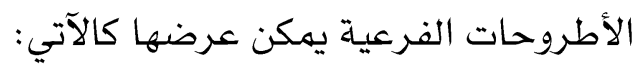

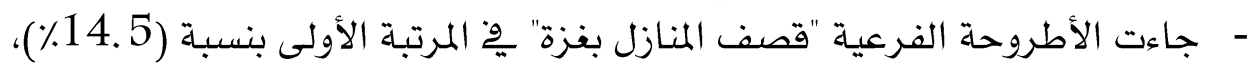

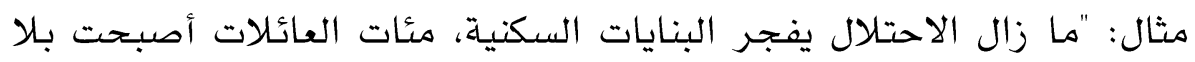

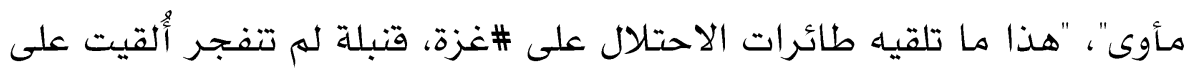

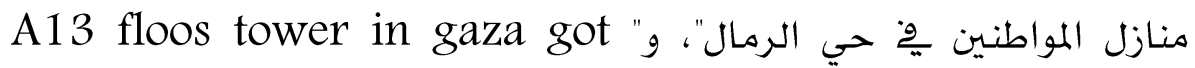
targeted by huge and massive Israeli airstrikes الاحتلال يْخ غزة منازل، هذه خيبة وليست بنك أهداف، يقوم باستهداف المنازل

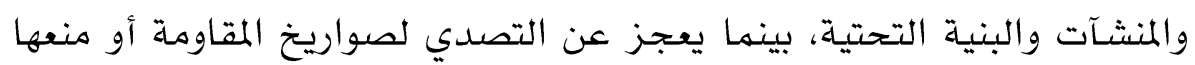

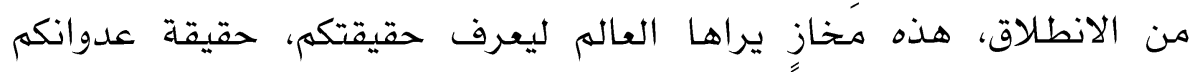
المتواصل على شعبنا منذ عقود" .

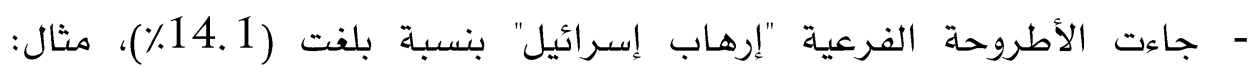

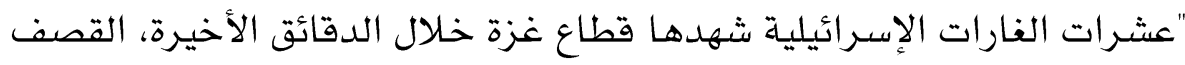

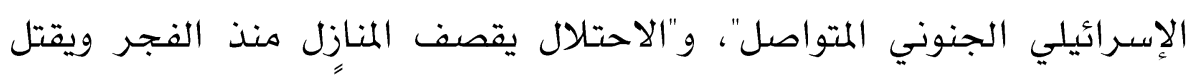

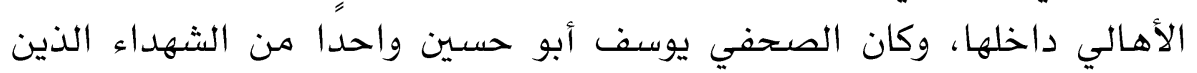

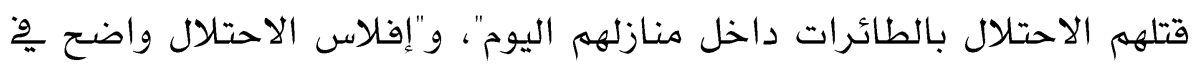

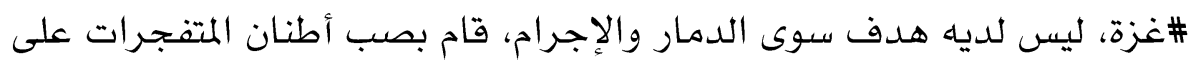

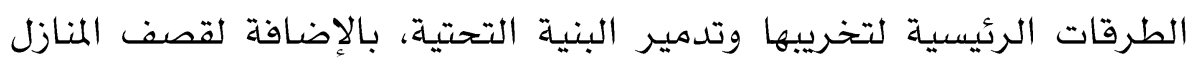

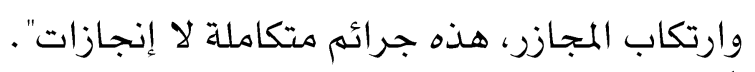

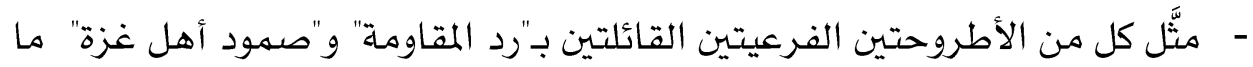

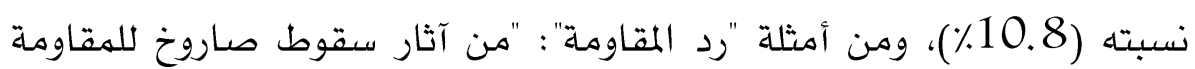

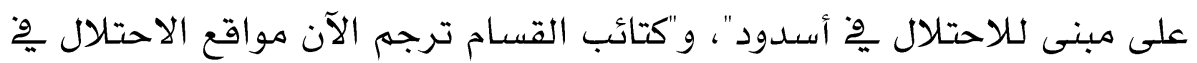

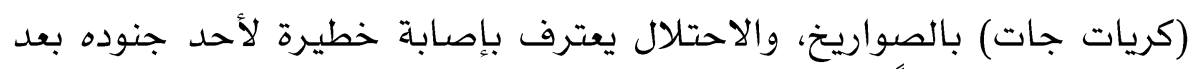

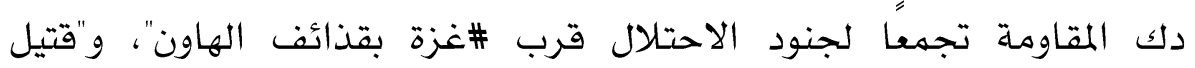

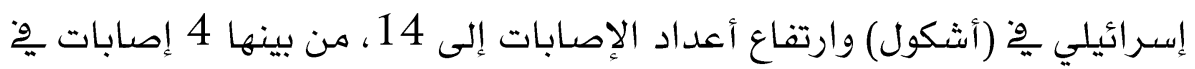

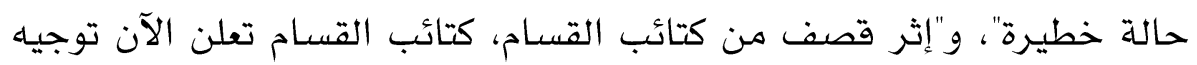

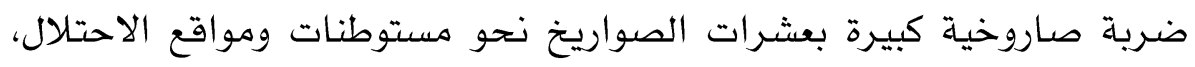

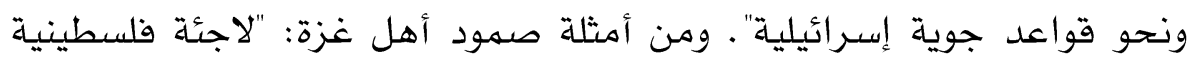

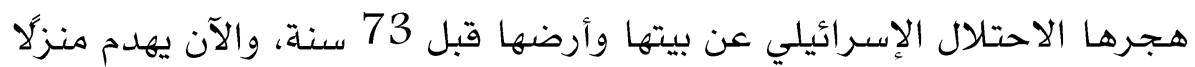


آخر لها خلال عدوانه على قطاع \#غزة، وٌِّ مقابل ذلك تدعم المقاومة وتتحدى

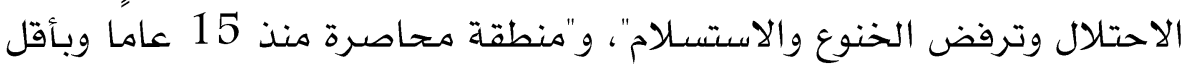

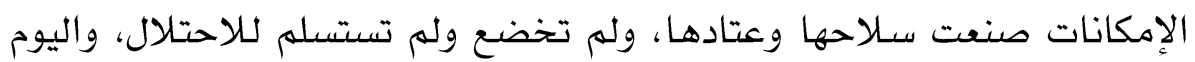

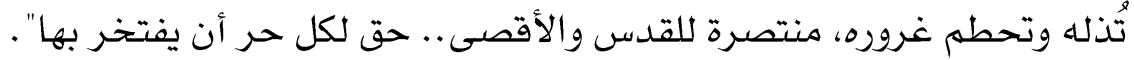

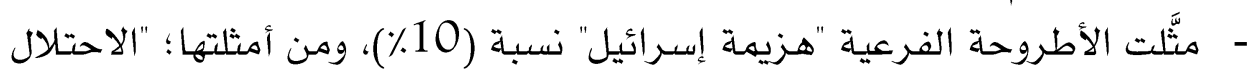

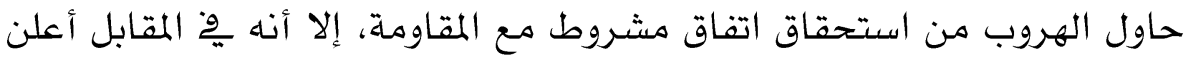
هزيعته السياسية بنفسه، فما فعله هو انسحاب وليس مجرد وقف إطلاق النار"،

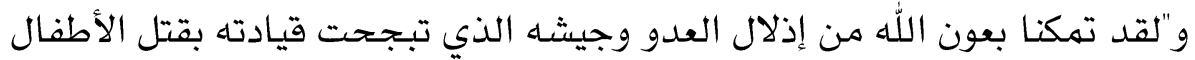

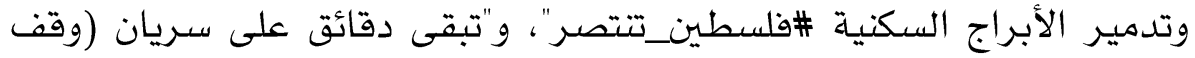
إطلاق النار) وما زالت المقاومة تدك من \#غزة مواقع الاحتلال بالقذائف

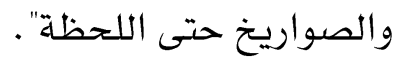

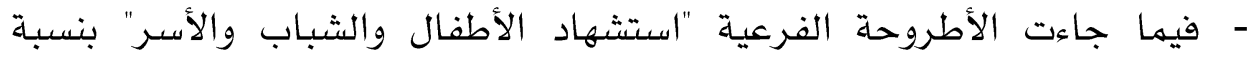

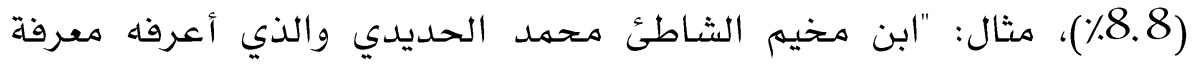

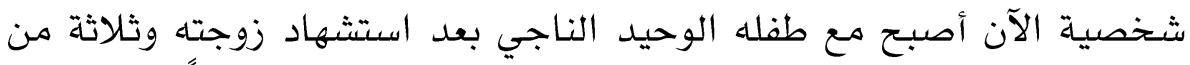

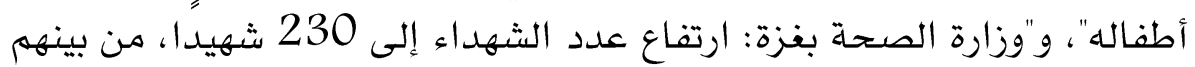

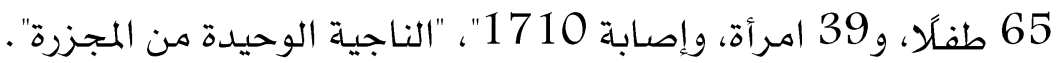

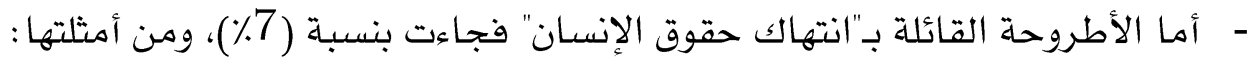

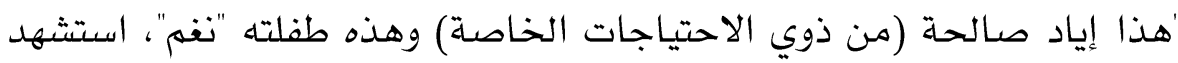

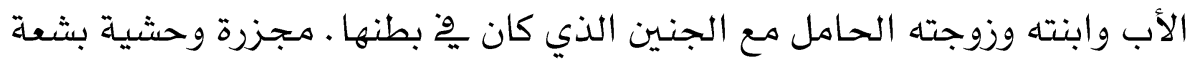

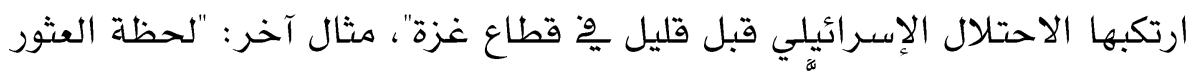

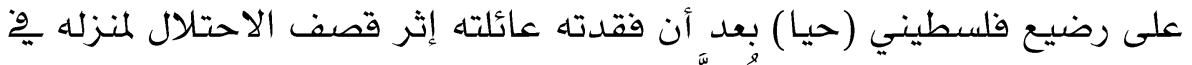

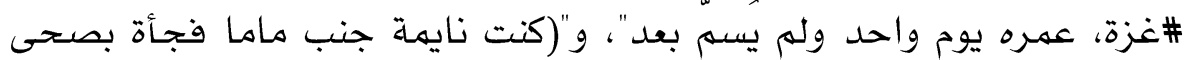

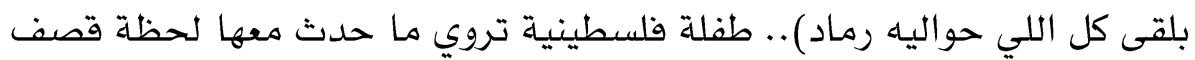

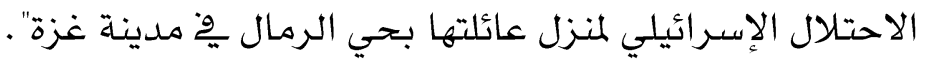

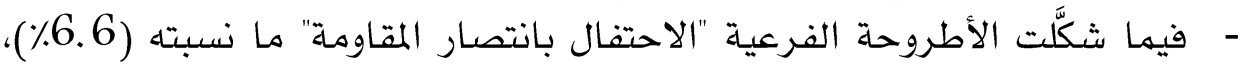

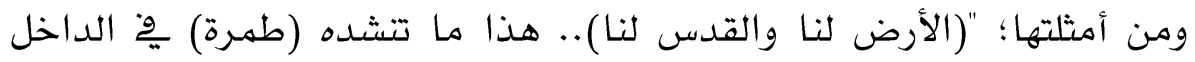

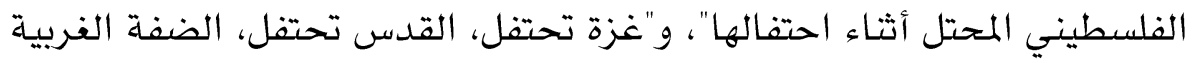

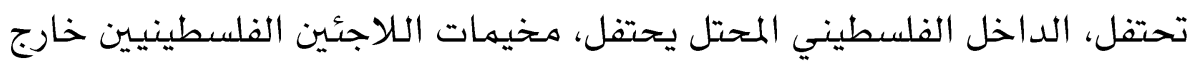

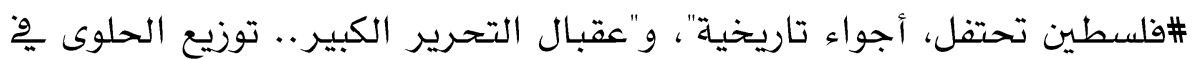


People in " ساحات \#المسبد_الأقصى احتفالًا وابتهاجًا بالنصر الفلسطيني" . "Gaza celebrating eid alfitr again \#Gaza \#GazaVictory ومن ثَمَّ تعددت الأطروحات الفرعية التي قََّّهها خطاب الدبلوماسية الشعبية

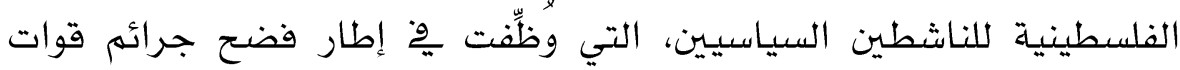
الاحتلال وإرهاب إسرائيل، إضافة إلى تصوير مدى صمود أهل غزة، ودور

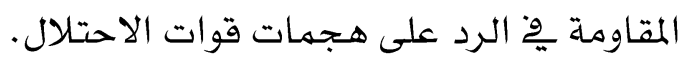

8- القوى الفاعلة

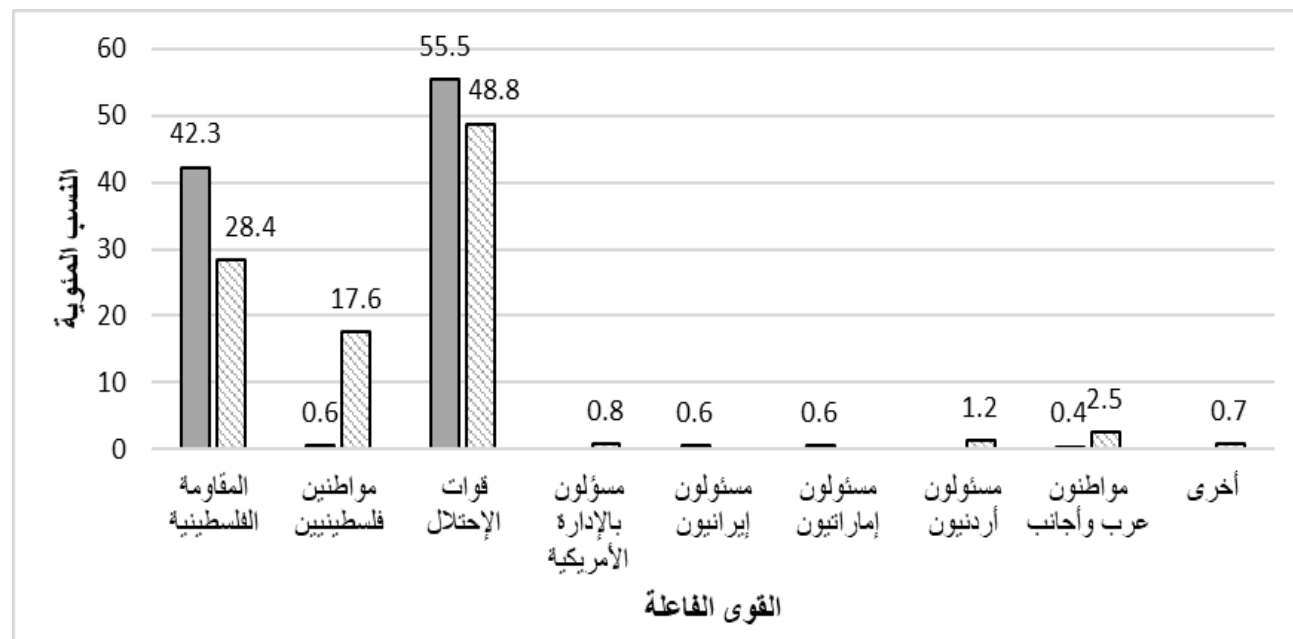

خطب النثطاء الفلسطينينه خطاب الثلاعب السياسيه

شكل رقم (8): يوضح القوى الفاعلة ِِّ كل من خطاب التلاعب السياسى وخطاب الناشطين الفلسطينيين

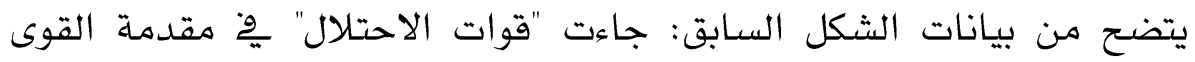

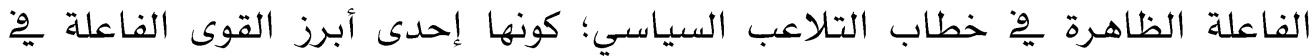

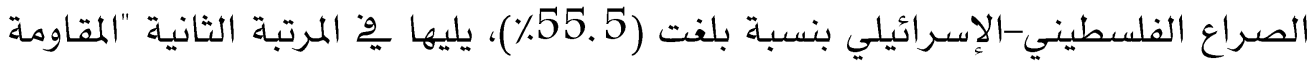

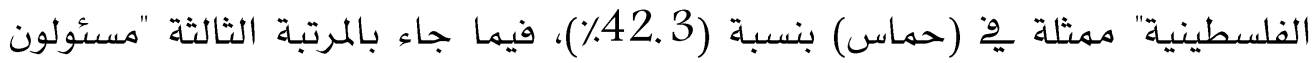

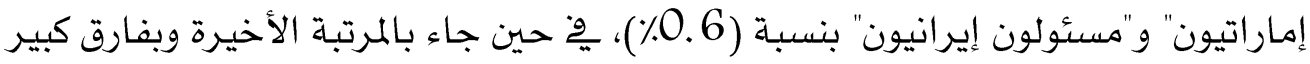

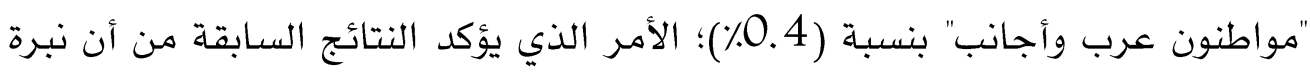

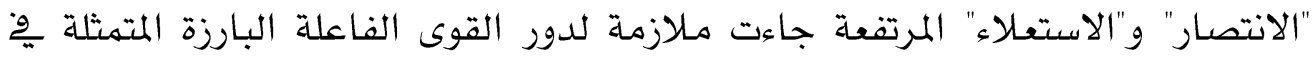

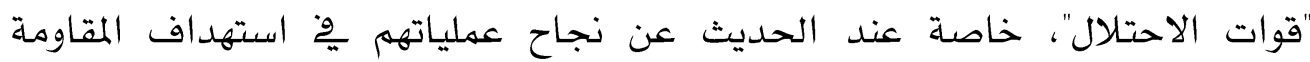

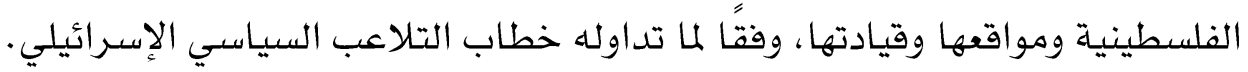


أما بالنسبة للقوى الفاعلة الظاهرة ِوْ خطاب الناشطين السياسيين، فكانت "قوات الاحتلال" أبرز القوى الفاعلة بنسبة (48.8٪)، وارتبط الحديث عنها بِّة سياق

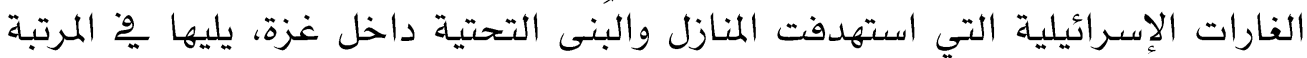

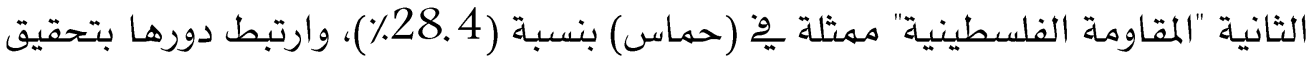
الانتصار على قوات الاحتلال خلال معركة (سيف القدس)، وِّْ المرتبة الثالثة جاء

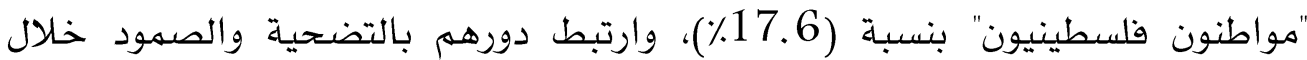

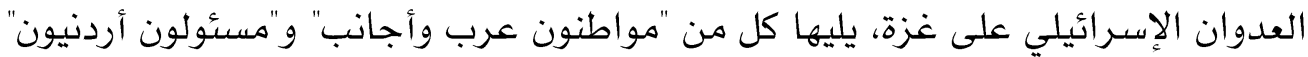

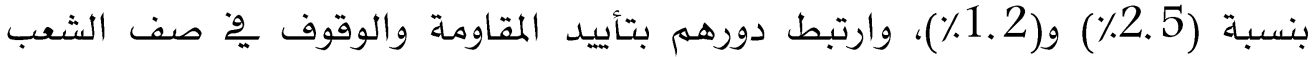

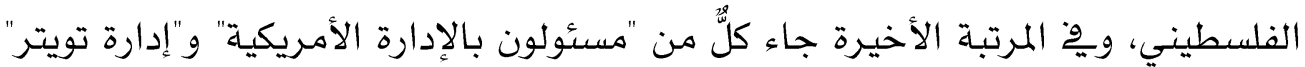
بنسبة (0.8٪) و(0.7٪) على التوالي، وارتبط دور الإدارة الأمريكية بدعم إسـرائيل

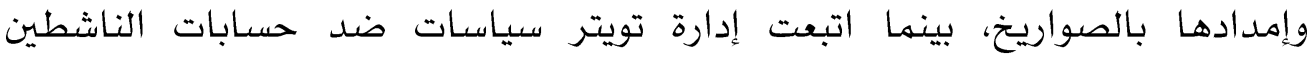

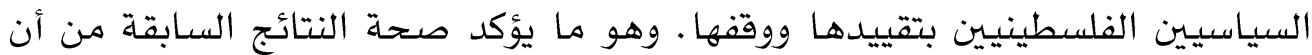

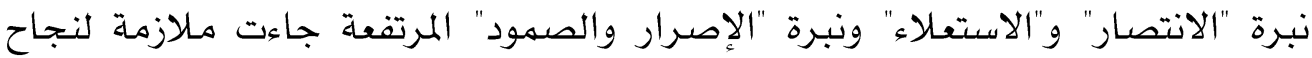
معركة (سيف القدس) فِ استهداف قوات الاحتلال ومواقعها، وما تكبدته الأخيرة من الإن

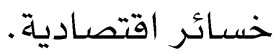

\section{9-صفات القوى الفاعلة وأداورها}

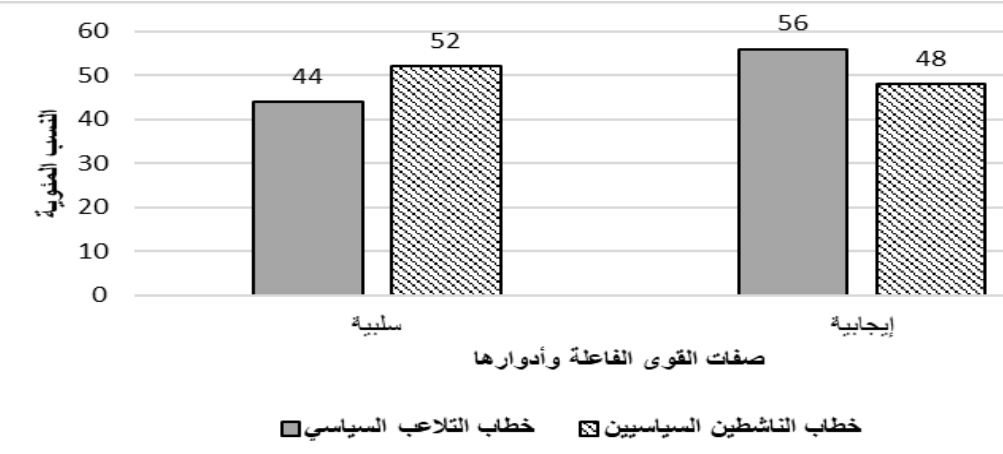

شكل رقهم (9) : يوضح صفات القوى الفاعلة وأدوارها ِِّ كل من خطاب التلاعب السياسى وخطاب الناشطين الفلسطينيين

يتضح من بيانات الشكل السابق: جاءت صفات القوى الفاعلة وأدوارها

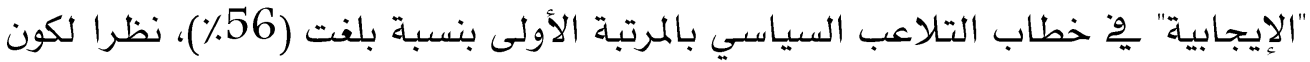

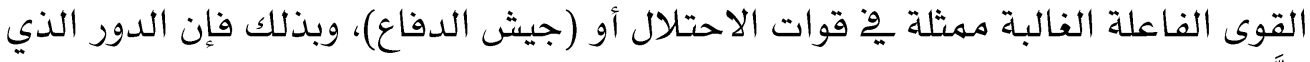

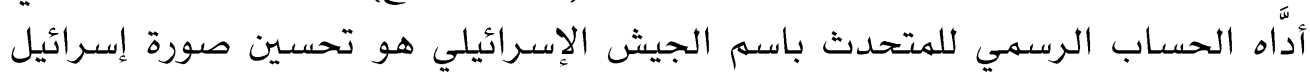




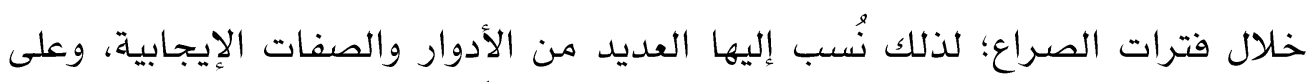

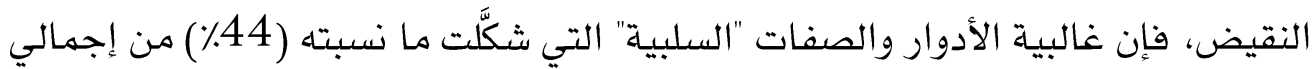

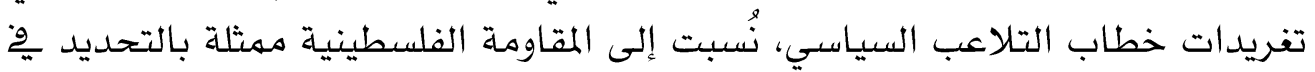
(حماس) وجناحها العسكري (كتائب القسام). - - الصفات المنسوبة لقوات الاحتلال: مؤمنون، ساهرون، مستعدون، مدافعون، ذورو إرادة. - الأدوار المسنَدة إلى قوات الاحتلال: الحفاظ على أهنه واستقراره، واعتقال

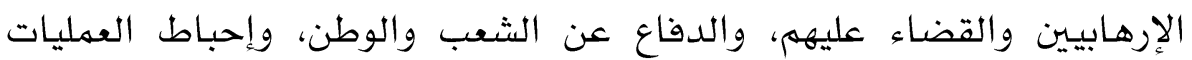

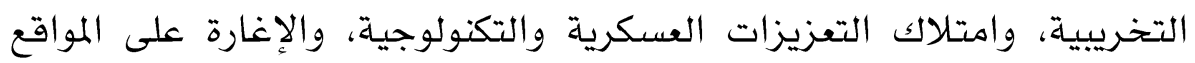
الإرهابية، ولا يقتلون المدنيين. - الصفات المنسوبة للهقاومة: إرهابيون، قتلة، مفترون، مخريون، فاقدو البصيرة، مثيرو الشغب، ظالمون، تخريبيون، مجرمون، معتدون، كاذبون. الإنهان.

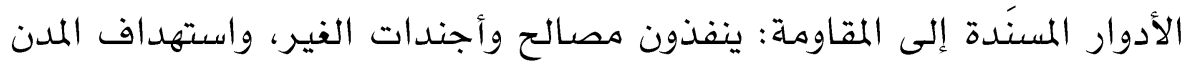

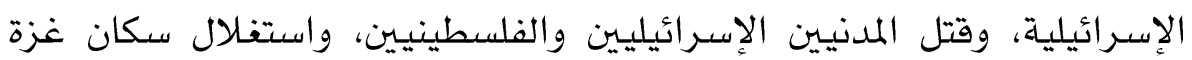

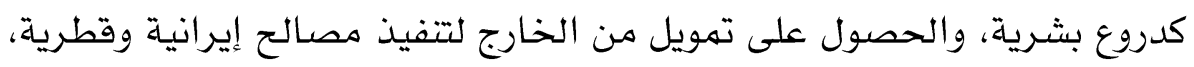

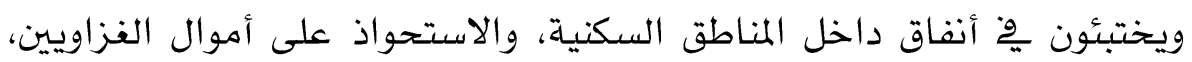

$$
\text { ويقتلون الأطفال، ويرتكبون جرائم حرب. }
$$

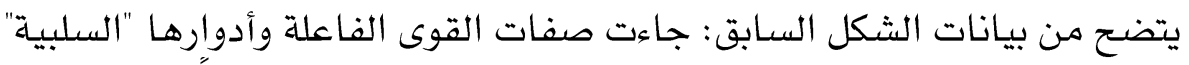

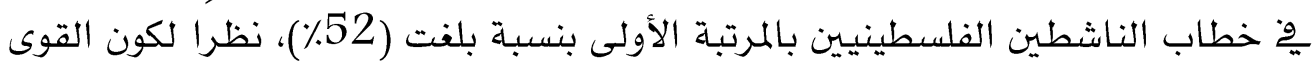

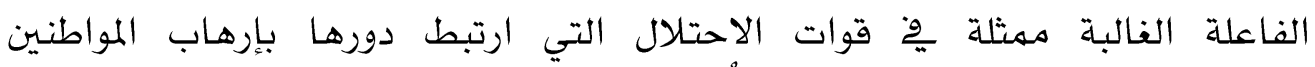

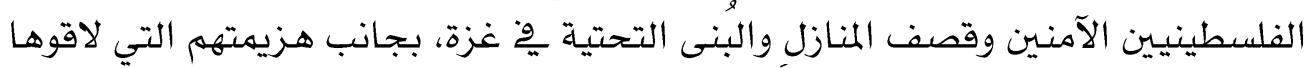

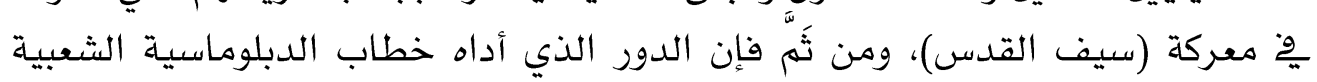

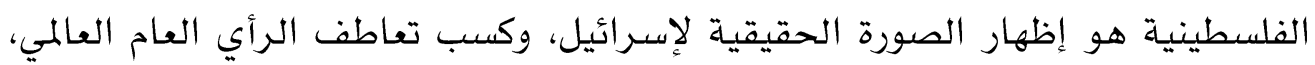

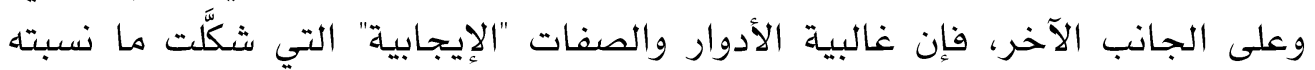

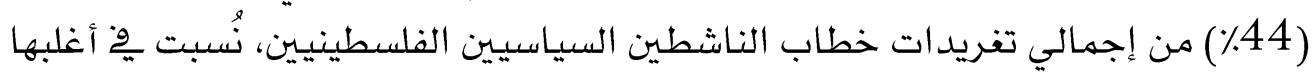
إلى المقاومة الفلسطينية ممثلة بالتحديد وِ القسام).

- الصفات المنسوبة لقوات الاحتلال: إرهابيون، جبناء، قتلة، كاذبون، مغتصبون،

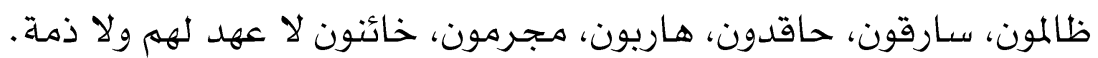


- الأدوار المسنَدة لقوات الاحتلال: قتل الأبرياء، وارتكاب مذابح وهجازر وحشية،

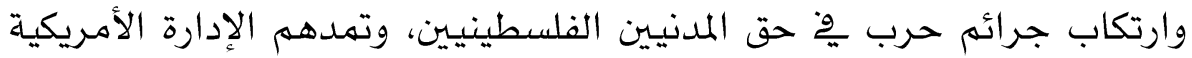

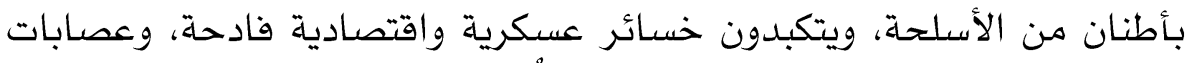

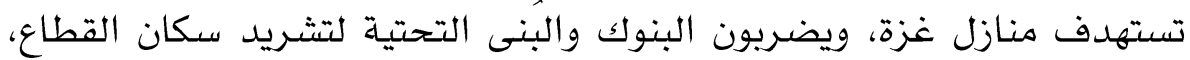
ويشنون غارات كثيفة على الأحياء السكنية.

- الصفات المنسوبة للمقاومة: صامدون، مدافعون، مناضلون، باسلون، منتصرون.

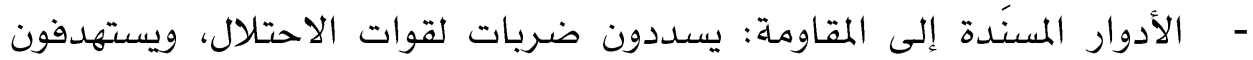

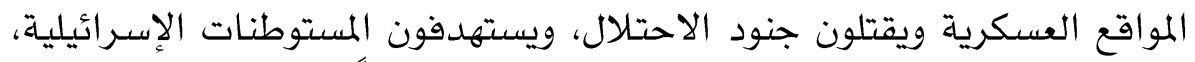
وينتصرون للقدس، ويدافعون عن غزة، ويستشهدون دفاعا عن القضية.

$$
\text { 10-مرجعية الخطاب }
$$

جدول رقم (5) : يوضح نسب وتكرارات مرجعية الخطاب بالحسابات عينة الدراسة

\begin{tabular}{|c|c|c|c|c|}
\hline \multicolumn{2}{|c|}{ خطاب الناشطين } & \multicolumn{2}{|c|}{ خطاب التلاعب السياسى } & \multirow{2}{*}{ مرجعية الخطاب } \\
\hline$\%$ & 5 & $\%$ & 5 & \\
\hline 7 & 42 & 1.6 & 5 & سياسية \\
\hline 5.1 & 31 & 2.8 & 9 & دينية \\
\hline 1.8 & 11 & 1.6 & 5 & تاريخية \\
\hline 1.2 & 7 & 1 & 3 & اقتصادية \\
\hline 2.5 & 15 & 1.2 & 4 & حقوقية/ قانونية \\
\hline 2 & 12 & 1 & 3 & فكرية \\
\hline 55.2 & 332 & 82.4 & 263 & أمنية \\
\hline 18.4 & 111 & 5 & 16 & اجتماعية/ إنسانية \\
\hline 6.8 & 41 & 3.4 & 11 & أحداث واقعية \\
\hline
\end{tabular}

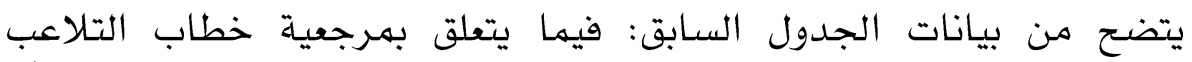

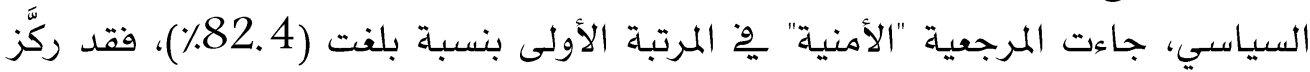

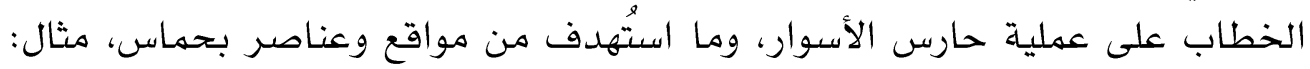

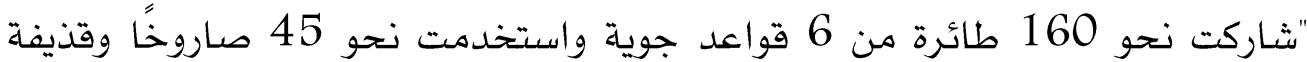

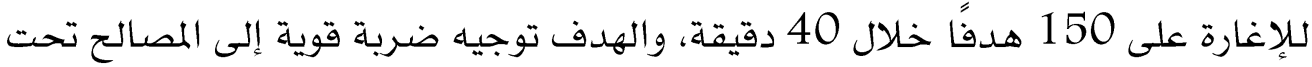
الأرضية \#تمترو_حماس". وبِّ المرتبة الثانية جاءت المرجعية "الاجتماعية والإنسانية" بنسبة (5٪)، ويظهر ذلك من خلال إظهار خطاب التلاعب السياسي مدى حرصها على المئية 
أرواح المدنيين وتعاطفه مع سكان غزة المستغلين- من وجهة نظر الخطاب- كدروع بشرية

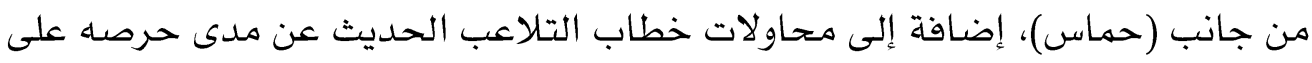

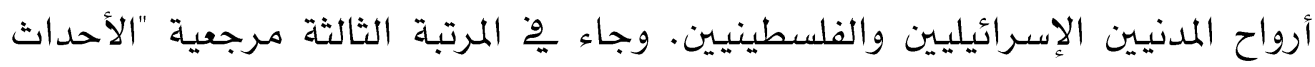

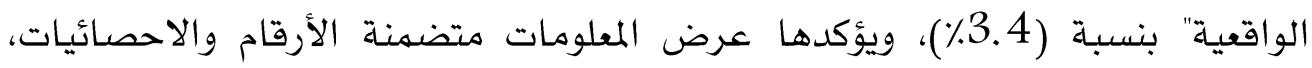

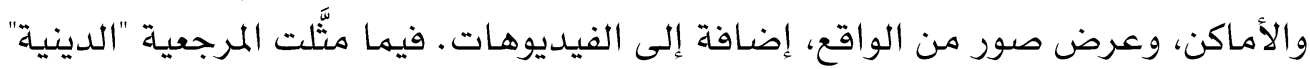

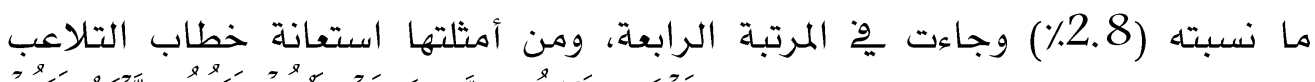

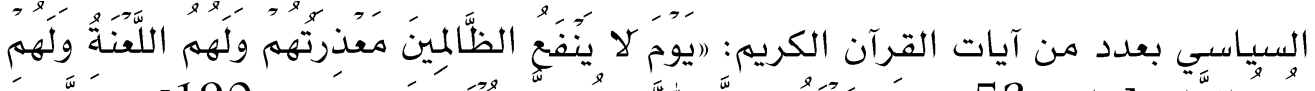

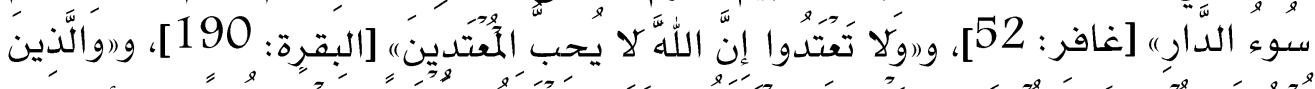

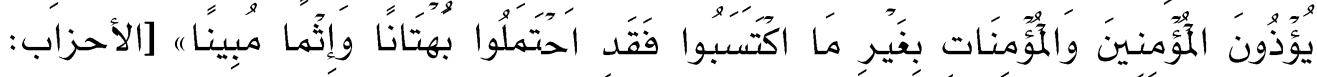

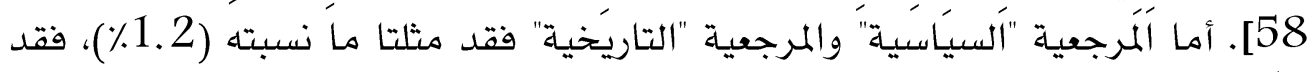

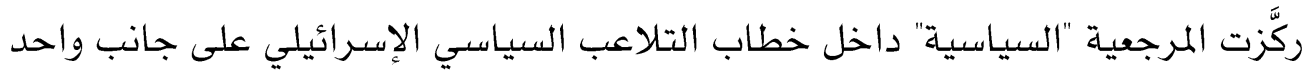

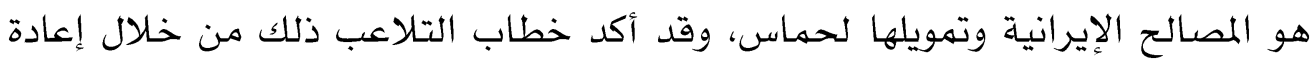

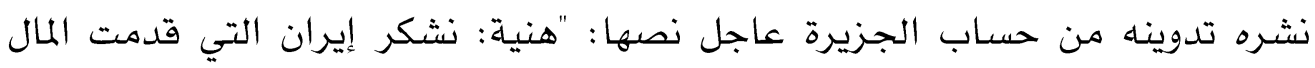

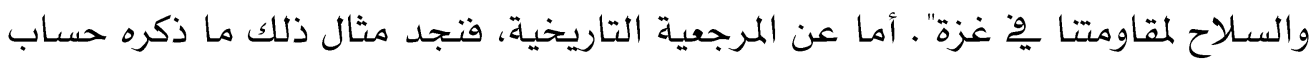

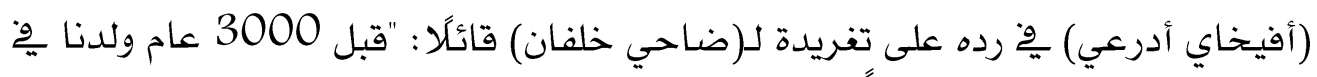

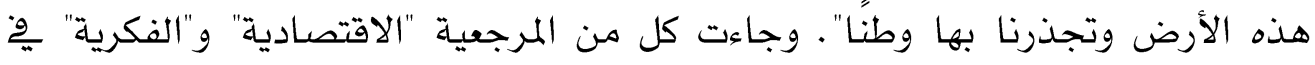

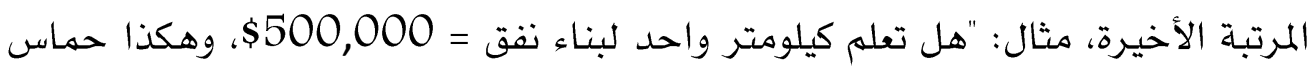

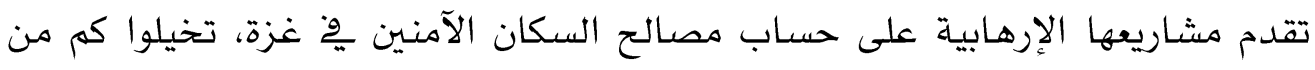

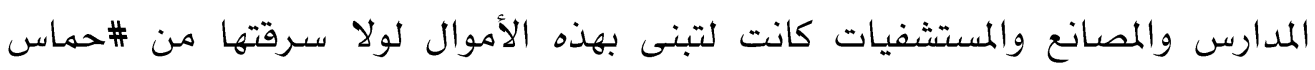

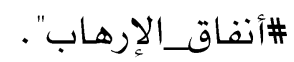

ويتضح من بيانات الجدول السابق: فيها يتعلق بمرجعية خطاب الناشطين الإبنا

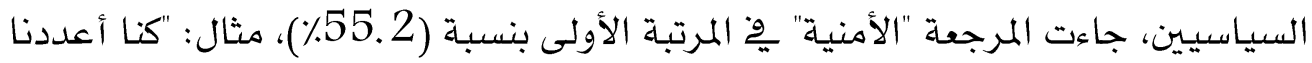

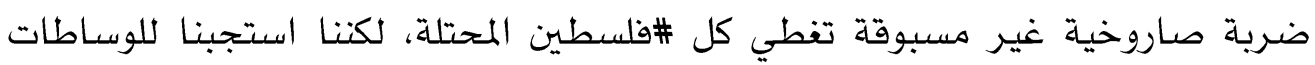

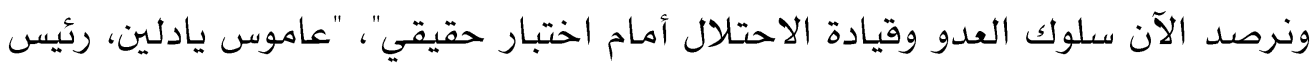

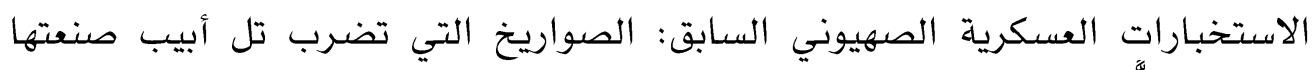

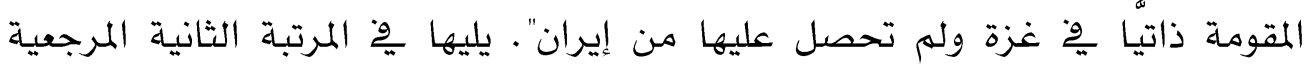

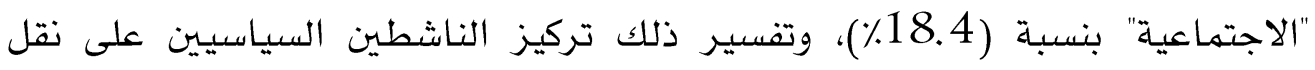

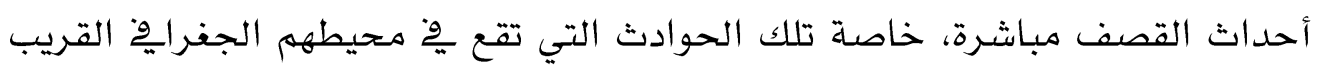

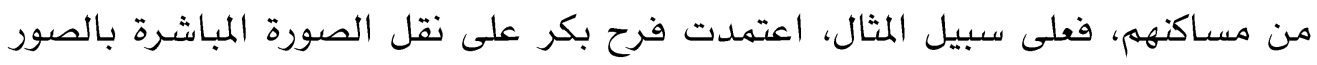




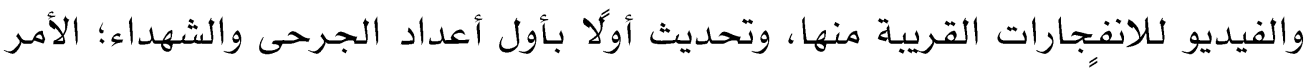

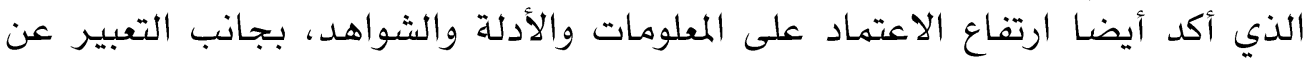

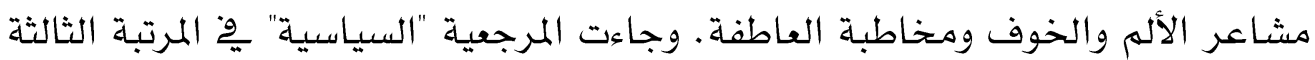

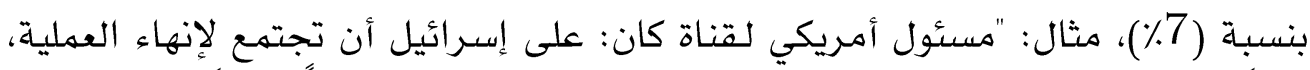

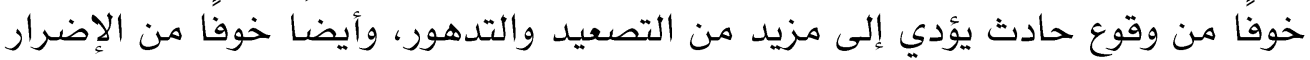

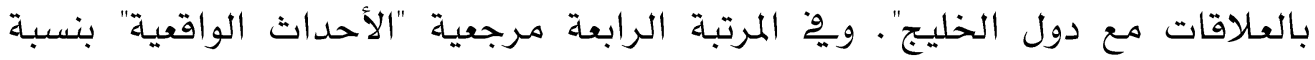
(6.8٪)، مثال: "لحظة قيام طائرات الاستطلاع باستهداف مواطنين بشكل مباشر أثناء

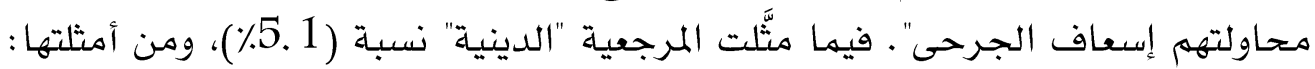

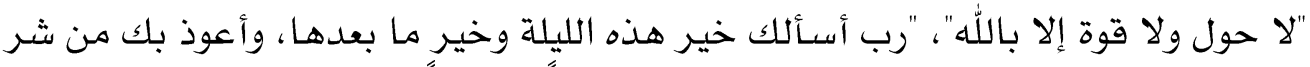

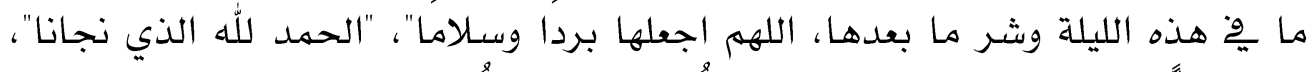

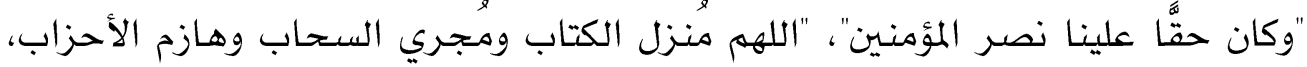

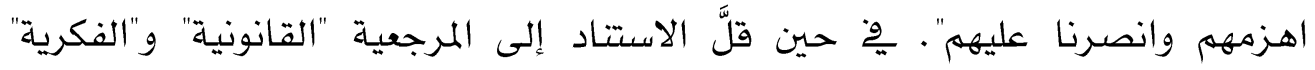

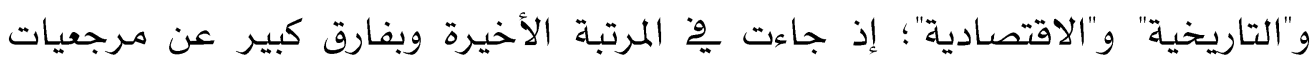

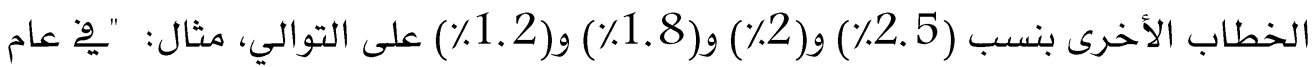

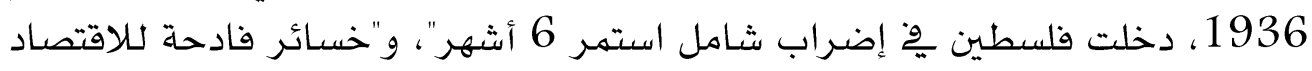

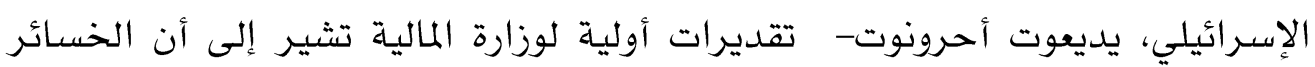

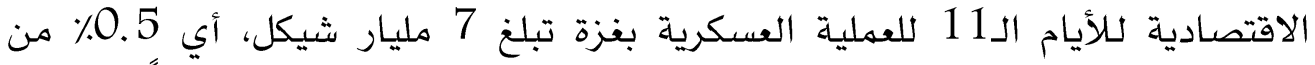
إجمالي الناتج القوهي، وهي ضعف خسائر عدوان 2014 الذي استهر 50 يوهًا" .

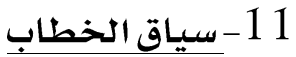

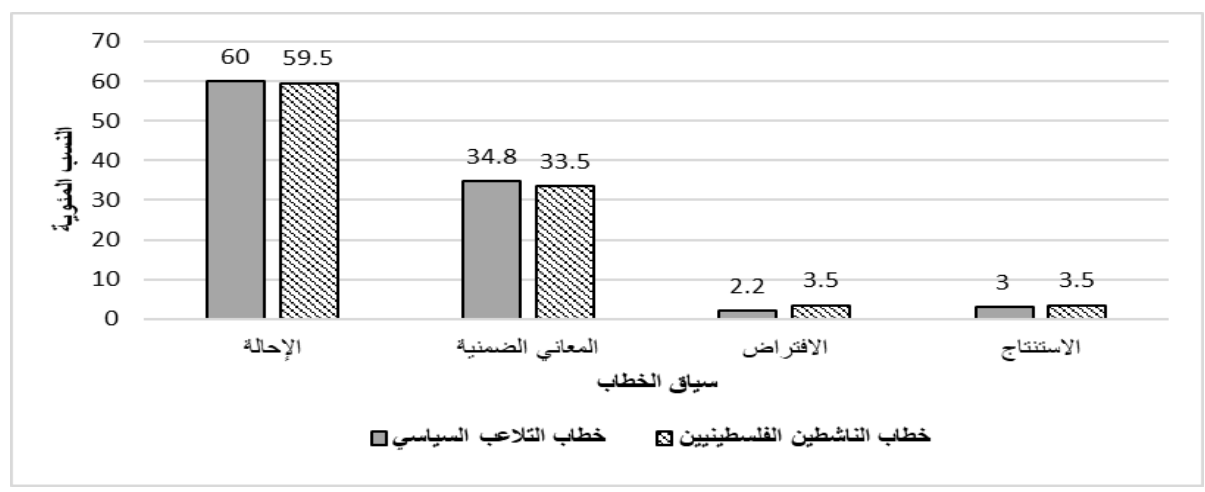

شكل رقم (10) : يوضح سياق الخطاب بٌِ كل من خطاب التلاعب السياسى وخطاب الناشطين الفلسطينيين 


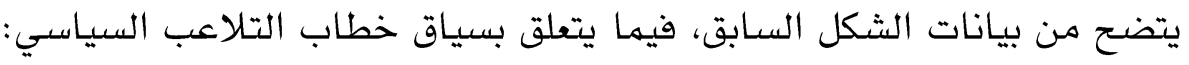

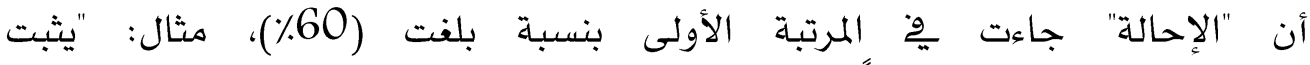

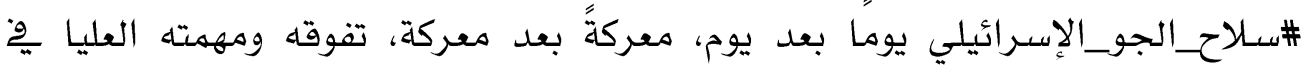

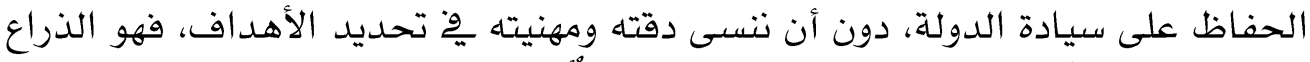

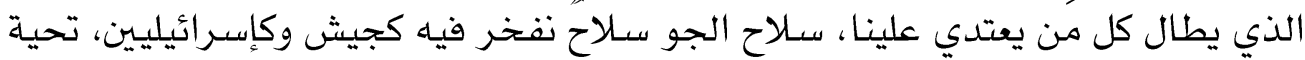

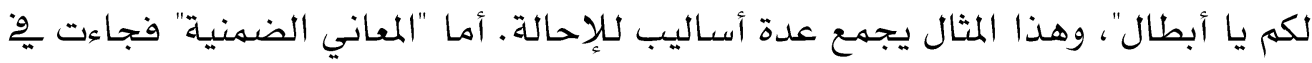

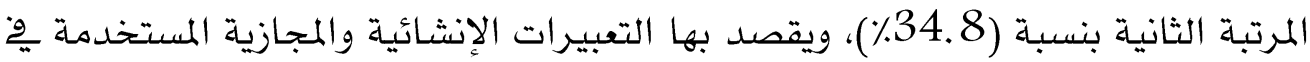

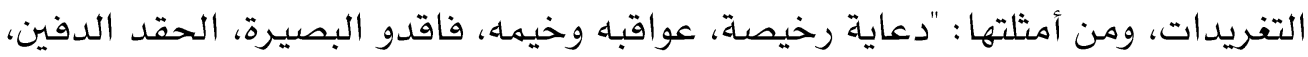

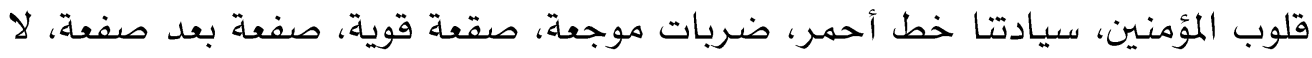

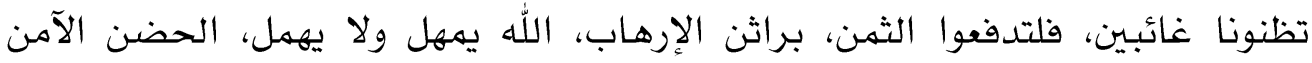

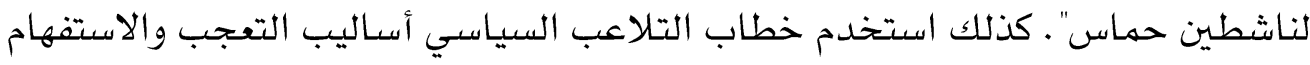

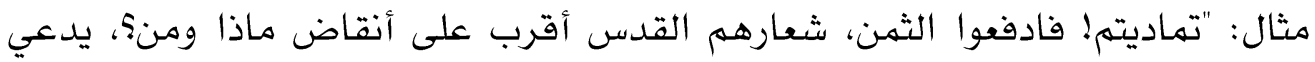

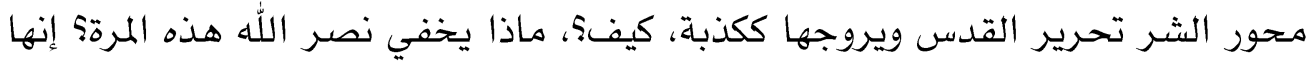

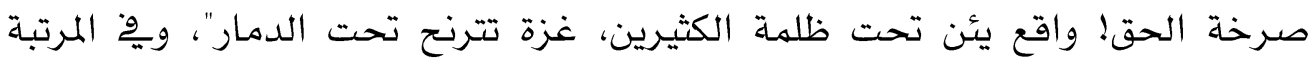

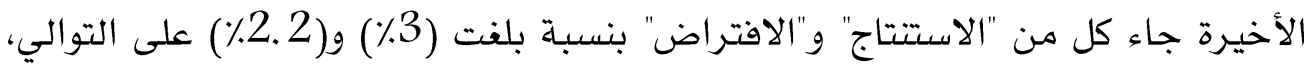

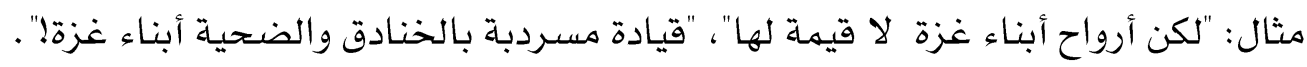

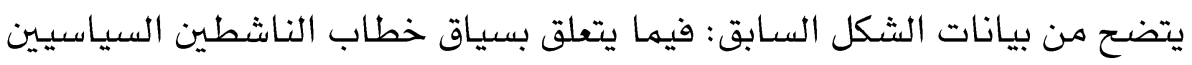

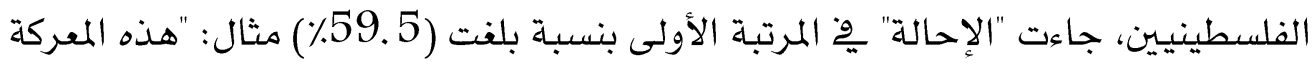

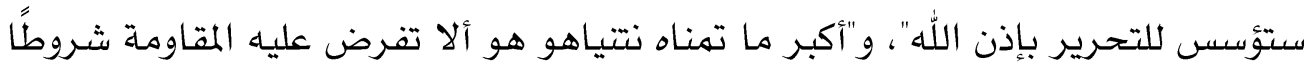

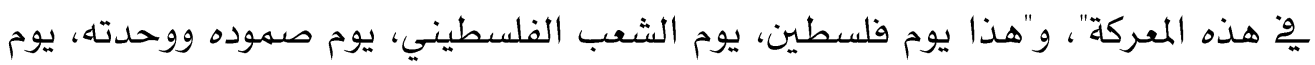

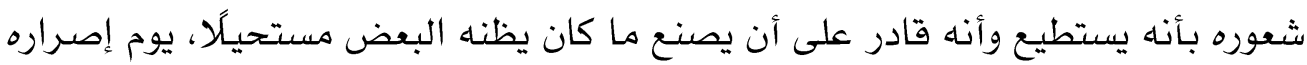

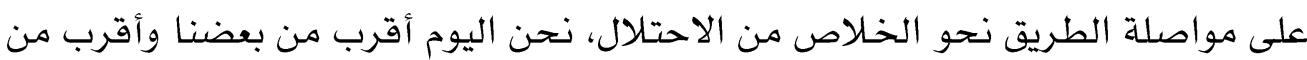

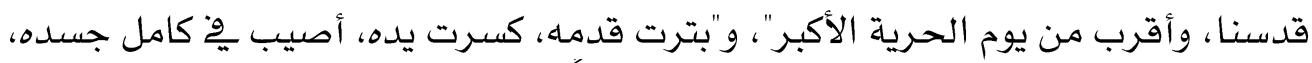

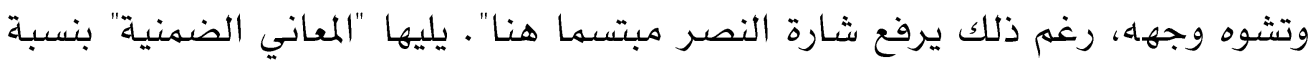

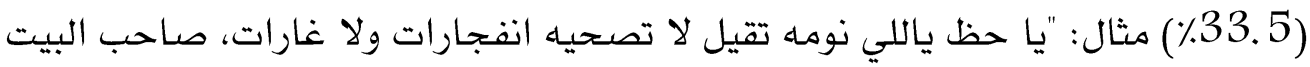

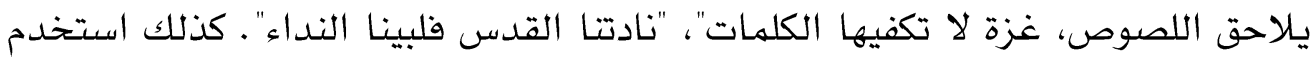

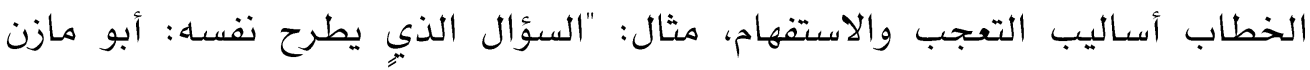

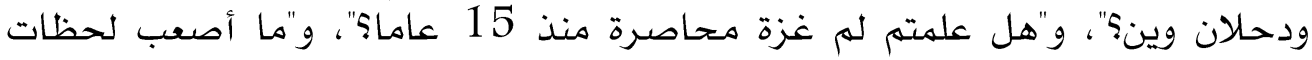

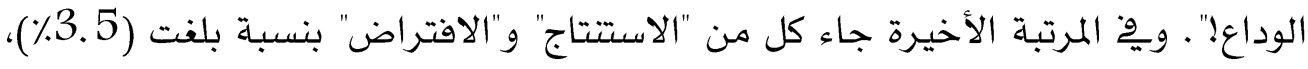


مثال: "هل تعلمون أن اليوم 25 مايو هو ذكرى استقلال ما يُسمى بدولة إسرائيل؟ حمأ

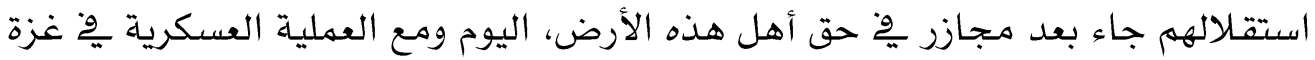

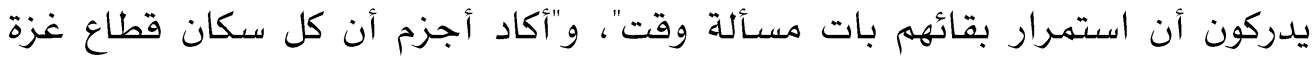

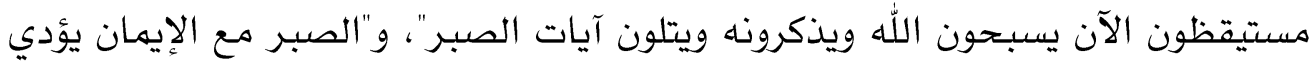

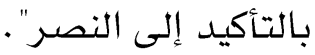
12 - الإستراتيجيات اللهير" الاتصالية

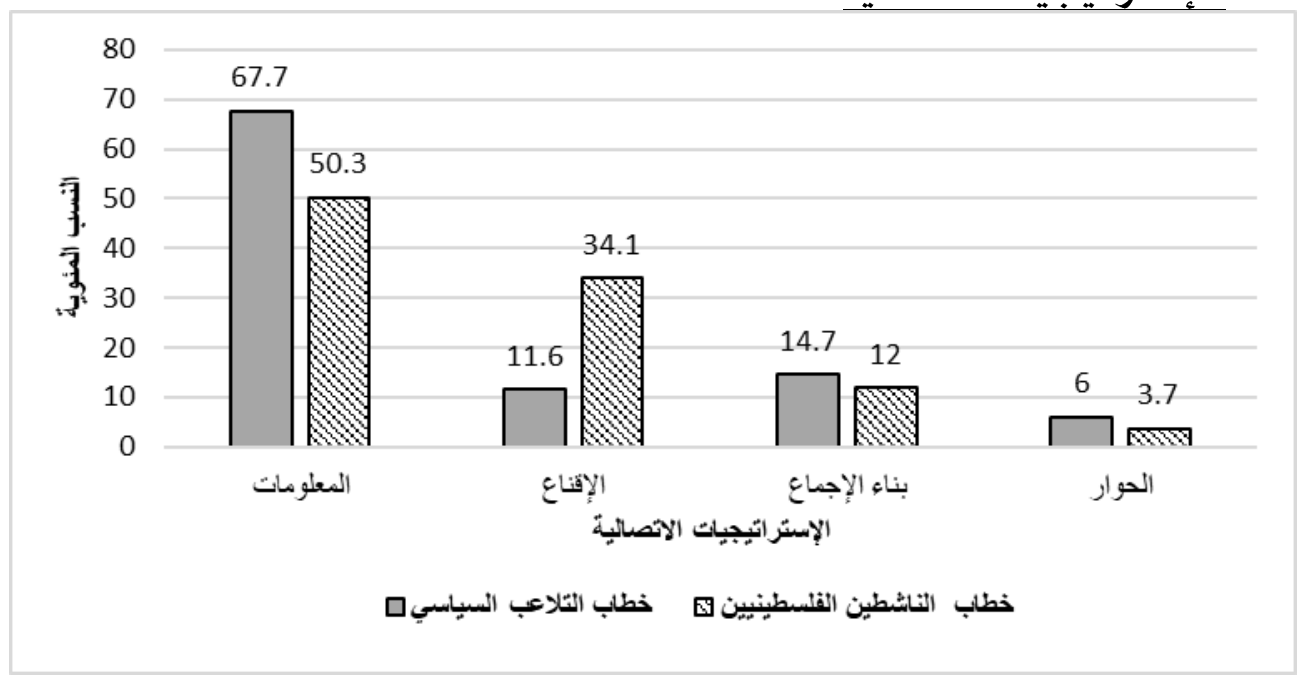

شكل رقم (1 11 ): يوضح الإستراتيجيات الاتصالية ِِّ كل من خطاب التلاعب السياسى وخطاب الناشطين الفلسطينيين

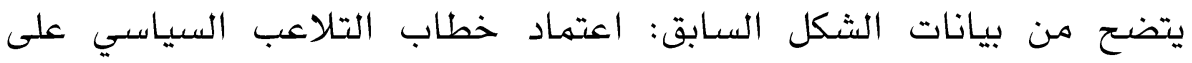

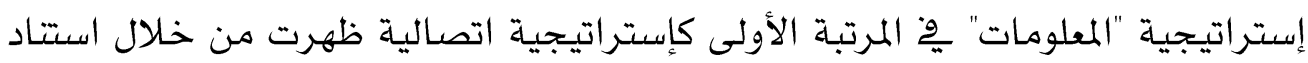

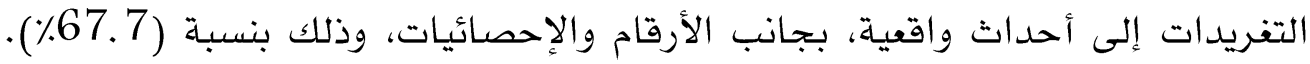

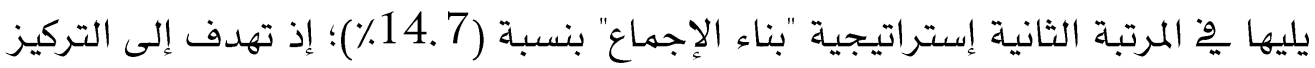

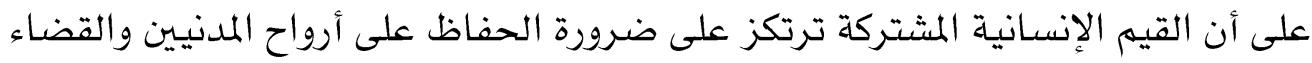

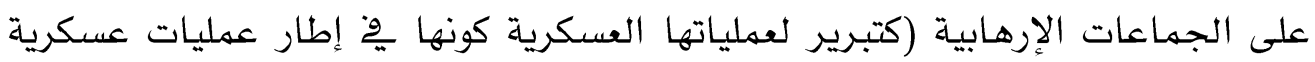

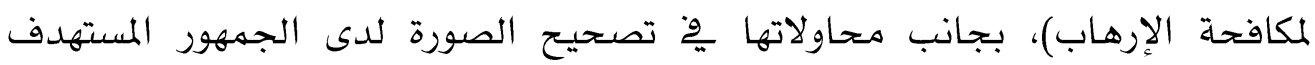

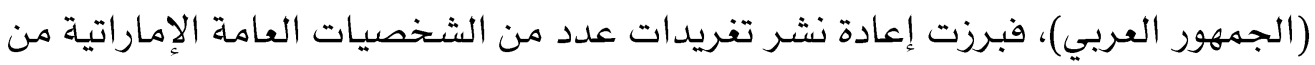

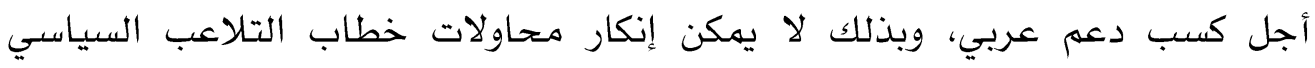

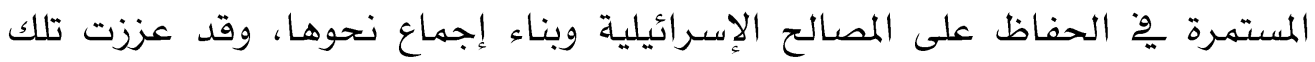

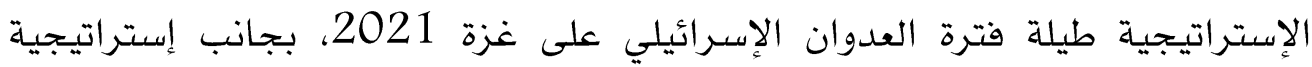

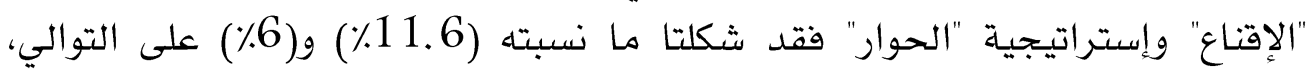


لتغيير الصورة الذهنية للاحتلال ومحاولة إيجاد تقارب، وتفاعل إيجابي نحوها، ومن ثمٍ

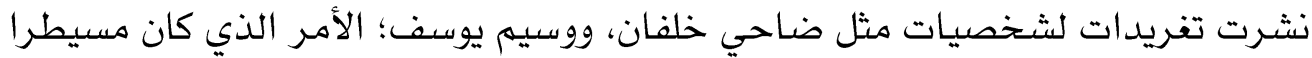

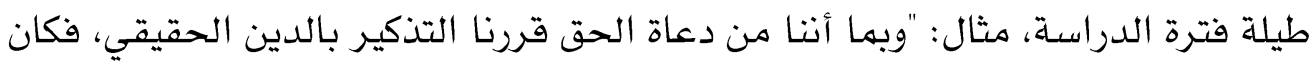

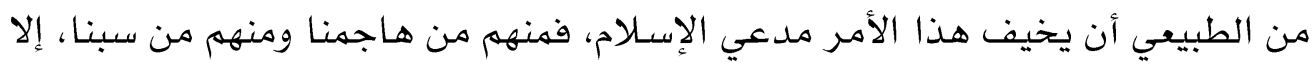

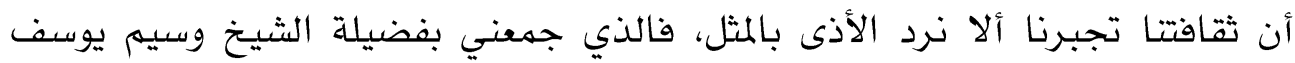
waseem_yousef

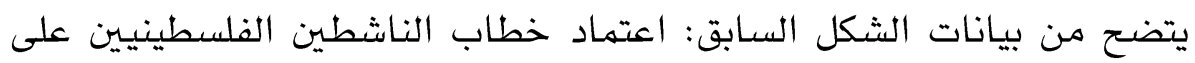
إستراتيجية "المعلومات" يِّ المرتبة الأولى كإستراتيجية اتصالية ظهرت من خلال استتاد التهات

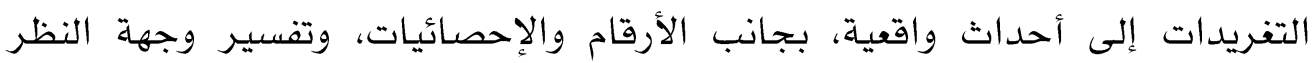

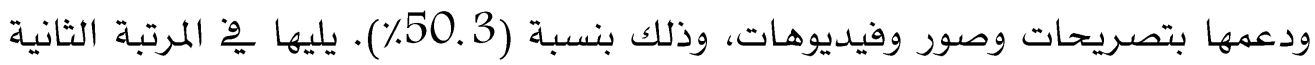

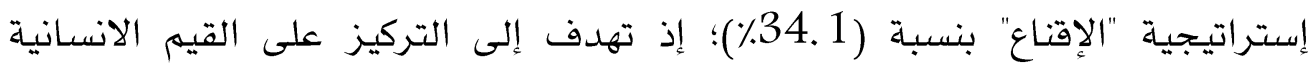

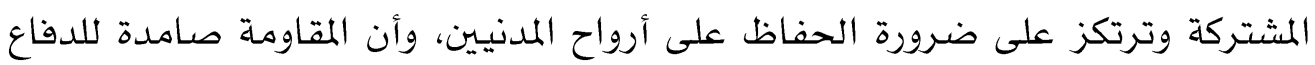

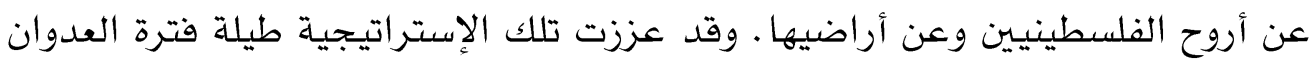

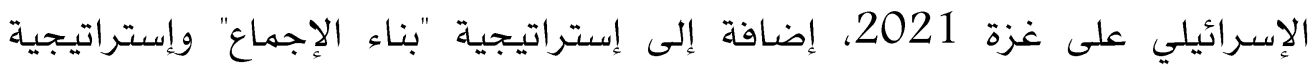

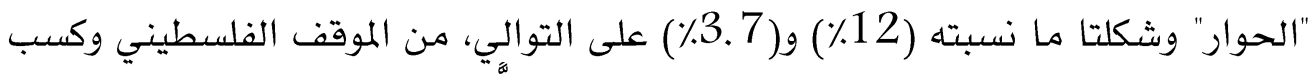

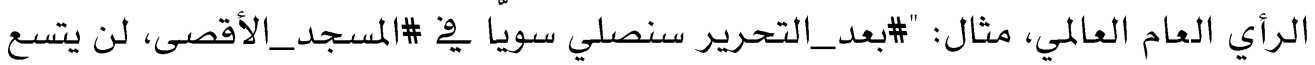
للملايين، وتهتد جموع المصلين لشوارع \#القدس، سنزور حيفا ويافا وعكا والخليل،

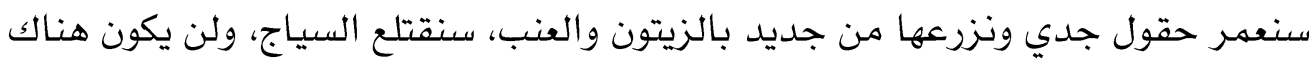

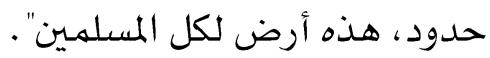

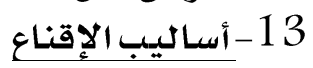

جلدول رقم (6): يوضح نسب وتكرارات أساليب الإقناع للخطاب بالحسابات عينة الدراسة

\begin{tabular}{|c|c|c|c|c|}
\hline \multicolumn{2}{|c|}{ خطاب الناشطين } & \multicolumn{2}{|c|}{ خطاب التلاعب السياسى } & \multirow[t]{2}{*}{ أساليب الإقناع } \\
\hline$\%$ & 5 & $\%$ & s & \\
\hline 57.3 & 345 & 46.7 & 149 & الأدلة والشواهد \\
\hline 2.8 & 17 & 28.5 & 91 & عرض جانب واحد فقط \\
\hline 0.2 & 1 & 0.6 & 2 & ترتيب الحجج \\
\hline 2 & 12 & 2.8 & 9 & تفنيد وجهة النظر \\
\hline 1.7 & 10 & 0.6 & 2 & تأثير رأي الأغلبية \\
\hline 2.3 & 14 & 7.8 & 25 & التكرار \\
\hline 33.7 & 203 & 12.9 & 41 & الجهـع بـين أكثر مـن أسلوب \\
\hline
\end{tabular}


يتضح من نتائج الجدول السابق: فيما يتعلق بأساليب الاقناع المستخدمة ِوِ

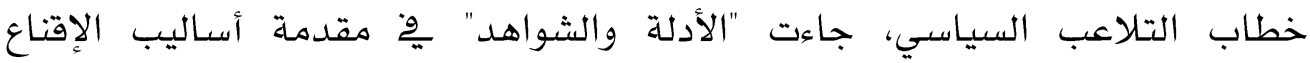

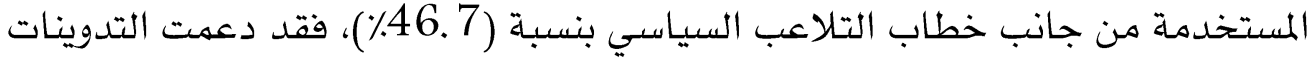
الخطاب بصور، وفيديوهات، وخرائط، وأرقام وإحصائيات، وهو ما يؤكد النتائج السـابقة

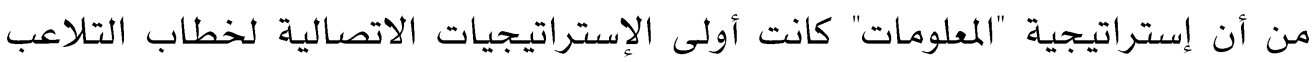

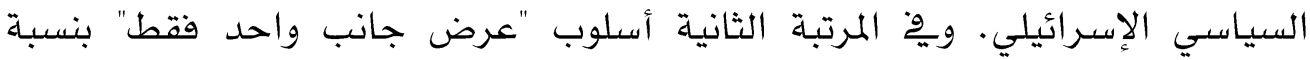

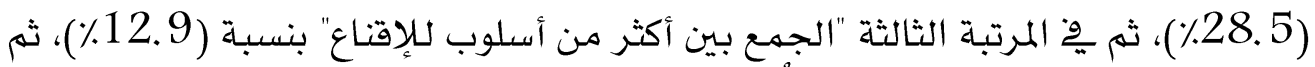

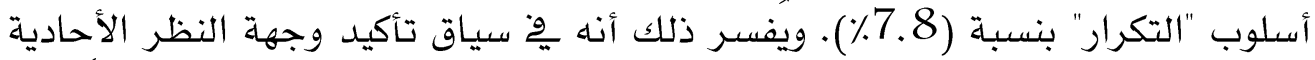

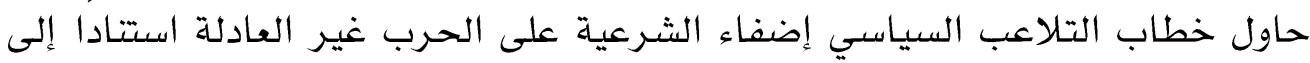

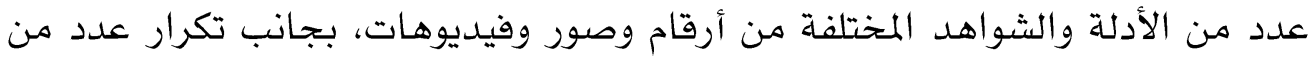
الشعارات والكلمات المحورية والأساليب اللغوية داخل التفريدات، ولتحقيق ذلك بفاعلية التهاتية

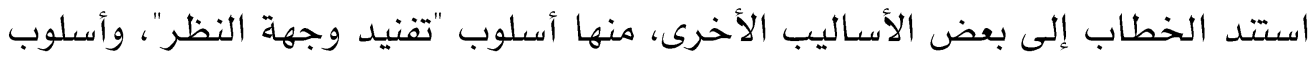

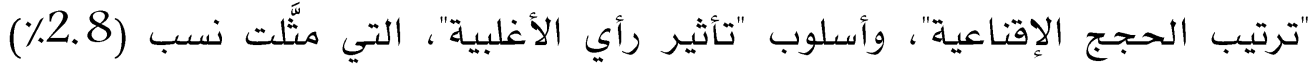

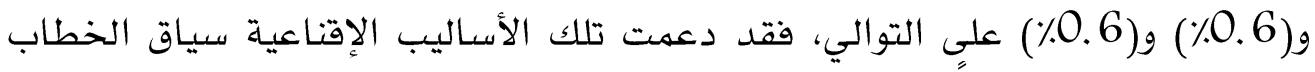

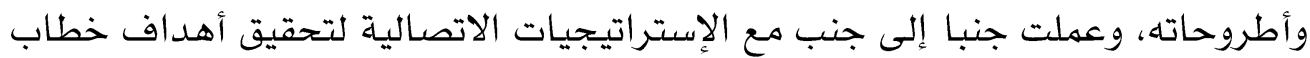

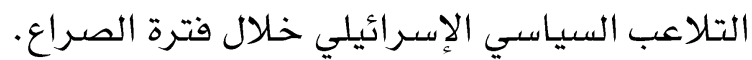

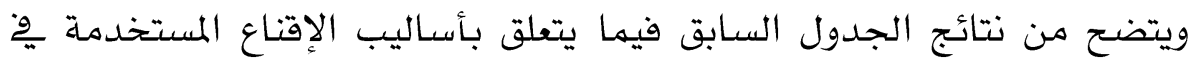

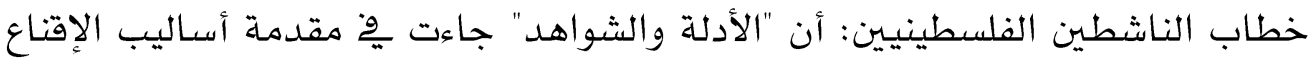

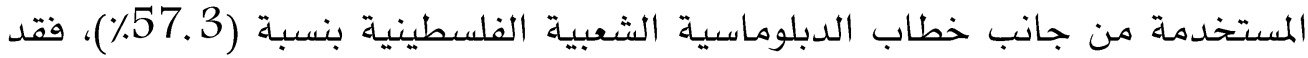
دعمت التدوينات الخطاب بصور واقعية، وفيديوهات، وأرقام وإحصائيات، وهو ما يؤكد

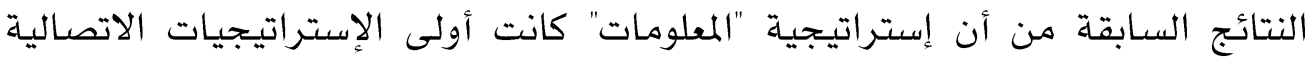

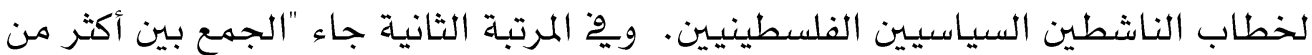

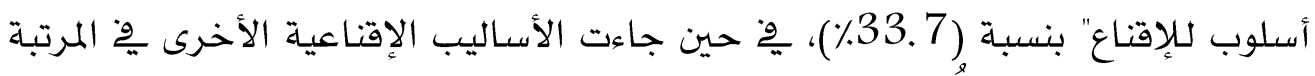

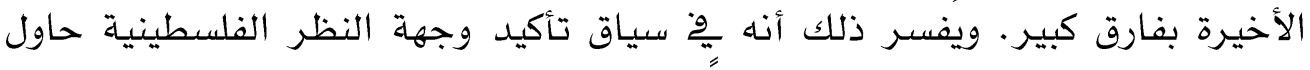

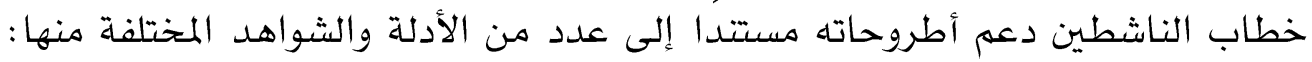

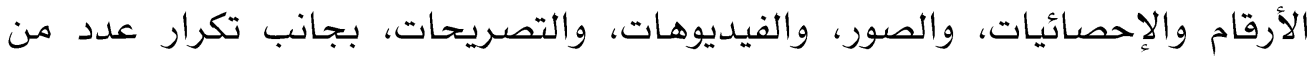

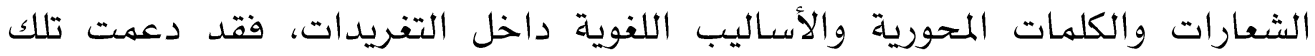

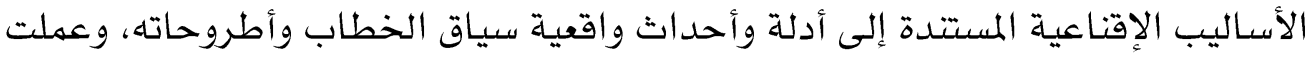


جنبا إلى جنب مع الإستراتيجيات الاتصالية لتحقيق أهداف خطاب الدبلوماسية الشعبية

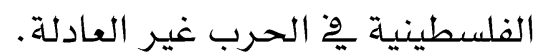

ويلاحظ تقارب كلا الخطابين من حيث أسـاليب الإقناع المستخدمة، فكانت "الأدلة والشواهد" يوْ مقدمة تلك الأساليب؛ مها يشير إلى دعم كلا الخطابين

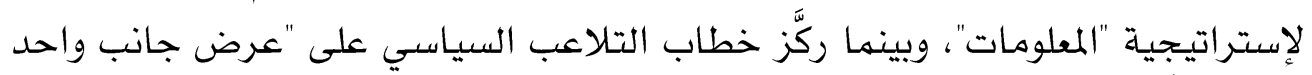
فقط"، ركَّز خطاب الدبلوماسية الفلسطينية على "الجمع بين أكثر من أسلوب للإقتاع" من أجل توضيح وجهة النظر، وهو ما يؤكد النتائج السابقة من اعتماد خطاب الناشطين

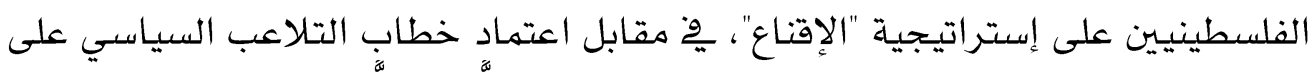

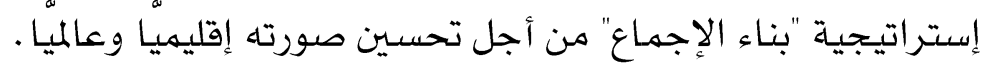
14

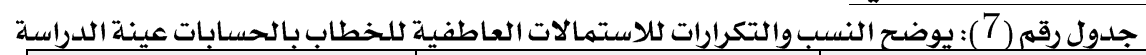

\begin{tabular}{|c|c|c|c|c|}
\hline \multicolumn{2}{|c|}{ خطاب الناشطين } & \multicolumn{2}{|c|}{ خطاب التلاعب السياسى } & \multirow[t]{2}{*}{ الاستمالات العاطفية } \\
\hline$\%$ & 5 & $\%$ & 5 & \\
\hline 26.6 & 204 & 7.3 & 24 & مخاطبـة العاطفة \\
\hline- & - & 6.7 & 22 & المبالغة والتهويل \\
\hline 16.3 & 125 & 15.3 & 50 & الشعاراتوالرموز \\
\hline 54.6 & 418 & 43.4 & 142 & أساليب لغوية \\
\hline 2.2 & 17 & 23.2 & 76 & التخويف \\
\hline 0.1 & 1 & 2.1 & 7 & التشهير والتشويه \\
\hline 0.1 & 1 & 1.8 & 6 & حكم وأمثال \\
\hline
\end{tabular}

يتضح من بيانات الجدول السابق: استخدام خطاب التلاعب السياسي "الأسـاليب اللغوية" كإحدى الاستهالات العاطفية ِِ المرتبة الأولى بنسبة (43.4٪)، فقد

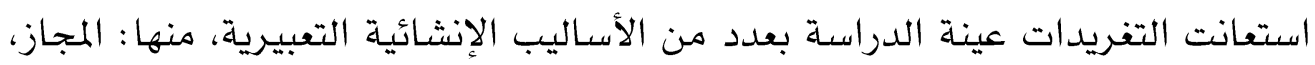
والصفات، والأسـاليب البلاغية، ووظفتها يخ سياق "أسلوب التخويف" الذي جاء يخ المرتبة الثانية بنسبة (23.2٪)، ومن أمثلة الأسـاليب اللفوية : "على العاله أن ينقذ غزة من براثن

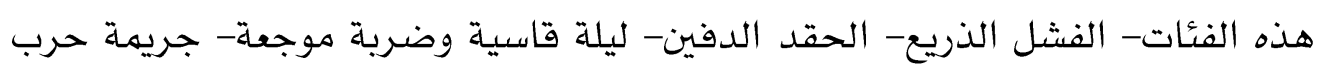
مزدوجة- أبشع أنواع الاستغلال- تلمله جراحها- النصر الوهمي الأكيد- الضريات

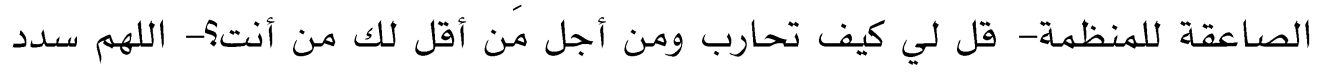
ضربات الحق لتصرها على الباطل- تتساءلون عن سبب ارتقاع الإصابات مِّ صفوف المدنيين داخل قطاع غزة؟- إنها صرخة حقإ- من أين يأتي العيد وقد بلغ السيل الزبى 


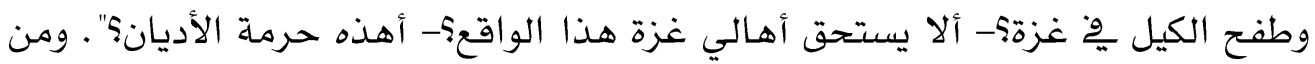

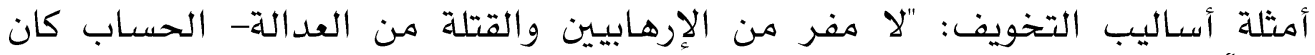

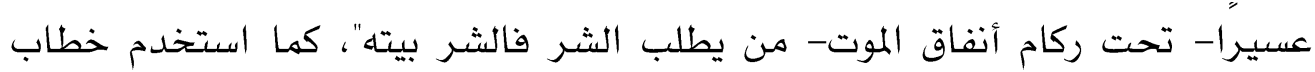

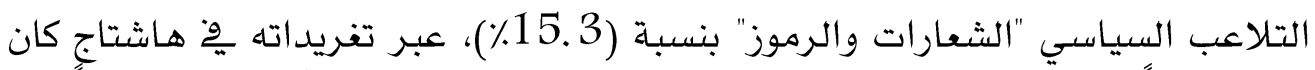

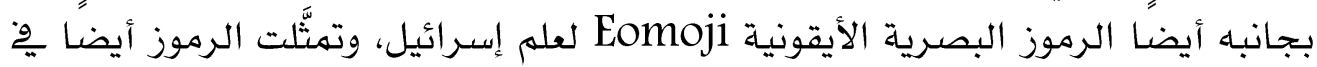

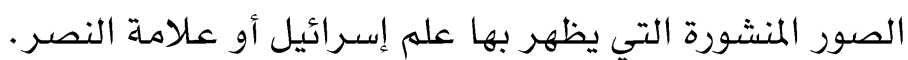

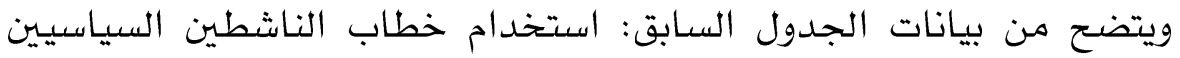

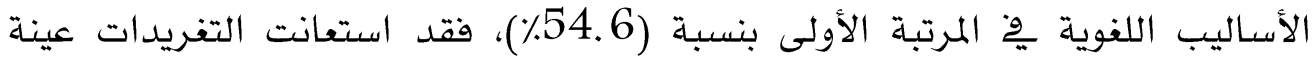

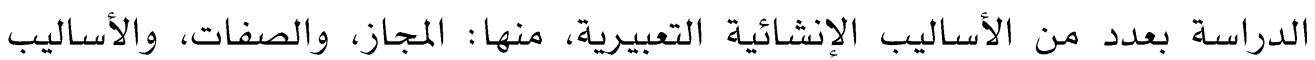

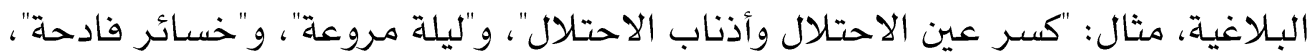

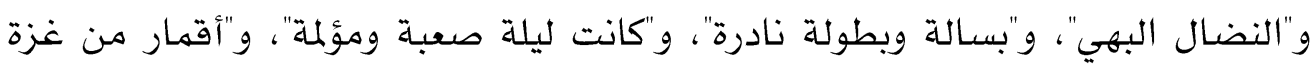

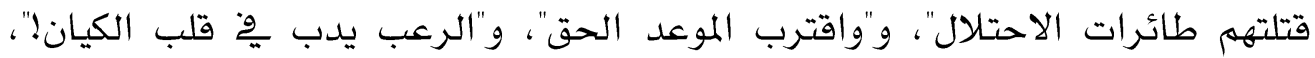

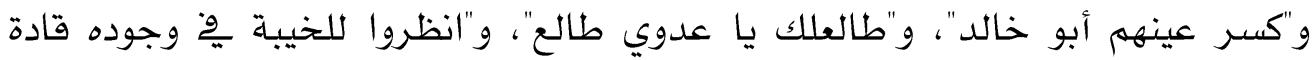

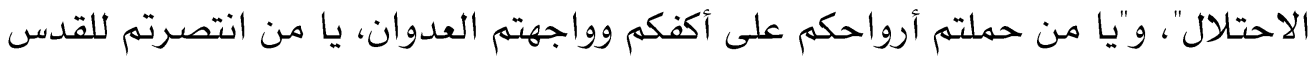

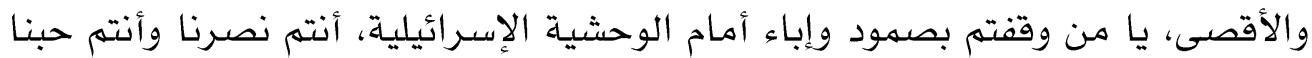

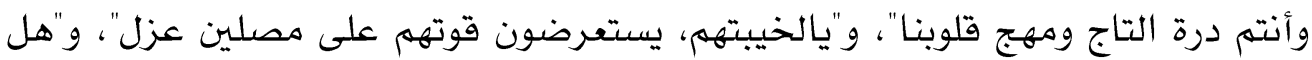

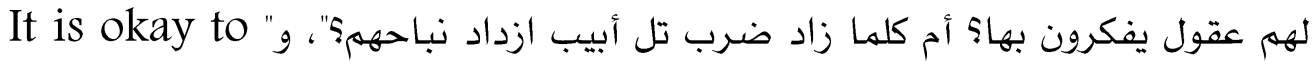
Work while bombs are everywhere? This is life in Gaza الأولى جاء أسلوب "مخاطبة العاطفة" ضهن الاستمالات العاطفية التي اعتمد عليها

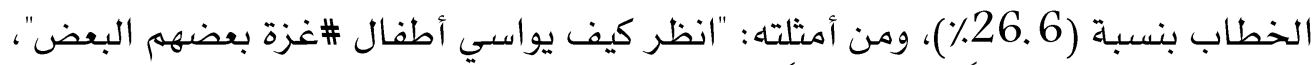

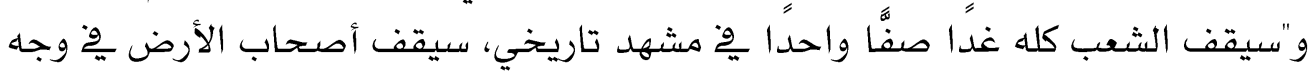

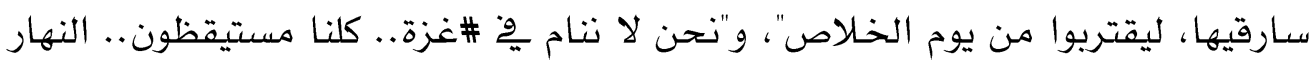

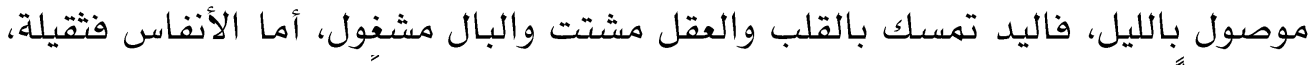

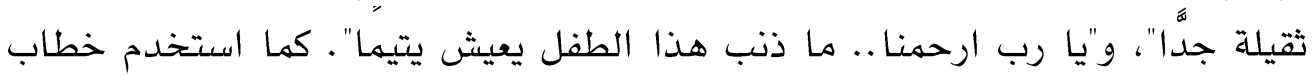

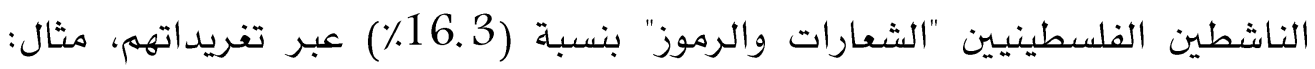
القدس لنا، وغزة العزة، وألف تحية مع عزة.. للمقاومة بغزة، إضافة إلى علامة التهات النصر التي ظهرت ِِّ الصور والفيديوهات. 


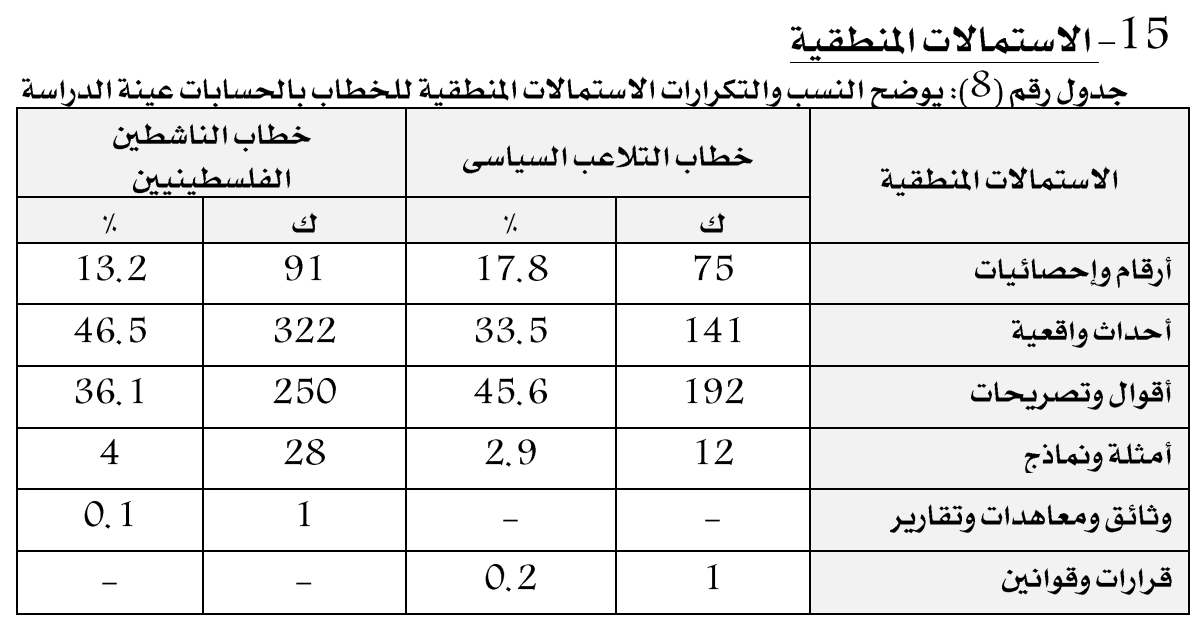

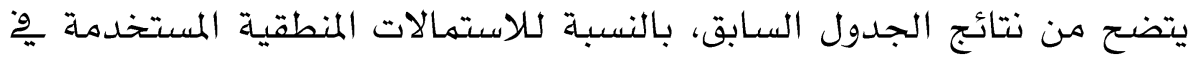

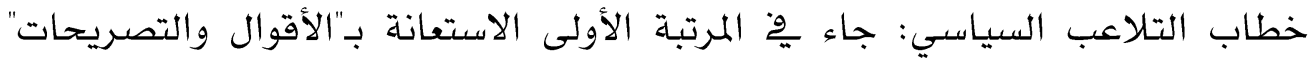

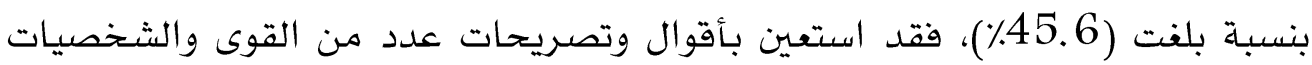

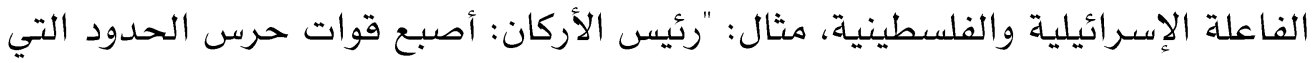

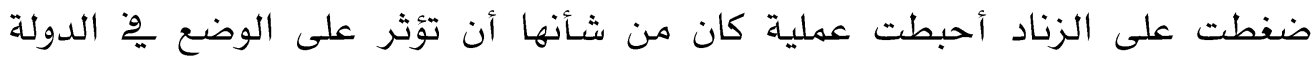

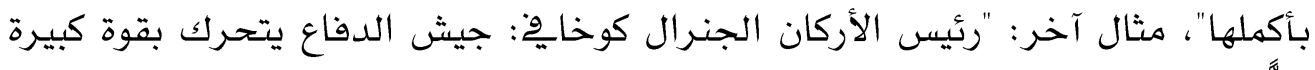

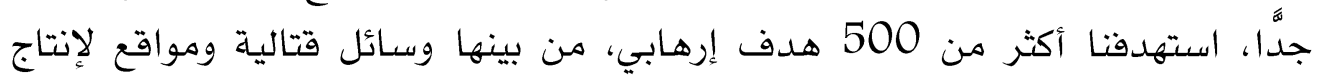

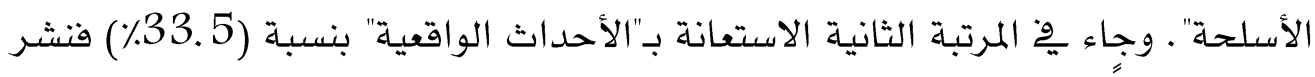

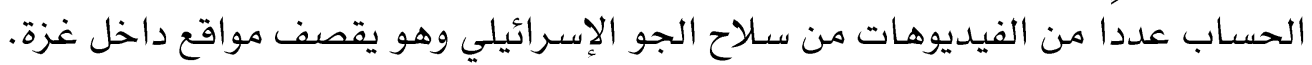

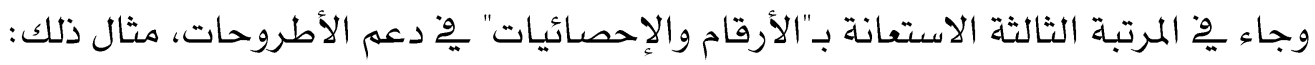
"لقد تمكن جيش الدفاع من توجيه ضريات لأهداف إستراتيجية لحماس، وتمكن من

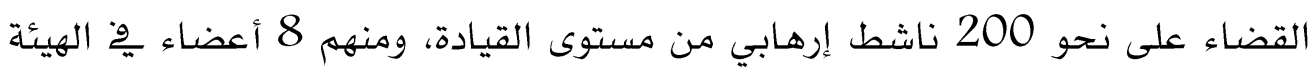

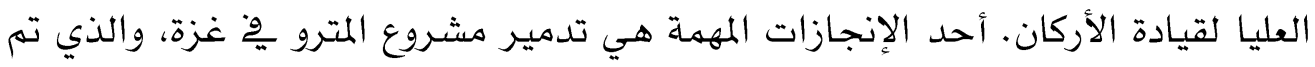

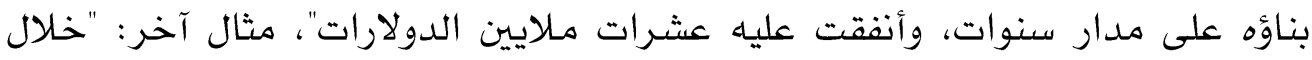

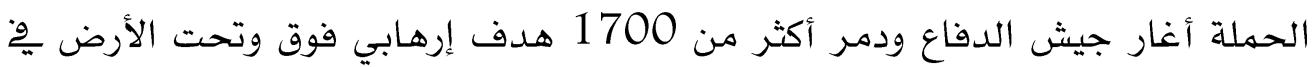

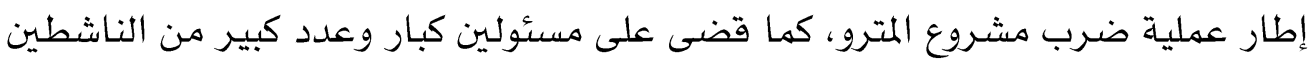

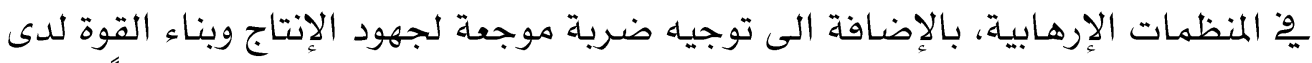

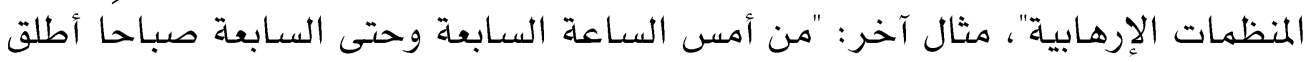

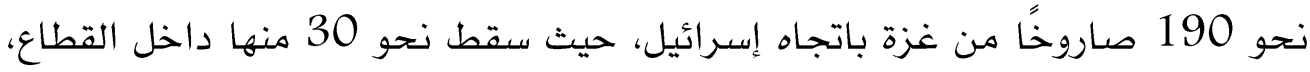

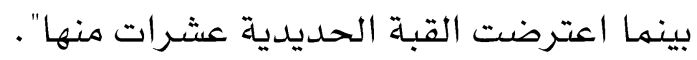


ويتضح من نتائج الجدول السابق: بالنسبة للاستمالات المنطقية المستخدمة ِوح

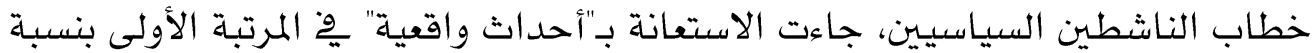

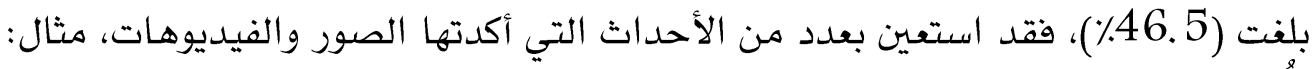

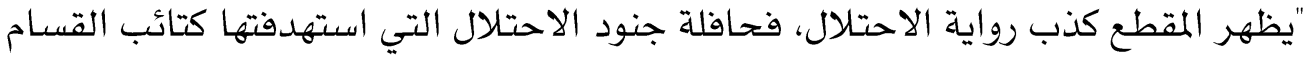
قرب حدود \#غزة لم تكن فارغة، بل كانت تتحرك ومأهولة، الاحتلال يتكتم عن خسائره

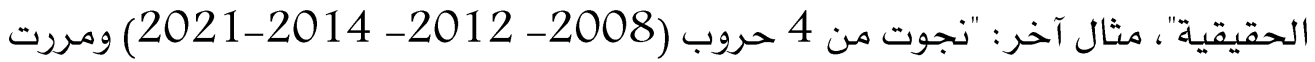

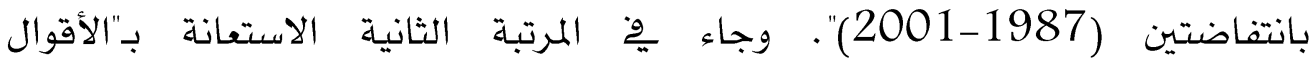
والتصريحات" لعدد من القوى والشخصيات الفاعلة الإسرائيلية والفلسطينية بنسبة

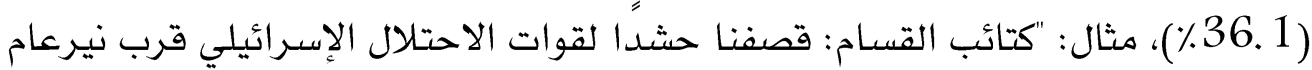

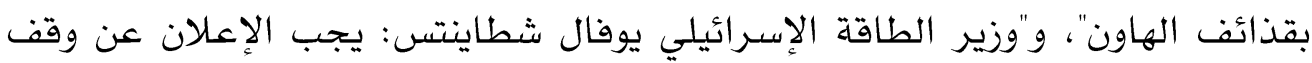

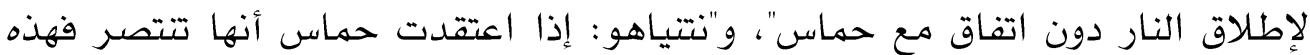

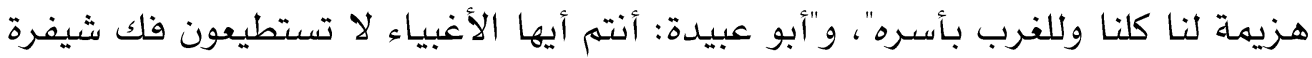

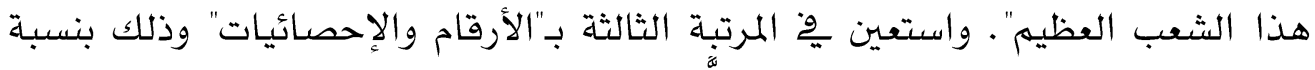

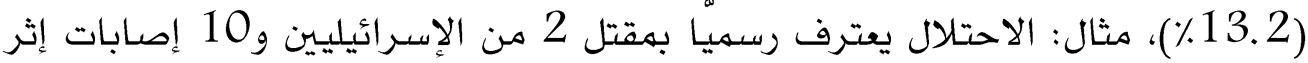

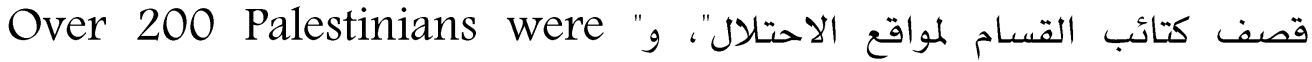
injured, including 88 who were hospoialized. One Palestinian . "lost an aye ولتحقيق فاعلية الرسالة الاتصالية الرقمية الممثلة يُّ تغريدات قوات الاحتلال

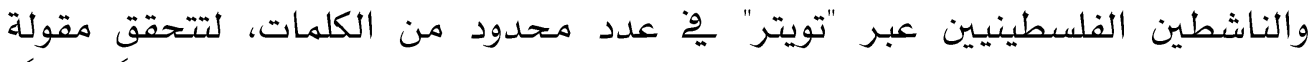

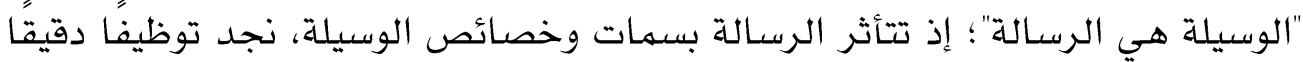

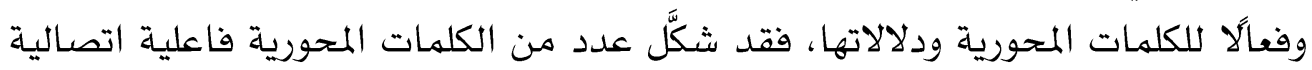

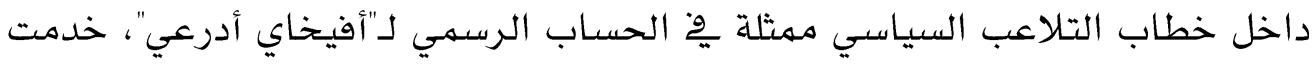

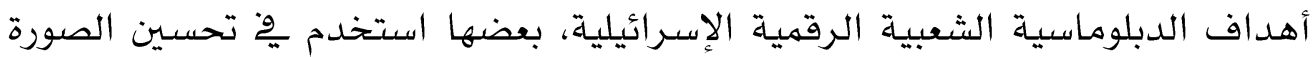

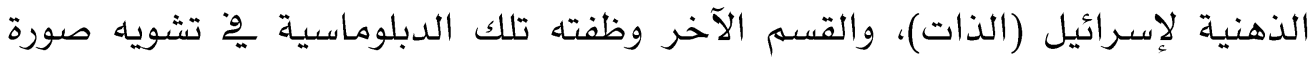
المقاومة (الآخر).

- الكلمات المحورية المستخدمة بِ التعبير عن جيش الدفاع (الذات): أمة، أمناه

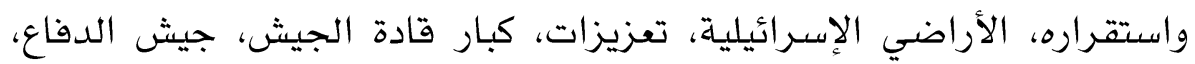

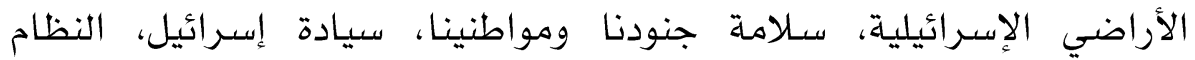


الدفاعي الأول پِّ العالم، أجهزة الدفاع، الاستخبارات الإسرائيلية، الجهود الدفاعية.

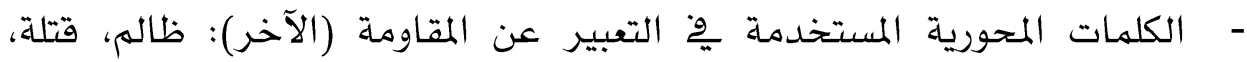
تخريبية، مفترون، إرهابيين، مثيرو الشغب، منظمات إرهابية، جهاد الفنادق، مصالح إرهابية.

كما شكلَّ عدد من الكلمات المحورية فاعلية اتصالية داخل خطاب الدبلوهاسية الشعبية

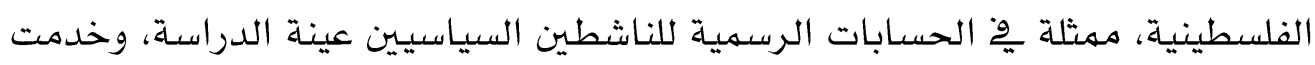
أهداف تلك الدبلوماسية، بعضها استخدم پِّة تحسين التعبير عن صورة (الذات)

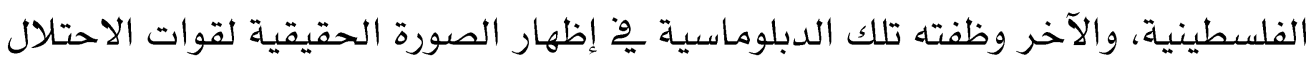

(الآخر)

- الكلمات المحورية المستخدمة بِّ التعبير عن الفلسطينيين (الذات): مصلون،

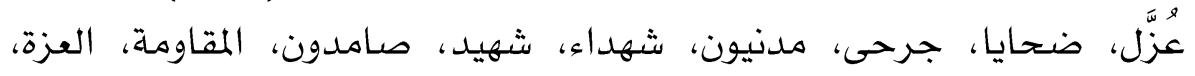

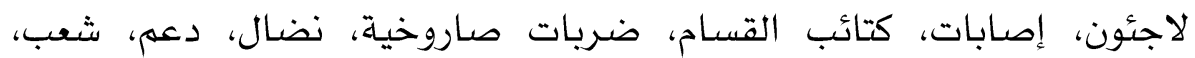

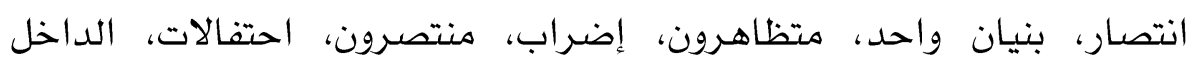

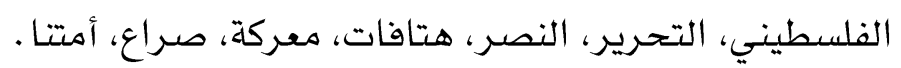

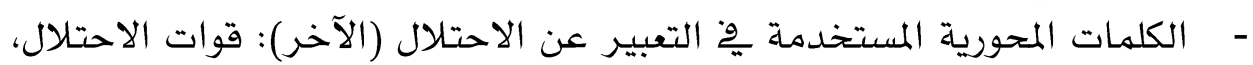

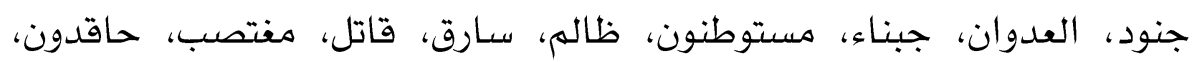

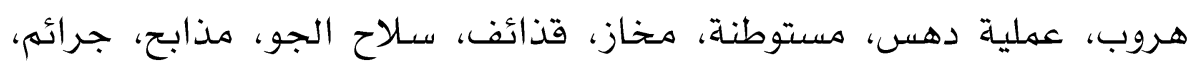

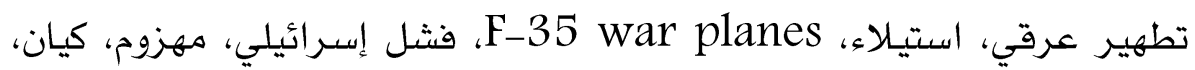
صهيوني. خاتهـة الدراسة:

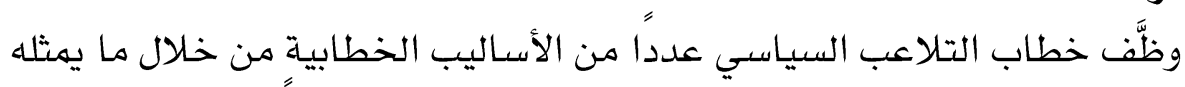

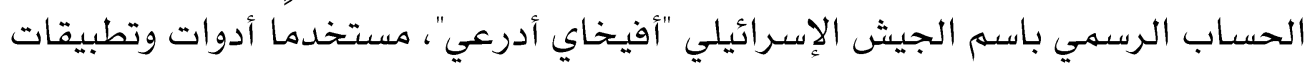

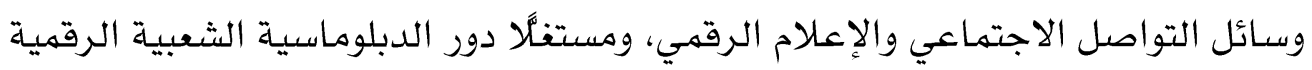

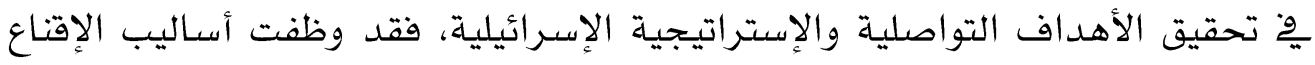

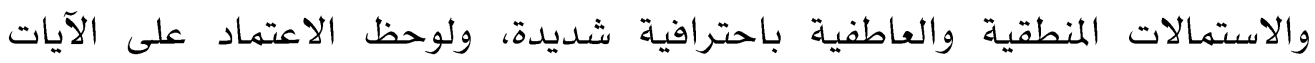

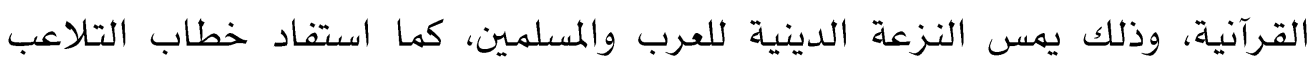

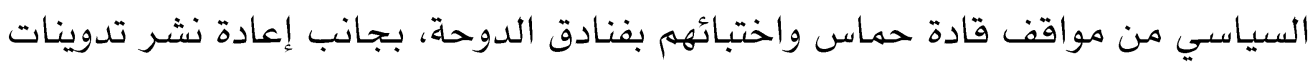

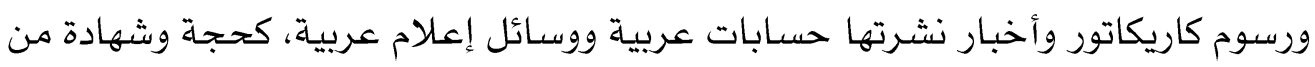




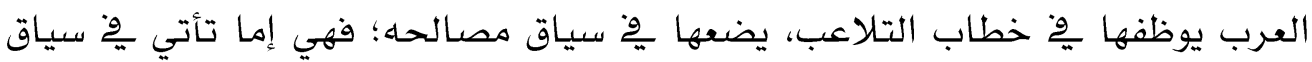

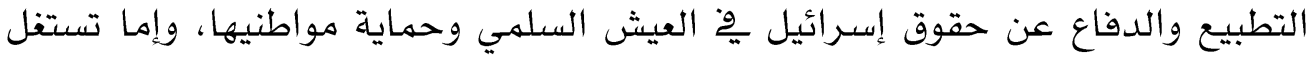

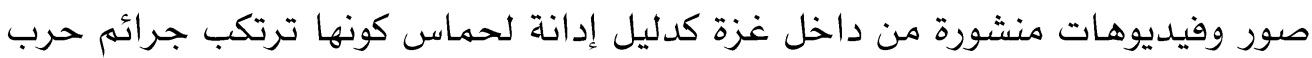

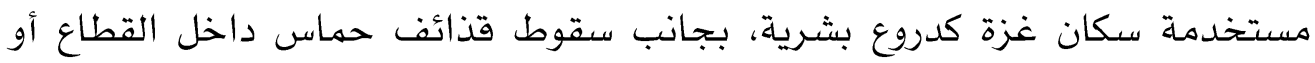

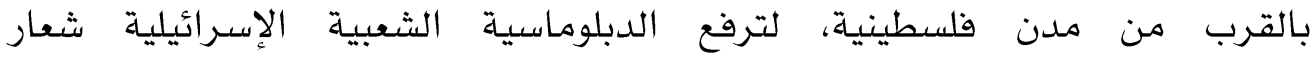

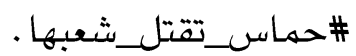
كما لوحظ خلال فترة الدراسة اختقاء النبرة التتازلية من اليوم الأول حتى اليوم السادس عشر، حين وقف إطلاق النار، وقد اعتمدت أساليب الدبلوماسية الاتصالية لخطاب التلاعب السياسي يُّ ذلك رفع شعار \#حماس_تحت_القصف، و\#يش_الدفاع، بجانب أخبار استهداف مواقع وعناصر من حماس. ومن خلال الحرب الحرب النفسية واستخدام نبرة تجمع بين السخرية والتحريض، نجد أن الدبلوماسية الإسرائيلية عبر

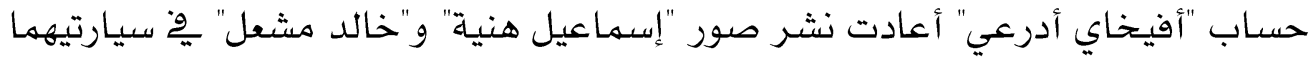

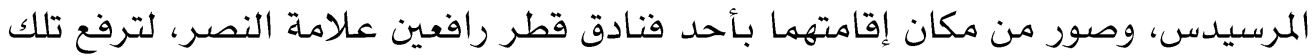

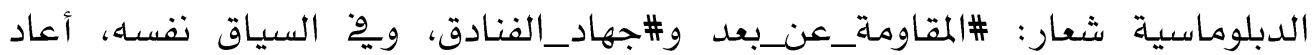

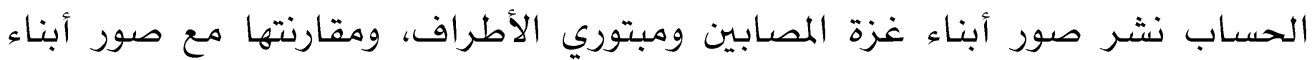
"إسماعيل هنية" المعافين.

وقد أكد خطاب التلاعب السياسي عملياته المستمرة التي تستهدف حماس،

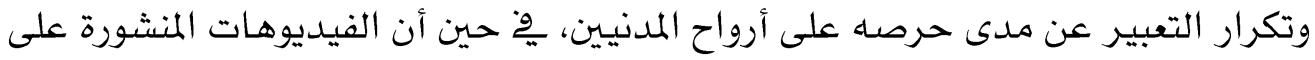

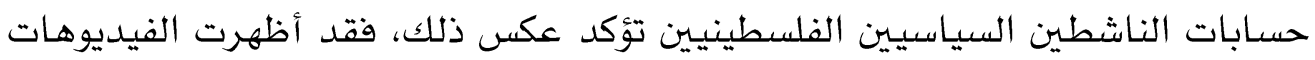

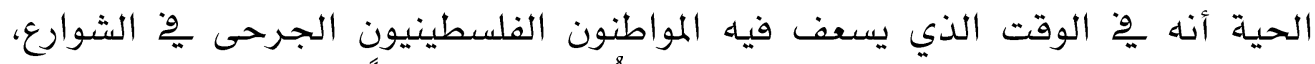

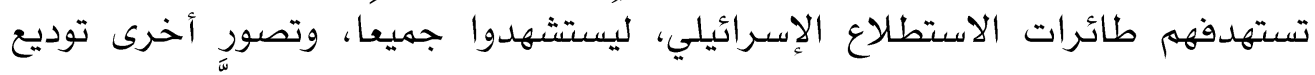

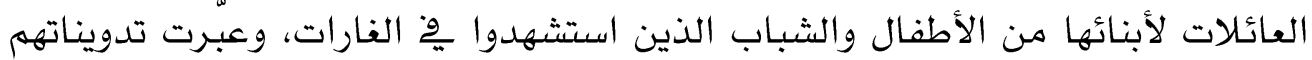

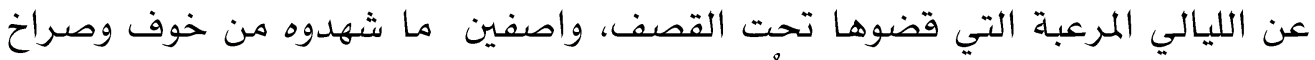

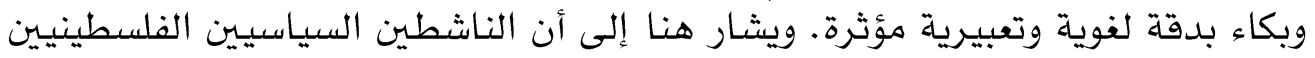

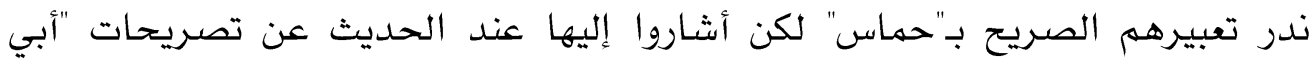

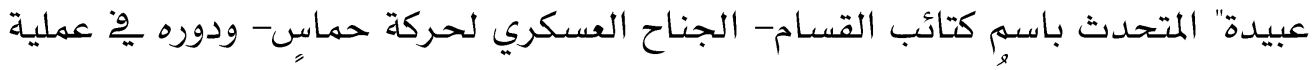
"سيف القدس"، وله يشر إلى "إسماعيل هنية" أو "خالد مشعل"، فغالبا ما كان التأكيد أن الن الن

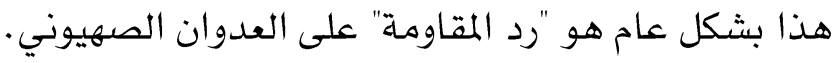




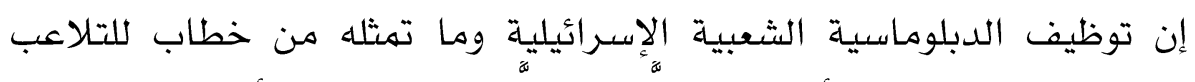

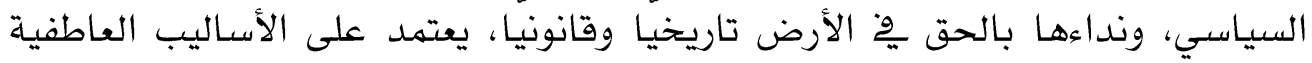

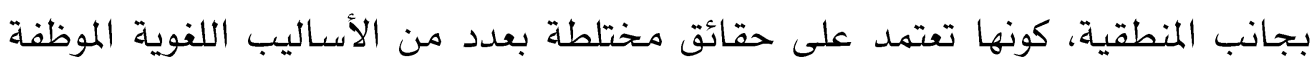

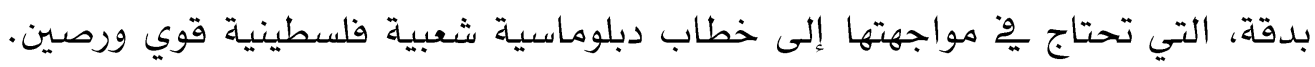

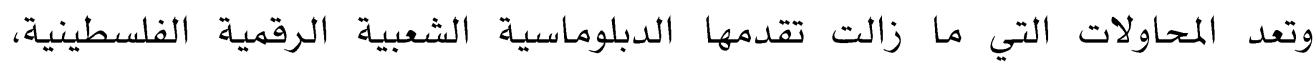

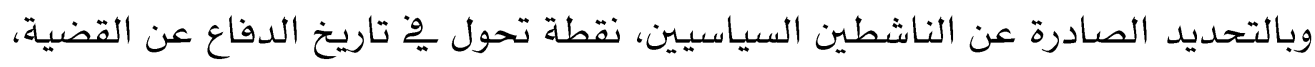

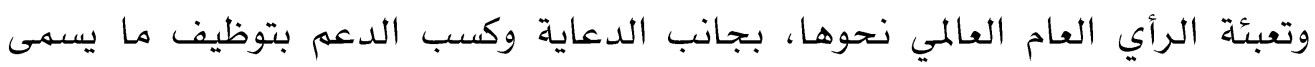

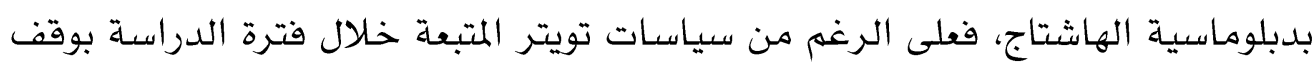

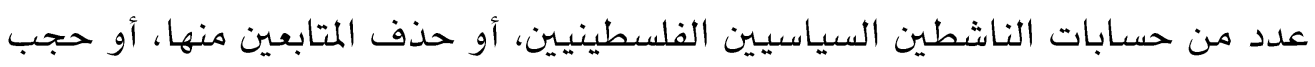

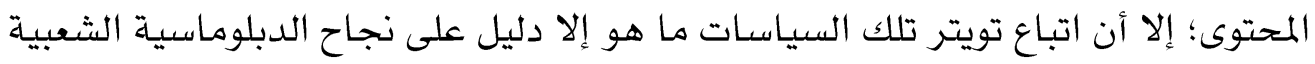

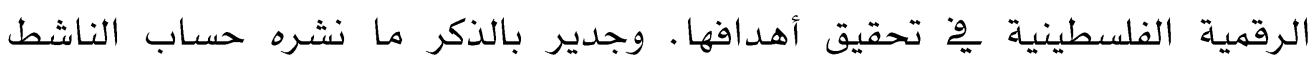

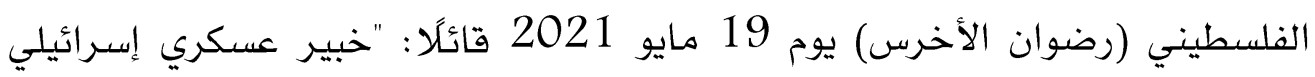

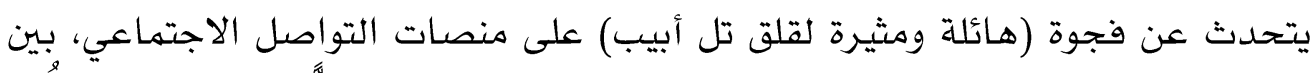

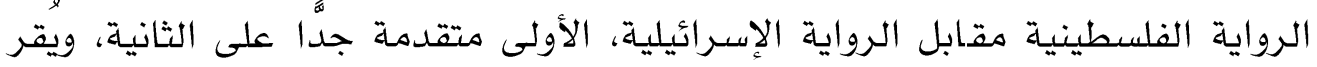
بالفشل والهزيمة بِّه هذا الميدان".

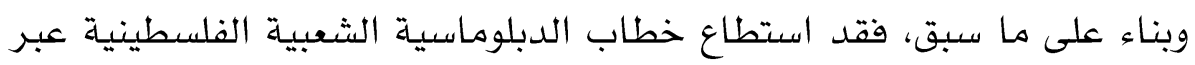
"تويتر" الوقوف وِّم مواجهة خطاب التلاعب السياسي من خلال عدد من الأساليب يمكن

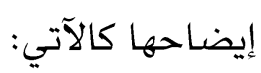

الاستتاد إلى "الأدلة والثواهد" يوْ عرض الحجج الإقناعية، وتوظيفها جنبًا

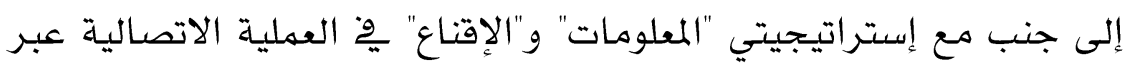

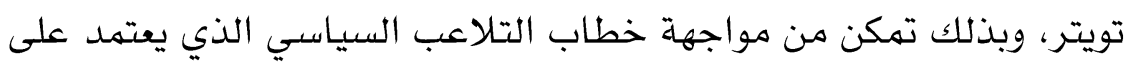

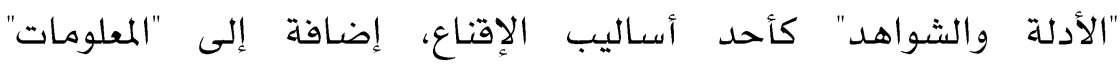
كإستراتيجية اتصالية.

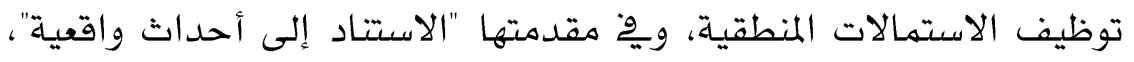

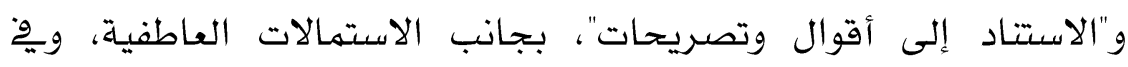

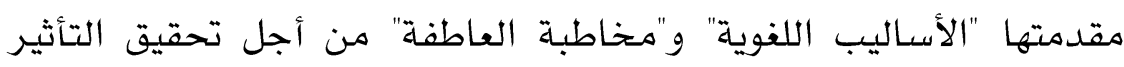

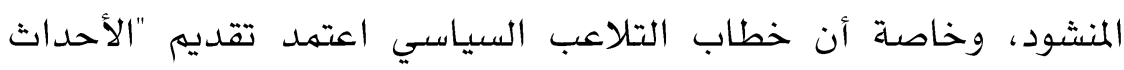

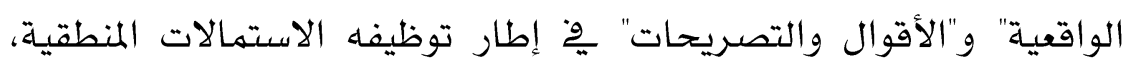


إضـافة إلى الإفراط يخ استخدام "الأسـاليب اللغوية" يْ سياق تقديم أحداث |الصراع.

تطويع خصائص "تويتر" التقنية، وعلى رأسها الهاشتاج، لتحقق الدبلوماسيـة الشعبية الفلسطينية أفضل استخدام لـ"دبلوماسيةٍ الهاشتاج"، فقد نشرت تغريدات الناشطين السياسيين الفلسطينيين عددا من الهاشتاجات بلفت

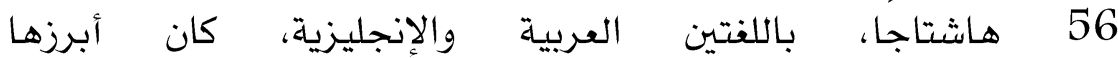
أنقذوا_حي_الشيخ_جراح، وشغزة_تحت_القصف. اعتهاد خطاب الدبلوماسية الشعبية الفلسطينية للناشطين السياسيين على المرجعية "الأمنيـة" للخطاب ِوخ المقام الأول، يليها المرجعية "الاجتماعية

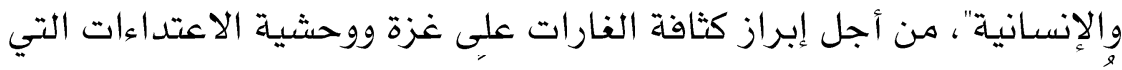
وصفت بـ"مجازر" و "الإبادة الجهاعيـة"، مدعما ذلك بصور وفيديوهات وأرقام وإحصائيات، وبذلك استطاع خطاب الناشطين مواجهة خطاب التلاعب السياسي الذي ركزّز أغلب اهتهامها على "المرجعية الأمنية".

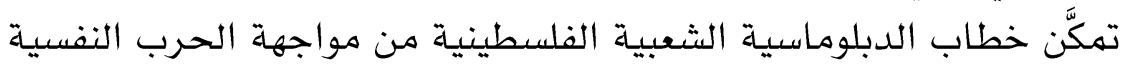

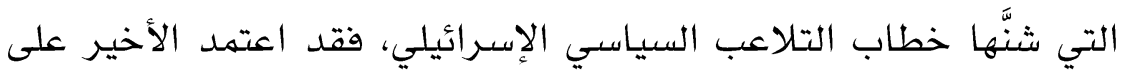
نبرة "الانتصار" بدرجة كبيرة عبر تفريدات الحساب الرسسي لـ"أفيخاي أدرعي"، وظهر ذلك من خلال النبرة التي استخدمها الناشطون السياسيون

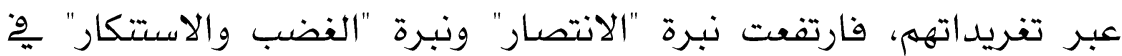
التعبير عن مواقفهم تجاه الصراع.

\section{توصيات اللدراسـة:}

ضروروة إنشاء منصة رقهية تعبر عن الدبلوماسية الشعبية الفلسطينية، تقدم بعدة لغات، أهمها : العربية، والإنجليزية،، والعبرية، لمخاطبة الرأي العام العربي والإسـرائيلي، بجانب الرأي العام العالمي، وتحقق عددا من الأهداف،

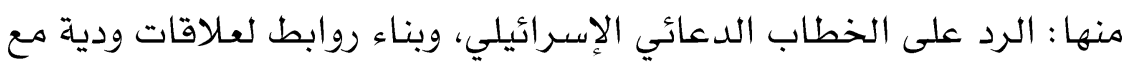
الشعوب الأخرى، وكسب الرأي العام العالمي وتعبئته تجاه القضية، وإيجاد مساحات مشتركة للتعاون مع الشعوب الأخرى مبنية على الثقة والاحترام المتبادل.

أهمية دراسـة الدبلوماسية الشعبية، خاصسة الفلسطينية، وتقديم تصورات نظرية وتطبيقية، من أجل تعزيز وجودها ِوْ الفضاء الإلكتروني، وضهان 


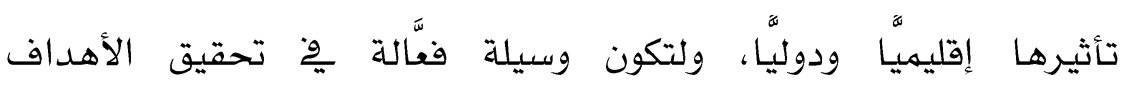

$$
\begin{aligned}
& \text { الإستراتيجية الفلسطينية. } \\
& \text { يجب أن يقوم على تلك المنصدة كوادر مدرية من الإعلاميين والكتّاب } \\
& \text { والناشطين السياسيين الفلسطينيين، بحيث يمتلكون أدوات التعامل مـع } \\
& \text { الدبلوماسسية الشعبية الرقمية، واعون بأسـاليب الدعاية الإسـرائيلية المضـادة، }
\end{aligned}
$$

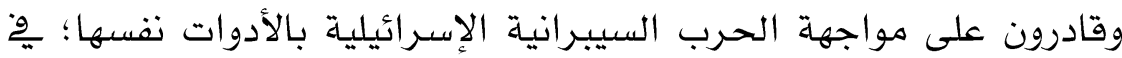

$$
\begin{aligned}
& \text { سبيل دحض خطاب التلاعب السياسي يِّ الصراع الفلسطيني- الإسـرائيلي. }
\end{aligned}
$$$$
\text { مصسادر الدراسـة ومـراجعها: }
$$

1 Payne, Gregory. "Reflections on Public Diplomacy: People-to-People CommunicationJ. Payne, Gregory", American Behavioral Scientist, Vol.(XX), no.(X), 2009, pp. $1-27$.

2 Surowiec, Pawel, Miles, Christopher. "The populist style and public diplomacy: kayfabe as performative agonism in Trump's Twitter posts", Public Relations Inquiry, Vol. 10, No. (1), 2021, pp.5-30.

3 Collins, Stephen D., DeWitt, Jeff R., LeFebvre, Rebecca K. "Hashtag diplomacy: twitter as a tool for engaging in public diplomacy and promoting US foreign policy", Place Branding and Public Diplomacy, Vol. (15), 2019, pp.78-96.

$$
4
$$

- Kenzhekanova, Kuralay, Zhanabekova, Magulsim, and Konyrbekova, Tolkyn. "Manipulation in Political Discourse of Mass Media", Mediterranean Journal of Social Science, Vol. (6), No. (4), 2015, p.p.325-332.

- Ushchyna, Valentyna. "Manipulative use of risk as a stance in political communication", Discourse \& Society, Vol. (29), No. (2), 2018, pp.198-221.

- Paul, Chilton. "Political terminology". In: andbook of Communication in the Public Sphere: Handbooks of Applied Linguistics, Vol. (4), 2008, pp. 226-242

5 Zeitzoff, Thomas. "Does Social Media Influence Conflict? Evidence from the 2012 Gaza Conflict”, Journal of Conflict Resolution, Vol. 62, No. (1), 2018, pp.29-63.

6 Pennington, Rosemary. "Witnessing the 2014 Gaza War in Tumblr", The International Communication Gazette, Vol. 82, No. (4), 2020, pp. 365-383.

7 أبو نقيرة، أيمن خميس ربيع. "تغطية الإعلام التركي الناطق بالعربية على شبكات التو اصل الاجتماعي لقضية

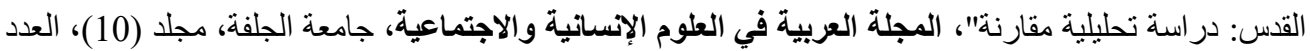

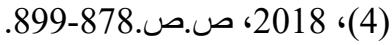


${ }^{8}$ Asthana, Sanjay. "Youth, self, other: A study of Ibdaa's digital media practices in the West Bank, Palestine", International Journal of Cultural Studies, Vol. (20), No. (1), 2017, pp.100-117.

9 Abu Mualla, Saied. "Palestinian-Israeli Cyber Conflict A :Analytical Study of the Israeli Propaganda on Facebook Adraei's page as an example", Journal of the Arab University, Vol (3), No (2), 2017, pp.52-75.

10 Evans, Matt. "Information dissemination in new media: YouTube and the IsraeliPalestinian conflict”, Media, War \& Conflict, Vol. (9), No. (3) 2016, pp. 325-343.

11 Hitchcock, Jennifer. "Social Media Rhetoric of the Transnational Palestinian-led Boycott, Divestment, and Sanctions Movement", Social Media + Society, 2016, pp.112.

12 و افي، أيمن منصور. "اتجاهات الثباب الفلسطيني نحو الثائعات أثناء العدوان الصهيوني على قطاع غزة 2014:

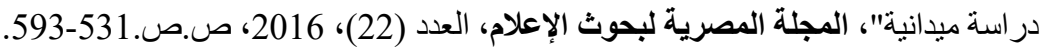

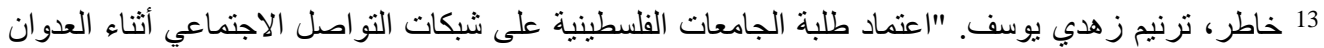

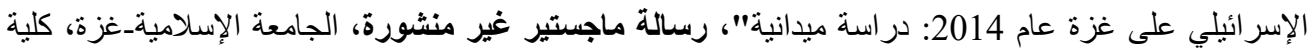

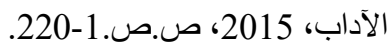

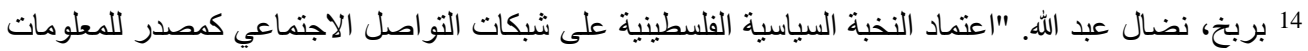

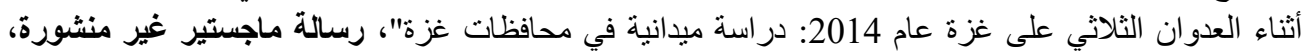

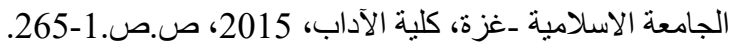

15 أبو جبر، عمرو. "وسائل التواصل الاجتماعي والعدوان على غزة"، مجلة البيان، العدد (327)، 2014،

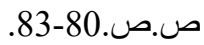

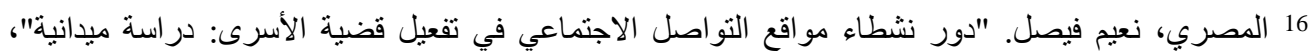

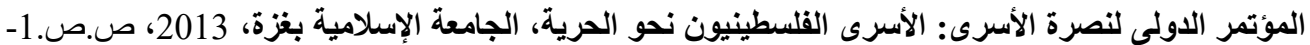

17 Zeitzoff, Thomas. "Using Social Media to Measure Conflict Dynamics: An Application to the 2008-2009 Gaza Conflict”, Journal of Conflict Resolution, Vol. (55), No. (6), 2011, pp. 938-969.

18 طالب، موسى علي محمود. "جهود وسائل الإعلام في تزويد الجامعات الفلسطينية بالمعلومات حول قضية

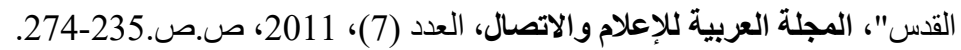

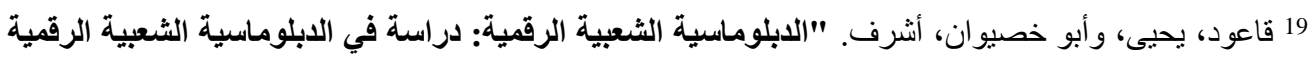
الفلسطينية حملة (الهب 194 194) نموذجًا"، المركز الديمقراطي العربي للارباسات الإستراتيجية و السياسية

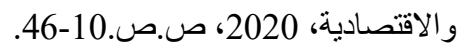
20 علوان، مصطفى شكري. "صورة الأنا والآخر في مضامين مواقع التواصل الاجتماعي الإسرائيلية المقدمة

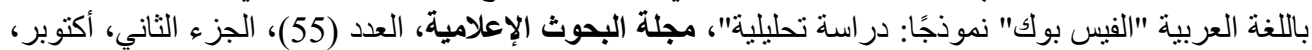

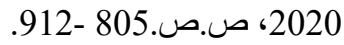

${ }^{21}$ Zeitzoff, Thomas. Op.cit., pp.29-63. 
22 Manor, Ilan and Crilley, Rhys. "Visually framing the Gaza War of 2014: The Israel Ministry of Foreign Affairs on Twitter", Media, War \& Conflict, Vol. (11), No. (4), 2018, pp.369-391.

23 عبد اللطيف، آلاء فوزي. "الإستراتيجيات الاتصالية للابلوماسية العامة الإسرائيلية عبر الإنترنت: دراسة تحليلية"، رسالة ماجستير غير منشورة، كلية الإعلام، جامعة القاهرة، 2015.

24 Siapera, Eugenia. "Tweeting \#Palestine: Twitter and the mediation of Palestine", Journal of Cultural Studies, 2014, Vol. (17), No. (6), pp. 539-555.

25 عبد الخالق، يسرا حسني. "الدبلوماسية الثعبية الإسر ائيلية الموجهة للشعوب العربية على الفيس بوك: دراسة

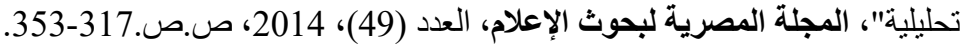

${ }^{26}$ Fuchs, Christian. “Communication and Capitalism: A Critical Theory”, London: University of Westminster Press, 2020, pp.69-71.

${ }^{27}$ Silverstone, Roger. "Complicity and collusion in the mediation of everyday life". New Literary History, Vol. (3)3, No. (5), 2002, pp. 745-764.

${ }^{28}$ Fuchs, Christian. Op. cit., pp.69-71.

${ }^{29}$ Zeitzoff, Thomas, Kelly, John, and Gilad, Graphika. 'Using social media to measure foreign policy dynamics: An empirical analysis of the Iranian-Israeli confrontation (2012-13)", Journal of Peace Research, Vol. 52, No. (3), 2015, pp. 368-383.

30 عبد المعطي، نها السيد. "دور وسائل الإعلام الجديد في صنع القرار السياسي في مصر في مرحلة التحول

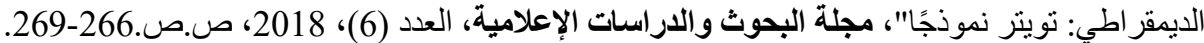

${ }^{31}$ Livingstone, Sonia. "On the mediation of everything: ICA presidential address 2008”, Journal of Communication, Vol. (59), No. (1) 2009, pp.1-18.

${ }^{32}$ Krotz, Friedrich, "Explaining the Mediatisation Approach", Javnost: The Public, Vol. (24), No. (2), 2017, pp. 103-118.

${ }^{33}$ Siapera, Eugenia. Op.cit., p.552.

${ }^{34}$ Ibid, pp. 553.

35

- Anthonissen, Christine. "Interaction between Visual and Verbal Communication: Changing Patterns in the Printed Media", In Weiss, Gilbert and Wodak, Ruth. "Critical Discourse Analysis Theory and Interdisciplinary", 2003, pp. 297 -300.

- Bell, A. and Garrett, P. "Approaches to Media Discourse", Oxford: Blackwell,1998.

36 O'Connor, Patricia E. "Activist Sociolinguistics in a Critical Discourse Analysis Perspective". In Weiss, Gilbert, and Wodak, Ruth. "Critical Discourse Analysis Theory and Interdisciplinary", 2003, pp. 223-237. 
${ }^{37} \mathrm{Hu}$, Lingshu and Kearney, Michael Wayne, "Gendered Tweets: Computational Text Analysis of Gender Differences in Political Discussion on Twitter", Journal of Language and Social Psychology, 2020, pp.1-2.

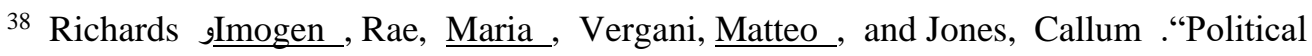
philosophy and Australian far-right media: A critical discourse analysis of The Unshackled and XYZ", Thesis Eleven, Vol. (163), No. (1), 2021, pp.103-130.

39 كمال، يعيقل. "دور الاتصال في الخطاب السياسي الفيلمي: مقاربة سيميائية تداولية لنماذج الخطاب السياسي

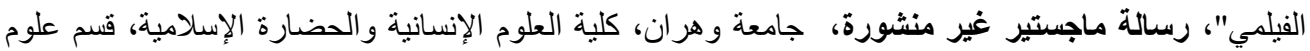

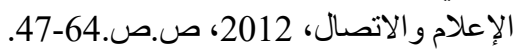

${ }^{40}$ Khan, Mohsin Hassan, Qazalbash, Farwa, Adnan, Hamedi Mohd, Yaqin, Lalu Nurul, and Khuhro, Rashid Ali. "Trump and Muslims: A Critical Discourse Analysis of Islamophobic Rhetoric in Donald Trump's Selected Tweets", SAGE Open, 2021, pp. 116.

${ }^{41}$ Syukri, Muhammad gNur, Muh. Azhar, and Karunia, Karina Alifiana. "Analysis of Law Discourse Through Van Dijk Model Approach", Advances in Social Science, Education and Humanities Research, Vol. (4361), 2020, pp.1111-1116.

${ }^{42}$ Vilares, David, Thelwall, Mike, and Alonso, Miguel A. "The megaphone of the people? Spanish SentiStrength for real-time analysis of political tweets", Journal of Information Science, Vol. (41), No. (6) 2015, pp. 799-813.

$$
43 \text { عبد المعطي، نها السيد. مرجع سابق، ص. } 251 .
$$

44 التميمي، جنان بنت عبد العزيز. "الخطاب اللغوي في التواصل التبل الثبكي التغريد (Twitter): خصائصه اللغوية

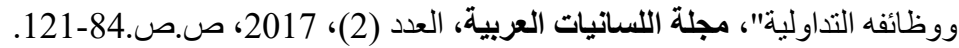

${ }^{45}$ Giglietto Fabio and Lee, Yenn. "A Hashtag Worth a Thousand Words: Discursive Strategies Around \#JeNeSuisPasCharlie After the 2015 Charlie Hebdo Shooting", Social Media + Society, 2017 pp.1-15.

$$
46 \text { قائمة بأسماء الأساتذة المحكمين وفقًا للترتيب الأبجدي: }
$$

د. سهى عبد الرحمن المهدي، مدرس الصحافة بقسم علوم الاتصال و الإعلام، كلية الآداب، جامعة عين شمس. 


\section{References}

- Payne, Gregory. "Reflections on Public Diplomacy: People-to-People CommunicationJ. Payne, Gregory", American Behavioral Scientist, Vol.(XX), no.(X), 2009, pp. $1-27$.

- Surowiec, Pawel, Miles, Christopher. "The populist style and public diplomacy: kayfabe as performative agonism in Trump's Twitter posts", Public Relations Inquiry, Vol. 10, No. (1), 2021, pp.5-30.

- Collins, Stephen D., DeWitt, Jeff R., LeFebvre, Rebecca K. "Hashtag diplomacy: twitter as a tool for engaging in public diplomacy and promoting US foreign policy", Place Branding and Public Diplomacy, Vol. (15), 2019, pp.78-96.

- Kenzhekanova, Kuralay, Zhanabekova, Magulsim, and Konyrbekova, Tolkyn. "Manipulation in Political Discourse of Mass Media", Mediterranean Journal of Social Science, Vol. (6), No. (4), 2015, p.p.325-332.

- Ushchyna, Valentyna. "Manipulative use of risk as a stance in political communication”, Discourse \& Society, Vol. (29), No. (2), 2018, pp.198-221.

- Paul, Chilton. "Political terminology". In: andbook of Communication in the Public Sphere: Handbooks of Applied Linguistics, Vol. (4), 2008, pp. 226-242

- $\quad$ Zeitzoff, Thomas. "Does Social Media Influence Conflict? Evidence from the 2012 Gaza Conflict”, Journal of Conflict Resolution, Vol. 62, No. (1), 2018, pp.29-63.

- Pennington, Rosemary. "Witnessing the 2014 Gaza War in Tumblr", The International Communication Gazette, Vol. 82, No. (4), 2020, pp. 365-383.

- $\quad$-Abu naqayrat, A. (2018). "taghtiat al'iielam alturkiu alnaatiq bialearabiat ealaa shabakat altawasul alaijtimaeii liqadiat alquds: dirasat tahliliatan muqaranata", almajalat alearabiat fi aleulum al'iinsaniat walaijtimaeiati, jamieat Aljulfati, 4(10),.878-899.

- Asthana, Sanjay. "Youth, self, other: A study of Ibdaa's digital media practices in the West Bank, Palestine", International Journal of Cultural Studies, Vol. (20), No. (1), 2017, pp.100-117.

- Abu Mualla, Saied. "Palestinian-Israeli Cyber Conflict A :Analytical Study of the Israeli Propaganda on Facebook Adraei's page as an example", Journal of the Arab University, Vol (3), No (2), 2017, pp.52-75.

- Evans, Matt. "Information dissemination in new media: YouTube and the Israeli-Palestinian conflict", Media, War \& Conflict, Vol. (9), No. (3) 2016, pp. 325-343. 
- Hitchcock, Jennifer. "Social Media Rhetoric of the Transnational Palestinianled Boycott, Divestment, and Sanctions Movement", Social Media + Society, 2016, pp.1-12.

- -Wafi, A., Mansur, A. (2016). "aitijahat alshabab alfilastinii nahw alshaayieat 'athna' aleudwan alsahyunii ealaa qitae ghazat 2014: dirasat maydaniati", almajalat almisriat libuhuth al'iielami, aleadad (22), .531-593.

- -Khatir, T. (2015). "aietimad talabat aljamieat alfilastiniat ealaa shabakat altawasul alaijtimaeii 'athna' aleudwan al'israyiylii ealaa ghazat eam 2014: dirasat maydaniatin", risalat majistir ghayr manshuratin, aljamieat al'iislamiatighazat, kuliyat Aladab, 1-220.

- prabakh, N. (2015). "aietimad alnukhbat alsiyasiat alfilastiniat ealaa shabakat altawasul alaijtimaeii kamasdar lilmaelumat 'athna' aleudwan althulathii ealaa ghazat eam 2014: dirasat maydaniat fi muhafazat ghazati", risalat majistir ghayr manshurati, aljamieat alaslamiat -ghazat, kuliyat Aladab, .1-265.

- -Abu Jabar, O. (2014). "wasayil altawasul aliajtimaeii waleudwan ealaa ghazati", majalat albayani, (327), 80-83.

- -Al-Masry, F.(2013). "dawr nushata' mawaqie altawasul alaijtimaeii fi tafeil qadiat al'asraa: dirasatan maydaniatan", almutamar alduwlaa linusrat al'asraa: al'asraa alfilastiniuwn nahw alhuriyati, aljamieat al'iislamiat bi Ghaza,.1-51.

- Zeitzoff, Thomas. "Using Social Media to Measure Conflict Dynamics: An Application to the 2008-2009 Gaza Conflict", Journal of Conflict Resolution, Vol. (55), No. (6), 2011, pp. 938-969.

- -Mahmud, T. (2011). "juhud wasayil al'iielam fi tazwid aljamieat alfilastiniat bialmaelumat hawl qadiat alquds", almajalat alearabiat lil'iielam walaitisali, (7),.235-274.

- -Qaoud, Y., Abu Khesiwan, A. (2020). "aldiblumasiat alshaebiat alraqamiati: dirasat fi aldiblumasiat alshaebiat alraqamiat alfilastiniat hamla (ahbid 194) nmwdhjan", almarkaz aldiymuqratii alearabii lildirasat al'iistratijiat walsiyasiat walaiqtisadiati, .10-46.

- -Shukri, M. (2020). "surat al'ana walakhir fi madamin mawaqie altawasul alaijtimaeii al'iisrayiyliat almuqadamat biallughat alearabia "alfis buk" nmwdhjan: dirasat tahliliati", majalat albuhuth al'iielamiati, 55(2), 805 -912.

- $\quad{ }^{46}$ Manor, Ilan and Crilley, Rhys. "Visually framing the Gaza War of 2014: The Israel Ministry of Foreign Affairs on Twitter", Media, War \& Conflict, Vol. (11), No. (4), 2018, pp.369-391. 
-Abd Allatifi, A. (2015). "al'iistratijiaat alaitisaliat lildiblumasiat aleamat al'iisrayiyliat eabr al'iintirnti: dirasat tahliliata", risalat majistir ghayr manshurtin, kuliyat al'iielami, jamieat Alqahira.

Siapera, Eugenia. "Tweeting \#Palestine: Twitter and the mediation of Palestine", Journal of Cultural Studies, 2014, Vol. (17), No. (6), pp. 539-555.

- $\quad$-Aabd Alkhaliq, Y. (2014). "aldiblumasiat alshaebiat al'iisrayiyliat almuajahat lilshueub alearabiat ealaa alfis buk: dirasat tahliliata", almajalat almisriat libuhuth al'iielami, (49), 317-353.

- Fuchs, Christian. "Communication and Capitalism: A Critical Theory", London: University of Westminster Press, 2020, pp.69-71.

- Silverstone, Roger. "Complicity and collusion in the mediation of everyday life”. New Literary History, Vol. (3)3, No. (5), 2002, pp. 745-764.

- Zeitzoff, Thomas, Kelly, John, and Gilad, Graphika. "Using social media to measure foreign policy dynamics: An empirical analysis of the Iranian-Israeli confrontation (2012-13)", Journal of Peace Research, Vol. 52, No. (3), 2015, pp. 368-383.

- $\quad$-Abd Almueti, N. (2018) "dur wasayil al'iielam aljadid fi sune alqarar alsiyasii fi misr fi marhalat altahawul aldiymuqrati: twitir nmwdhjan", majalat albuhuth waldirasat al'iielamiati, (6), .266-269.

- Livingstone, Sonia. "On the mediation of everything: ICA presidential address 2008”, Journal of Communication, Vol. (59), No. (1) 2009, pp.1-18.

- Krotz, Friedrich, "Explaining the Mediatisation Approach", Javnost: The Public, Vol. (24), No. (2), 2017, pp. 103-118.

- Anthonissen, Christine. "Interaction between Visual and Verbal Communication: Changing Patterns in the Printed Media", In Weiss, Gilbert and Wodak, Ruth. "Critical Discourse Analysis Theory and Interdisciplinary", 2003, pp. 297 -300.

- Bell, A. and Garrett, P. "Approaches to Media Discourse", Oxford: Blackwell,1998.

- O’Connor, Patricia E. “Activist Sociolinguistics in a Critical Discourse Analysis Perspective". In Weiss, Gilbert, and Wodak, Ruth. "Critical Discourse Analysis Theory and Interdisciplinary”, 2003, pp. 223-237.

- $\mathrm{Hu}$, Lingshu and Kearney, Michael Wayne, "Gendered Tweets: Computational Text Analysis of Gender Differences in Political Discussion on Twitter", Journal of Language and Social Psychology, 2020, pp.1-2.

Richards gImogen, Rae, Maria, Vergani, Matteo, and Jones, Callum . "Political philosophy and Australian far-right media: A critical discourse 
analysis of The Unshackled and XYZ", Thesis Eleven, Vol. (163), No. (1), 2021, pp.103-130.

-Kamali, yueiqilu. "dawr alaitisal fi alkhitab alsiyasii alfilmii: muqarabatan simiayiyatan tadawuliatan linamadhij alkhitab alsiyasii alfilmii", risalat majistir ghayr manshuratin, jamieat wahran, kuliyat aleulum al'iinsaniat walhadarat al'iislamiati, qism eulum al'iielam walaitisali, 2012, sa.sa.64-47.

Khan, Mohsin Hassan, Qazalbash, Farwa, Adnan, Hamedi Mohd, Yaqin, Lalu Nurul, and Khuhro, Rashid Ali. "Trump and Muslims: A Critical Discourse Analysis of Islamophobic Rhetoric in Donald Trump's Selected Tweets", SAGE Open, 2021, pp. 1-16.

- Syukri, Muhammad sNur, Muh. Azhar, and Karunia, Karina Alifiana. "Analysis of Law Discourse Through Van Dijk Model Approach", Advances in Social Science, Education and Humanities Research, Vol. (4361), 2020, pp.1111-1116.

- Vilares, David, Thelwall, Mike, and Alonso, Miguel A. "The megaphone of the people? Spanish SentiStrength for real-time analysis of political tweets", Journal of Information Science, Vol. (41), No. (6) 2015, pp. 799-813.

- -Altamimi, J. (2017). "alkhitab allughawii fi altawasul alshabakii altaghrid (Twitter): khasayisih allughawiat wawazayifih altadawuliatu", majalat allisaniaat alearabiati, (2), 84-121.

- Giglietto Fabio and Lee, Yenn. "A Hashtag Worth a Thousand Words: Discursive Strategies Around \#JeNeSuisPasCharlie After the 2015 Charlie Hebdo Shooting”, Social Media + Society, 2017 pp.1-15. 